STATE OF ILLINOIS

DEPARTMENT OF REGISTRATION AND EDUCATION

DIVISION OF THE

NATURAL HISTORY SURVEY

THEODORE H. FRISON, Cbief

\begin{tabular}{lll}
\hline \hline Vol. XX & BULLETIN & Article IV \\
\hline \hline
\end{tabular}

\title{
The
}

\section{Stoneflies, or Plecoptera, of Illinois}

THFOIORE H. FRISON

PRINTED BY AUTHORITY OF THE STATE OF ILLINOIS

URBANA, ILLINOIS

JANUARY 1935 


\section{STATE OF ILLINOIS \\ Honorable Henry Horner, Guvernor DEPARTMENT OF REGISTRATION AND EDUCATION \\ Honorable John J. Haliman, Dirertor}

\section{BOARD OF NATURAL RESOURCES AND CONSERVATION \\ Honorable John J. Hallihan, Chairman}

William Trelease, D. Sc., L.L. D., Biology William A. Noyes, Ph. D., Ll. D., Henry C. Cowles, Ph. D., D. Sc., Forestry Chem. D., D. Sc., Chemistry John W. Alvord, C. E., Engineering Edson C. Bastin, Ph. D., Geology Arthur Cutts Willard, D. Eng., Ll. D., President of the University of Illinois

\section{NATURAL HISTORY SURVEY DIVISION \\ URBANA, ILLINOIS \\ Scientific and Technical Staff \\ Theodorf. H. Frison, Ph. D., Chief}

\section{SECTION OF ECONOMIC ENTOMOLOGY}

IV. P. Flint, B. S., Chief Entomologist

C. C. Compron, M. S., Associate Entomologist

M. D. Farrar, Ph. D., Research Entomologist

S. C. Chandler, B. S., Southern Field Entomologist

J. H. Bigger, B. S., Centra! Field Entomologist

L. H. Shropshire, M. S., Northern Field Entomologist

E. R. McGovrax, Ph. D., Research Fellow in Entomology

IV. E. McCauley, B. S., Assistant Entomologist

\section{SECTION OF AQUATIC BIOLOGY}

David H. Thompson, Ph. D., Zoologist

F. D. Huxt, Field Naturalist .

D. F. Hansen, A. M., Assistant Zoolagist

D). J. O'Donnell, M. S., Assistant Zoologist

\section{SECTION OF INSECT SURVEY}

H. H. Ross, Ph. D., Systematic Entomologist

CARL O. Mohr, Ph. D., Associate Entomologist, Artist

L. H. Townsend, M. S., Assistant Entomologist

SECTION OF APPLIED BOTANY AND PI.ANT PATHOLOGY

L. R. TeHon, Ph. D., Botanist

J. C. Carter, Ph. D., Assistant Botanist

G. H. Boewe, M. S., Field Botanist

SECTION OF GAME RESEARCH AND MANAGEMENT

R. E. Yeatter, Ph. D., Game Specialist

\section{SECTION OF FORESTRY}

L. E. Sawyer, B. S. F., Extension Forester

\section{PUBLICATIONS}

Carroll Chournard, M. A., Editor

This paper is a contribution from the Section of Insect Survey. 


\section{HOREWORD}

This report grows out of studies begun in the fall of 1926 when the writer was first impressed with the abundance and variety of the fall and winter stonefly population in Illinois. Field observations coupled with the rearing and collection of stoneflies were focused from 1926 to 1929 chiefly on our fall and winter fauna, resulting in the publication by myself in 1929 of a detailed report concerning the "Fall and Winter Stoneflies, or Plecoptera, of Illinois." After the appearance of this paper attention was directed mainly to the species constituting our spring and summer stonefly fauna and a minimum of effort and time has since been spent in study of the fall and winter species.

The present paper, then, is a summary of our stonefly studies which have been more or less continuous since 1926. For completeness this report has not been limited to the spring and summer forms but includes an entire survey of the plecopteran fama of Illinois, which makes it possible to present a classification unrestricted by the scasonal idiosyncrasies of species, genera or families. It offers, too, an opportunity to add further data concerning some of the fall and winter species not available at the time of the 1929 paper, and perhaps most important, it enables the presentation of a balanced and comparative picture of the stoneflies of this state.

The writer lats been greatly aided during the course of the study by various individuals and by the literature recording the observations and studies of other workers with this group of aquatic insects. I an indebted to Professors P. W. Claassen and J. G. Needham of Cornell university for the privilege of studying the extensive Plecoptera material in the collection of that institution, and for the donation of specimens and many other courtesies; for the loan or donation of material, to Dr. Nathan Banks of the Museum of Comparative Zoology, Cambridge, Mass., Protessor Ferris Neave of the University of Manitubi, Winnepeg. Professor Chauncey Juday, University of Wisconsin, Madison, I)r. 
D. I. Rasmussen, U. S. Forest Service, Ogden, Utah, Professor H. E. Jaques, Iowa Wesleyan college, Mt. Pleasant, Iowa, and to Dr. R. D. Bird of the Dominion entomological laboratory, Treesbank, Man.

Mr. W. J. Spencer, superintendent of the Sears hydroelectric station at Rock Island, Ill., has greatly facilitated our studies by first indicating to us the accumulation of insect material on bar racks of hydroelectric stations and by allowing us to establish a rearing station on the property under his charge.

A second rearing station was maintained for several years on the property of the Charleston water company, Charleston, Ill., adjacent to the Embarrass river, and I am indebted to them for this privilege.

Within the Survey I am indebted to Mr. Carroll Chouinard, editor, for taking care of the many details connected with the publication of this paper, to Dr. H. H. Ross, systematic entomologist, for aid with collection and rearing of material and with the final preparation of this article, and I am especially indebted to Dr. C. O. Mohr, associate entomologist, for his assistance in the collection and rearing of material and most of all for preparation of the many drawings.

Urbana

June 1, 193t 'T. H. F. 


\section{CONTENTS}

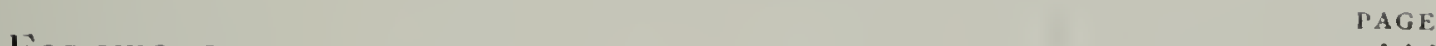

FOREWORD ...................... i i

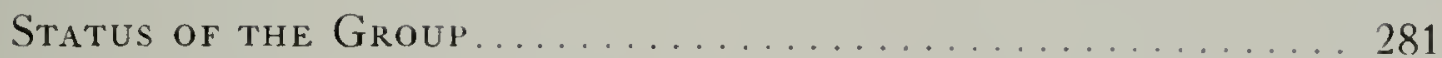

First studies by Walsh.--List now nearly static. -New classification proposed.-Sex and stage associations.

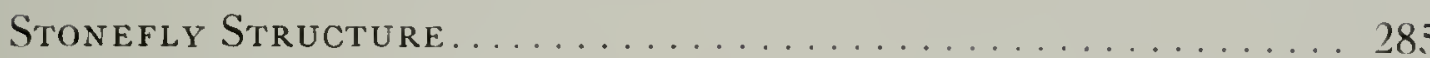

Adults. - Nymphs.

Biology of the Order......................... 288

Distribution.-Habitat preferences.-Seasonal adijustments.-Hahits of adults.-Habits of nymphs.--Enemies.

Collecting, Rearing and Preserving Stonefieies. . . . . . . . . 30.3

Collecting adults.-Collecting nymphs.-Rearing methods. Preservation of material.

Catalog of Species, inciuding ciassification, desc:kiption, HABITS AND RECORDS OF ILLINOIS STONEFLIES. . . . . . 307

Classification.-More homogeneous grouping.-Basis of present division.New classification of the Plecoptera of North America. - List of species of the Plecoptera of Illinois.-Plates I-XIV illustrating keys.-Key to families of the Plecoptera of North America.-Pteronarcidae.-Taeniopterygidae. Nemouridae.-Leuctridae.-Capniidale-Perlidae.-Perlodidae.-Chloroperlidae.

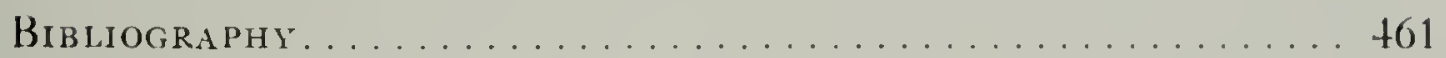

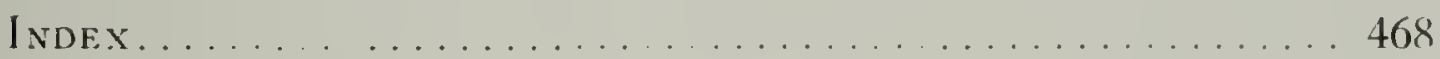




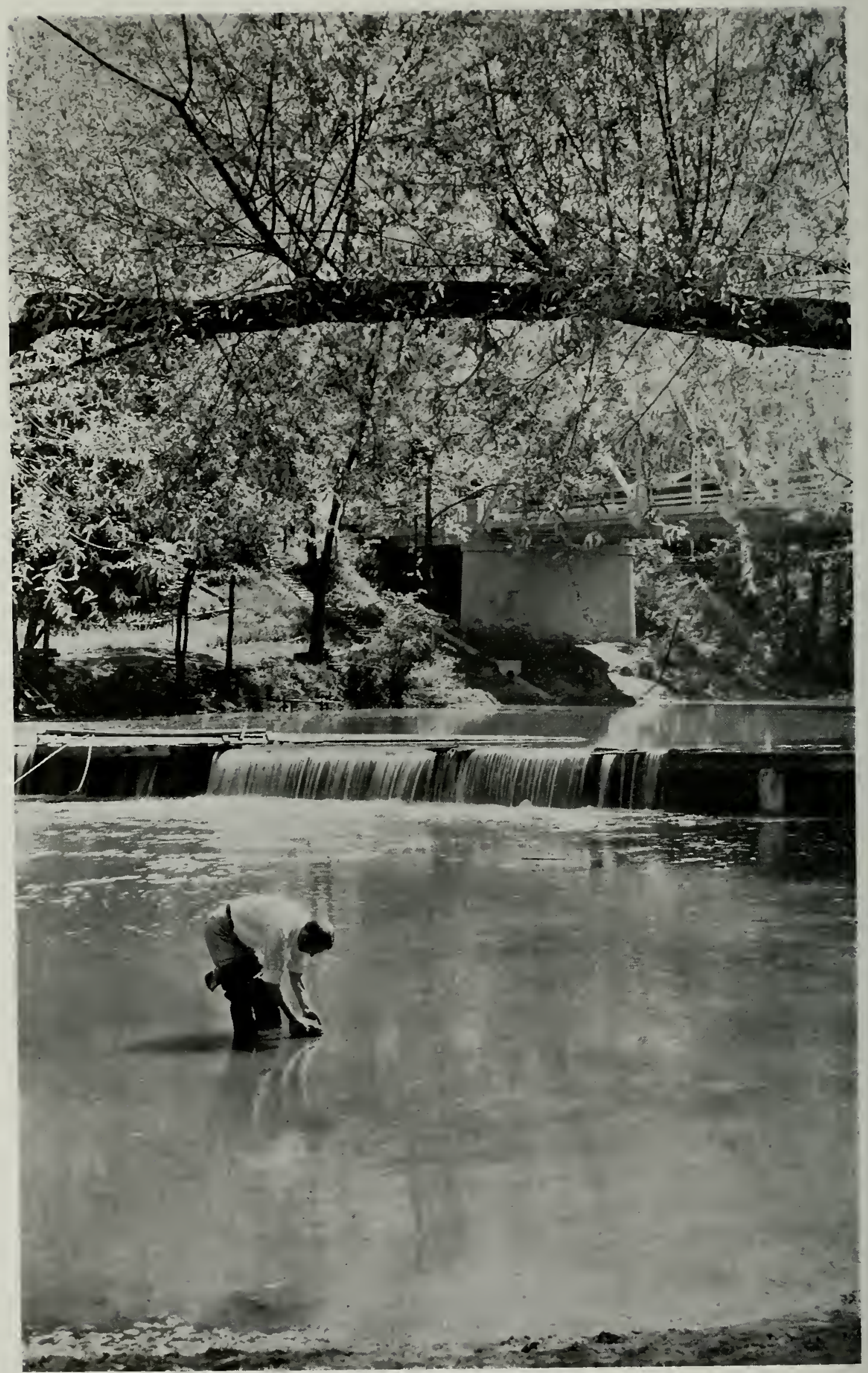

Salt Fork river in park at Homer, Illinois. Submerged rocks, leaves and debris in the shallows of such a habitat often furnish the collector with nymphs of Neophasganophora capitata, Acroneuria evoluta, Neoperla clymene and Perlesta placida. 


\section{The \\ Stoneflies, or Plecoptera, of Illinois}

THEODORE H. FRISON

\section{STATUS OF THE GROUP}

7 HE sTonefly FaUxa of Illinois has never attracted more than slight attention from entomologists. This has been partially due to an insistance upon pinning the adults after the manner em-
ployed for preserving beetles, butterflies and most other insects-a method which inevitably results in shriveled specimens, to impede recognition of structural characters needed in making identifications and to render then so unattractive that the average entomologist is not interested. 'Two more conditions foster this neglect of the order: the adults are rarely seen in numbers by those not especially searching for them, and frequently adults and nymphs are not readily and accurately associated except by rearing.

First studies by Walsh.- The one Illinois entomologist who was an outstanding exception to the general attitude was Benjamin Dann Walsh. His major publishings date from 1868 , when as first state entomologist he issued the "First Annual Report on the Noxious Insects of the State of Illinois." His paper concerning certain neuropteroid insects in Illinois $(1862)^{1}$ contained records and descriptions of stoneflies collected by himself mostly in the vicinity of Rock Island, and as Needham and Claassen (1925) state, "he collected so assiduously that the vicinity of Rock Island, Ill. has remained until recently one of the hest worked fields in America for the neuropteroid groups." In the present paper the records and descriptions of Walsh are recognized or placed in synonymy upon the basis of a few specimens named by him and now in the SurveY collection or studied by the author, also upon the placements given them by 
Needham and Claassen (1925) as a result of their study of types in the Museum of Comparative Zoology, Cambridge, Mass., and upon our studies of the stonefly fauna now existing at Rock Island and in Illinois in general, which give strong circumstantial evidence concerning the species occurring there in former years. I have placed in synonymy or recognized with much confidence all of the species of Walsh with one exception, Chloroperla nana, and this I believe may eventually be proved to be the same as Isoperla minuta Banks.

A revised tabulation of the species recorded by $W$ alsh from the vicinity of Rock Island in 1862 gives us a present list of 15 species. In the tabulation of species by states as given by Needham and Claassen (1925), Illinois is credited with 14 species, but since two species of Pteronarcys are listed whereas all our evidence indicates but one, this list of 1925 includes only 13 species. If all the Walsh records had been placed by Needham and Claassen their list would have given 17 species for this state. Our studies to date give us a total of 36 species of stoneHies for Illinois plus at least two and possibly a third species as yet known only as nymphs and not placeable to species at present time-a list more than double those of Walsh or Needham and Claassen.

The status of two Acroneuria nymphs and another nymph which I am tentatively placing as Neophasganophora need to be definitely established. Two of these, one Acroneuria and the Neophasganophora, are certainly species which are additions to our list. The second Acroneuria nymph now unnamed may represent a light phase of a species already reared and known, but there is also a possibility that it may be new to our list.

List now nearly static.- Our studies have been thorough and comprehensive enough over the past eight years from the standpoint of various watersheds, seasonal timing and quantity to prove that few additional species can be added to the present Illinois list. This is further supported by our personal studies in Minnesota, Wisconsin and Indiana, and from material collected by others in Iowa, Missouri, Oklahoma and Tennessee. Material from these seven states indicates a stonefly fauna which cannot contribute many records to our Illinois list.

Although Illinois contains only about one-fifth of the $200+$ species of stoneflies known at the present time from North America north of Mexico, every family which I recognize is included within our borders except one-Peltoperlidae. Likewise, most of the North American genera are represented. From this it will be seen that a consideration of the family and generic groupings of the Illinois species has involved practically a study of the North American fauna as a whole, and I have been 
FRISON: STONEFLIES, OR PLECOPTERA, OF ILLINOIS

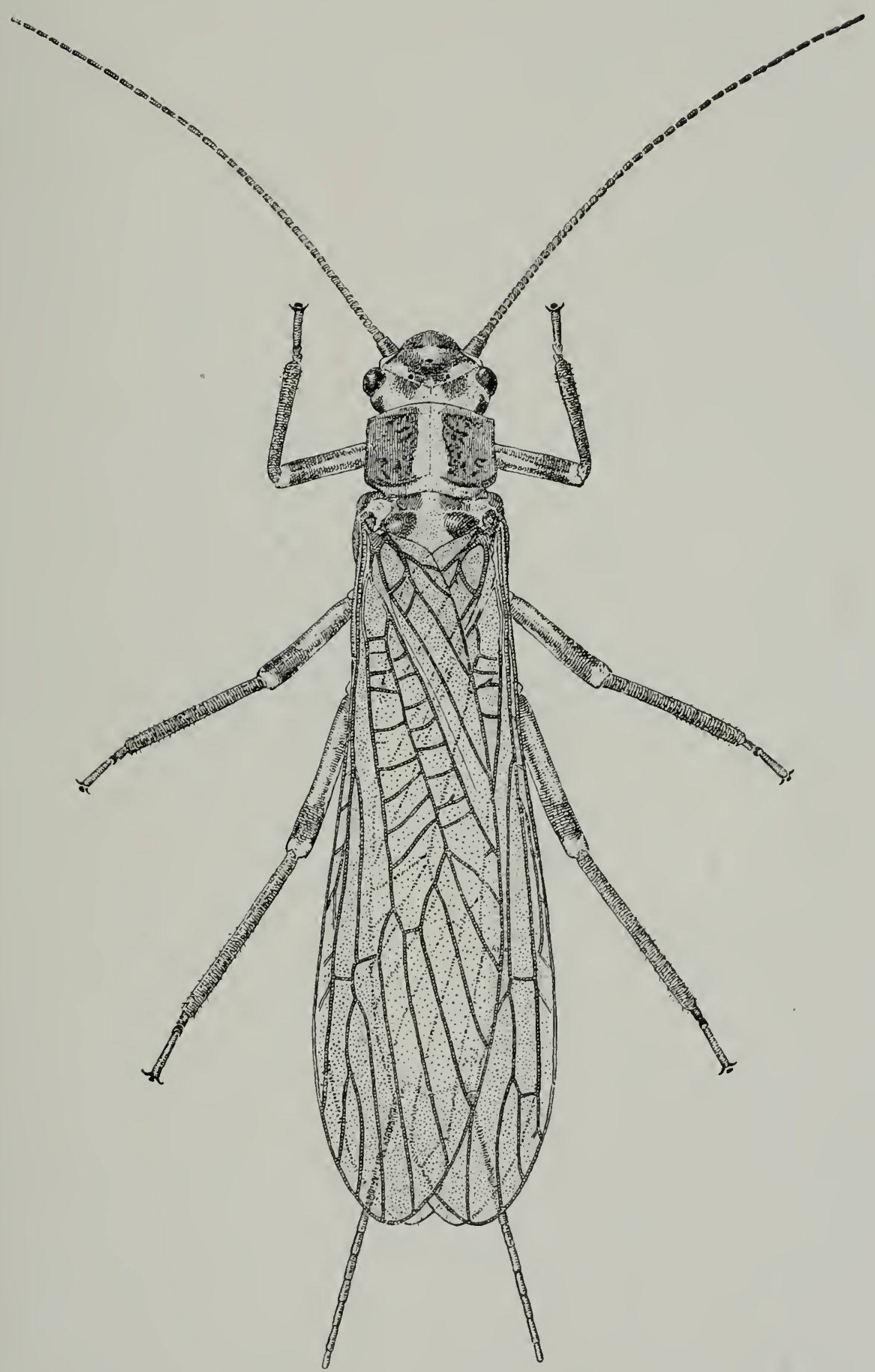

Fig. 1.-Rebresentative aduti of an Ilisols stoneflo, Isoperla confusa, female. 
compelled to think of my Illinois classification in such terms. Due to the kindness of various individuals throughout this country I have been able to study many species not found in Illinois and most species of particular importance in formulating a classification that is comprehensive.

New classification proposed.-Consideration of both nymphs and adults in these studies has convinced me that our past classifications contain many unnatural elements, particularly when many characters are evaluated in place of the few whose investigation has often become a fetish. As a result of this close study of adults as well as nymphs, in the laboratory as well as in the field, I am proposing a classification (p. 310) which

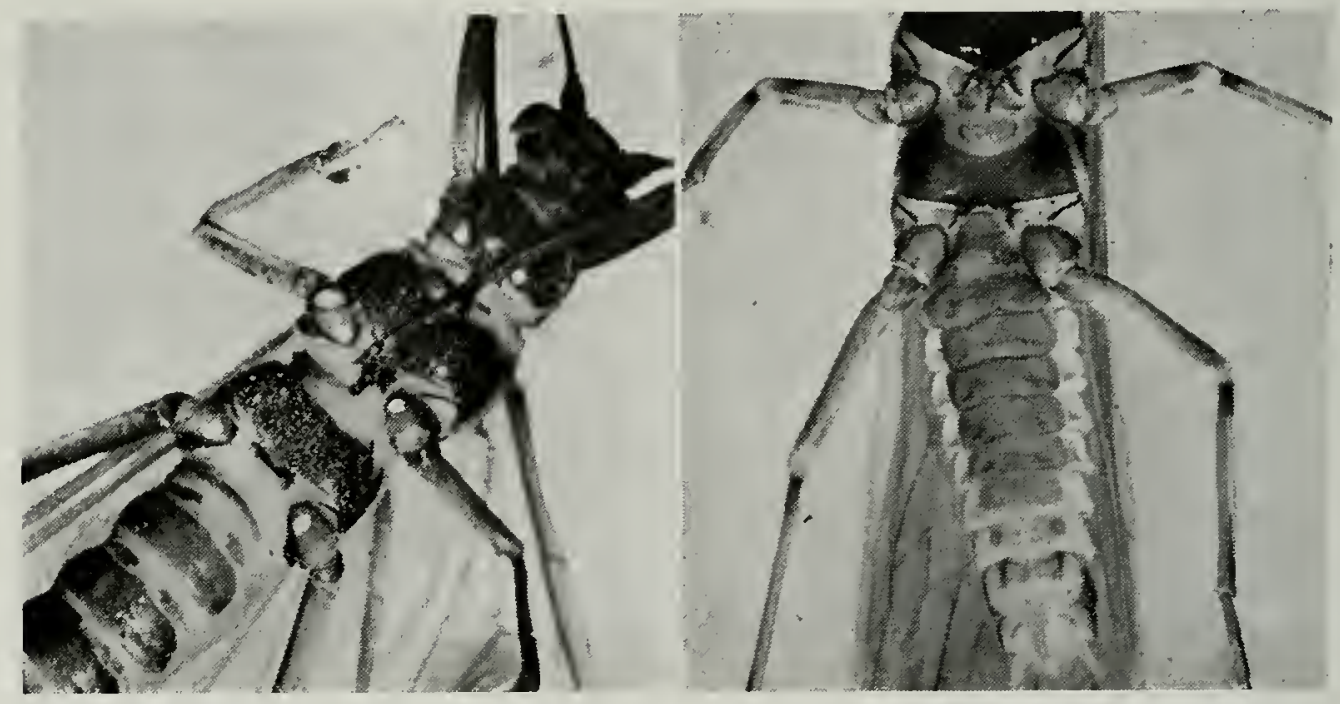

Fig. 2.-Ventral view of adult fenales, a.-(Left), Taeniopteryx nivalis, showing scars on coxae where tracheal appendages were attached to nymph. b.(Right), Strophopteryx fasciata, showing lack of scars on coxae as indicating no tracheal appendages on $n y m p h$.

departs from previous classifications of our North American stonefly fauna in concepts of families and genera. In some instances these changes coincide with the viewpoints of certain European students which have not been adopted by American students; in others they are new groupings or the remolding of old ones. It should be understood however that the classification here used is one independently formulated without regard to any special school, and is an attempt to develop a classification which can be supported by biology as well as by the morphology of both adults and nymphs. How well the prescnt classification fits this ideal will rest upon the results of future studies based upon a broad viewpoint.

With this in view I should like to repeat a statement from my previous report (1929) on the Illinois group, as follows: "The insect life of our inland streams affords a most interesting and profitable field for investigation; and the sooner we learn to place and evaluate this fauna correctly, the sooner we will be in a position to formulate conclusions 
and generalizations of importance in our efforts to understand our aquatic resources and to forward their intelligent use."

Sex and stage associations. - One of the objectives of the study of the stoneflies of Illinos has been the definite recognition and characterization of the various species found within the state. So that our concept of the various species might rest upon a secure foundation much effort has been spent to insure the correct association of males with females in the adult stage, and the nymphs or immature stages with their proper adults. Although such associations are often evident from a study of preserved specimens, due to aggregations of morphological characters in common, or other circumstantial evidence, conclusive proof of the correct associations of adult males and females and of nymphs with adults has been sought by rearings and careful field observations. Definite proof has been afforded by the capture of mating pairs. Although it is true that some of these associations between nymphs and adults hase been correlated previoushy and correctly by other workers outside of lllinos, well over half of the associations brought to light in this investigation are new and a goot many of the remaining halt are conciusivey established for the first time.

This investigation has forciby impressed upon the writer the great benefits to be gained by the correlation of field investigations and laboratory research. It is by sucin companion studies only that the sexes and immature stages of some species can be properly associatied for the first time, and the true taxonomic value of obscure specific characters revealed. 'There is a thrill and a practical angle ton in being able to visualize the preserved bodies that pass in review under our microscope as living entities once engaged in a siruggle for exisrence after the manner of their endowment by nature and in their natural cnviromments. A correctly named and preserved entomological specimen has its usefulness and place in our modern scheme of things in the same wall as has some standard unit of measurement in the custody of a bureatu of stindards of weights and measures, and perhaps more so because of the difficulty of adequate characterization. It is not however until such a specimen is associated with some knowledge of its place in nature that recognition of it can assumc general significance or be of practical value.

\section{STONEFLY STRUCITURE}

ADUlirs and nymphs of stoneflies present few formidable obstacles such :s a specialized terminology or complex morphological features, to hinder their identification. A minimum of study of either an adult or nymph will reveal that we are dealing with a generalized form which possesses many features common to neuropteroid insects in general. It does not requirc 
much imagination to see in the stonefly, too, evidences of kinship with an insect so often used in the laboratory as an introduction to insect morphology - the grasshopper.

Adults.-The adults, fig. 1, in general have practically the same characters as the nymphs. This similarity has not been utilized in the past as much as it should or could be used. Careful study of an adult makes possible a prediction concerning the general structure of the nymph and vice z'ersa. In general even the mouthparts of the adults are similar to those of the nymphs, except in the case of some species where certain

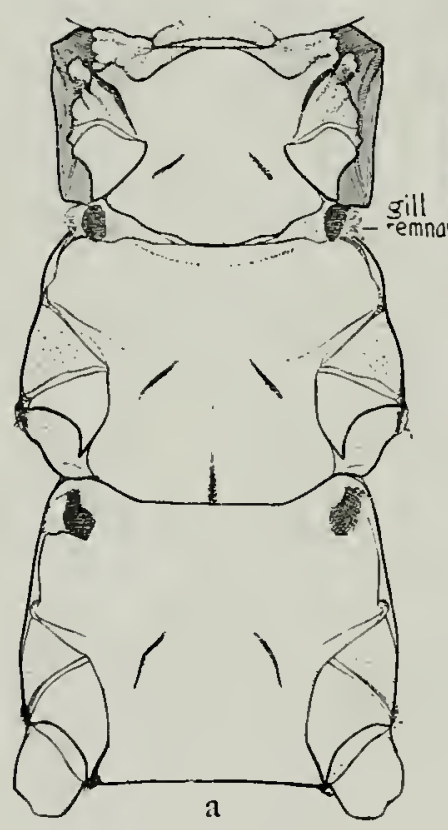

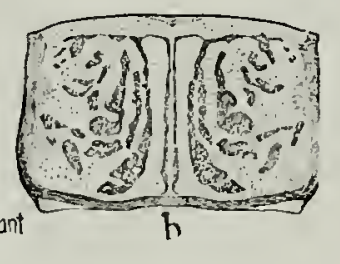

Fig. 3.-GILL STUBS AND COLOR PATTERN OFADULT Acroneuria abnormis. a. - Ventral view of thorax. $b$. -Dorsal view of prothorax of female. structures of the mouthparts are not functional. The number and location of nymphal gills are almost invariably indicated in the adult by some scar, fig. 2 , or remnant, fig. $3 \mathrm{a}$, of a gill. Descriptions of adults in the past have almost entirely overlooked the importance and usefulness of these vestigial structures and even detailed morphological studies of adults have been deficient in this respect (Clark 1934). Even the pattern of the raised rugosities on the pronotum of the adult, fig. $3 \mathrm{~b}$, is sometimes recognizable in the nymph. The wing pads of the nymphs, too, are often at a state of development where the venation of the adult wing can be perfectly interpreted, as stated by Claassen (1931). Likewise in a nymphal male about to produce an adult the genital structures may sometimes be seen through the nymphal skin to enable one to identify the species.

Nymphs. - The importance or value of characters used in the identification of stonefly nymphs varies greatly among the species, genera or families. In some instances color pattern and general size are sufficient for recognition of the species whereas in other instances the mouthparts, gills, etc. are very essential. In fig. + , which represents a hypothetical stonefly nymph, practically all terms used in this paper are associated with the structures to which they refer. Other figures in plates III, V, VII, XII, prepared to show greater detail of certain structures, are labeled to show the terms associated with them. (See p. 316 and following.)

In most cases the sex of Illinois stonefly nymphs can be determined by the condition of the setal fringe on the posterior margin of the eighth abdominal segment. In the males the fringe is continuous, and in the 
females interrupted, as is exemplified in Neophasganophora capitata, figs. 319,320 , p. +11 .

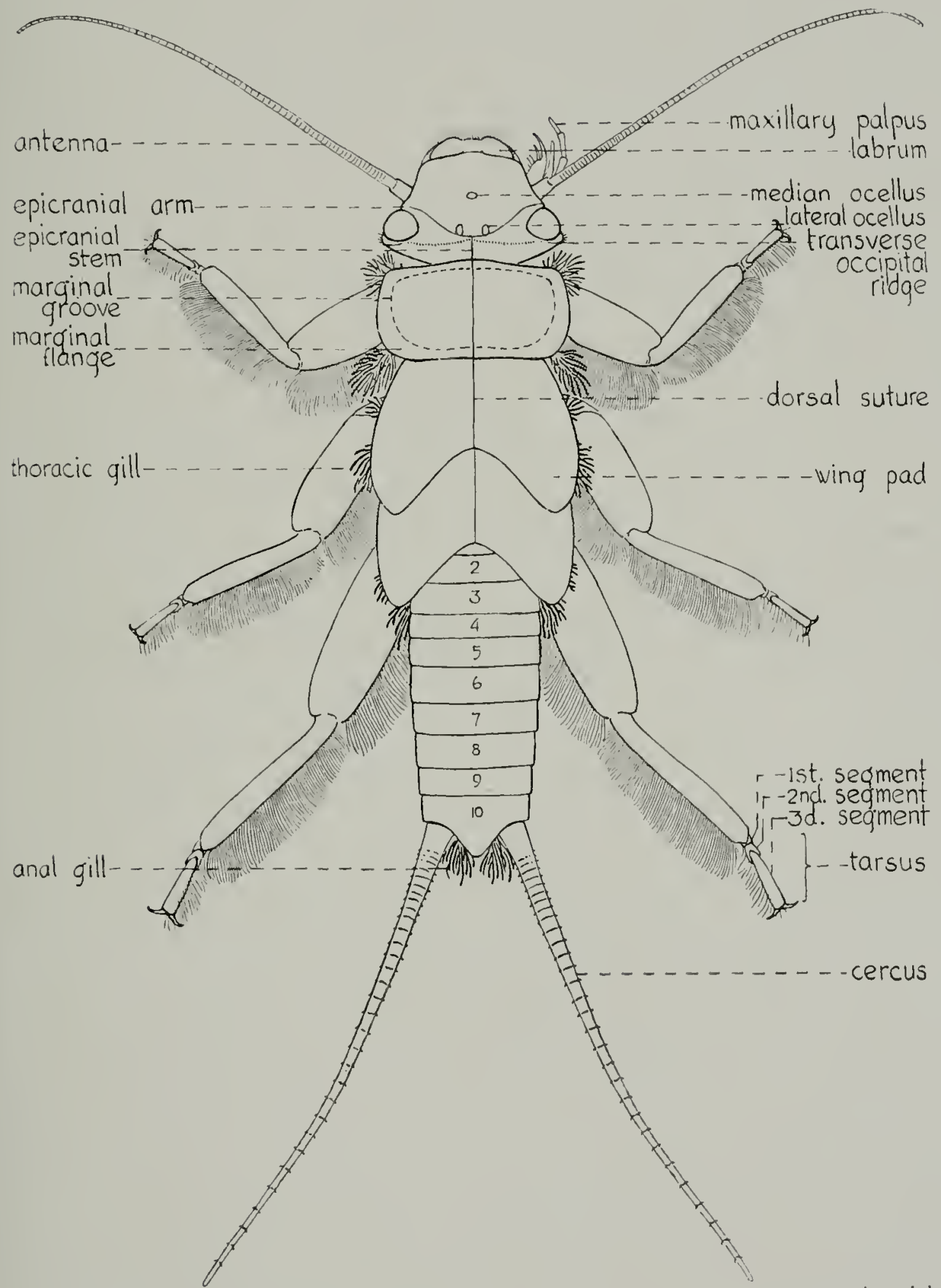

Fig. 4.-Stonefly parts. Dorsal view of a constructed stonefly nymph, with principal parts used in identification labeled.

The adults differ most noticeably from the nymphs in respect to identification by the addition in most all species of the fully developed 
wings, oftentimes the development of complex and characteristic genital structures, figs. 195, 2+2, the loss of fully developed gills where present in the nymphs, and sometimes degenerate, nonfunctional mouthparts. The specialized terminology of the wing veins is shown in fig. 171 and that of the genitalia in fig. 326. Other structures have approximately the same terminology as in the nymph. (See pp. 32t, 326, 330, +18.)

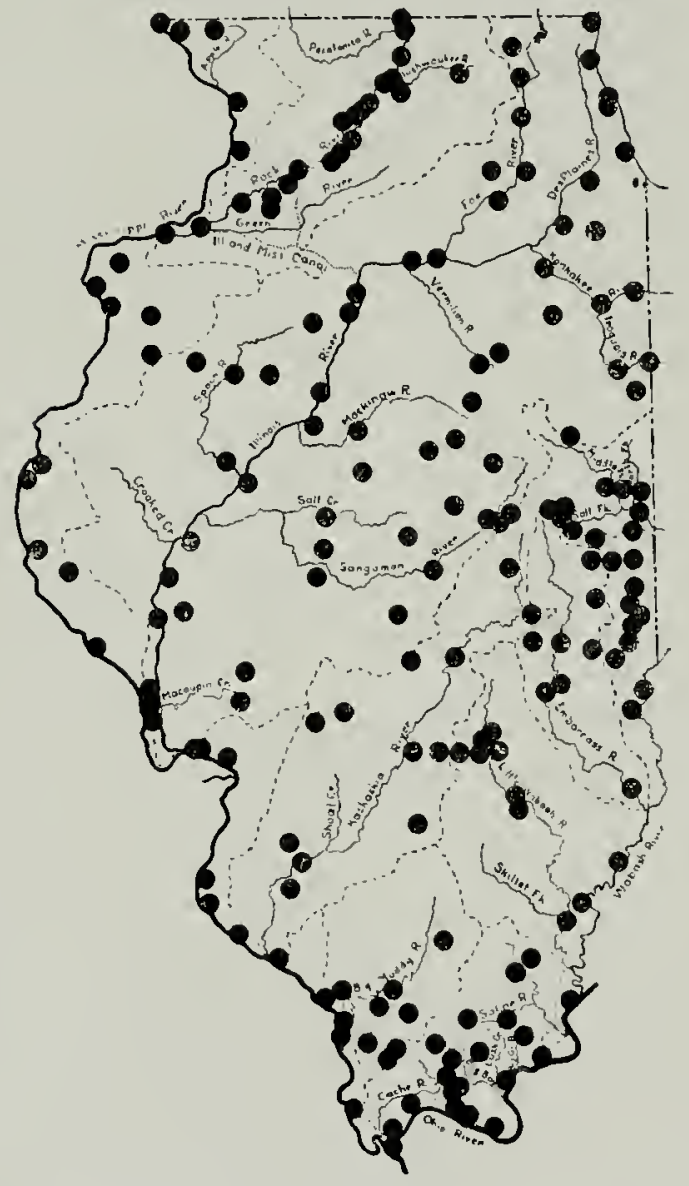

Fig. 5.-MAP of I llinois. Each dot represents one or more localities at which stoneflies were collected during the course of this study.

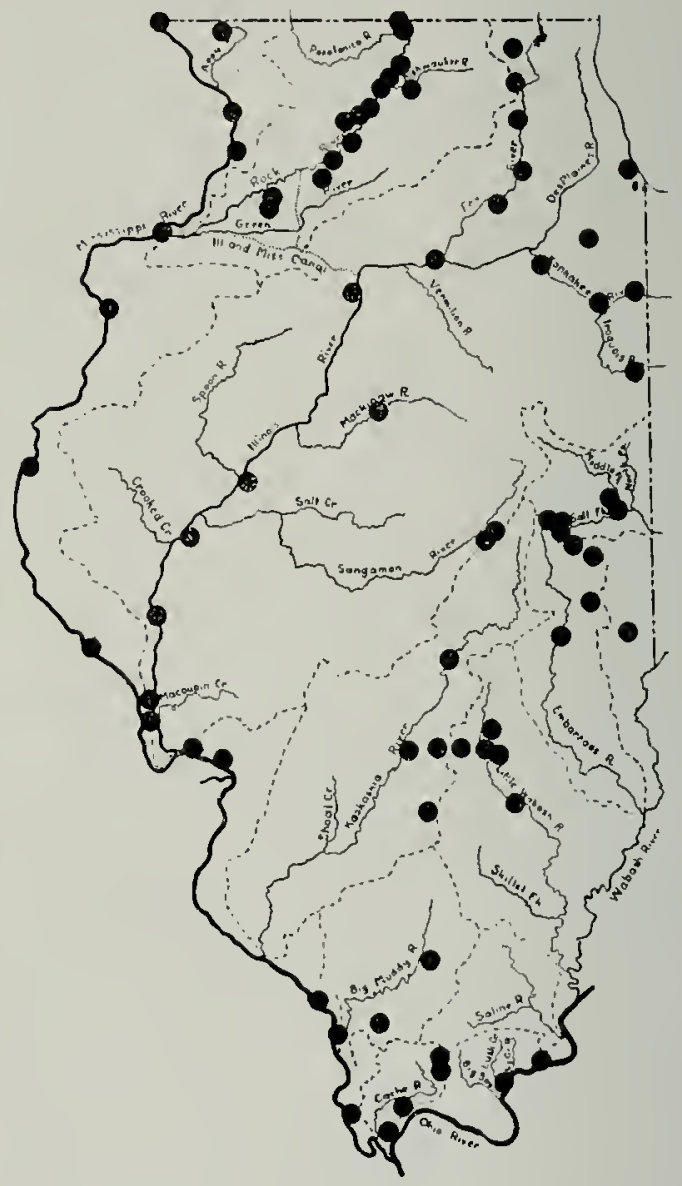

Fig. 6.-MAP of lllinois, SHOWing distribution of Perlesta placida. Each dot represents one or more localities at which this insect was taken.

The types of all new species or varieties described in this paper are deposited in the collection of the Illinois State Natural History SURVEY.

\section{BIOLOGY OF THE ORDER}

THE following are brief comparative accounts of some aspects in the life of stoneflies found in Illinois which are of general biological or ecological interest. More specific data appear in connection with the remarks concerning each species.

Distribution.- The stoneflies of this state, although comparatively poor in number of species for an order, follow the rule of other large 
units of closely related species in displaying differences in zoögeographical distribution within our boundaries. Analysis of our fauna in comparison with other states shows it to be made up largely of species which may bo classed as common to most states in the Mississippi valley and eastem North America, together with a few elements more characteristic of areas: to the north and southeast of our horders. 'The Rocky mountain or

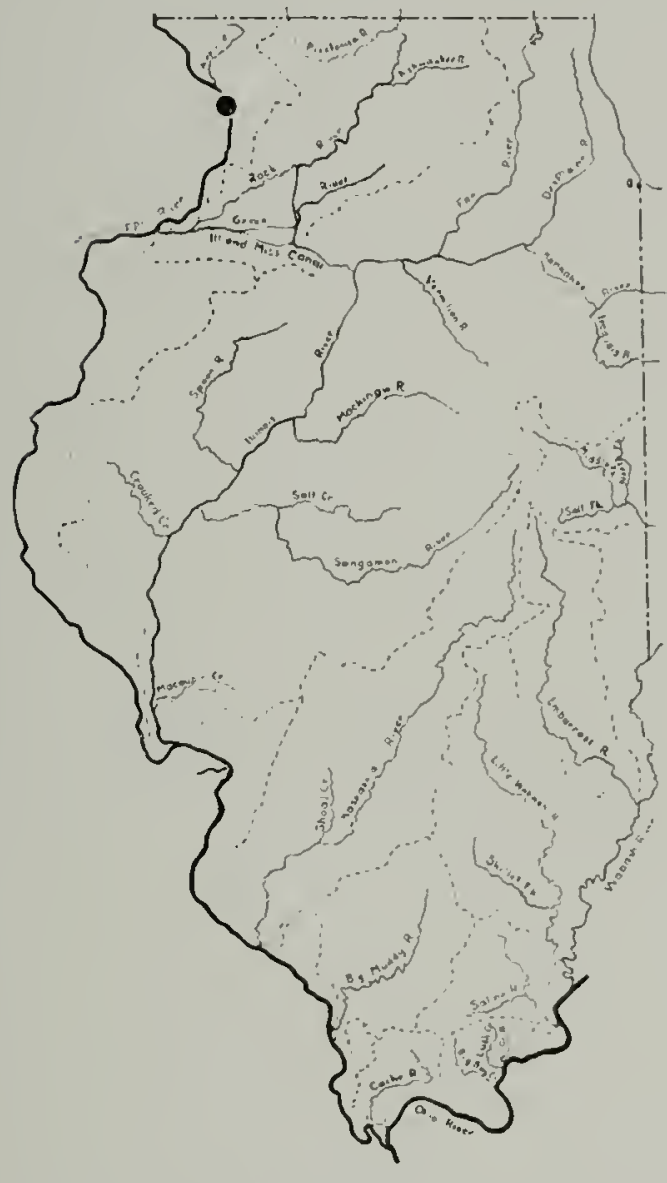

Fig. 7.--Map of lllinois, showING OCCURRENCE OF Togoperla media. This species has been taken but once in the state, in the Mississippi river.

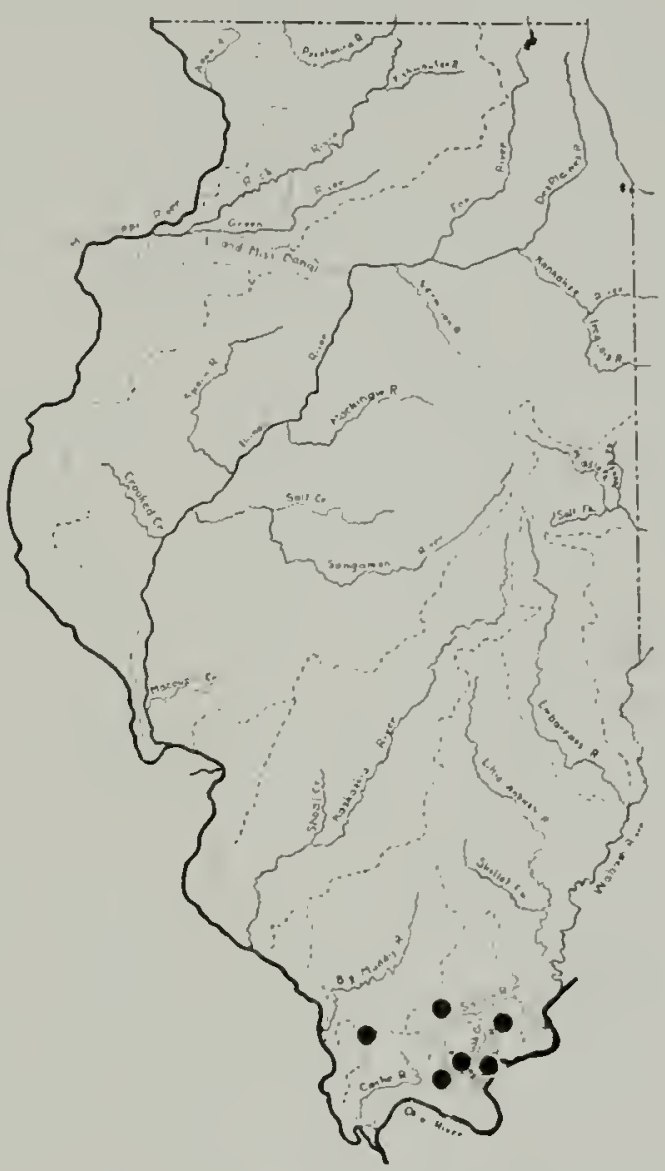

Fig. 8.-MAl of Illinols, SHOW JNG DISTRJBUTION OF Allocapria forbesi. This species is restricted to the Ozark uplitt in extreme southern Illinois.

extreme western element in our stonefly fauna is entirely lacking, unless it is represented by two species of nymphs which have not as yet been associated with a name, or by a pair of adults whose general distribution outside Illinois is unknown.

It is likely that many of our Illinois stoneflies can be collected in any part of the state where streams of the size and character required by the nymphs are available, fig. 5. Under this grouping we may list our most common species, Acromeuria aburmis, Allocapnia granulata, Allocapnia rivipara, Isoperla bilineata. Neoperla ilymene. Perlesta placida, fig. 6, Strophopteryx fasciata and Taeniopteryx mizalis. One of our species. Togoperla media, has been taken only once in extreme northwestern Illi- 
nois, fig. 7, and our studies in Wisconsin indicate that it is a more northern form becoming most numerous in the colder waters of extreme northern Wisconsin. Several species, such as Allocapnia pygmaea, Allocapnia forbesi, fig. 8, Leuctra claasseni and Isoperla decepta, represent more southeastern or southern forms.

Instances of discontinuous or sporadic distribution are afforded by such species as Allocapnia recta, Allocapnia illinoensis, Hydroperla varians and Isoperla mohri. Our records for Hydroperla harti indicate that this

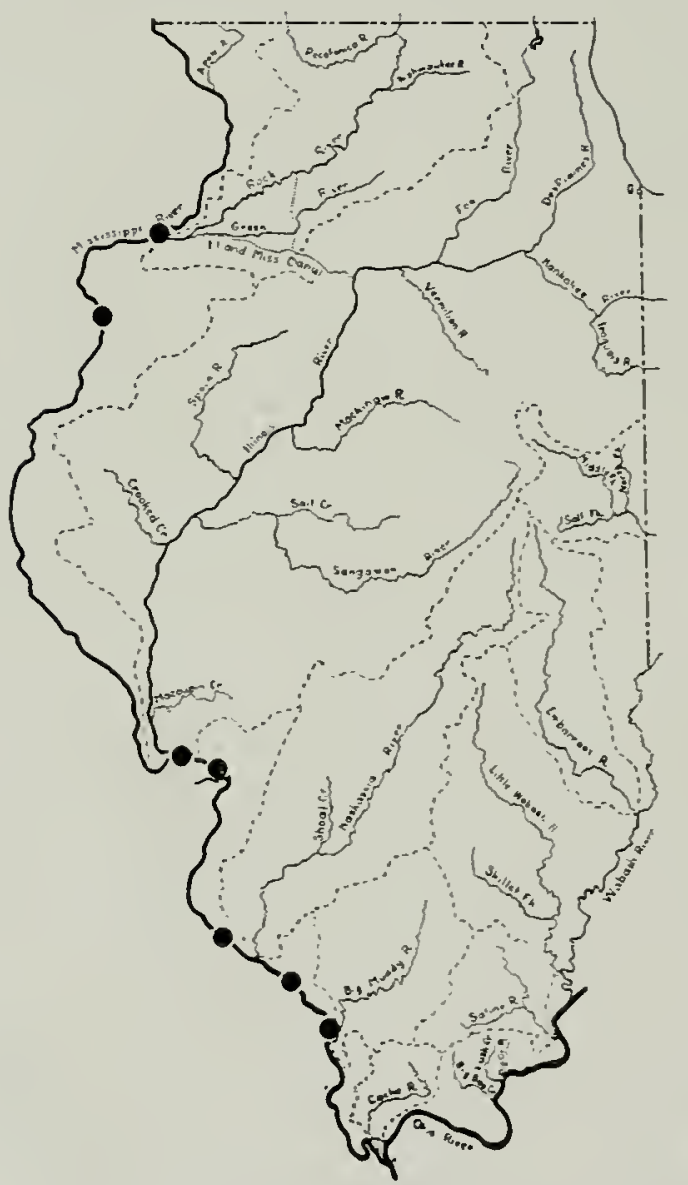

Fig. 9.-MAP of Illinois, ShOWiNG THE DISTRIBUTION OF Hydroperla harti. This species has been taken from only seven localities in Illinois, but these are distributed the length of the Mississippi river. species has an extreme affinity for the inain course of the Mississippi river. fig. 9. Two other interesting local distributional areas as we now know them are as follows: the abundance and concentration of $H_{y} d r o p e r l a$ crosbyi and Isoperla minuta in rich soil areas which in an earlier and natural state were once mainly prairie, and our failure to find Isoperla richardsoni elsewhere than in the Rock river. Taeniopteryx pariula is another species seemingly with a preference for the larger watercourses of the state without regard for latitude or longitude. Some species, such as Nemoura zenosa, Atoperla ephyre, Perlinelln drymo, Acroneuria ruralis, Acroneuria internata, Acroneuria arida, Pteron. arcys nobilis and Isoperla confusa, have such a spotty distribution that local differences, river sizes, etc. are probably the determining factors in their distribution in this state, rather than watershed areas or differences in zonal preference.

Habitat preferences.-In discussing the fall and winter stoneflies the writer (1929) went into considerable detail to develop the idea that marked and different habitat preferences were displayed among the nymphs of the members of the fall and winter fauna. Expansion of our field investigations to include those forms emerging as adults in the spring and summer months has brought added emphasis to the fact that species competition among the stoneflies is eliminated to a great extent.throughout 


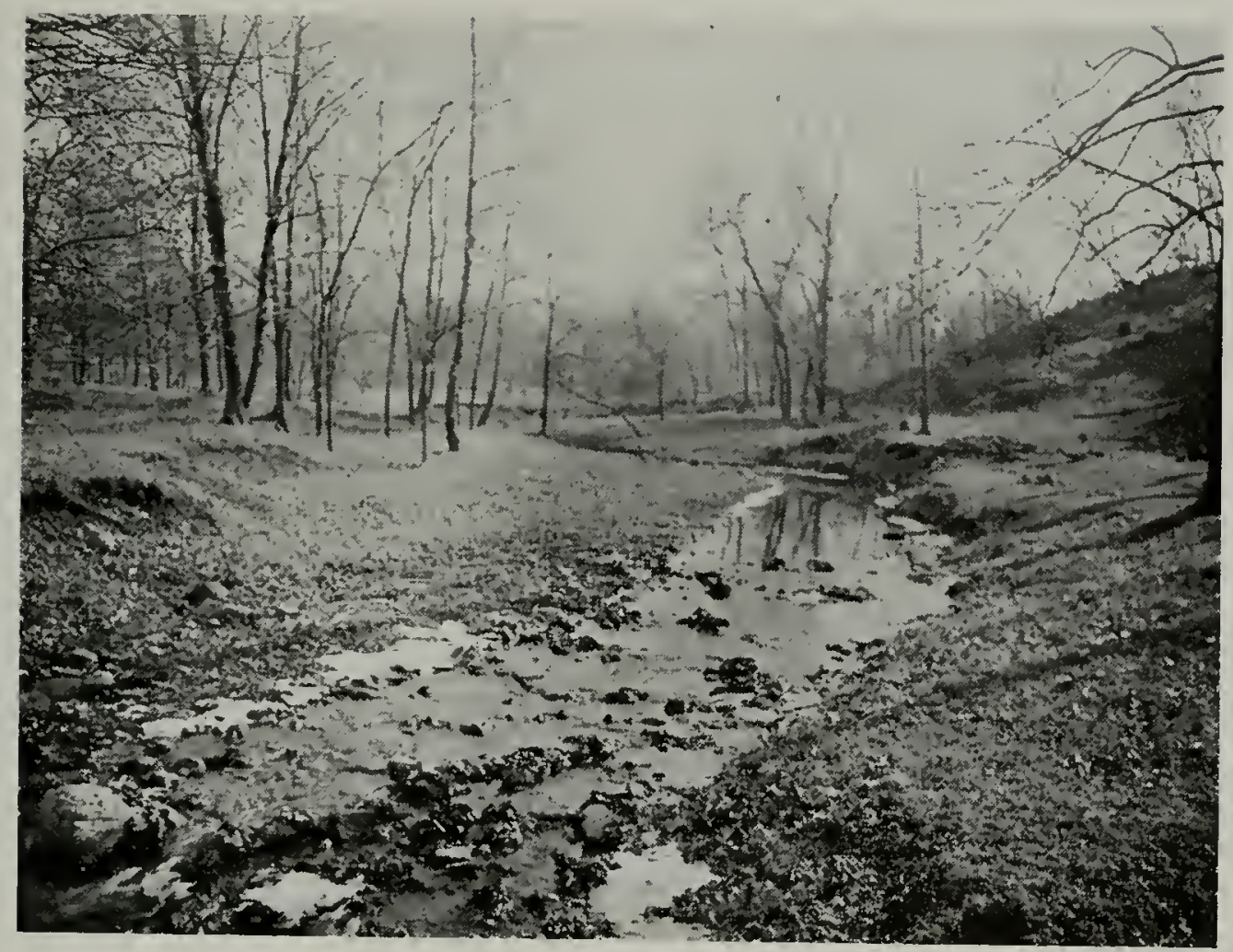

Fig. 10. - Ty'rical small stream habitat of Illinols stoneflies. This tributary, which flows into the Salt Fork near Oakwood, afforded collection of Allocapnia mystica and $A$. vivipara.

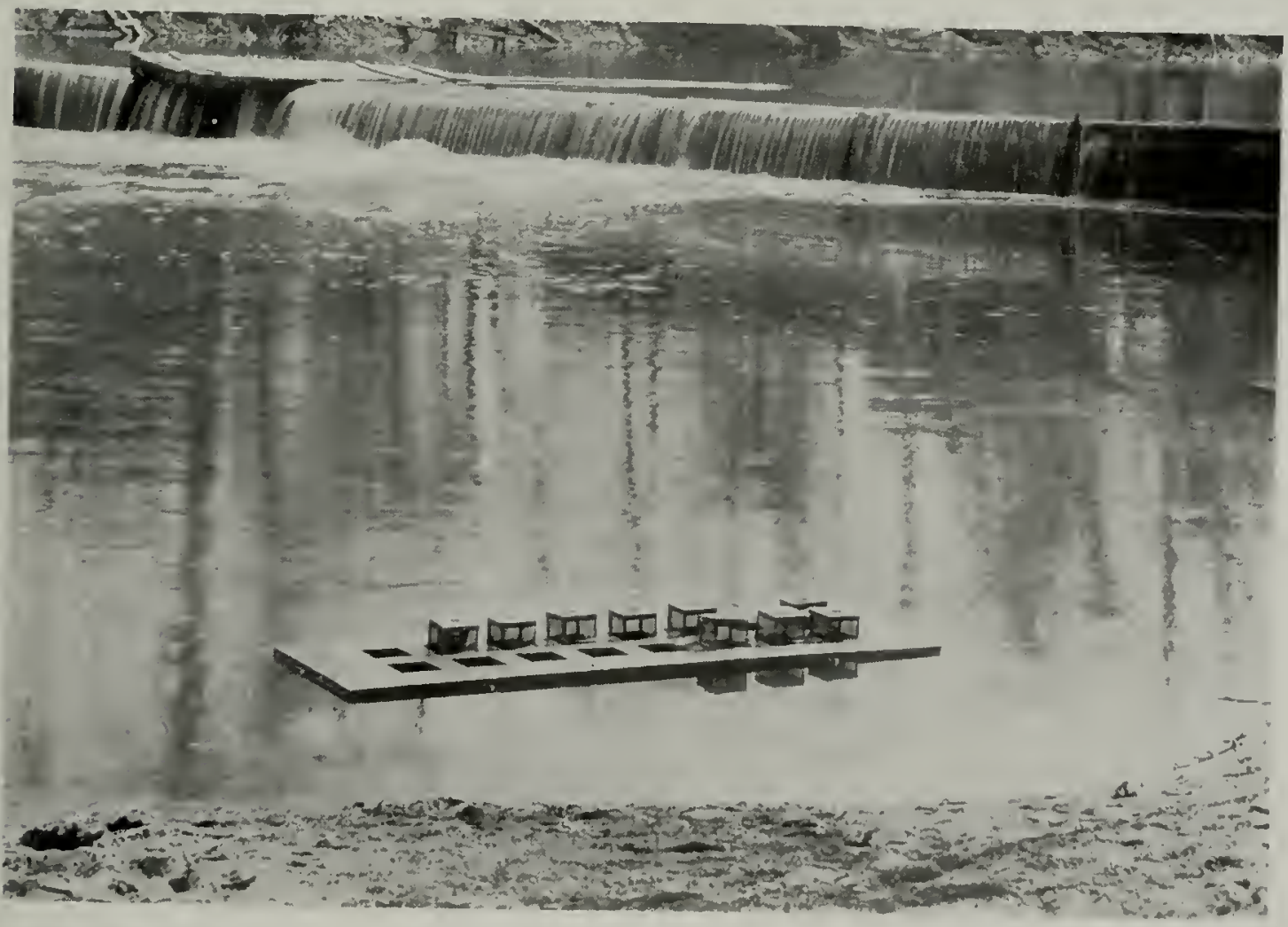

Fig. 11.- Raft of rearing cages in natural habitat. Shallows below dams such as this on the Salt Fork at Homer yield Strophopteryx fasciata and Neophasganophora capitata. 
the entire year by the differences in habitat preferences of the nymphs. Of course I do not mean that two species of nymphs belonging to the same general seasonal succession and having practically the same feeding habits never occur together. As a rule however the combination of seasonal succession, feeding habits and habitat preferences is such as greatly to reduce competition.

Many species, such as Allocapnia recta, Allocapnia illinoensis, Allocapnia mystica, Allocapnia pygmaea, Isoperla decepta, Isoperla mohri and

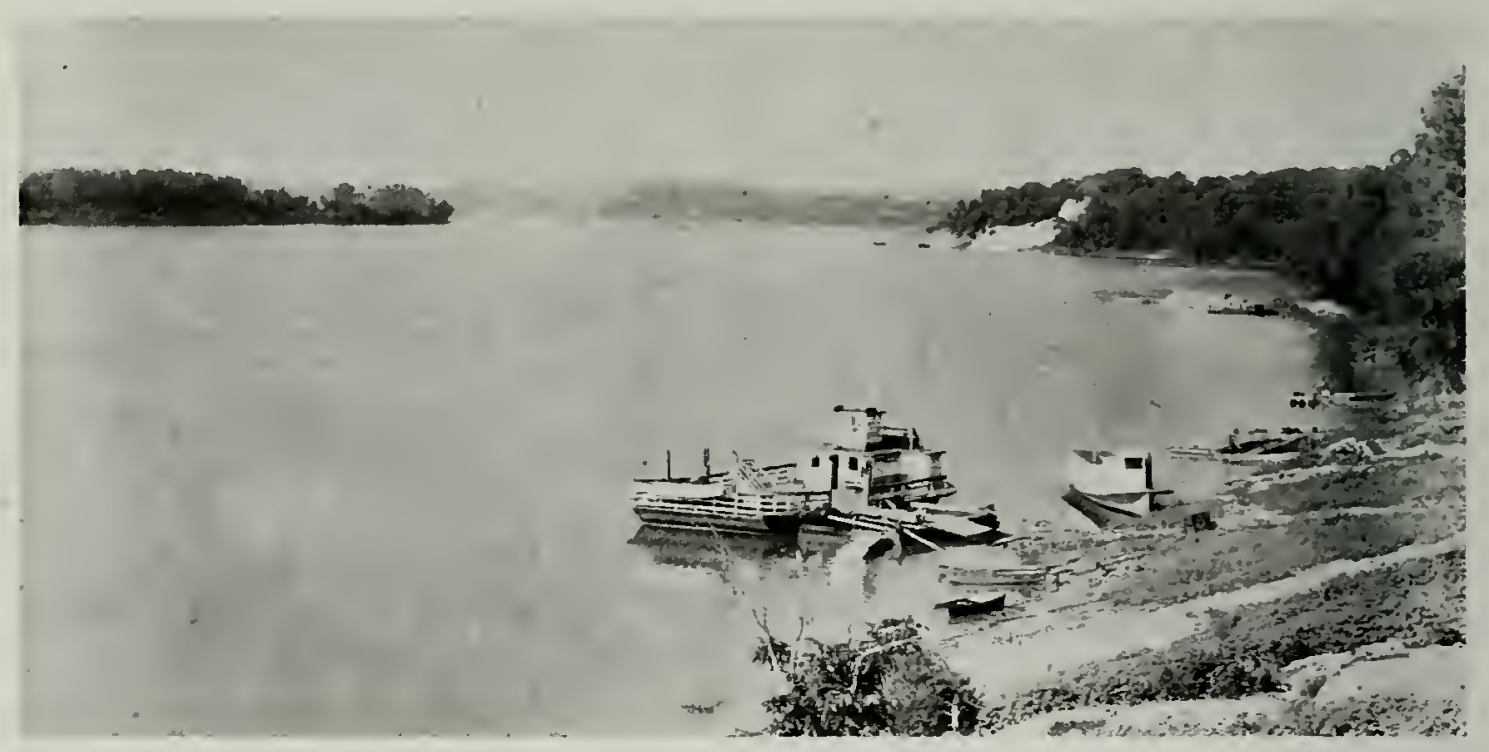

Fig. 12. - Trpical large river habitat of Illinois stoneflies. At such places along the Ohio near Elizabethtown Taeniopteryx nivalis and Acroneuria abnormis were collected.

Leuctra claasseni, are found in Illinois only in very small streams, fig. 10. Others, such as Pteronarcys nobilis, Acroneuria ruralis, Taeniopteryx parvula and Isoperla bilineata, are found mostly in the large rivers, fig. 12. One factor accounting for this habitat preference is the fact that large. stoneflies requiring more than one year to complete their development are excluded from small streams which often go dry. Medium sized streams, fig. 13, usually offer the best variety of stoneflies because they are often frequented by the large as well as the smaller species. Within certain limits one can generalize to the effect that stream size preferences on the part of stoneflies are correlated with body sizes of the nymphs or adults; or the larger the stonefly the larger the stream preferred, and vice versa.

Stream size is however only one of the elements involved in habitat preferences. Carnivorous species must frequent those places teeming with other forms of aquatic invertebrate life and herbivorous species demand places where their food is abundant. Some species prefer the faster water of a stream whereas others prefer sluggish water. In my experience the nymphs of Neophasganophora capitat 7 are most abundant in rapid water 
where the river bed is rocky, or in rapids below dams, such as exists at Homer, fig. 11, Oregon and Sterling, Illinois. Acroneuria ruralis, on the other hand, is usually found in trash in deeper water having less current.

Many species, such as Hydroperla crosbyi, Taeniopteryx nivalis, Isoperla confusa and various species of Allocapnia, congregate in masses of leaves which lodge against rocks or vegetation growing in or protruding from the water, fig. 1t. These same species also frequent the shallow margins of streams where they hide under the leaves which collect in the

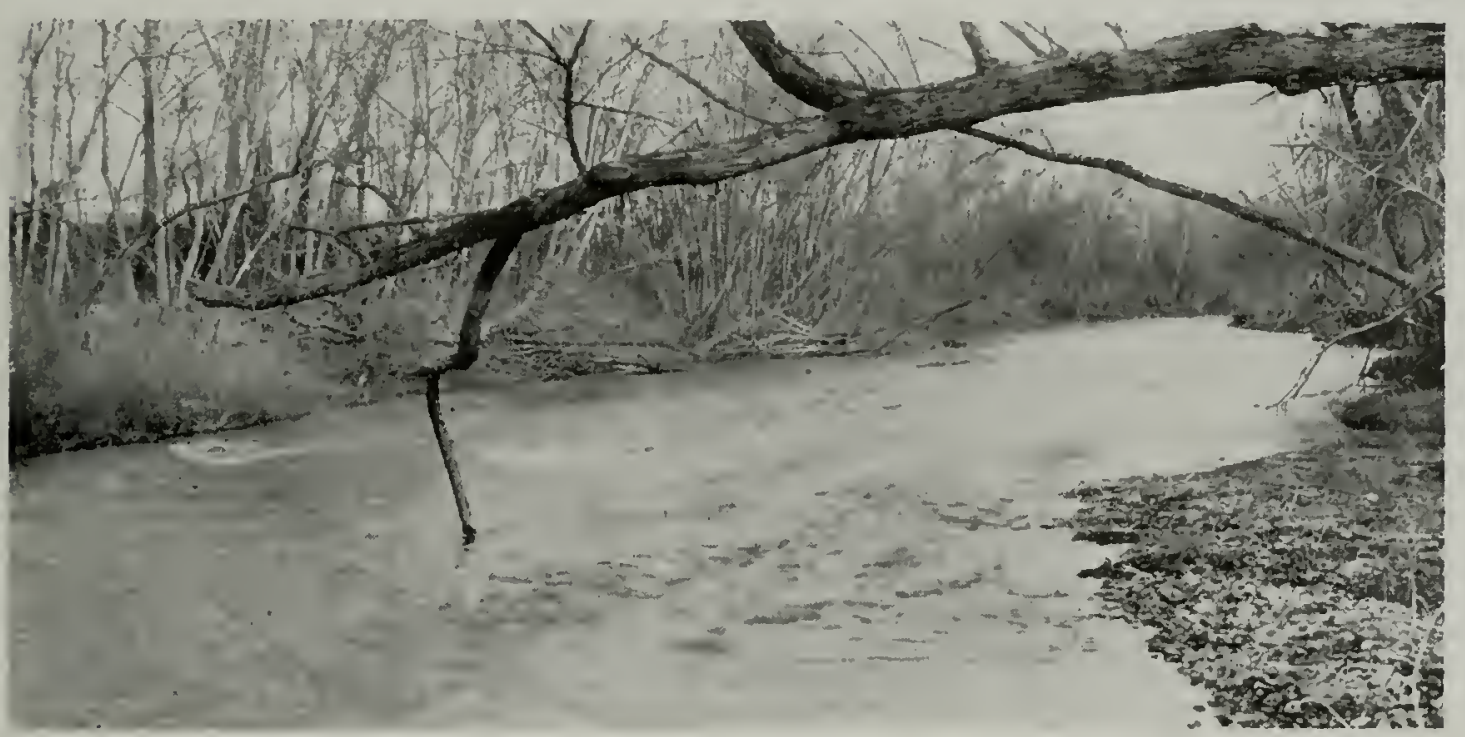

Fig. 13. - TYPICAL MEDIUM SIZED STREAM Habitat OF Illinols STONEFlies. At such places along the Embarrass near Charleston and in similar streams throughout the state, Acroneuria internata, Pteronarcys nobilis and Hydroperla crosbyi are to be found.

water along the banks. The nymphs of Perlesta placida and Neoperlat clymene exhibit in my experience a preference for hiding away in the algae and other forms of aquatic vegetation growing on and among the rocks in fairly rapid water.

The type of bottom of a stream, as already indicated in what has been said regarding certain species, is an important factor in governing the concentrations of different species of stonefly nymphs. Isoperla decepta and Isoperla mohri have been found only in small streams with a considerable amount of sand bottom and Isoperla minuta in abundance only in small streams rich in organic matter and with muddy bottoms.

From the standpoint of habitat preferences the adults of stoneflies are less noteworthy than the nymphs because of their restricted life span and type of activities. The adults are usually found close to the waters in which the nymphs develop but at times fy considerable distances away from water. The nocturnal forms are frequently attracted to lights. The egg laying habits of the adult females do have a direct bearing on con- 
centrations of nymphs; females of species frequenting the larger or medium sized streams fly into or drop their egg masses into the water where the nymphs will find conditions most satisfactory, and females of many of the smaller species which inhabit very small streams crawl into the water at points where the nymphs thrive best.

Seasonal adjustments. - In a discussion of the seasonal adjustments of stoneflies we are forced to consider mainly the adults. This is because the nymphs are difficult to find when in their first instars, the duration

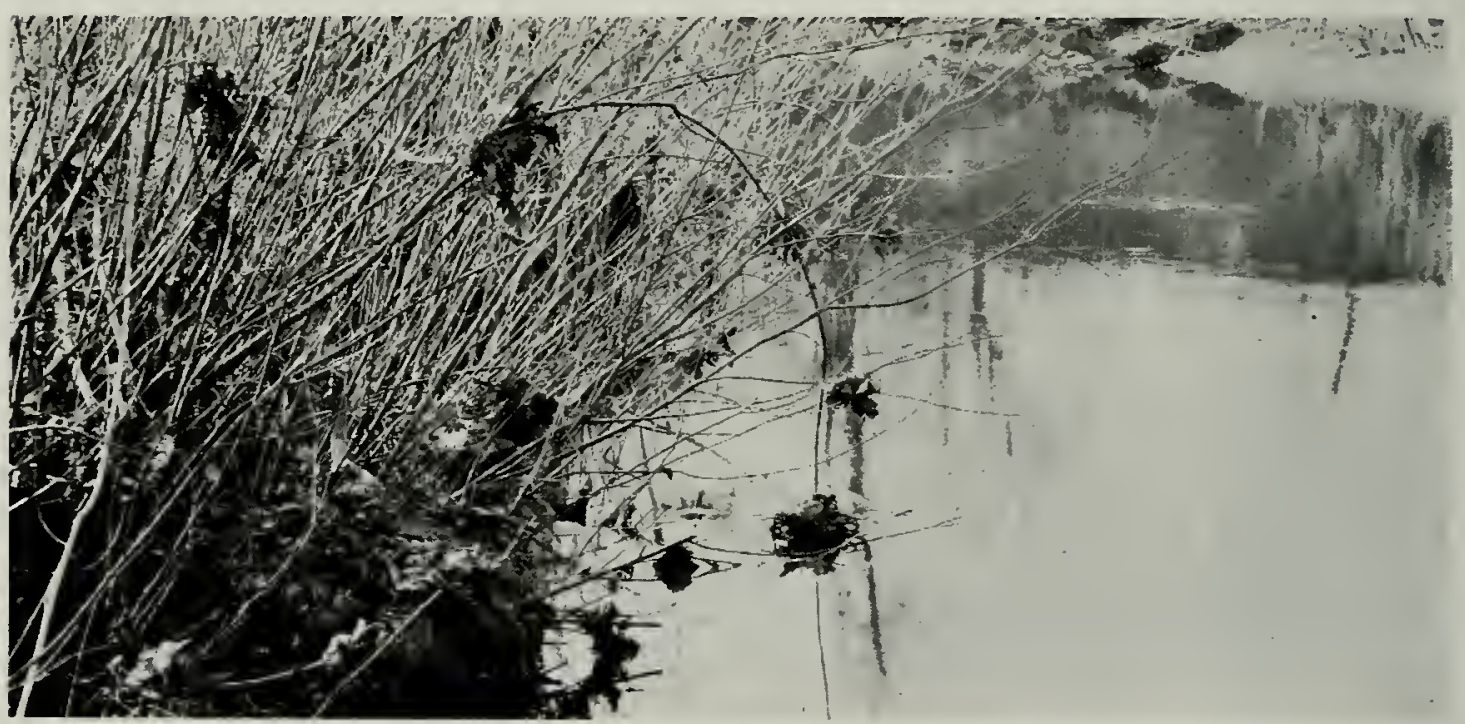

Fig. 14.-TyPical MEDIUM SIZED StREAM HABITAT OF ILLINOIS STONEFlies. Leaves and debris at the end of branches trailing in the water along Big Creek near Oliver and in similar streams throughout the state are the favorite habitat of Isoperla confusa and Hydroperla crosbyi.

of the egg stages is practically unknown, and due to some species requiring more than a year to reach maturity there is an overlapping of generations. The adults however present an exceptional picture of seasonal adjustments and we are able with the data in our possession to give a very adequate picture for this order as a whole. Detailed information relating to collection dates for the species is presented in connection with the accounts or descriptions of each, beginning page 334 .

One of the most striking features of the seasonal succession of stoneflies in Illinois is the existence of a varied and abundant fall and winter fauna which gives us a continuous seasonal range of species from late fall until late summer. Most large groups of insects familiar to the general entomologist or layman emerge as adults in the spring, summer or fall and during the winter montlss hibernate in some stage or other. The fact that about one-third of the species of the order Plecoptera in Illinois emerge as adults, mate, feed and carry on all essential activities for the perpetuation of their species in the coldest months of the year is indeed 


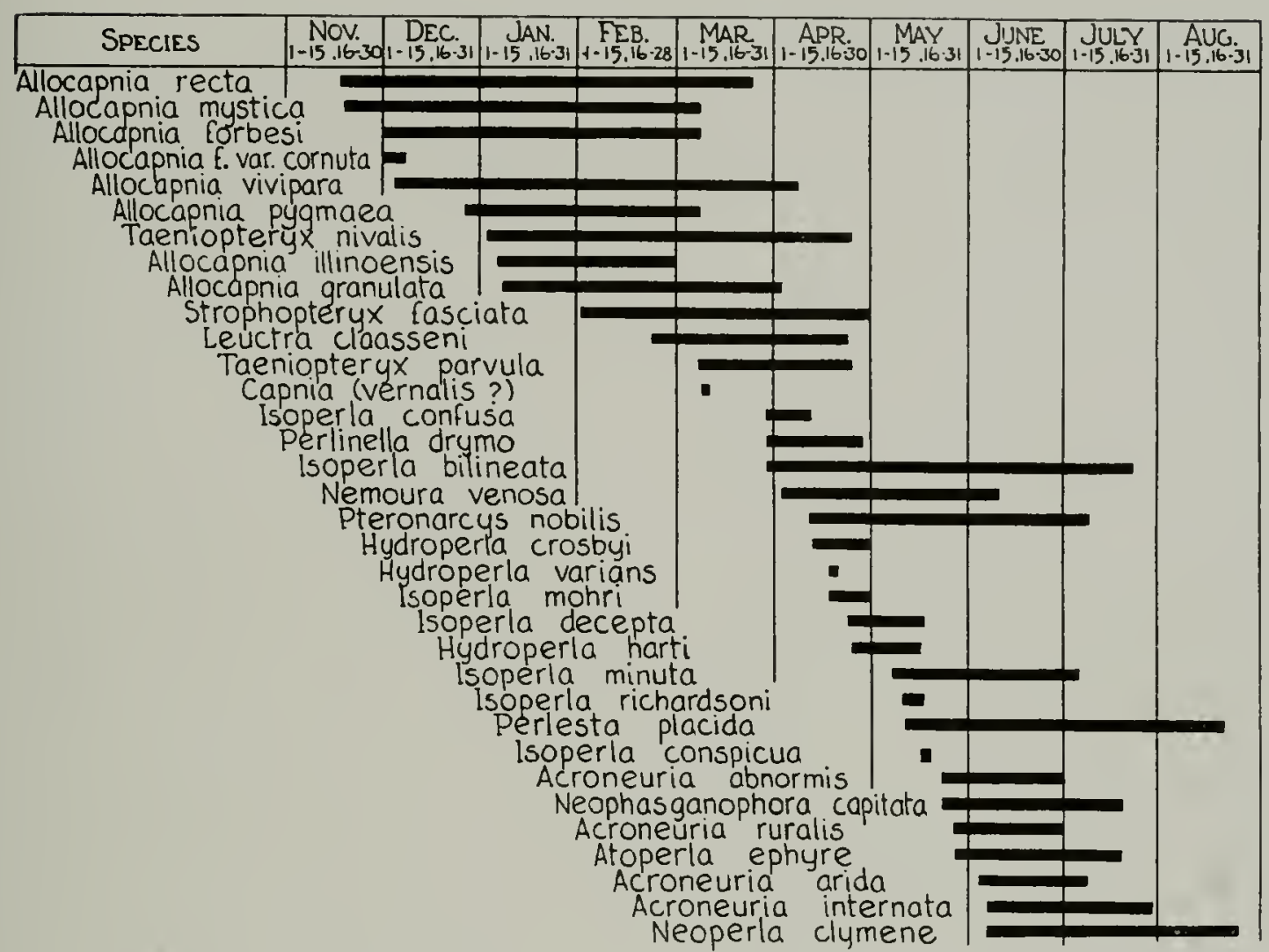

Fig. 15. - Seasonal distribution. Adults of the 34 species of Illinois stoneflies charted here are timed to occur almost throughout the year. Two species listed in this work are omitted from the graph because of insufficient data.

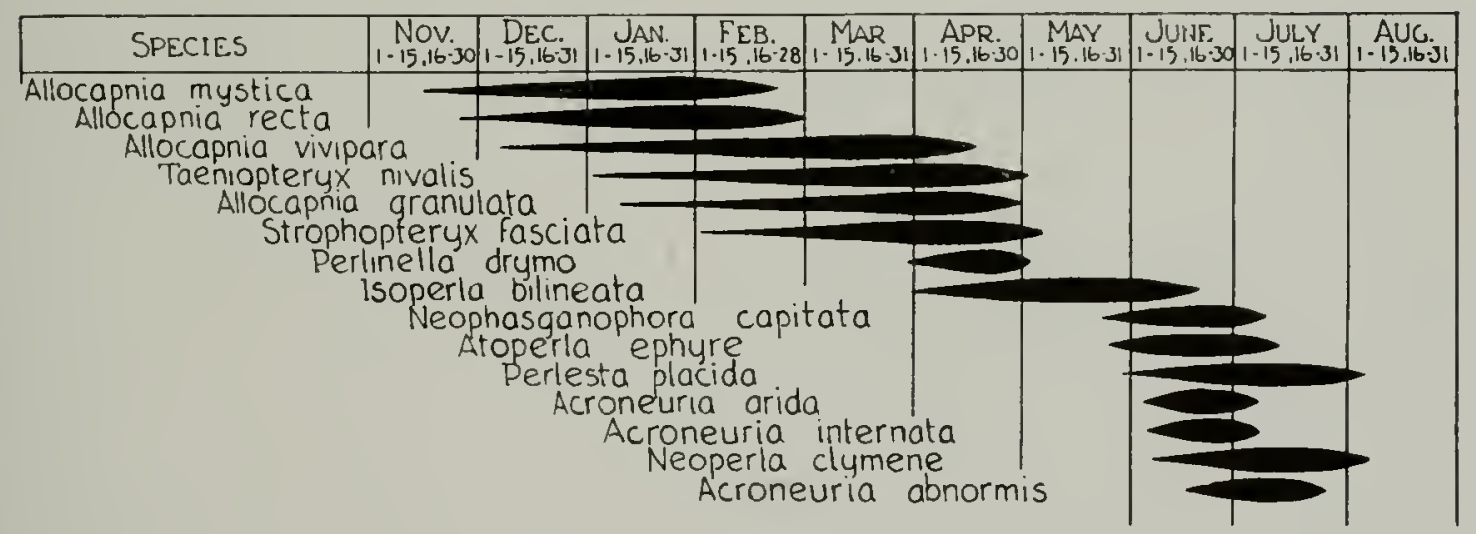

Fig. 16.-Seasonal succession. The widest part of the spindle indicates the time of maximum abundance of adults for each of these 15 stonefly species which occur in the vicinity of Oakwood, Illinois.

unique among the major insect orders of the state, and something meriting more emphasis in general texts. I have previously commented (1929) on this as follows: "Such phenomena cannot fail to excite wonder and forcefully bring to mind the wonderful adaptiveness of the insect world -one of the chief reasons why insects so outnumber all other kinds of animal life."

In figure 15 I have plotted the seasonal distribution of the adults 
of $3+$ species of 1 llinois stoneflies based upon our collections and rearing data. For the most abundant and common species the seasonal ranges indicated on the graph adequately picture the time of occurrence of the adults. Two of the 36 species now definitely listable by species name in our Illinois faunal list have been left out of the graph because seasonal data are lacking, or because we have not collected or reared them. Figure 15 shows the extraordinary scattering of adults throughout almost the entire year, the concentration of herbivorous species during the colder months and the tendency for the species most abundant and widely distributed to occur as adults over a comparatively long period.

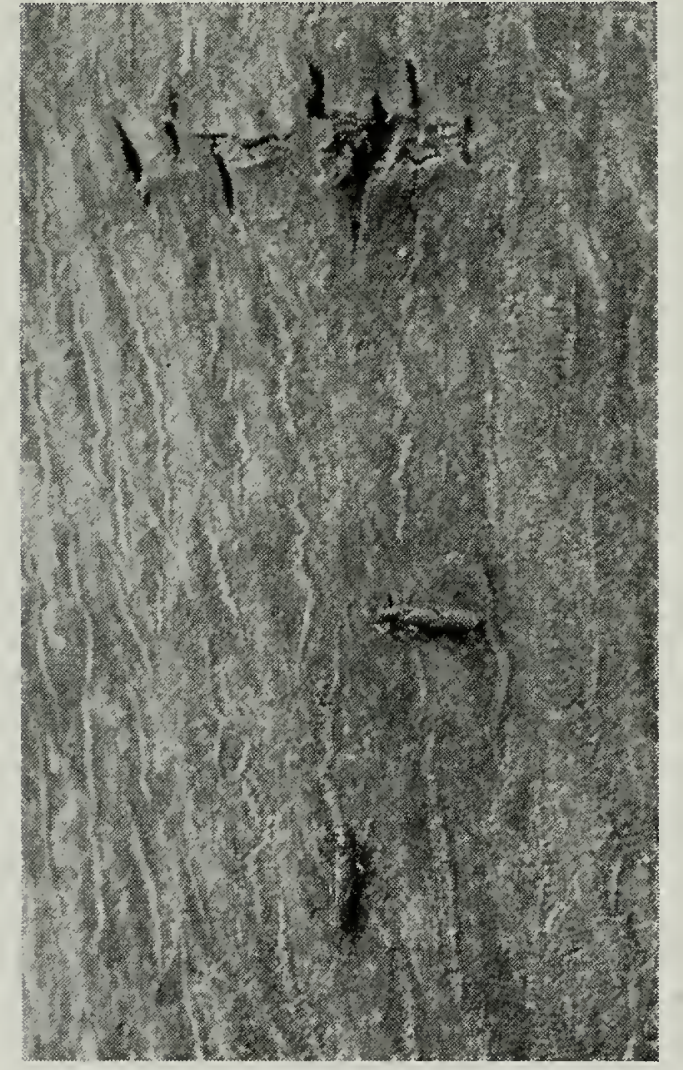

Fig. 17.-STONFflies FEeding ON ALGAE FROM TREE TRUNK. These adult females of Allocapnia mystica were observed December 27, 1928, near Oakwood, Illinois.

It should be explained, of course, that these long seasonal ranges for the adults of certain species as shown in fig. 15 are subject to contraction sometwhat in proportion to the size of the territory, especially north to south, covered by the available data. Climatic differences between northern and southern Illinois are sufficient to hasten the date of emergence in the southern end of the state and to retard it in the north.

To illustrate that the seasonal succession of adults is a very pronounced phenomenon even in a restricted locality, another graph, fig. 16 , is presented, illustrating the seasonal timing of adults of 15 species which occur in the vicinity of Oakwood, Ill., a small town near the Salt Fork river not far from Urbana and readily accessible at all times of year. This graph confirms the above general conclusions drawn from fig. 15. If this graph differs in any way, it is that the winter species are more apt to be found as adults during a longer period than the summer forms-something more obscured in fig. 15 because of the more extreme north and south latitudes considered. The spindles of fig. 16 indicate the extent and duration of specific abundance and further point out the scattering throughout the year of species mentioned in connection with the first graph. Although many species overlap, the timing of their maximum abundance differs. 
As our studies of the fauna of Illinois progress it will be most interesting to compare one order of aquatic insects with another and to correlate the whole from an ecolugical point of view. The thoroughness of our quantitative and qualitative collecting, enabling comparative studies, is indicated by the numerous localities which have provided the data for this paper, as shown in fig. 5 .

Habits of adults. - Already discussed in part, the adult habits will again be referred to in the catalog of species, beginning page 307 . Here then it may be profitable merely to summarize general information which inay be of interest and use to those who are not special students of the stoneflies.

FEEDING.- I have discussed (1929) in considerable detail the feeding habits of the fall and winter species and shown that adults belonging to the genera Allocapnia, Taeniopteryx and Strophopteryx are herbivorous and that blue-green algae are a favorite food, fig. 17. Observations since then definitely expand this group of herbivores to include Leuctra, Nemoura and at least two species of Isoperla. The remaining genera, and partly Isoperla, are nonfeeders.

By and large, if we separate the genera on the basis of whether they feed in the adult stage we have one group of feeders which contains the fall and winter stoneflies, except for a few Isoperla, and a second group which are nonfeeders, recruited from the spring and summer forms. The adults which feed are possessed of well formed and sclerotized mandibles, and in those which do not feed the mandibles are flabby. Thus a study of the mouthparts of the adult is almost a sure clue as to whether the adults feed.

In discussing Isoperla, a generic name which I use in a broad sense, I have indicated that future studies will probably show the necessity for breaking up this single genus into several. The fact that Isoperla as now used contains species which do and do not feed in the adult stage, correlated with mouthpart development, is evidence in this direction. Roughly, the nonfeeders correspond to the Systellognatha or Subulipalpia, as compared later in explaining the classification introduced in this paper, p. 308, and the feeders correspond to the Holognatha or Filipalpia.

The fact that many stonefly adults feed is not so generally understood and much of our general literature is in need of change because it conveys the impression that stoneflies do not feed in the adult stage.

Another interesting point in connection with the feeding habit of adults is that diurnal forms are liable to be feeders whereas the nocturnal forms are most liable to he the nonfeeders. The two species of Isoperla, minuta and decepta, which I have observed to feed, are diurnal whereas 
such nocturnal forms as 1 . bilineata are nonfeeders. This correlation holds well for the fall and winter forms because they are all diurnal species, but it breaks down more in the spring and summer forms. For instance Neophasganophora capitata is active during the day but I have never observed it feeding and its mouthparts do not indicate such a habit. The same also applies to Illinois species of the genera Hydroperla, Perlinella and certain species of Isoperla. Most true nocturnal forms however, such as Acroneuria and Neoperla, are nonfeeders and it so happens that Pteronarcys, morphologically belonging to the group of species constituting the fall and winter fauna, is essentially nocturnal and a nonfeeder.

MATING.-The time of stonefly mating depends upon whether the adults are diurnal or nocturnal. It begins as soon as both sexes appear,

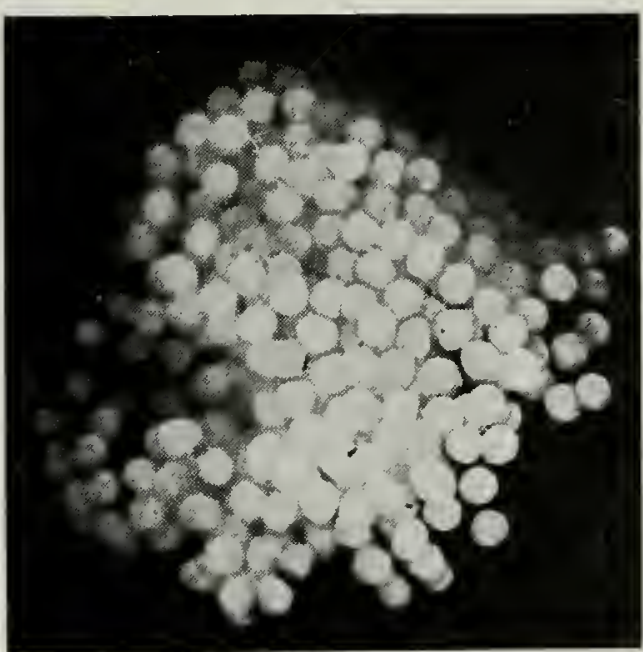

Fig. 18.-EgGs of Taeniopteryx nivalis. Each egg mass of this winter stonefly may contain as many as 1400 or more eggs. the males usually being somewhat protandrous, and reaches its height in the warmer days or nights during the time of maximum abundance. As noted in the case of the fall and winter forms (Frison 1929), the freshly emerged females of the spring and summer forms are most sought by the males. Sometimes a single female is surrounded by a large number of males-an evident aid to collecting in the case of diurnal species. The courtship of the sexes of Allocapnia has been previously described by myself (1929). Except for variations due to morphological differences in genital structures the mating habits of must stoneflies are essentially alike. As far as I have been able to ascertain mating never takes place while the adults are flying and hence differs in this respect from some aquatic insects which mate while flying over the surface of the water where the eggs are deposited.

oviposition.-Marked differences exist in the egg laying habits of various species. The habits of such genera as Taeniopteryx, Strophopteryx and Allocapnia were described in detail in my previous paper, from which the following paragraphs are taken:

"A marked difference in egg laying habits was found to exist in the Oakwood region between the species of fall and winter stoneflies inhabiting large streams and those living in small brooks. Those preferring large streams, such as $T$. mivalis, $S$. fasciata and $A$. gramulata, usually deposit their eggs directly in the river, particularly at rapids where the swirling 
and turbulent water sparkles in the sunshine on bright day's. A short time previous to the deposition of the eggs, the females of these species seek resting places on bridges, trees and other objects near the river and by a rhythmic contraction of the abdomen gradually force from the oviduct, a little at a time, a matrix containing many eggs. One such egg mass produced by a female of $T$. nizalis contained $1+07$ eggs, fig. 18 ; and it is probable, judging by their size, that most egg masses of $T$ '. nivalis, $s$. fasciata and $A$. granulata contain approximately the same number.

"These three species differ as a rule in the manner of holding the egg mass while it is being formed. The female of $S$. fasciata keeps her abdomen extended for its full length almost horizontally, or parallel with the object on which she rests, so that the egg mass, which is rather irregular in shape, is partly concealed beneath the abdomen. T. mivalis, and to a still greater extent $A$. gramulata, bend the end of the abdomen upward and forward, so that the usually globular egg mass is much more easily seen, and a superficial observation might cause one to think it was being carried on the back of the abdomen.

"By the simple expedient of catching females with egg masses and submerging them in water, it was found that the egg masses soon fall from the female, the matrix holding together the numerous eggs dissolves, and the individual eggs separate. Subsequent observations showed that the females could voluntarily release the egg masses when ready to do so, without awaiting the disintegrating effect of the water. It is possible that the egg masses are sometimes dropped into the water by the females without alighting upon it, but in the instances witnessed at close range, the females lighted upon the surface of the water, almost instantly released their egg masses and then flew up and away again. No doubt some females of Taenioptery $x$ and Strophopteryx crawl with their egg masses to the water's edge and deposit their eggs, and I have seen such a performance upon the part of a female of 1 . granulata.

"Much evidence was obtained in the Oakwood area to show that the females of $A$. recta, $A$. mystica and $A$. viripara rarely if ever lay their egge while flying over the water, but rather that they deliberately crawl into the water at its edge or at other places where stones, sticks and leaves are partly submerged. Several times I found females of A. recta carrying egg masses into the water to release them. Since the females of $\%$ rivipara are normally short winged in this part of Illinois, it is easy to understand why some of them do little if any flying above the small streams in which they lay their eggs, but in southern Illinois where there is a strong tendency for the females of this species to develop long wings, there is no such restriction upon their flying. There seems to be no good reason why A. recta and A. mystica do not fly more than they do." 
Observations since 1929 confirm my belief then that $A$. vivipara is not viviparous under natural or most field conditions. Many vivipara females have since been observed carrying their egg masses as do other Allocapnia.

The spring and summer forms produce egg masses as do all the fall and winter forms, but the eggs constituting these masses are usually

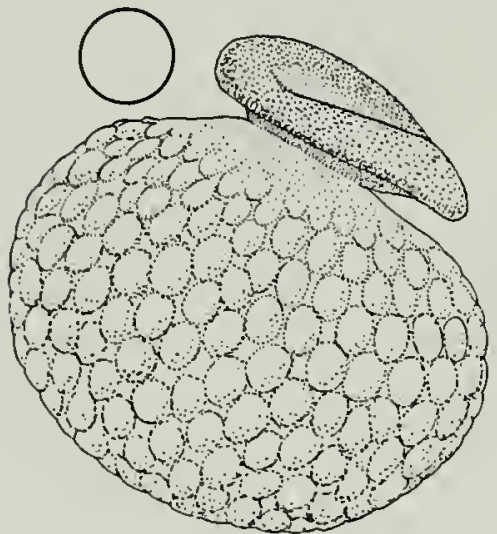

19

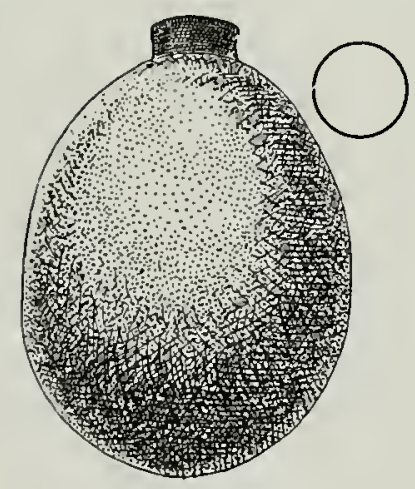

22

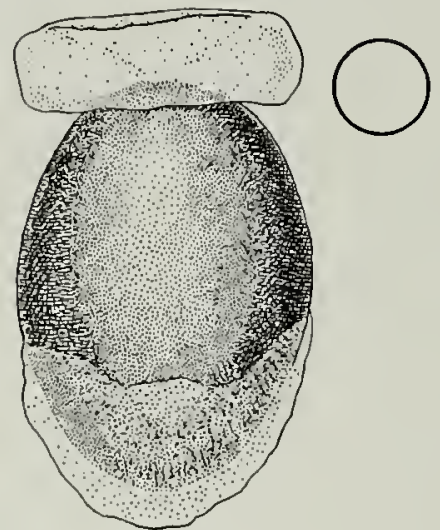

20

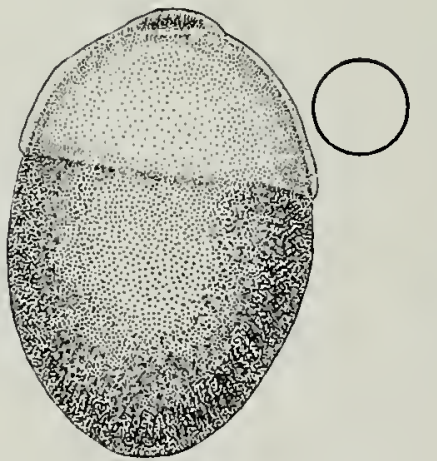

23
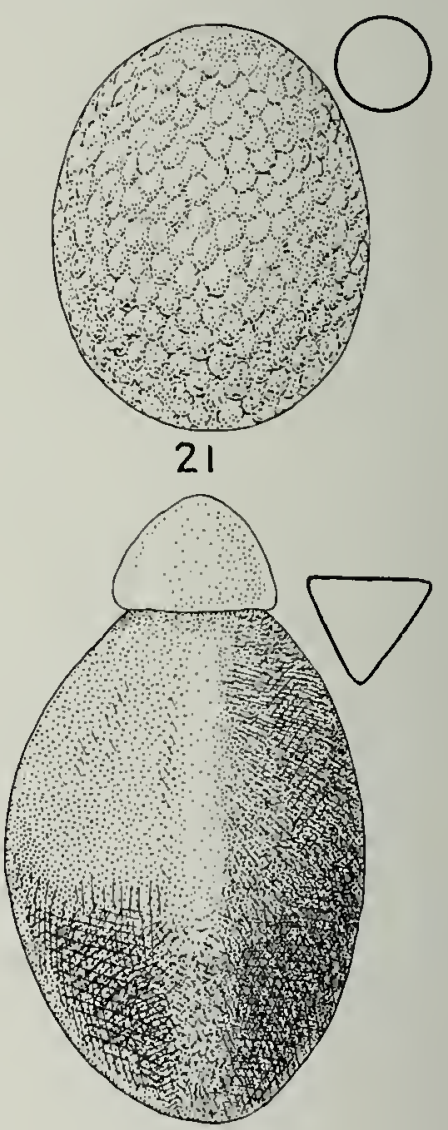

24

Figs. 19-24. - Eggs of STONEFLIES, SIDE VIEW with CROSS SECTION IN OUTLINE. 19.- Pteronarcys nobilis. 20.-Neophasganophora capitata. 21.--Isoperla bilineata. 22.--Perlesta placida. 23.-Acroneuria abnormis. 24.-Hydroperla harti.

fewer, darker and have a harder shell. In fact, as Needham and Claassen (1925) have indicated by illustrating the eggs of certain species, the eggs often are an excellent guide as to the identity of the species. The eggs vary in size, in shape and in reticulations, figs. 19-24, and might well be the subject of a special study.

Although in many groups it will be impossible to distinguish species on the basis of the eggs alone, they must not be overlooked as sources of evidence for natural groups of related species. Hydroperla, proposed as a new genus in this paper, has an egg triangular in cross section, fig. 24, which differs markedly from other species such as Neophasganophora capitata and Togoperla media, formerly included in the same genus. The eggs were not the basis of my generic splitting in the first place but they 
certainly do not gainsaly the propriety of this division. Where the eggs have not become specialized, a similarity may exist among many genera without meaning much more than common ancestry of some sort, but markedly different eggs obviously can never support arguments for close relationships.

The spring and summer forms of stoneflies, in my experience, never crawl into the water with their egg masses as do certain dlocapnia and Nemoura, but drop their egg masses into the water while flying over it. The abdomen, too, is rarely turned upwards and backwards to such a degree that the egg mass appears as being carried on the back of the abdomen as in the case of Allocapnia and to a lesser extent in Taeniopteryx.

Habits of nymphs. - The name stoneflies indicates some connection hetween these insects and stones, but it is many cases without significance. 'The nymphs of some species do hide under or among stones in streams and the adults are sometimes found on stones at times when the nymphs are crawling out of the water and ready to produce adults. In many instances however the nymphs are not associated with stones and the adults are found anywhere that there is food if they are species which feed, or where they can find a protected place to rest during their inactive lours. In other words, the term stoneflies as applied to these insects in Illinois is pretty much a misnomer.

FEEDING.-In my paper of 1929 I stated in regard to the nymphs: "It appears... that all of the fall and winter stoneflies of Illinois are herbivorous." Studies since then give no cause for modifying this statement. However, among those species which because of time of emergence I have roughly termed the spring and summer forms, there is variation in respect to food habits.

Under older classifications the Perlidae, containing the most common spring and summer species, was a mixture of genera having either carnivorous, herbivorous or omnivorous habits. In the classification used in this paper the Perlidae comprises a group of species essentially belonging to the late spring and summer fauna, and having in the nymphs carnivorous habits. The Perlodidae, as here separated, are apparently carnivorous. or at least the nymphs I have studied are so. The Chloroperlidae, also separated from Perlidae in this paper, show a mixture of feeding habits. The one species of Chloroperla from lllinois is herbivorous, as apparently are Isoperla bilineata and $I$. mimuta. Other species of Isoperla however, such as duplicata, moliri, confusa, decepta and richardsoni, are carnivorous or at least at times have such habit. The genus Isoperla in the broad sense used in this paper has every indication of being an unnatural unit and it is hoped that in future attention will be drawn to morphological characters which will clearly separate the various complexes. 
EMERGENCE.-It has been my observation that diurnal species of stoneflies emerge mostly during early morning and that nocturnal species emerge late in the evening or at night. I know of no instance in which the adults pop out of the water free of the nymphal skin as in some aquatic groups, or have another molt after leaving the water and flying as in the case of the Ephemerida. In all instances the nymphs crawl out of the water on rocks, vegetation or any object protruding out of the

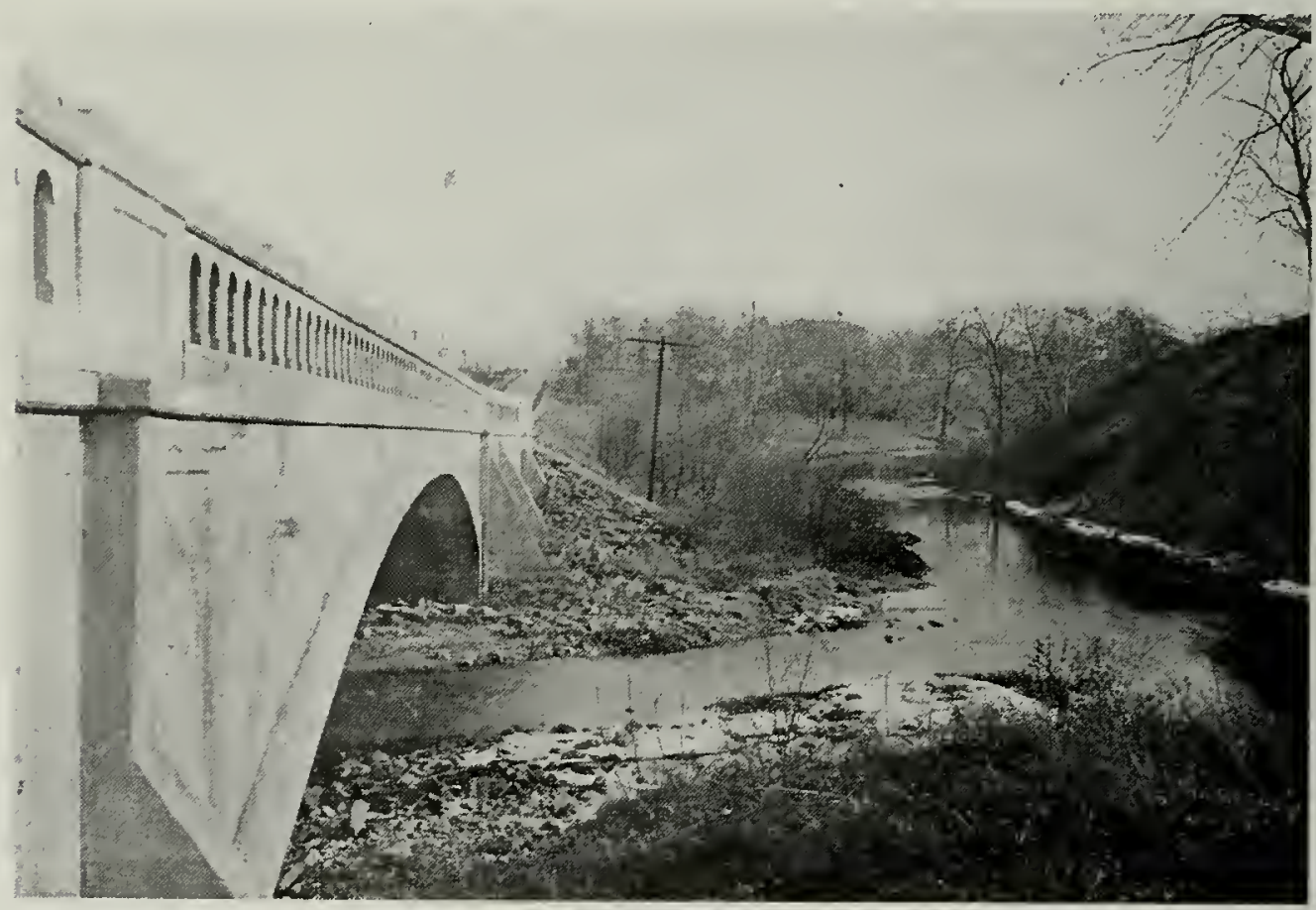

Fig. 25. Shall river habitat of Illinois stoneflies. Various species of the winter group develop in such streams and on sunny days crawl up and congregate on bridges.

water. There, after a short rest, the nymphal skin splits down the back, as has been described by the writer (1929), and the soft adult crawls out. After a short time the rings and body structures harden and the adult crawls or flies away.

DEVELOPMENT.-Our method of rearing adults from nymphs was aimed at securing accurate association of adults with nymphs, with a minimum of time and effort, and scant attention was paid to the number of developmental instars. In fact, except for the observations of Samal (1923), Schoenemund (1912) and WVu (1923), very few reliable data have been gathered concerning the number of instars in stonefly nymphs. These students indicate that there are many instars, IVu giving 22 for Nemoura rallicularia, Schoenemund 36 for Perla cephalotes and Samal 22 instars for Perla abdominalis.

The size classes of nymphs and seasonal occurrences offer some clue, however, to the total time of the life cycle. In Illinois it appears that 
all species of Allocapnia, Nemoura, Leuctra, T'aeniopteryx, Strophopteryx, Perlesta, Neoperla, Isoperla and Hydroperla require a year for their life cycle. Pteronarcys and Acronemia certainly require a longer time and probably two or three years.

Enemies. - I can add to a discussion of stonefly enemies rery little more than what I stated in 1929 , except to record a case of an aldult of Perlesta placida being caught and eaten by a robin when this species if stonefly was exceedingly ahundant at Oregon, 111.

\section{COLLECTING, REARING AND PRESERVING STONEFLIES ?}

SIXCE stonefly nymphs live in streams and the adults on land, quite different methods are necessary for their capture. The nymphs are usually easier to collect because they occur over a longer period of the year, are more numerous and have a more restricted habitat than the adults.

Collecting adults. - The variety of ways in which stonefly adults may be collected is surprising in spite of the few species in our fauna and their restricted habitat distribution. During the warmer days of fall, winter and early spring, adults of the winter species may be found on concrete bridges, fence posts and other objects near the streams in which the insects develop. The attraction of light colored bridges such as that in fig. 25 for stonefly adults has enabled us to get a large number of records of the winter species very easily, simply by driving along highways and stopping to examine each bridge. On the warmest of winter days tree trunks covered with green algae attract considerable numbers of stoneflies. In addition to these higher places the adults may be found under stones and trash near the water's edge and frequently in numbers on trees and logs that have fallen partly into a stream. Beating heavy brush hanging over a stream will sometimes dislodge adults and knock them into the water, from the surface of which, since they float, they may be picked with ease.

The smaller and more numerous spring species, such as members of Perlesta and Isoperla, may be collected by sweeping the foliage along the banks of rivers and streams. This method will also net some individuals of the larger species, such as Hydroperla and deroneuria, but these may be found more easily by examining likely hiding places, such as sweet clover heads and stems, bunches of weeds and willows near the river. A thorough search of piling, piers and bridges will be found profitable. for practically all species of the summer as well as for the winter group.

Lights attract a considerable number of the summer forms, such as Isoperla bilineata. Pteronarcy's mobilis, certain species of Acroneuria and

${ }^{2}$ This seretion is the contribution of II. iI. loss, systrmatic cutomologist. Ins, surs STATr Natinal IIstory SUEVIY. 

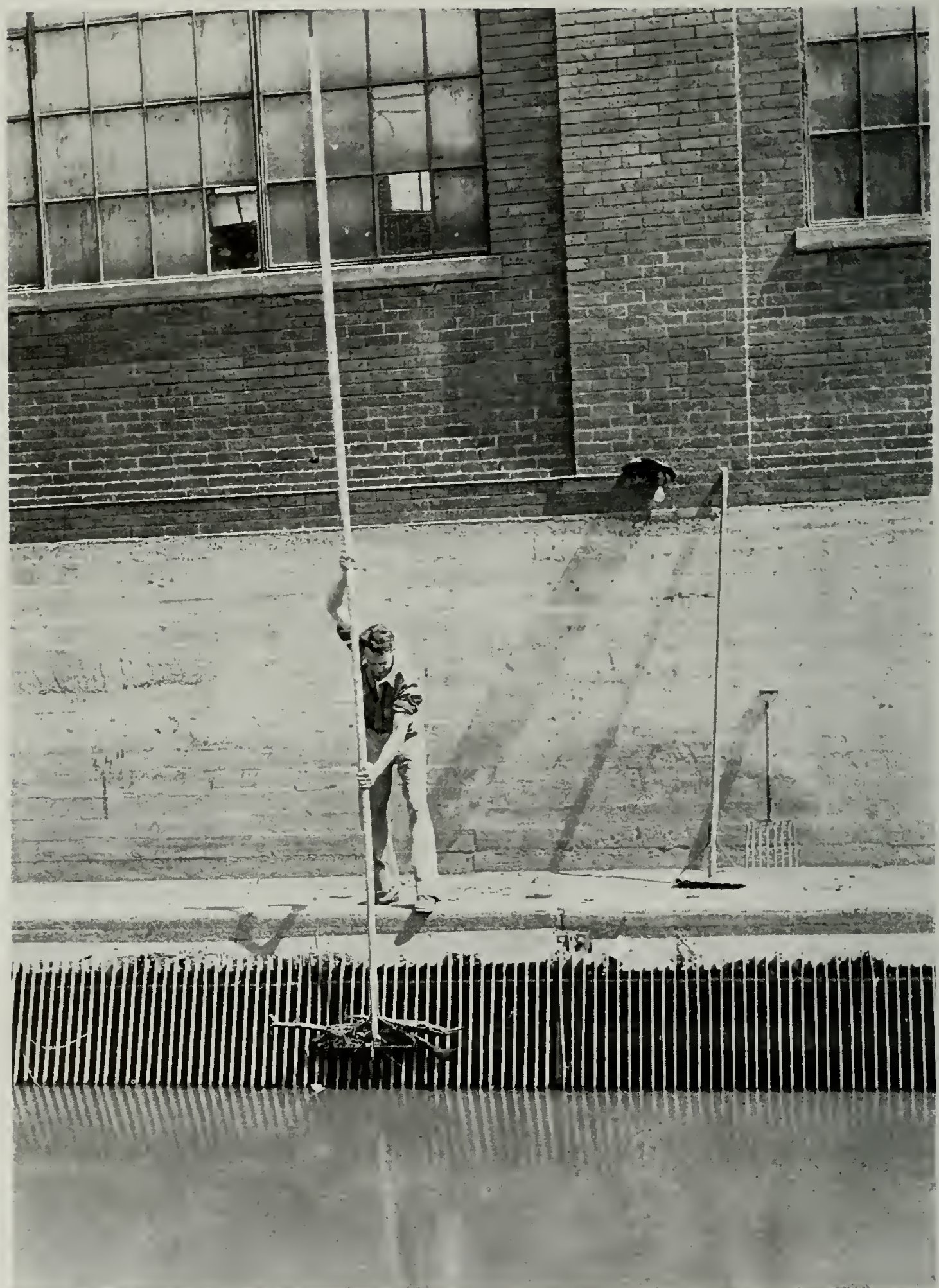

Fig. 26.-Portion of a bar RACK at hldRoElectric plant on the Rock RIVER AT ROCK ISLAND. Debris raked up from the bases of these racks supplies many stonefly nymph, especially in Acronewria and 1 soperla.

others. In Illinois specimens have been collected at lights five miles from the nearest streams. Sometimes working with lights is the only profitable method of obtaining large numbers of a species. 
Collecting nymphs. - Since the nymphs are entirely aquatic their collection is simplified compared with that of the adults, which are terrestrial. In Illinois the nymphs are restricted to the cleaner and less polluted streams with fair current. The various species have both a definite habitat preference and a definite seasonal appearance. For this reason collecting should be done in streams of all sizes, and several times during the year. Some species occur only locally so that it is advisable to include all possible streams, no matter how similar they look, in the collecting schedule. In the smaller streams the nymphs are usually found in masses of leaves either matted on the bottom, packed against stones or other objects projecting partly out of the water or gathered into knots at the ends of branches trailing in the water as in fig. 14.

Some of the larger species occurring in rivers have been secured in large numbers from debris raked up from the foot of the bar racks of hydroelectric plants, fig. 26. It was discovered at Rock Island in the spring of 1928 that nymphs of practically every species occurring in the river lodge in the mass of waterlogged leaves, branches and trash which gather at the bottom of these bar racks. Similar collecting since in the Rock and Kankakee rivers has afforded series of many large river species which can he obtained only rarely by other means. It is doubtful if random collecting could possibly have provided sufficient material for the rearing and adequate study of some of these species.

In the Mississippi river another type of good collecting place has been found. Nymphs of some dcroneurin species congregate in large numbers under the stone slabs at the end of wing dams which jut out into the swifter part of the stream.

Since 1926, when this study was begun, collecting trips have been made periodically over the state in order to complete a thorough survey of Illinois stoneflies. The trips were planned so that each portion of the state was visited in late fall, late winter and several times during spring and early summer. At each trip every kind of habitat was visited and as much material as possible was secured. This evidence was gathered to bring out the exact distribution of species within the state, the seasonal succession of these species, differences in time of appearance from south to north and details of ecological preferences.

Rearing methods. - The methods used during this study were aimed at obtaining full grown or nearly full grown nymphs for rearing so that the time of handling and observation would be reduced to a minimum. No attempt was made to discover such facts as rate of growth or number of instars, the only object being the correlation of nymphs and adults of the same species. The ease and certainty of many rearings was made possible by retention of almost all the nymphal characters in the cast 
skin upon emergence of the adult. Because of this the association of at single adult with the nymphal skin from which it emerged constituted positive evidence of the specific identity of nymph and adult.

For the winter stonefly groups such as Allocapnia and Strophopteryx the following procedure was found very satisfactory. Several full grown nymphs were placed in a small tin with a few wet leaves; the tins were

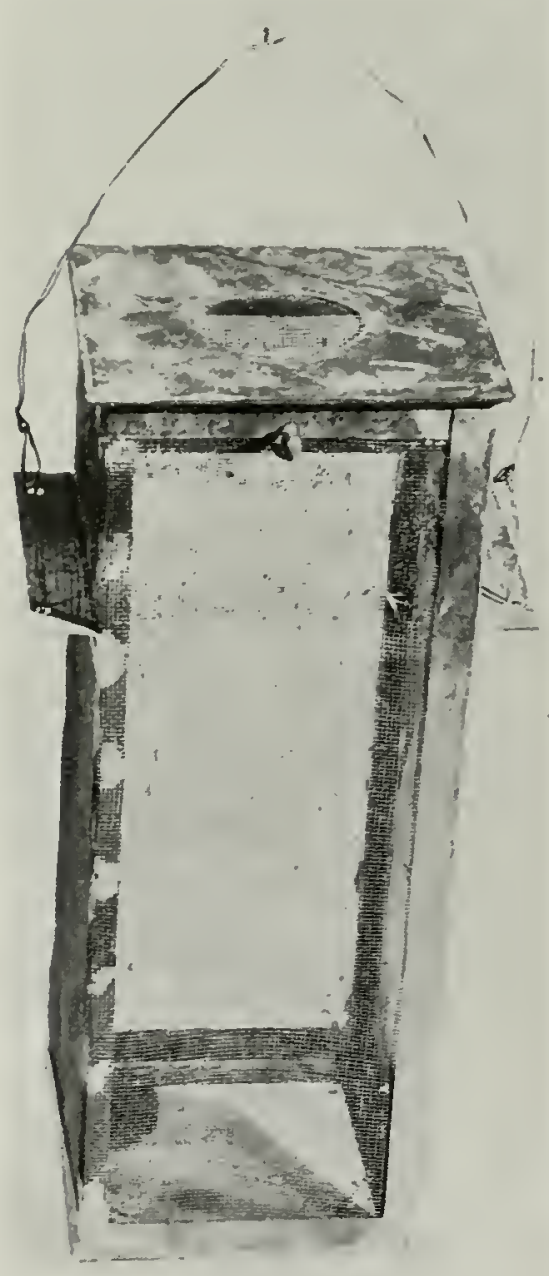

Fig. 27.-STONEFIY REARING CAGE. These cages made of copper strip and fine wire mesh are dropped into holes in large rafts and allowed to float in the natural habitat of the stonefies. kept tightly covered, insuring a moist chamber, and in these small cages the nymphs usually completed their last growth and emerged as adults. With these winter groups the method was very successful due primarily to the ease of obtaining large numbers of nymphs which were on the verge of becoming adults and in many instances of finding pure cultures of one species in a stream. Isoperla decepta also was reared in this manner.

Several of the larger species, especially members of the genus Acroneuria, were reared in a similar fashion. During the adult emergence season bar racks of hydroelectric plants were visited at night when the nymphs were crawling up the bars and out of the water to transform into adults. Each of these nymphs was placed in a separate cage until transformation had taken place. The adult was then placed in a smaller and more conveniently handled container with its cast skin until the full adult color was attained. The adult and cast skin were then preserved together in fluid. A night's work during the height of the emergence season sometimes netted 10 to 40 specimens reared in this manner.

Many species were raised in cages suspended in the water by a raft as in fig. 11 . The cages were constructed as shown in fig. $27 ; 12$ inches high by $+1 / 2$ inches square, made of fine mesh copper screen with a removable top set into the cage and secured by two screws, one at each side. A bracket running the width of the cage and projecting three-quarters of an inch from it was soldered on two opposite sides of the cage 3 inches from the top. Wooden rafts 6 feet long by 2 
feet wide were constructed with 16 holes $+3 / 4$ inches square, in two rows. The cages were lowered into these, and were suspended by the brackets so that three-quarters of the cage was under water. The immersed portion of the cage was furnished with leaves and litter from the stream bed, after which the nymphs of a certain species of stonefly were placed in it. The raft with its laden cages was anchored in running water. A large number of species was reared in this way, including members of Isoperla, Nemoura and practically all the larger species.

Preservation of material.-Both nymphs and adults have been preserved in fluid, preferably 80 per cent ethyl alcohol. If stoneflies are pinned the bodies shrink to such an extent that it is impossible to make out genitalic and other characters by which they are classified. Only a small amount of material should be put in a vial and the fluid ought to be changed after the first day. This will prevent a large amount of discoloration and blackening.

A 3 dram vial $65 \mathrm{~mm}$. high and $17 \mathrm{~mm}$. wide, with a ring neck has been found very convenient for all species. It will hold a single specimen of the largest species and a large number of the small species. Valuable small specimens are put in a small shell vial; this is filled with Aluid, plugged with cotton and dropped plugged end down into a 3 dram vial; the larger vial is then filled about three-quarters full of fluid and corked. This combination furnishes a safe housing for small types and dissected parts.

Labels bearing full collecting data should be put inside each vial; specimens without such information are practically worthless. Vials should be checked once a year, at which time discolored fluid may be changed and new corks or additional fluid may be added where necessary.

\section{CATALOG OF SPECIES}

INCLUDING CLASSIFICATION, DESCRIPTION, HABITS AND RECORDS OF ILLINOIS STONEFLIES

Classification.-The classification of families used in this report does not agree with that of any other North American student of stoneflies. The one I am proposing here follows the work of such European students as Klapalek (1909b), Rousseau (1921) and Schoenemund (1928) in recognizing the breaking up of the old Nemouridae into the families Taeniopterygidae, Leuctridae, Capniidae and Nemouridae, and the former Perlidae into Perlodidae and Perlidae. In addition to accepting Pteronarcidae, as all students dealing with our fauna have done, this classification accepts the further segregation of Chloroperlidae from the Perlidae as previously divided by Rousseau, and the new family Peltoper- 
lidae of Claassen (1931). In other words I am convinced that the lumping of all our North American species of Plecoptera into four families, namely the Capniidae, Nemouridae, Pteronarcidae and Perlidae, conceals many relationships and gives us families of a very heterogeneous composition. Most of our American students have studied only the adults and then based their conceptions of the larger units mainly on wing venation and a few other characters. Study of the nymphs brings to light many additional characters which are valuable guideposts to relationships.

More homogeneous grouping.- The present classification is believed to contain numerous elements of strength when evaluated either from the standpoint of adults or nymphs. Wing venation, genital structures, mouthparts, presence or absence of gills, and many other structures have been considered. One of the strongest arguments for the arrangement given here is that this classification based upon structure conforms to biological habits of the stoneflies as well. Although we are confronted with more major groups or families, each family is more homogeneous in habits or from any other point of view. There is also the confirmatory evidence of the nymphs which under the family arrangement here proposed form more homogeneous groups than is the case under the old classification. In the Perlidae, for instance, as formerly used we had a large group of carnivorous and herbivorous nymphs, some with gills entirely lacking and others with copious gills, and adults of numerous types and patterns. A great deal of this heterogeneity is removed by the division of the old Perlidae into three families-the Perlidae, Perlodidae and Chloroperlidae.

It is obvious to any serious student of the Plecoptera of North America that two main lines of descent are represented. One of these lines includes the Pteronarcidae, Peltoperlidae, Taeniopterygidae, Nemouridae, Leuctridae and Capniidae, and has been styled as the suborder Holognatha by Enderlein (1909) and as the Filipalpia by Klapalek (1909b). The other main line is represented by the families Perlidae, Perlodidae and Chloroperlidae, and has been called the suborder Systellognatha by Enderlein (1909), the Subulipalpia by Lestage (1921), and Setipalpia by Klapalek (1909b). Certain peculiar families of the southern hemisphere, particularly from Australia, New Zealand and Chile, best studied by Tillyard (1921), fall within the Holognatha or Filipalpia.

Enderlein and Klapalek have based their suborders upon two different characters but both achieve about the same combination of families. Enderlein based his two major divisions upon whether the adults had well developed or rudimentary mandibles. This does not always hold in the same genus, as illustrated by well developed functional mandibles in Isoperla decepta and the flabby nonfunctional mandibles of $I$. bilineata. Nevertheless Enderlein's character for division is fundamentally strong. Klapa. 
lek's principle of division was whether or not the terminal palpal segments were successively more slender or approximately as thick as the basal ones. Here again there is some inconsistency in the groups but fundamental relationships are linked with this character.

Basis of present division.- I believe that the best and most fundamental character for the segregation of these two groups consists in the type of mouthparts in general. One group composed of the Taeniopterygidae, Nemouridae, Leuctridae, Capniidae, Pteronarcidae and Peltoperlidae possesses a labium with the paraglossae and glossae extending forward about the same distance and arranged alongside of one another in the same horizontal plane, figs. $115-119$, p. 320. Peltoperlidae is perhaps the farthest from this type of those families mentioned. Roughly this is the Holognatha of Enderlein and the Filipalpia of Klapalek.

The other group is composed of the Perlidae, Perlodidae and Chloroperlidae, which possesses a labium with the paraglossae extending much farther forward than the glossae, the latter deeply inset below and between the paraglossae so as to appear almost as basal segments of them, figs. 120$1+3$, p. 320. This is a group approximately equivalent to the Systellognatha of Enderlein and the Subulipalpia of Klapalek.

Within each of these main lines of descent we see a serial progression of genera or species from a generalized to a more specialized type. In the Holognatha or Filipalpia, the family Pteronarcidae in North America is to my mind the more generalized type and the Leuctridae and Capniidae the more specialized types. In the Systellognatha or Subulipalpia the Perlidae seem to me to represent the more generalized type and the Chloroperlidae the specialized type. This opinion is formulated after consider ation of the morphological details of both adults and nymphs, and also of their habits. To my mind the Chloroperlidae, Capniidae and Leuctridae appear to be groups still in a stage of active evolution.

Recently Neave (1934) has described a new genus of the Nemouridae (s. lat.) by the name of Megaleuctra. Since it has several characters in common with Nemoura, Leuctra and Taeniopteryx, I do not consider it evidence against recognition of these groups as families. I consider Megaleuctra as belonging to the family Leuctridae, and its characters common to Nemoura and other genera just mentioned as indicating its place in the Holognatha or Filipalpia where all these genera belong. If it did not have these characters it could not be a Nemouridae in the old sense.

Neave (1934) has also given us further information about another little known species named Capnia brezicauda Claassen. This species is placed by Neave in Capniidae but attention is called to its "nemourid affinities." I consider this species a member of the Leuctridae. 
Although this paper centers around the Illinois stonefly fauna, it has been necessary to consider family and generic classifications from the standpoint of the North American or world fauna as a whole, as evidenced by my remarks already given. A skeleton of this new classification down to genera appears below, followed by the list of species known to occur in Illinois.

\section{NEW CLASSIFICATION}

OF THE PLECOPTERA OF NORTH AMERICA

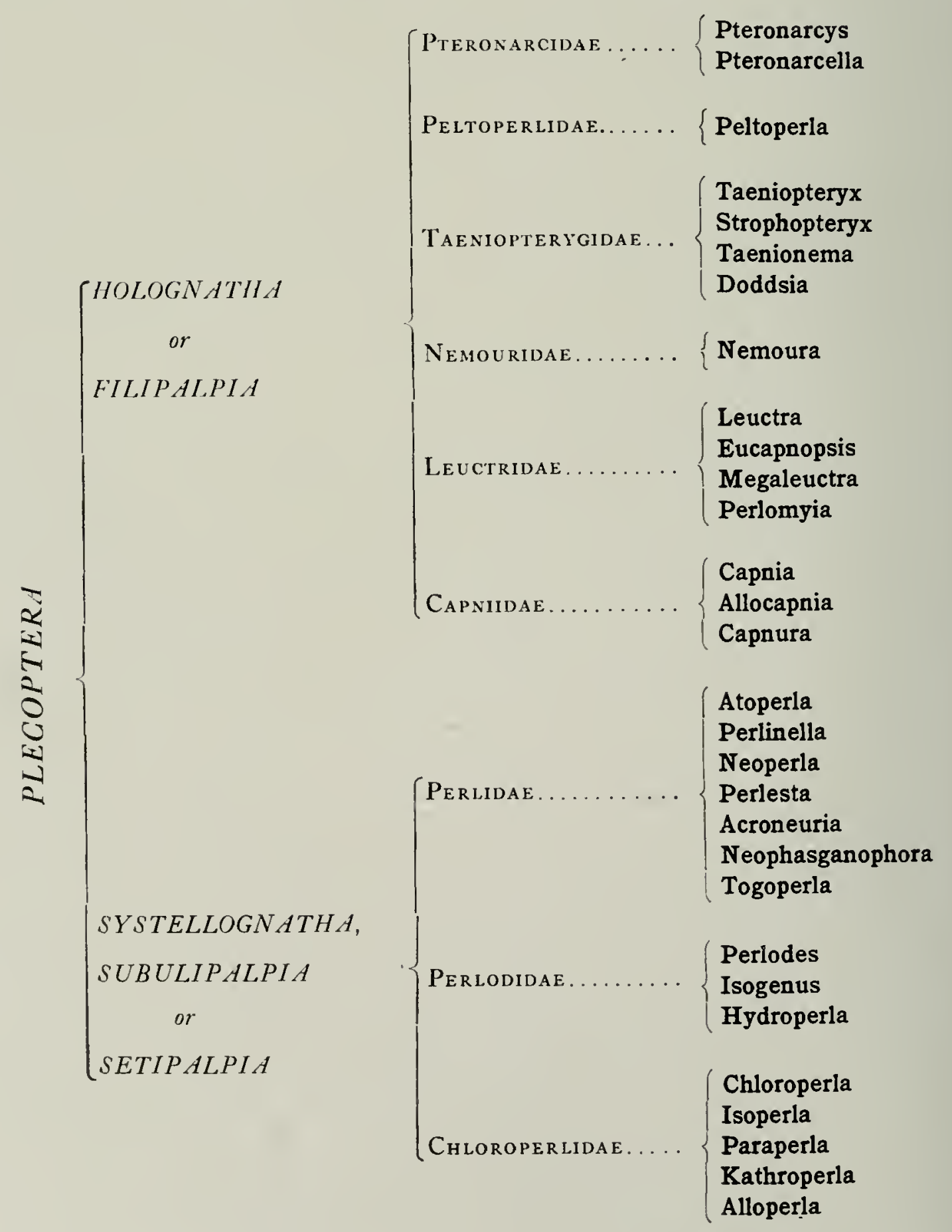




\section{LIST OF SPECIFS}

OF THE PI.ECOPTERA OF IILINOIS

\section{PTERONARCIDAE}

Pteronarcys Newman

Pteronarcys nobilis Hagen, p. 336

\section{TAENIOPTERYGIDAE}

Taeniopteryx Pictet

Taeniopterys nivalis (Fitch), p. 341 Taenioptery.x parula Banks, p. 345

\section{Strophopteryx Frison}

Strophopteryx fasciata (Burmeister), p. 347

\section{NEMOURIDAE}

Nemoura Latreille

Nemoura venosa Banks, p. 349

\section{LEUCTRIDAE}

Leuctra Stephens

Lenctra clansseni Frison, p. 354

\section{CAPNIIDAE}

\section{Capnia Pictet}

Capnia q (vernalis Newport?), p. 356

Allocapnia Claassen

Allocapnia forbesi Frison, p. 363

Allocapuia forbesi var. cornuta

Frison, p. 363

Allocapnia granulata (Claassen), р. 364

Allocapnia illinoensis lirison, p. 365 Allocapnia mystica Frison, p. 366 Allocapnia pygmaea (Burmeister), p. 367

Allocapnia recta (Claassen), p. 367 Allocapnia vivipara (Claassen), p. 370

\section{PERLIDAE}

Atoperla Banks Aloperla ephyre (Newman), p. 377
PERLIDAE-CONT')

Perlinella Banks

Perlinella drymo (Newman), p. 380

Neoperla Needham

Neoperla clymene (Newman), p. 381

Perlesta Banks

Perlesta placida (Hagen), p. 386

Acroneuria Pictet

Acroneuria abnormis (Newmin), p. 391

Acroneuria arida (Hagen), p. 395

Acroneuria internata (Walker), p. 401

Acroneuria ruralis (Hagen), p. 403 Acronemia sp. a, p. 405

Acroneuria sp. b, p. 407

Neophasganophora Lestage

Neophasganophora capitata (Pictet) p. 409

Togoperla Klapalek

Togoperla media (Walker), p. +12

Togoperla sp. a, p. 414

\section{PERLODIDAE}

Hydroperla Frison Hydroperla crosbyi (Neelham and Claassen), p. 419

Hydroperla harti Frison, p. 42.3

Hydroperla varians (Walsh), p. 426

\section{CHLOROPERLIDAE}

Chloroperla Newman

Chloroperla cydippe Newman, p. 431

Isoperla Banks

Isoperla bilineala (Say), p. 437

Isoperla clio (Newman), p. 439

Isoperla confusa Firison, p. 441

Isoperla conspicua Frison, p. 445

Isoperla decepta lirison, p. 447

Isoperla minuta (Banks), p. 4.53

Isoperla mohri Firison, p. 4.5 .5

Isoperla richardsoni Frison, p. 4.59 

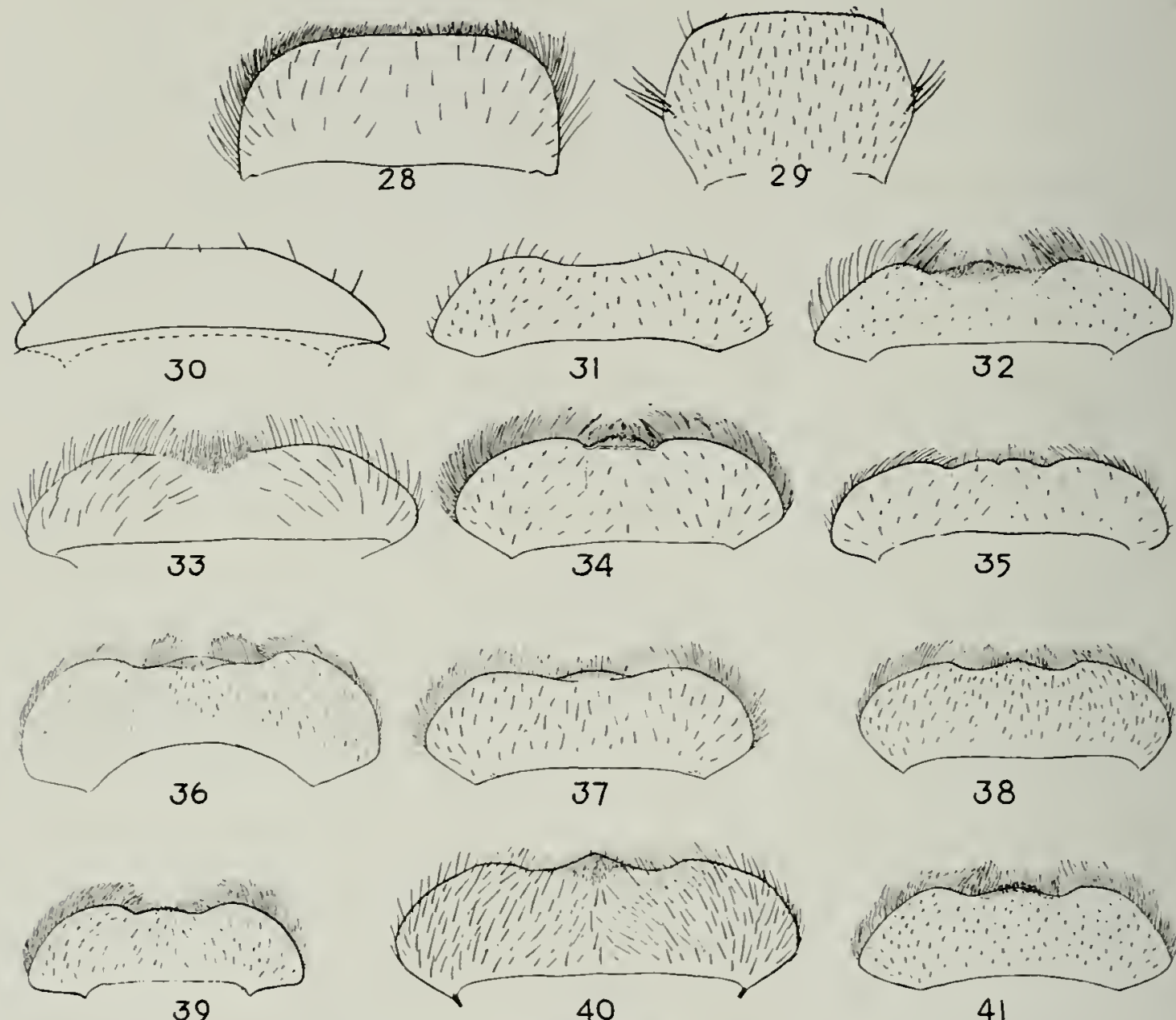

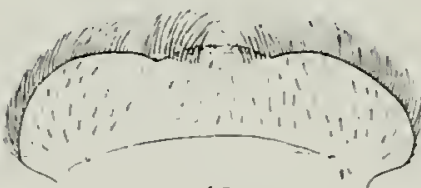

42

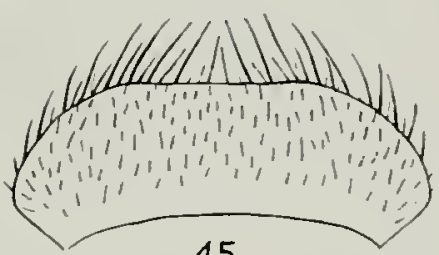

45

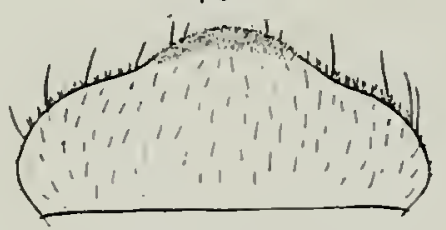

43

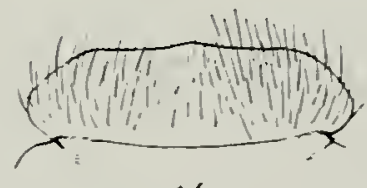

46

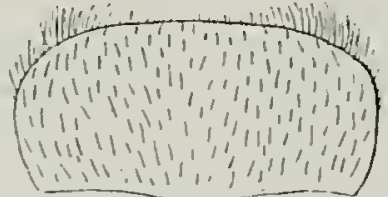

49

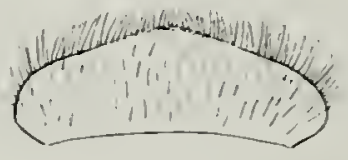

52

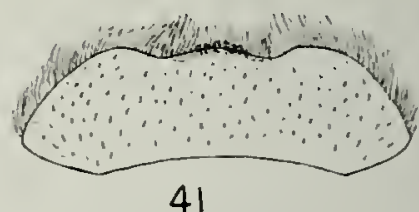

41

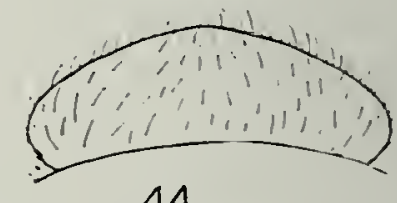

44

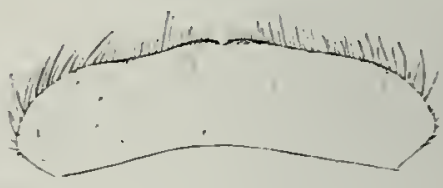

47

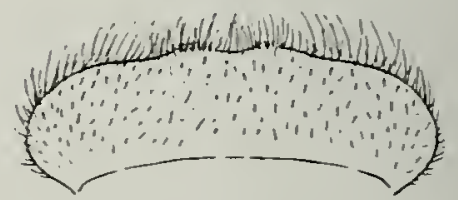

50

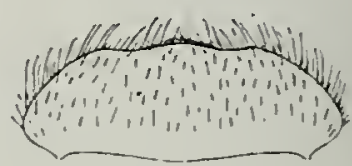

PLATE I 


\author{
PLATE I
}

\title{
Dorsal View of Labrum of NyMiph
}

Fig. 28.-Pteronarcys nobilis, male.

Fig. 29.- Nemoura venosa, female.

Fig. 30.-Atoperla ephyre, female.

Fig. 31.-Perlinella drymo, female.

Fig. 32.-Neoperla clymene, female.

Fig. 33.- Perlesta placida, female.

Fig. 34.- Acroneuria abnormis, female.

Fig. 35.-Acroneuria arida, female.

Fig. 36.-Acroneuria internata, female.

Fig. 37.-Acroneuria ruralis, female.

Fig. 38.--Acroneuria sp. $a$, female.

Fig. 39.-Acroneuria sp. $b$, female.

Fig. 40.-Neophasganophora capitata, female.

Fig. 41.-Togoperla media, male.

Fig. 42.-Togoperla sp. a, female.

Fig. 43.-Hydroperla crosbyi, female.

Fig. 44.- Hydroperla harti, female.

Fig. 45.-Chloroperla cydippe, female.

Fig. 46.-Isoperla bilineata, female.

Fig. 47.-Isoperla clio, female.

Fig. 48. - Isoperla confusa, female.

Fig. 49.-Isoperla decepta, female.

Fig. 50.-Isoperla duplicata, female.

Fig. 51.-Isoperla minuta, female.

Fig. 52.-Isoperla mohri, female.

Fig. 53.-Isoperla richardsoni, male. 

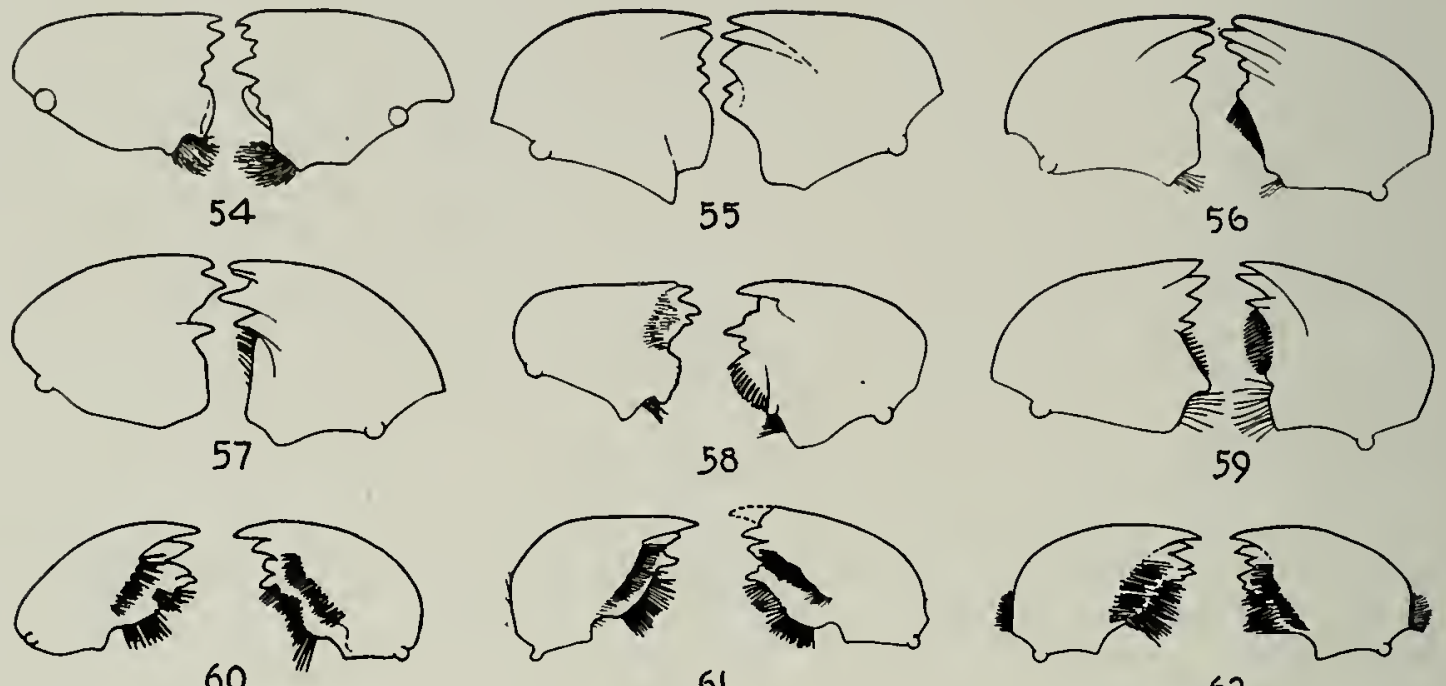

62
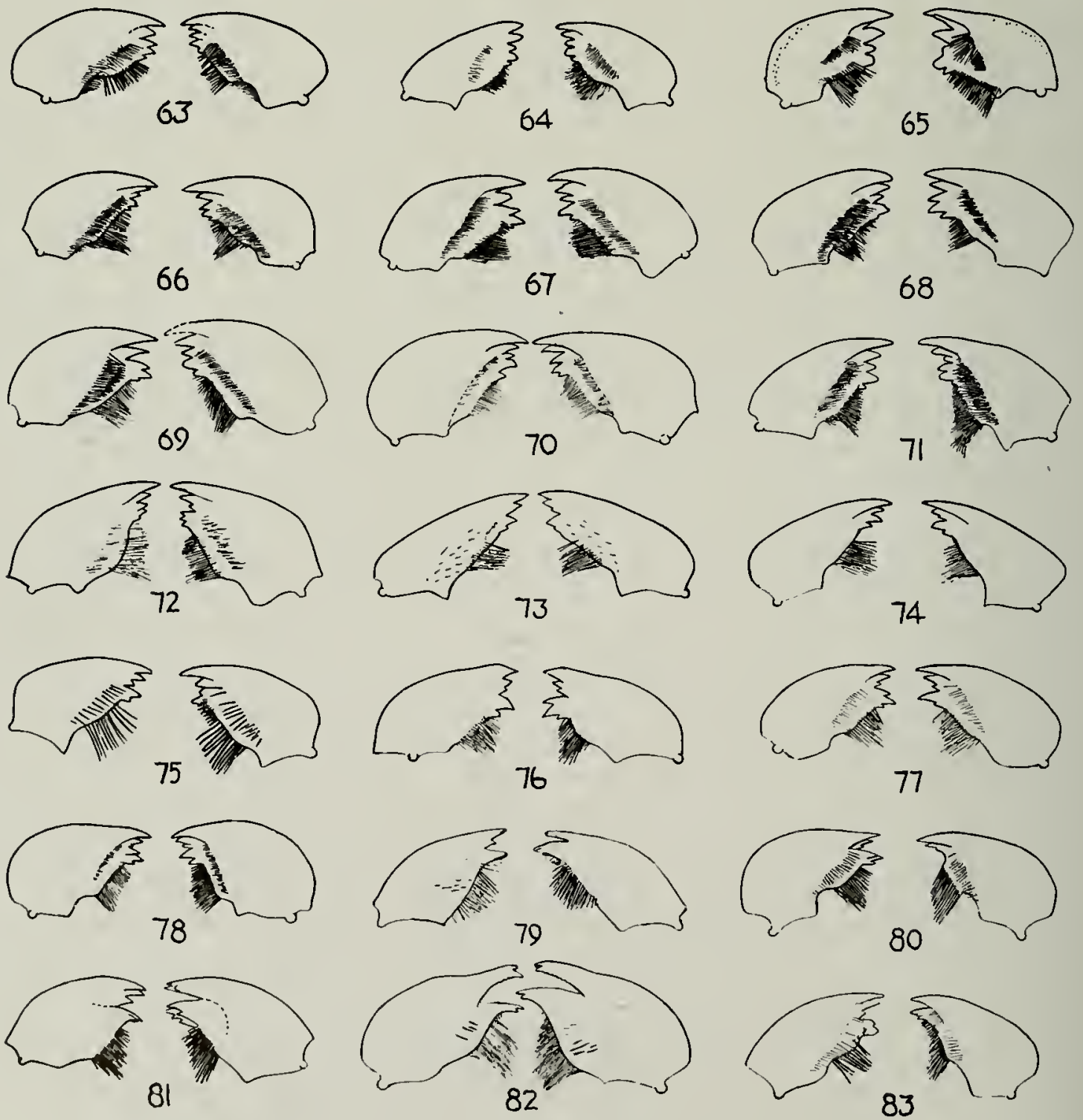

PLATE II 


\section{PLATE II}

\section{Ventral View of Mandibles of Nymph}

Fig. 54.-Pteronarcys nobilis, male.

Fig. 55.-Taeniopteryx nivalis, female.

Fig. 56.- Strophoptery $x$ fasciata, female.

Fig. 57.-Allocapnia vivipara, female.

Fig. 58.- Nemoura venosa, female.

Fig. 59.-Lenctra claasseni, female.

Fig. 60.- Atoperla ephyre, female.

Fig. 61.-Perlinella drymo, female.

Fig. 62.-Neoperla clymene, female.

Fig. 63.- Perlesta placida, female.

Fig. 64.- Acroneuria abnormis, female.

Fig. 65.-Acroneuria arida, female.

Fig. 66.-Acroneuria internata, female.

Fig. 67.- Acroneuria ruralis, female.

Fig. 68.-Acroneuria sp. a, female.

Fig. 69.-Acroneuria sp. b, female.

Fig. 70.-Neophasganophora capitata, female.

Fig. 71.-Togoperla media, male.

Fig. 72.-Togoperla sp. a, female.

Fig. 73.-Hydroperla crosbyi, male.

Fig. 74.-Hydroperla harti, male.

Fig. 75.-Chloroperla cydippe, female.

Fig. 76.-Isoperla bilineata, female.

Fig. 77.-Isoperla clio, female.

Fig. 78.-Isoperla confusa, female.

Fig. 79. - Isoperla decepta, female.

Fig. 80.- Isoperla duplicata, female.

Fig. 81.-Isoperla minuta, female.

Fig. 82.-Isoperla mohri, female.

Fig. 83.-Isoperla richardsoni, male. 


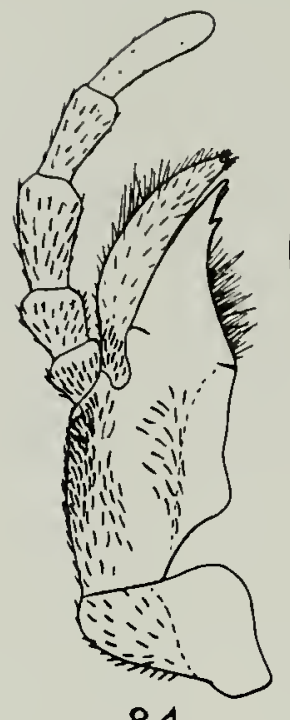

84
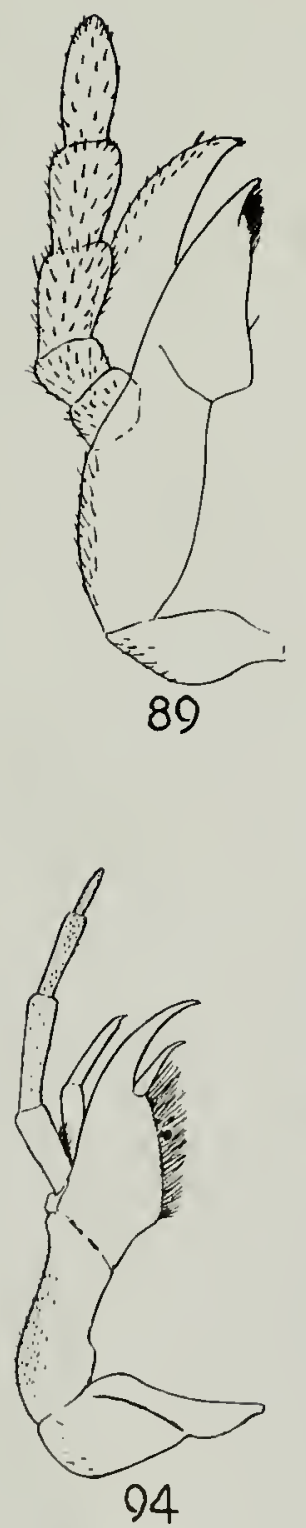
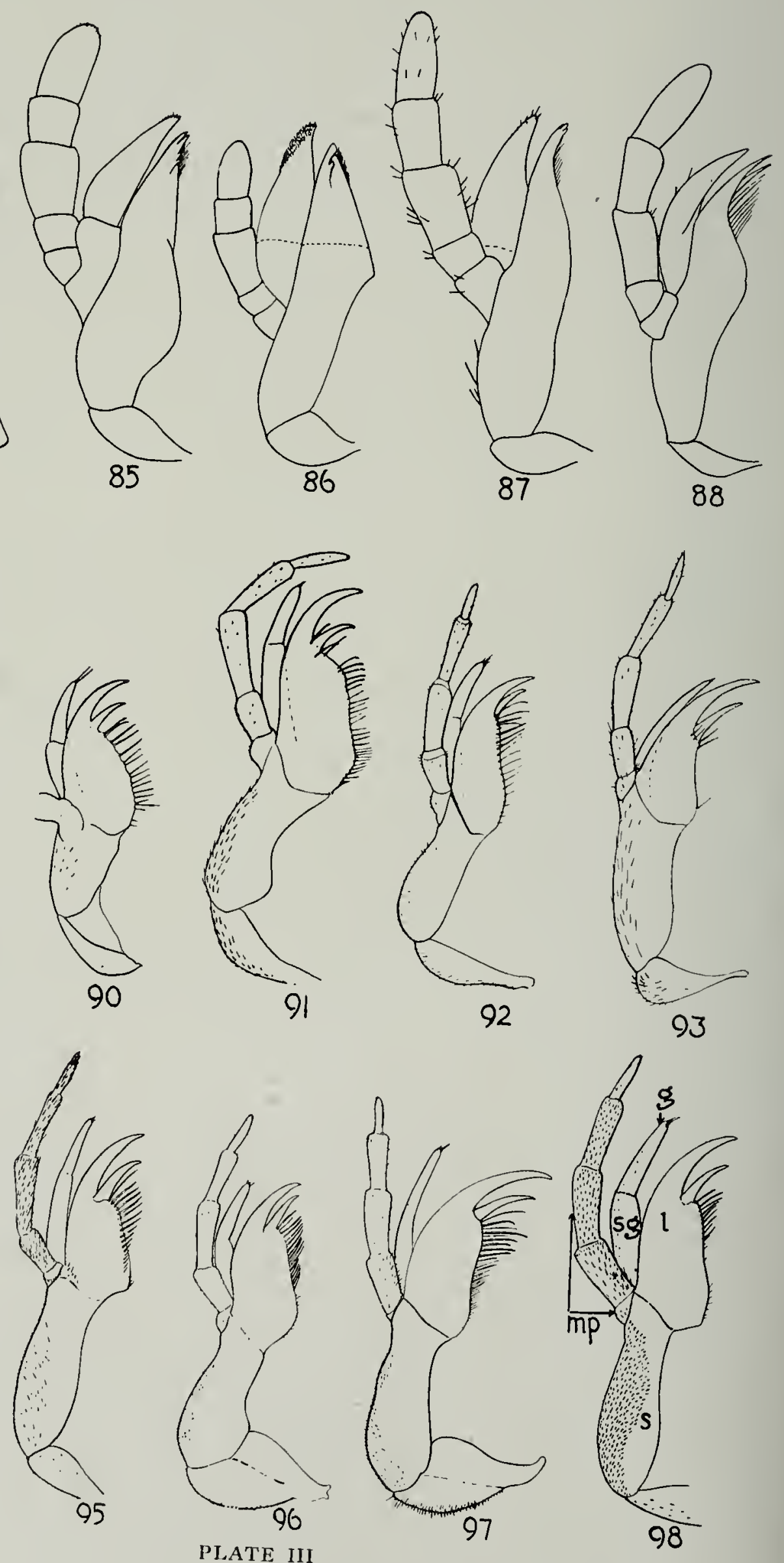


\section{PLATE III}

\section{Ventral View of Right Maxilla of Nymph}

Fig. 84.-Pteronarcys nobilis, male.

Fig. 85.-Taeniopteryx nivalis, female.

Fig. 86.- Strophopteryx fasciata, female.

Fig. 87.-Allocapnia vivipara, female.

Fig. 88. - Leuctra claasseni, female.

Fig. 89.- Nemoura venosa, female.

Fig. 90.-Atoperla ephyre, female.

Fig. 91.- Perlinella drymo, female.

Fig. 92.-Neoperla clymene, female.

Fig. 93.- Perlesta placida, female.

Fig. 94.-Acroneuria abnormis, female.

Fig. 95.- Acroneuria arida, female.

Fig. 96.-Acroneuria internata, female.

Fig. 97.-Acroneuria ruralis, female.

Fig. 98.-Acroneuria sp. a., female.

ABBREVIATIONS

$$
\begin{aligned}
& \text { g-galea } \\
& \text { l-lacinia } \\
& \text { mp-maxillary palpus } \\
& \text { s-stipes } \\
& \text { sg-subgalea }
\end{aligned}
$$



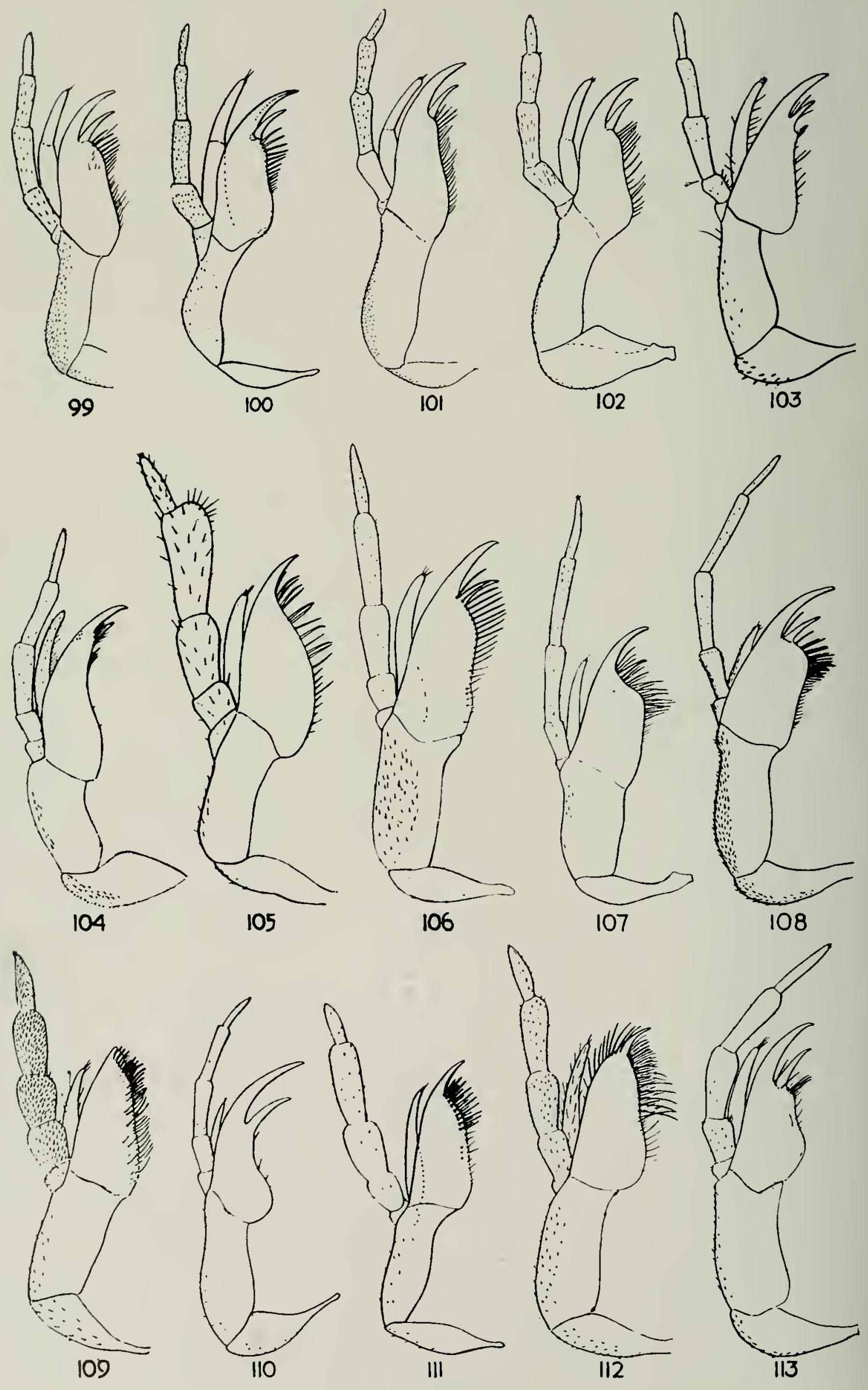

PLATE IV 
Ventral. View of Right Maxilla of Nymph-cont'd

Fig. 99.-Acroneuria sp. b., female.

Fig. 100.--Neophasganophora capitata, female.

Fig. 101.-Togoperla media, male.

Fig. 102.-Togoperla sp. a., female.

Fig. 103.- Hydroperla crosbyi, male.

Fig. 104.- -Hydroperla harti, male.

Fig. 105.-Chloroperla cydippe, female.

Fig. 106.-Isoperla bilineata, female.

Fig. 107.-Isoperla clio, female.

Fig. 108.-Isoperla confusa, female.

Fig. 109.-Isoperla decepia, female.

Fig. 110.-Isoperla duplicata, female.

Fig. 111.-Isoperla minuta, female.

Fig. 112.-Isoperla mohri, female.

Fig. 113.-Isoperla richardsoni, male. 

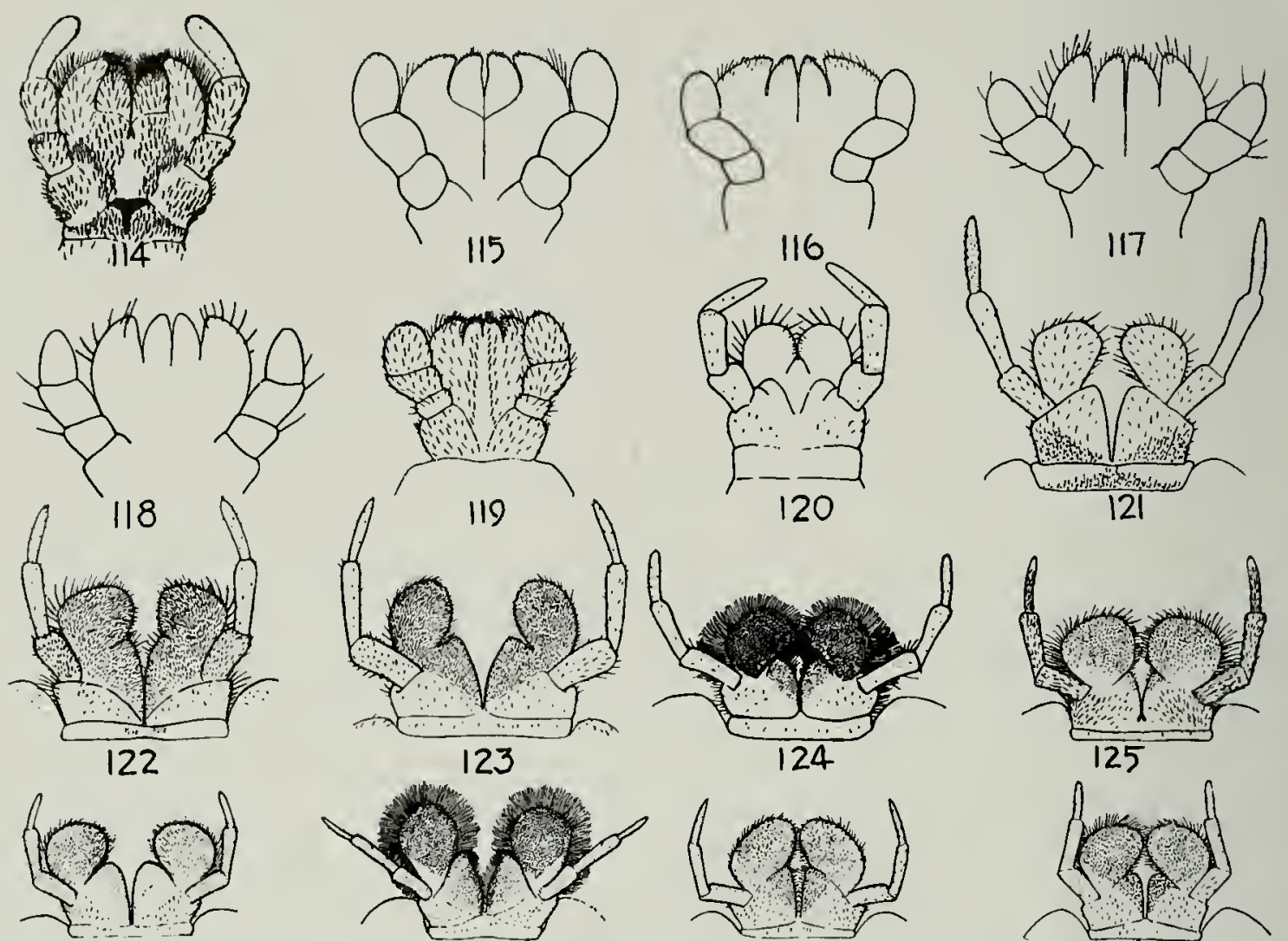

126
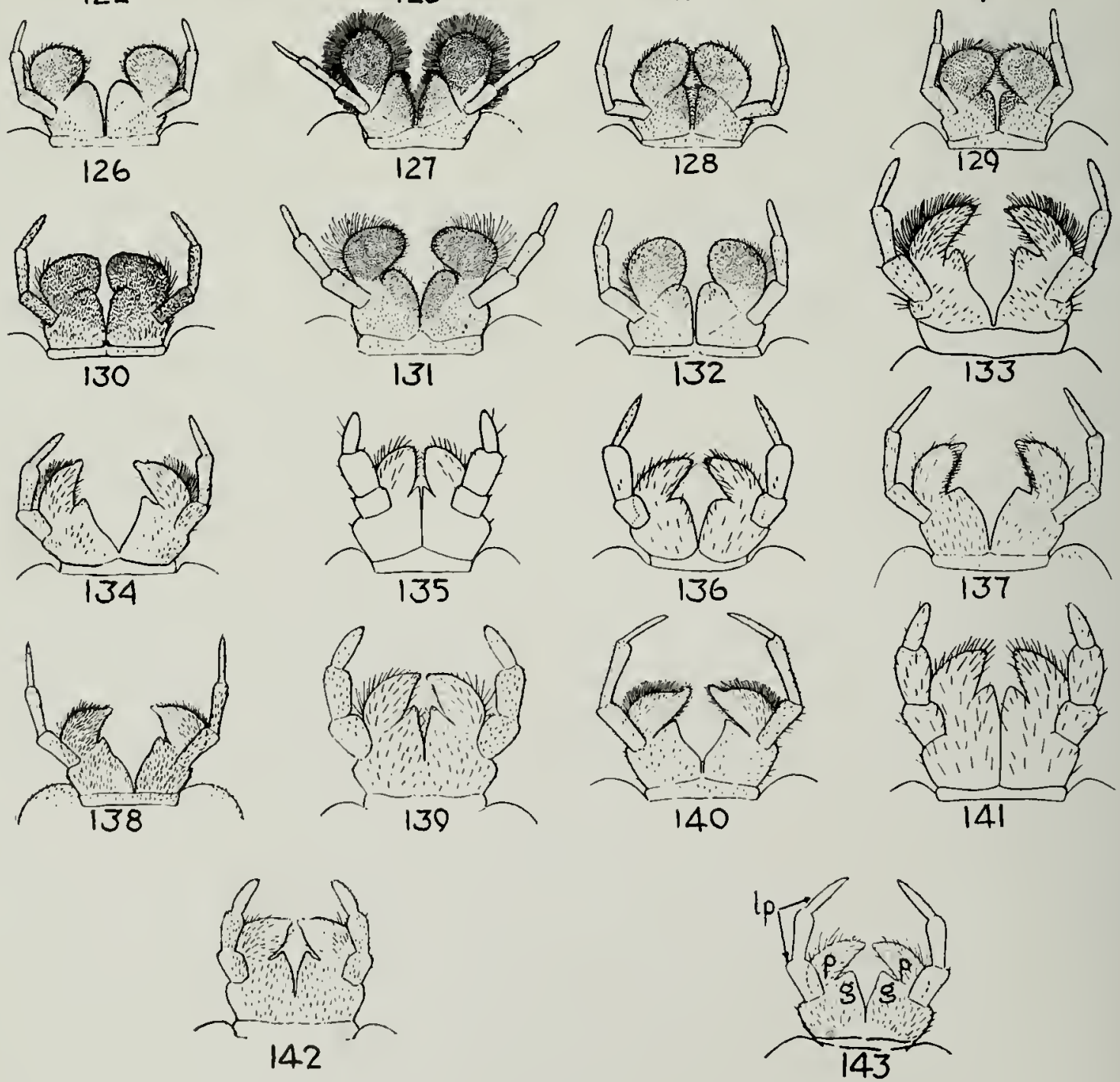

PLATE V 
PLATE V

\section{Ventral View of Labiuni of Nymph}

Fig. 114.- Pteronarcys nobilis, male.

Fig. 115.-Taeniopteryx nivalis, female.

Fig. 116.-Strophoptery x fasciata, female.

Fig. 117.-Allocapnia vivipara, female.

Fig. 118.-Leuctra clcasseni, female.

Fig. 119. - Nemoura venosa, female.

Fig. 120. - Atoperla ephyre, female.

Fig. 121.-Perlinella drymo, female.

Fig. 122.-Neoperla clymene, female.

Fig. 123. - Perlesta placida, female.

Fig. 124. - Acroneuric abnormis, female.

Fig. 125.-Acroneuria arida, female.

Fig. 126.-Acroneuria internata, female.

Fig. 127.-Acroneuria ruralis, female.

Fig. 128.-Acroneuria sp. a., female.

Fig. 129.-Acronetria sp. b., female.

Fig. 130.- Neophasganophora capitata, female.

Fig. 131.-Togoperla media, male.

Fig. 132.- Togoperla sp. a., female.

Fig. 133.-Hydroperla crosbyi, male

Fig. 134.-Hydroperla harti, female.

Fig. 135.-Chloroperla cydippe, female.

Fig. 136.-I Isoperla bilineata, female.

Fig. 137.-I soperla clio, female.

Fig. 138.-I Isoperla confusa, female.

Fig. 139. - Isoperla decepta, female.

Fig. 140.-Isoperla duplicata, female.

Fig. 141.-Isoperla minuta, female.

Fig. 142.-Isoperla mohri, female.

Fig. 143.-Isoperla richardsoni, male.

ABBREVIATIONS

g-glossa

lp-labial palpus

$\mathrm{p}$ - paraglossa 


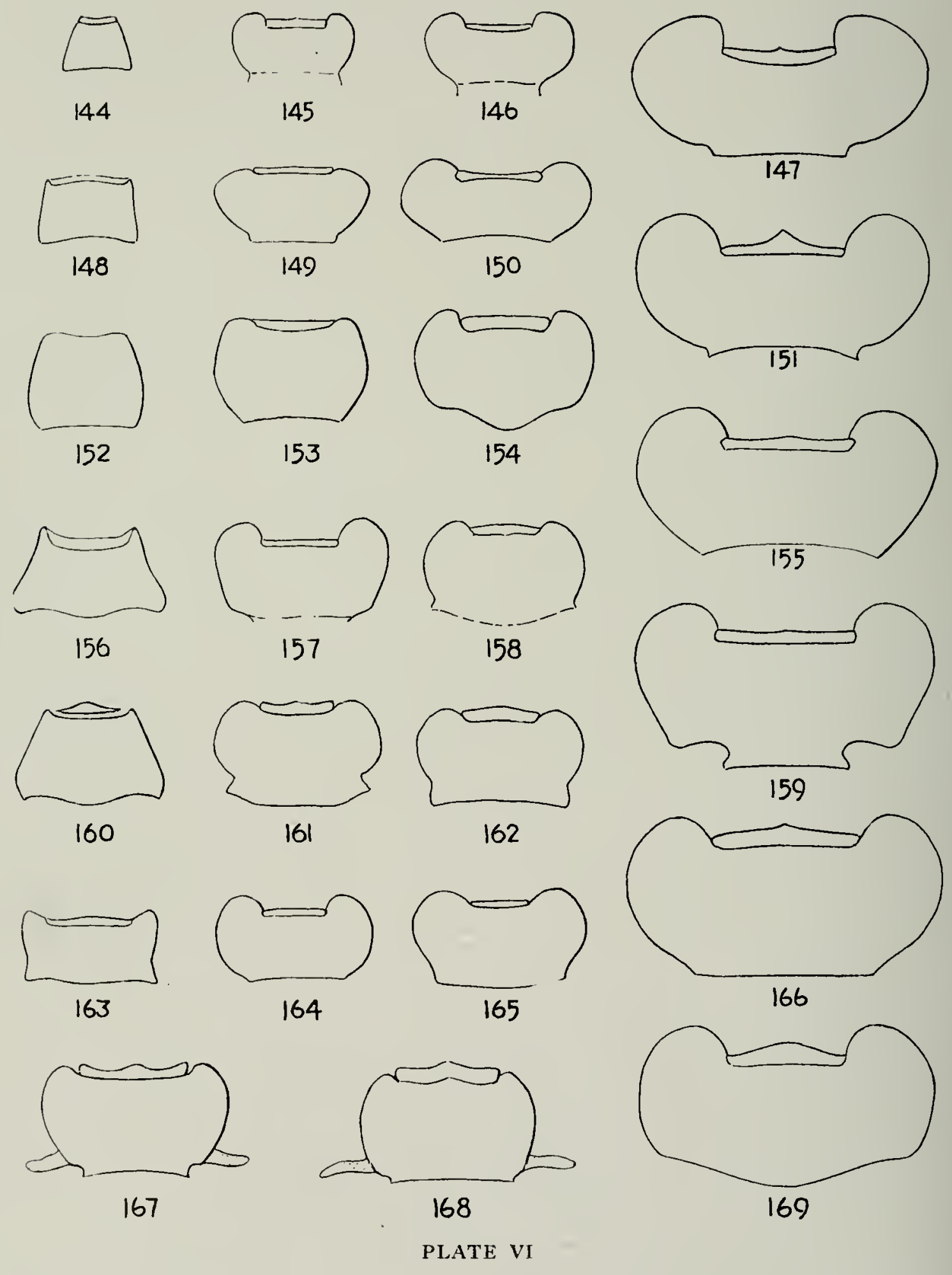




\section{PLATE VI}

Ventral View of Mentum and Subientum of Nymph

Fig. 144.-Allocapnia vivipara, female.

Fig. 145. - Isoperla clio, female.

Fig. 146.- Atoperla ephyre, female.

Fig. 147.-Acronetria ruralis, female.

Fig. 148.-Strophopteryx fasciata, female.

Fig. 149.- - Perlesta placida, female.

Fig. 150.-Neophasganophora capitata, female.

Fig. 151.-Acroneuria abnormis, female.

Fig. 152.-Nemoura venosa, female.

Fig. 153. - Leuctra claasseni, female.

Fig. 154.-Perlinella drymo, female.

Fig. 155.-Acronettria arida, female.

Fig. 156.-Taeniopteryx nivalis, female.

Fig. 157.- Togoperla sp. a., female.

Fig. 158.-I soperla minuta, female.

Fig. 159.- Acronetria internata, female.

Fig. 160.-Pteronarcys nobilis, female.

Fig. 161.-Isoperla bilineata, female.

Fig. 162.-Isoperla mohri, female.

Fig. 163. - Isoperla decepta, female.

Fig. 164.-Neoperla clymeme, female.

Fig. 165.--Isoperla confusa, female.

Fig. 166.-Acroneuria sp. a., female.

Fig. 167.-Hydroperla harti, male.

Fig. 168.-Hydroperla crosbyi, female.

Fig. 169.-Acroneuria sp. b, female. 

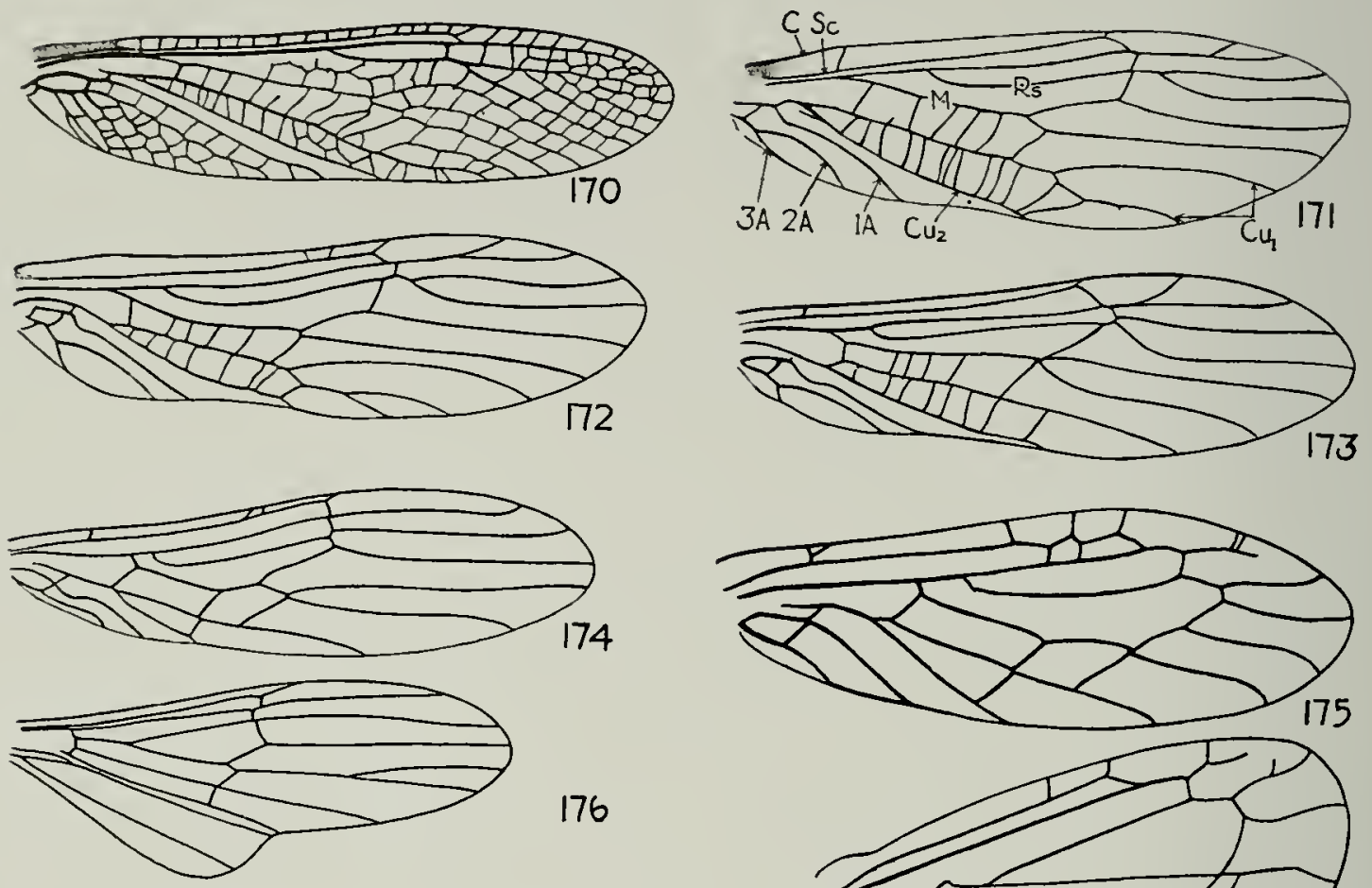

176
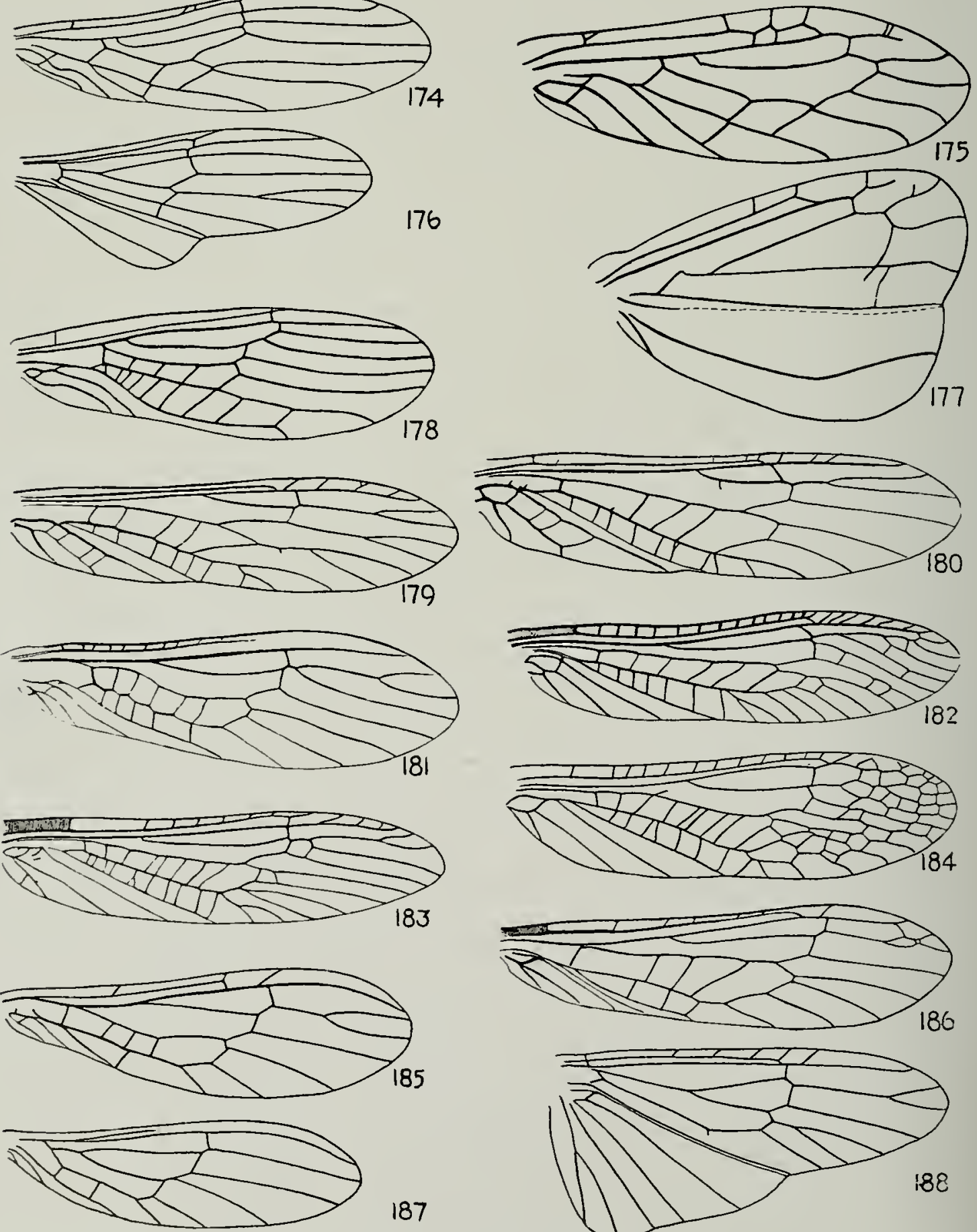

187

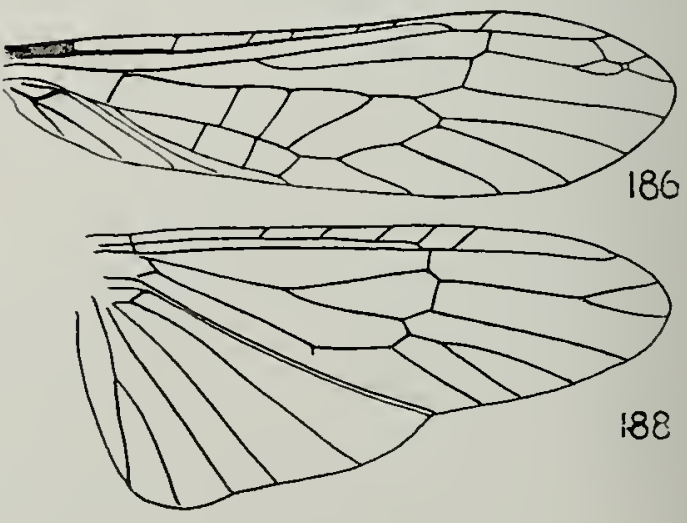

PLATE VII 


\section{PLATE VII}

\section{Dorsal View of Right Wings}

Fig. 170.-Pteronarcys nobilis, female. Forewing.

Fig. 171.-Taeniopteryx nivalis, female. Forewing.

Fig. 172.- Strophoptery $x$ fasciata, female. Forewing.

Fig. 173. - Nemoura venosa, female. Forewing.

Fig. 174.-Capnia sp., female. Forewing.

Fig. 175.-Allocapnia mystica, female. Forewing.

Fig. 176.-Capnia sp., female. Hind wing.

Fig. 177.- Allocapnia mystica, female. Hind wing.

Fig. 178.-Lenctra claasseni, female. Forewing.

Fig. 179. - Atoperla cphyre, female. lorewing.

Fig. 180.-Pcrlinella drymo, female. Forewing.

Fig. 181.-Neoperla clymene, female. Forewing.

Fig. 182.-Acroneuria abnormis, female. Forewing.

Fig. 183.-Hydroperla crosbyi, female. Forewing.

Fig. 184.- Perlodes dolobrata, female. Horewing. (After Needham and Claassen)

Fig. 185.-Chloroperla cydippe, female. Forewing.

Fig. 186. - Isoperla bilineata, female. Forewing.

Fig. 187.-Chloroperla cydippe, female. Hind wing.

Fig. 188.-Isoperla bilineata, female. Hind wing.

$$
\begin{aligned}
& \text { ABBREviATIONS } \\
& \mathrm{C} \text {-costa } \\
& \mathrm{Sc} \text {-subcosta } \\
& \mathrm{Rs} \text {-radial sector } \\
& \mathrm{M} \text {-media } \\
& \mathrm{Cu}_{1} \text {-cubitus } 1 \\
& \mathrm{Cu}_{2} \text {-cubitus } 2 \\
& 1 \mathrm{~A}-\text { first anal } \\
& 2 \mathrm{~A} \text { - second anal } \\
& 3 \mathrm{~A} \text {-third anal }
\end{aligned}
$$




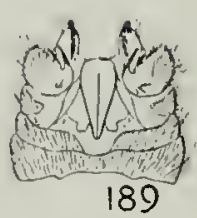

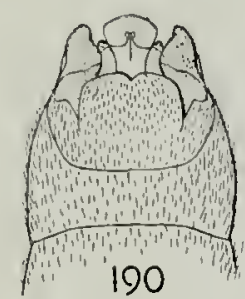

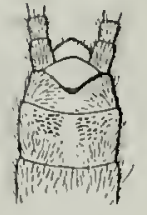

191

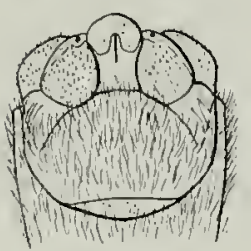

195

196

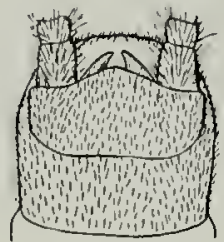

192

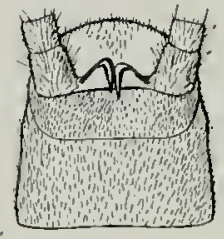

197

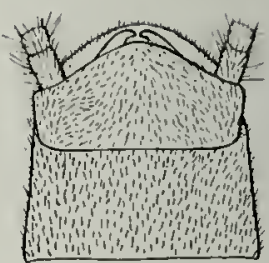

193

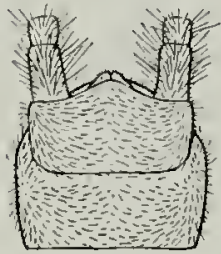

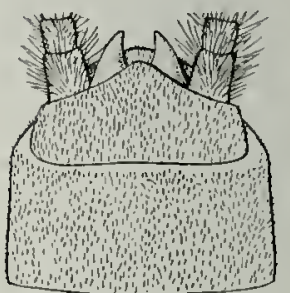

198
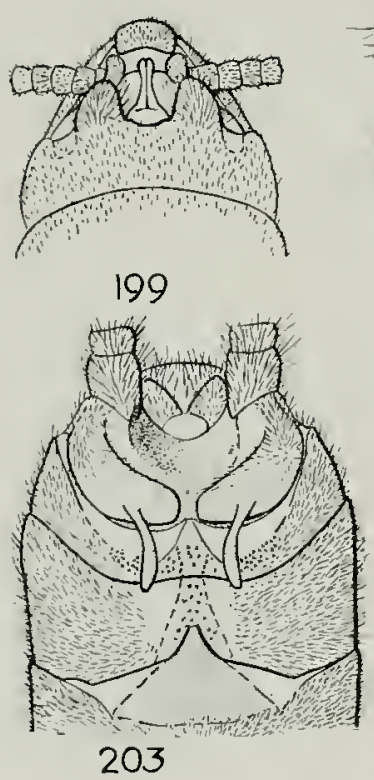

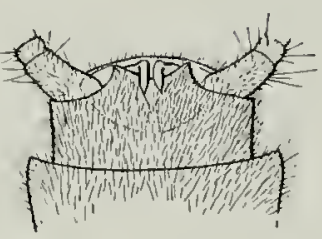

200

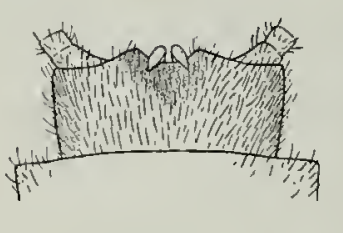

201
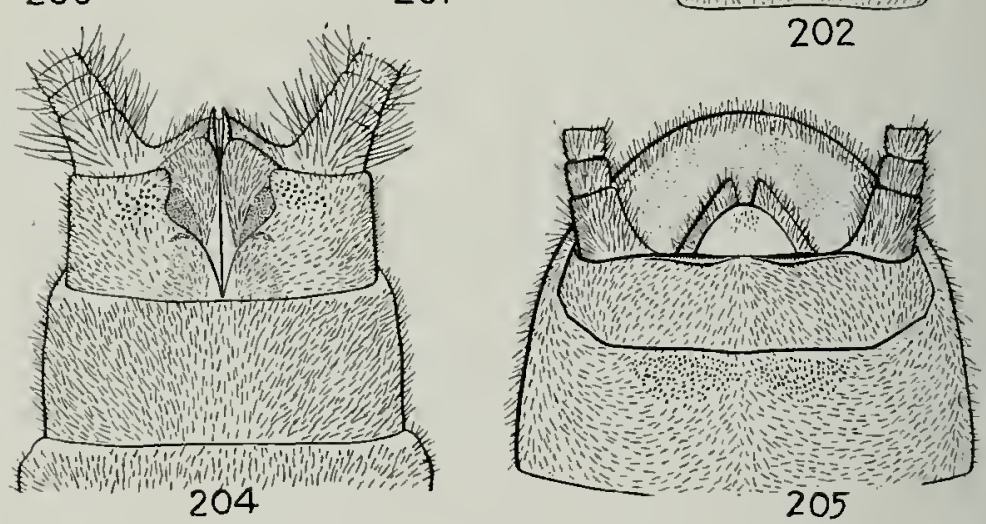

PLATE VIII

Dorsal View of Adult Male Terminal Abdominal. Segments

Fig. 189.- -Nemoura venosa.

Fig. 190.-Taeniopteryx parvula.

Fig. 191.-Chloroperla cydippe.

Fig. 192.-I Isoperla decepta.

Fig. 193.-Isoperla mohri.

Fig. 194.-Leuctra claasseni.

Fig. 195.-Taeniopteryx nivalis.

Fig. 196.-Isoperla minuta.

Fig. 197.-Isoperla richardsoni.

Fig. 198.-Isoperla bilineata.

Fig. 199.--Strophoptery $x$ fasciata.

Fig. 200.-Atoperla ephyre.

Fig. 201.- Perlinella drymo.

Fig. 202.-Perlesta placida.

Fig. 203.-Neoperla clymene.

Fig. 204.-I soperla duplicata.

Fig. 205.-Isoperla confusa. 

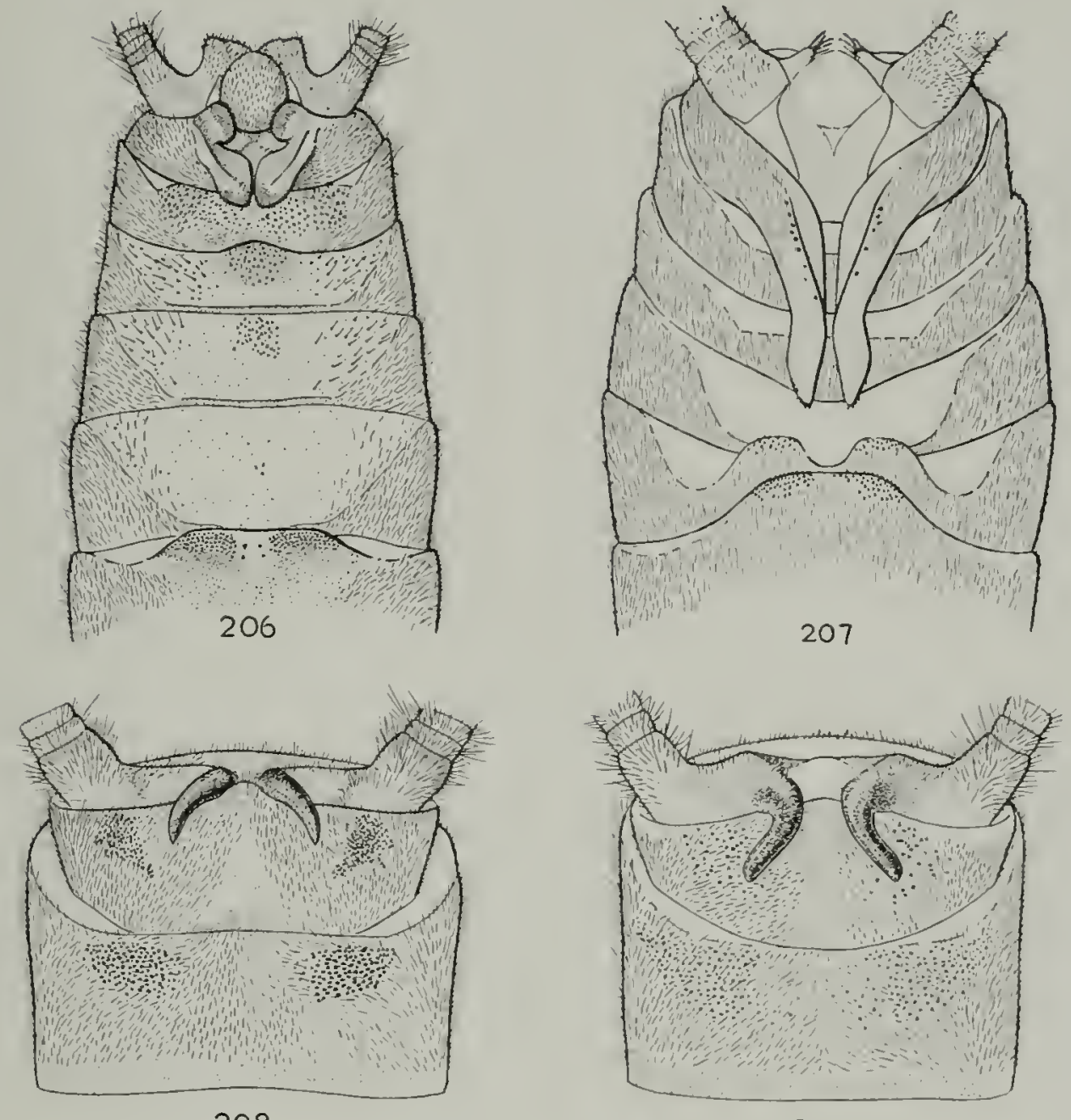

208

209

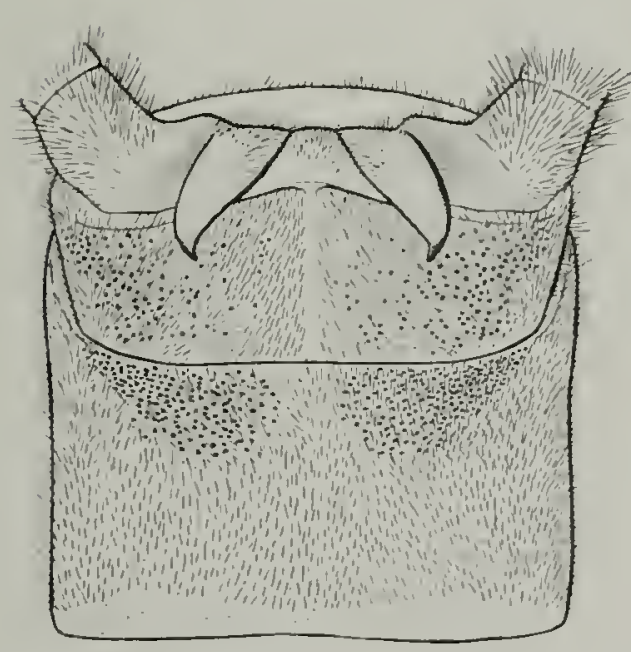

210

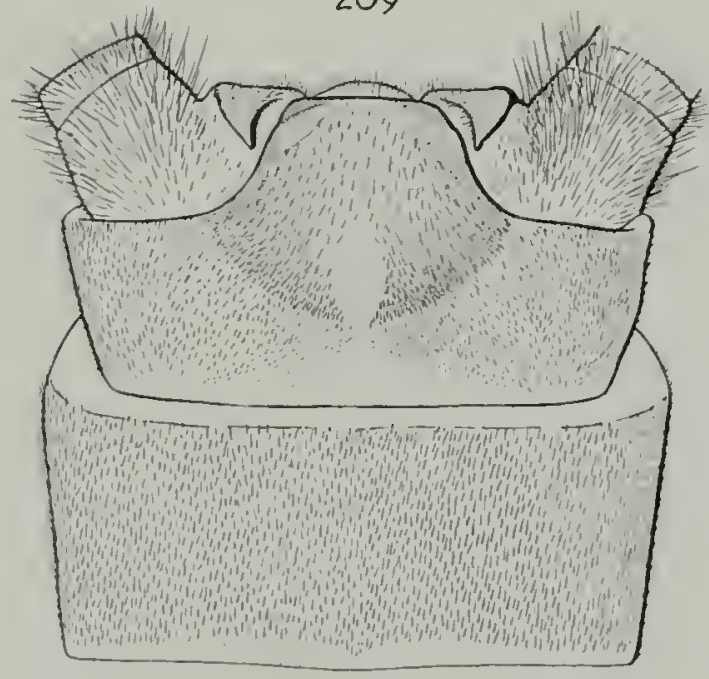

211

PLATE IX

Dorsal. View of Adult Male Terminal. Armonisai. SECBNENTS-CONT'D

Fig. 206.-Togoperla media.

Fig. 207. - Neophasganophora capitata.

Fig. 208. - Icronemira arida.
Fig. 209.-Acronewia internata.

Fig. 210.-Acronewria abnormis.

Fig. 211. - toronemia ruralis. 


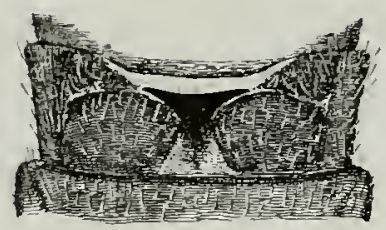

212

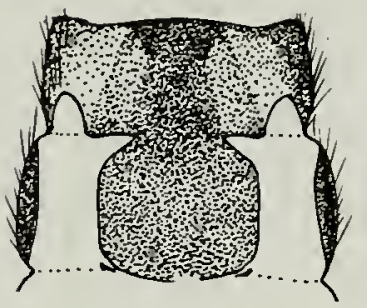

215

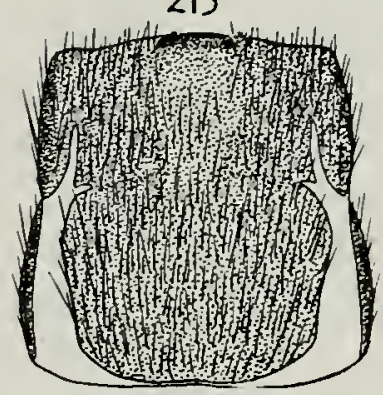

218

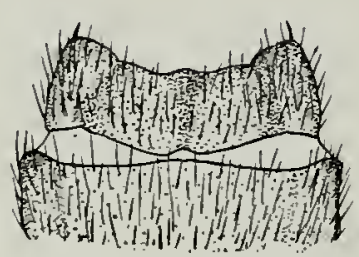

213

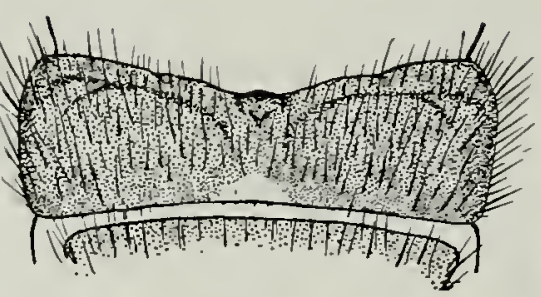

216

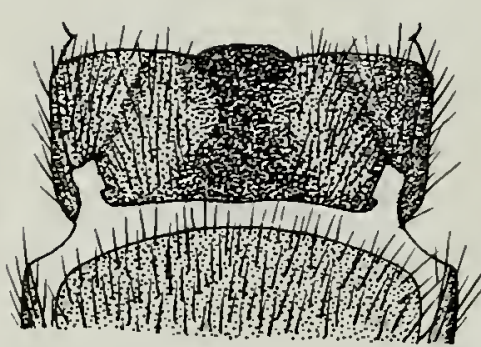

219

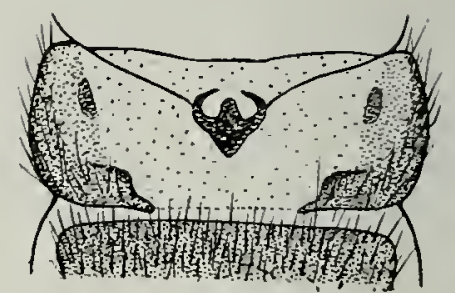

214

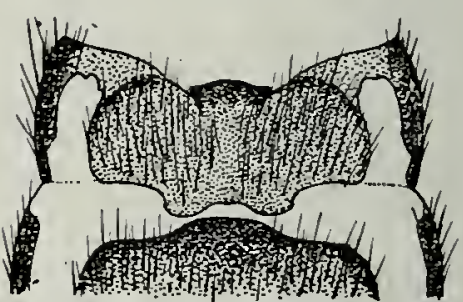

217

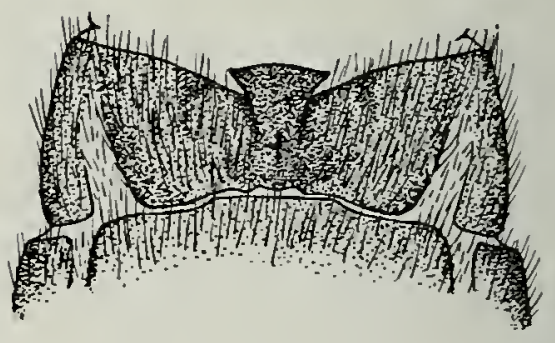

220

PLA'TE X

Seventh and Eighth Abdominal Sternites of Adult Female, Showing Subgenital Plate

Fig. 212.-Allocapnia illinoensis.

Fig. 213.-Allocapnia recta.

Fig. 214.-Taeniopteryx parvula.

Fig. 215.-Allocapnia pygmaea.

Fig. 216.-Taenioptery.x nivalis.

Fig. 217.-Allocapnia forbesi.

Fig. 218.-Allocapnia vivipara.

Fig. 219.-Allocapnia mystica.

Fig. 220.-Allocapnia granulata. 


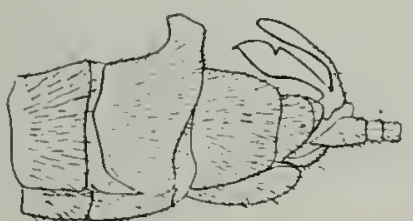

221
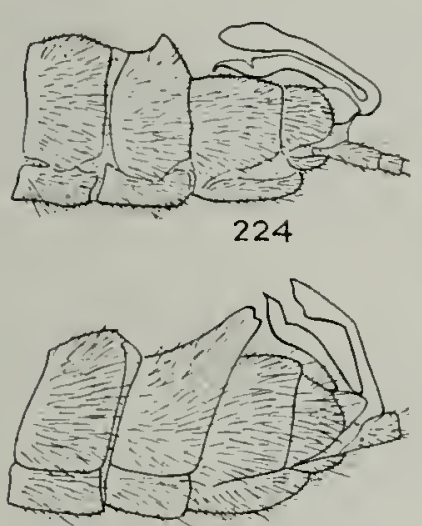

227

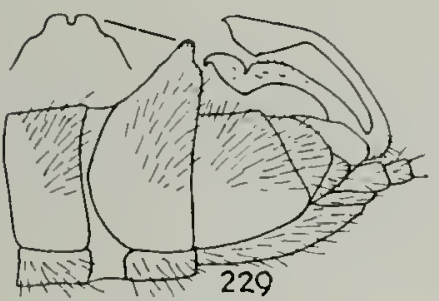

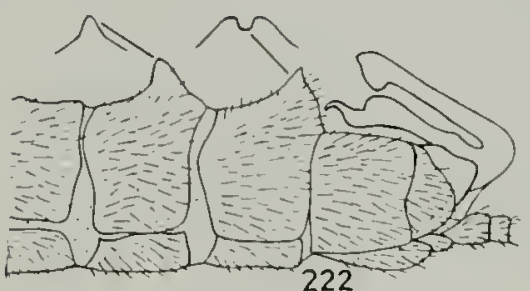
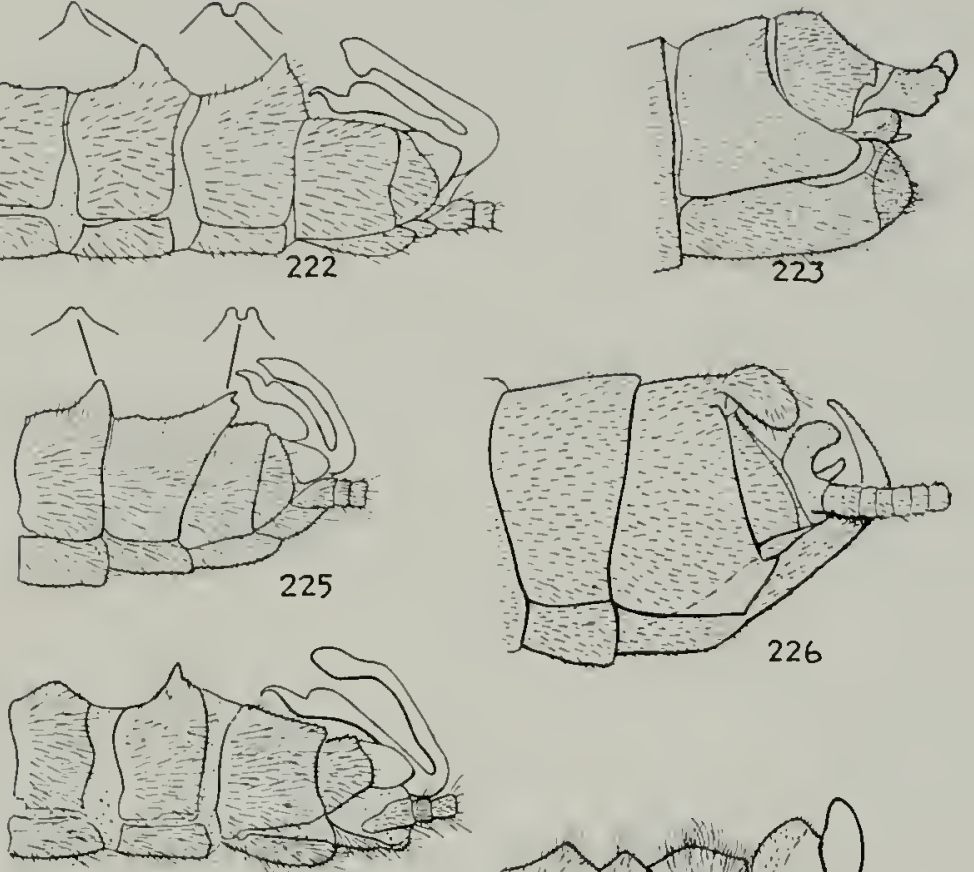

228

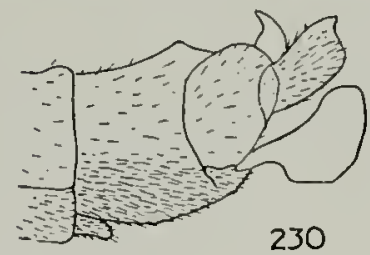

230

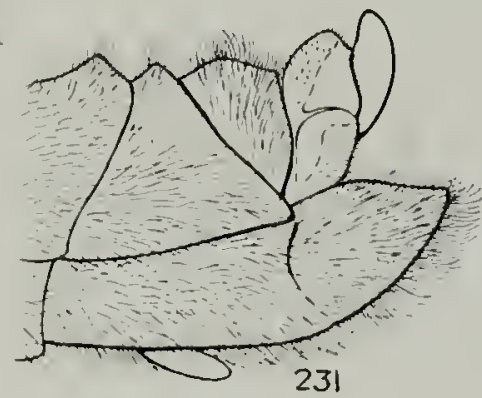

231

PLATE XI

Ianteral, View of Male Terminal. Agdominal. Segments and Genitalia

Fig. 221.-Allocapnia recta.

Fig. 222.-Allocapnia forbesi.

Fig. 223.-Taeniopteryx parvula.

Fig. 224.-Allocapnia pygmaea.

Fig. 225.-Allocapnia illinoensis.

Fig. 226. - Strophoptery.x fasciata.

Fig. 227.- Allocapnia granulata.

Fig. 228.- Allocapnia vivipara.

Fig. 229.- Allocapnia mystica.

Fig. 230.-Leuctra claasseni.

Fig. 231.-Taeniopteryx nivalis. 


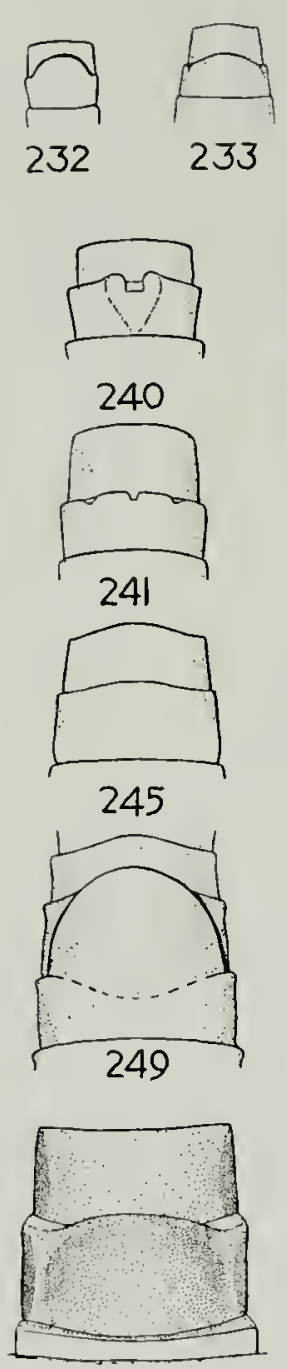

251

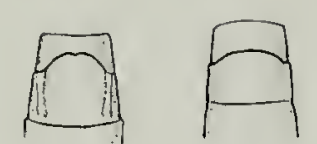

234235
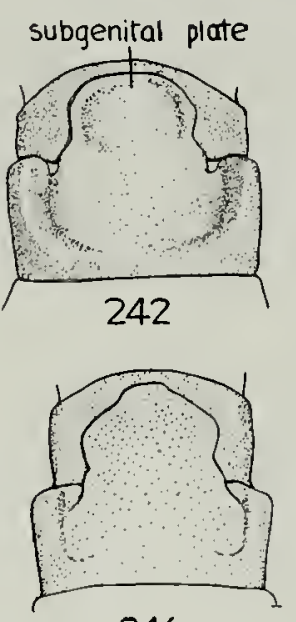

246

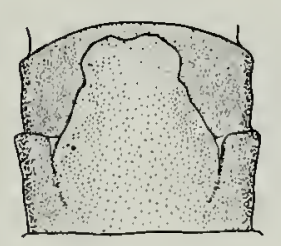

250

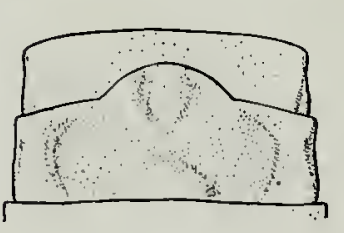

252

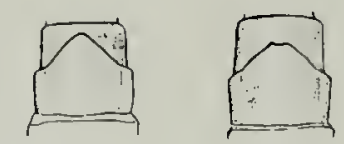

$236 \quad 237$

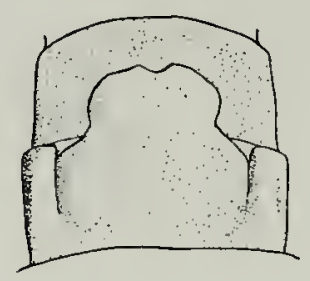

243

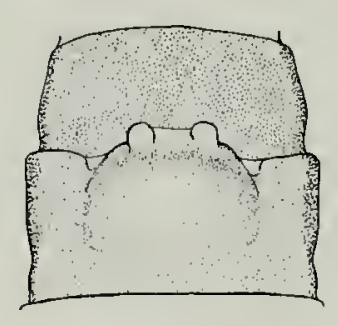

247

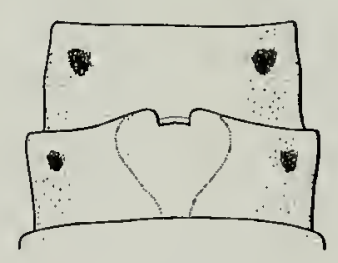

253

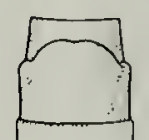

238

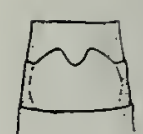

239
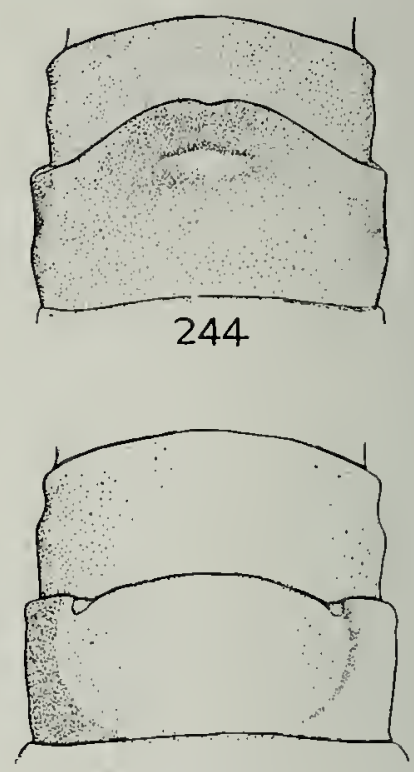

248

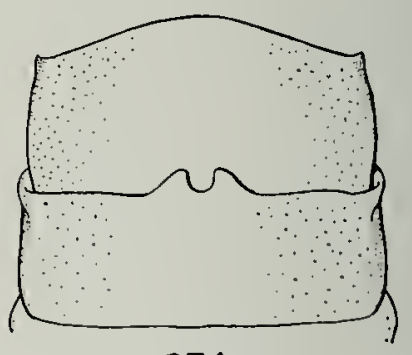

254

\section{PLATE XIY}

Female Abdominal Sternites, Showing Subgental Plate

Fig. 232.-Chloroperla cydippe.

Fig. 233.-Isoperla decepta.

Fig. 234.-Isoperla minuta.

Fig. 235.-Isoperla richardsoni.

Fig. 236.-Isoperla bilineata.

Fig. 237.-Isoperla bilineata.

Fig. 238.-Isoperla mohri.

Fig. 239.-I soperla conspicuia.

Fig. 240.-Atoperla ephyre.

Fig. 241.-Perlesta placida.

Fig. 242.-Acromenria arida.

Fig. 243.-Acroneuria arida.
Fig. 244.-Acroneuria ruralis.

Fig. 245.-Neoperla clymene.

Fig. 246.-Acronewria arida.

Fig. 247.-Acroneuria intermala.

Fig. 248.-Acroneuria abnormis.

Fig. 249.-Isoperla duplicata.

Fig. 250.-Acroneuria arida.

Fig. 251.-Isoperla confusa.

Fig. 252.-Neophasganophora capitata.

Fig. 253.-Perlinella drymo.

Fig. 254.-Togoperla media. 


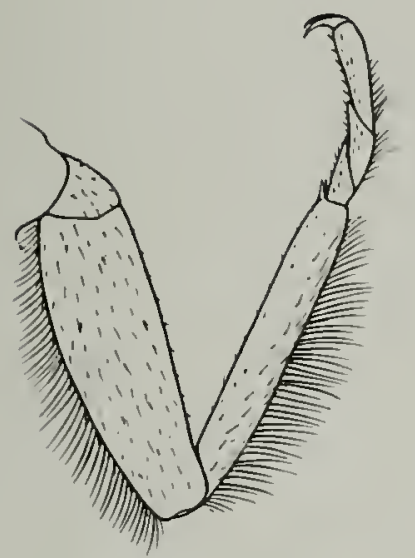

255

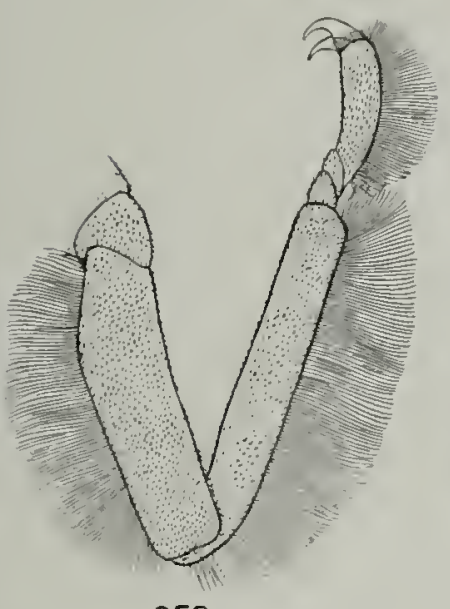

259
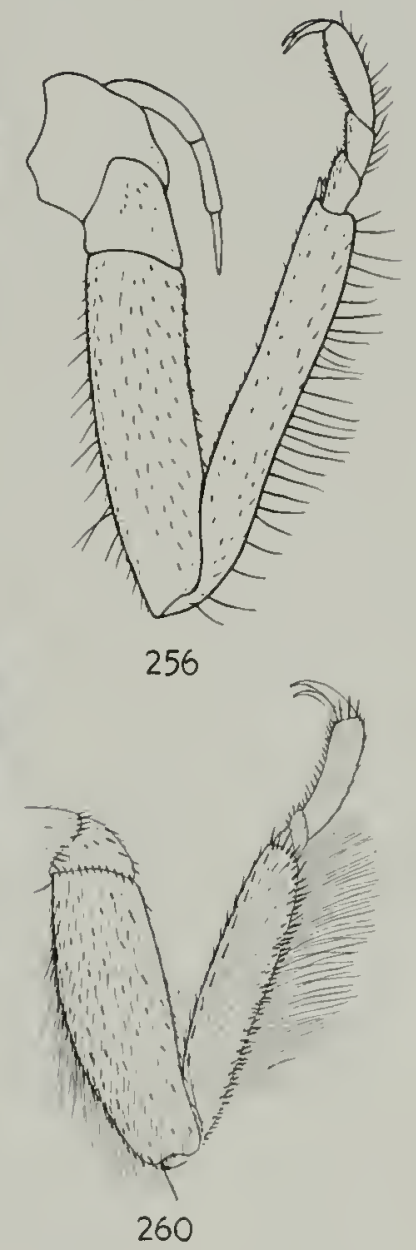

PI.ATE XIII

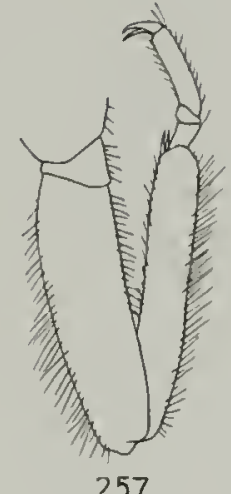

257

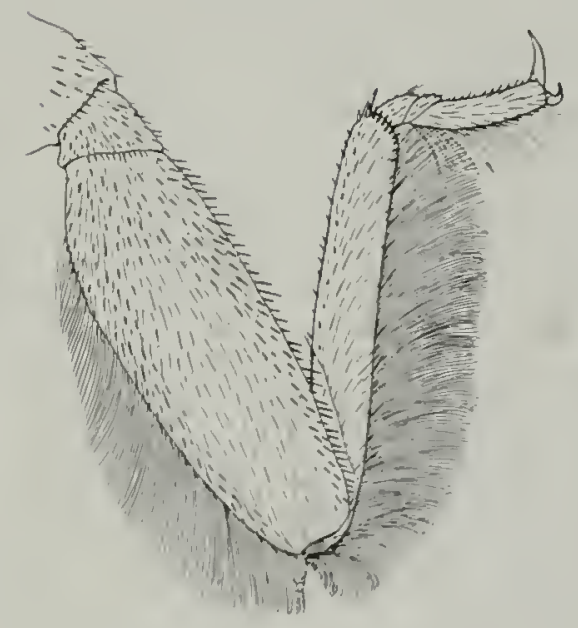

261

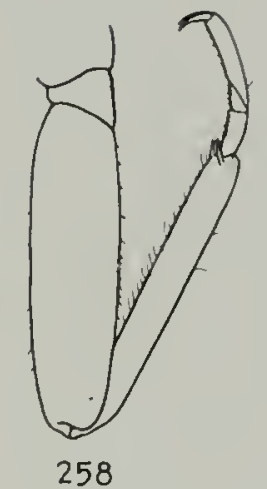

258 

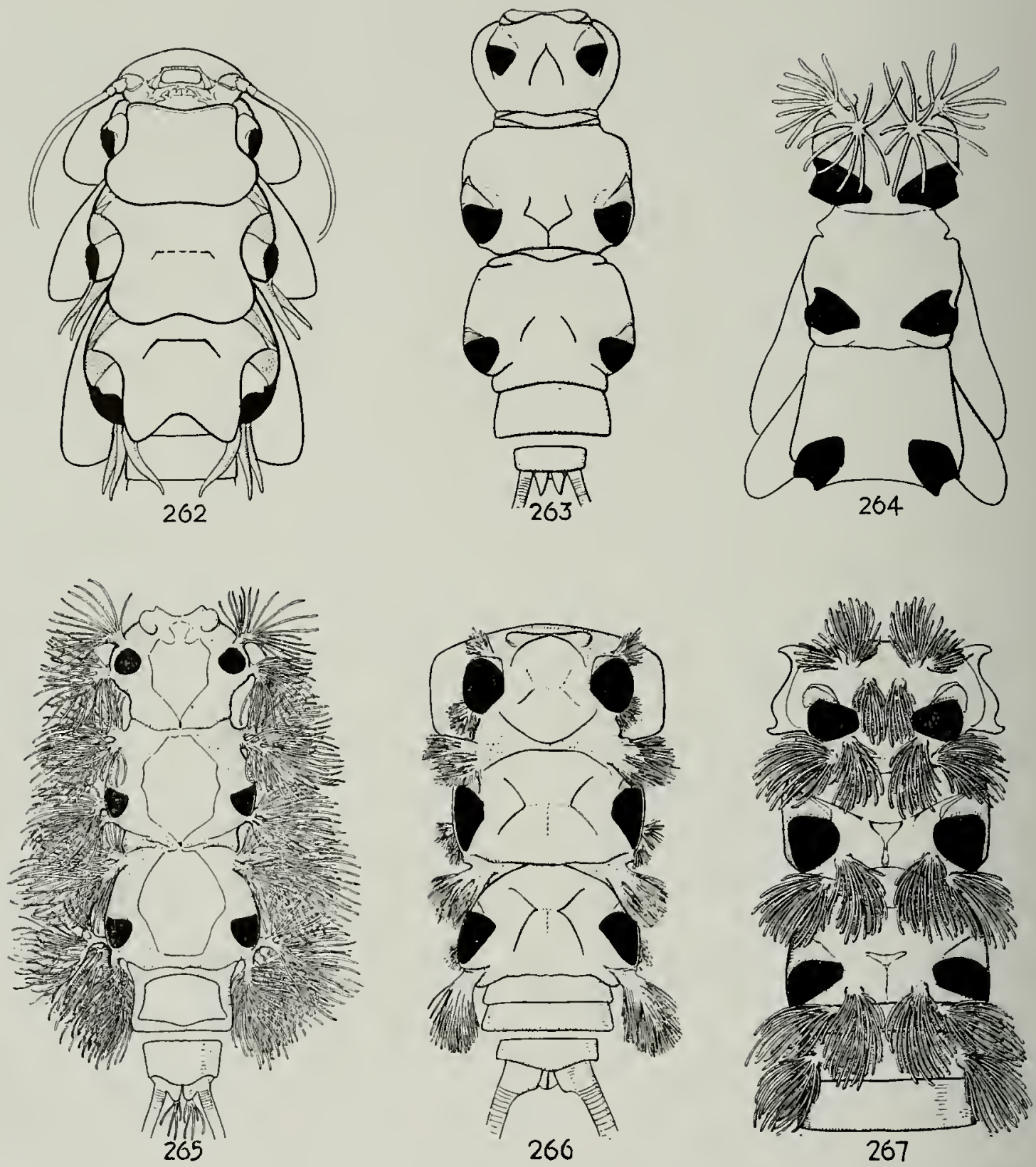

PI,ATE XIV

Ventral View of Thorax and Several Abdominal Segments of Nymphs, Showing Arrangement and Type of Gills (The black spots indicate leg attachments)

Fig. 262. - Peltoperla arcuata, female. Note overlapping shieldlike sternites. Fig. 263. - Isoperla bilineata, female. Note absence of gills.

Fig. 264.-Nemoura venosa, female.

Fig. 265.-Perlinella drymo, female.

Fig. 266.-Acroneuria internata, female.

Fig. 267.-Pteronarcys nobilis, female. 


\title{
KEY TO FAMLIES
}

\author{
OF THE PLECOPTERA OF NORTH AMERICA
}

Adults

1. Anal area of forewings with two or more rows of crossveins, fig. $170 .{ }^{3}$ Basal abdominal sternites with remnants of nymphal gills. PTERONARCIDAE, p. 334

Anal area of forewings entirely without crossveins, fig. 171, or with but one row, fig. 179. Basal abdominal segments without remnants of nymphal

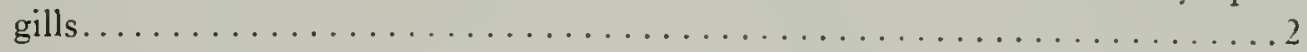

2. Cerci very short, one to eight segmented, figs. $223,226 \ldots \ldots \ldots \ldots \ldots$

Cerci long, always with more than 10 segments, fig. $1 \ldots \ldots \ldots \ldots \ldots \ldots$

3. Second tarsal segment about as long as other tarsal segments, figs. 255, $256 \ldots \ldots \ldots \ldots \ldots \ldots \ldots \ldots \ldots \ldots \ldots \ldots \ldots$ TAENIOPTERYGIDAE, p. 339

Second tarsal segment much shorter than the other tarsal segments, fig. 260 . .4

4. Apical marginal space beyond tip of subcosta with an oblique crossvein, fig. 173. Species often with gill remnants in cervical region, known Illinois species

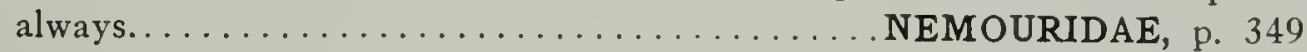

Apical marginal space beyond tip of subcosta without an oblique crossvein, fig. 178. No gill remnants visible.............. LEUCTRIDAE, p. 352

5. Forewing with a series of median and cubital crossveins, figs. 181, 182. First tarsal segment short, much shorter than third tarsal segment. Remnants of nymphal gills present or absent, fig. $2 \ldots \ldots \ldots \ldots \ldots \ldots \ldots$

Forewing without a series of median and cubital crossveins or at most with one or two median and one cubital crossvein, figs. 174, 176. First tarsal segment long, about as long as third segment. Remnants of nymphal gills

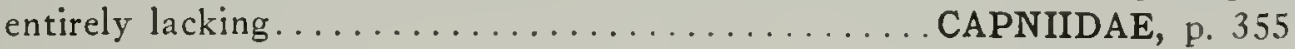

6. Cerci not longer than greatest width of prothorax. Prothorax much wider than head. (Not known from Illinois)............. PELTOPERLIDAE

Cerci much longer than greatest width of prothorax. Prothorax about as

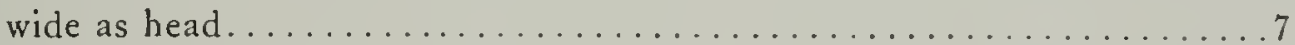

7. Remnants of nymphal gills on sides or venter of thorax, in position corresponding

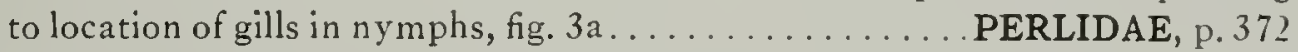

No remnants of nymphal gills on sides or venter of thorax . . . . . . . 8

8. Remnant of finger-like nymphal gills located near each side of outer basal corner of submentum, figs. 167, 168. Males with tenth tergite deeply cleft. Medium sized species with a body length usually more than $13 \mathrm{~mm}$. Species dominantly dark. Some species (Perlodes - not known from Illinois) with network of crossveins between branches of radius in apical portion of forewing, fig. $184 \ldots \ldots \ldots \ldots \ldots \ldots \ldots \ldots \ldots \ldots \ldots \ldots \ldots \ldots$. . . . . . 416

No remnant of finger-like nymphal gills located near each side of outer basal corner of submentum. Males without tenth tergite cleft, fig. 196, except for Isoperla duplicata, fig. 204, which is easily recognized by lobes on median posterior margin of both seventh and eighth abdominal sternites, fig. 341. Small to medium sized species with a body length usually much less than $13 \mathrm{~mm}$. Species ranging from dominantly yellow or whitish green to dark. All species without network of crossveins between branches of radius in apical portion of forewing, figs. $185,187 \ldots$ CHLOROPERLIDAE, p. 427

"Figs. 28-267 appear in I"lates 1-XI immediately preceding this log. Figs. 26s-ff. 1"un wh the species they illustrate, following this key. 
PIECOPTERA-KEY TO FAMILIES-CONT'D

\section{Nymphs}

1. Gills present on some of the ventral basal abdominal segments, fig. $267 \ldots$ $\ldots \ldots \ldots \ldots \ldots \ldots \ldots \ldots \ldots \ldots \ldots \ldots \ldots \ldots$ PTERONARCIDAE, p. 334

Gills absent on all ventral abdominal segments $\ldots \ldots \ldots \ldots \ldots \ldots \ldots \ldots \ldots 2$

2. Venter of thorax covered with large, overlapping, shieldlike plates, fig. 262.

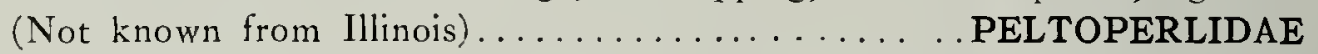
Venter of thorax without distinct, large, overlapping, shieldlike plates, fig. 266..3

3. Labium with paraglossae and glossae extending forward about the same distance and side by side in the same horizontal plane, figs. $115-119 \ldots \ldots .4$

Labium with paraglossae extending forward much farther than the glossae, the latter deeply inset below and between the paraglossae so as to appear almost as basal segments of them, figs. $120-143 \ldots \ldots \ldots \ldots \ldots \ldots \ldots$

4. Second tarsal segment, figs. 255, 256, approximately as long or longer than the first segment............... TAENIOPTERYGIDAE, p. 339

Second tarsal segment, figs. 257,258 , shorter than the first. . . . . . . . . .

5. Small and robust nymphs, fig. 281; hairy; hind wing pads extending considerably outward from the body at an angle. Gills present or absent, when present with branched gills, fig. 264, in ventral cervical region (known Illinois species) or with single filamentous gills near bases of legs.......

$\ldots \ldots \ldots \ldots \ldots \ldots \ldots \ldots \ldots \ldots \ldots \ldots \ldots \ldots$ NEMOURIDAE, p. 349

Small and slender nymphs, fig. 298; hairs few, fine or lacking; hind wing pads lying about parallel to longitudinal axis of body. No branched cervical gills nor filamentous gills near bases of legs................

6. Lateral margins of abdominal segments somewhat rounded, segments widest at posterior margin and narrower towards base, fig. 298. Wing pads, fig. 298, with one exception, fig. 297, present in half grown or full grown nymphs; hind wing pad with anal lobe or area extending far beyond middle of wing pad. Last abdominal segment with a conical projection in male, fig. 297. Anal gills never present................. CAPNIIDAE, p. 355

Lateral margins of abdominal segments almost straight, abdomen appearing cylindrical, fig. 283. Wing pads, fig. 283, always present in half grown to full grown nymphs; hind wing pad with anal lobe or area small and not extending much beyond middle of wing pad, fig. 283. Last abdominal segment without conical projection in either sex, fig. 283. Anal gills present at least in some species. (Illinois species with anal gills, fig. 284, but gills are easily broken off in preserved specimens and solikely not to be observed).

LEUCTRIDAE, p. 352

7. With a small membranous finger-like gill located near each side of outer basal angle of submentum, figs. $167,168 \ldots \ldots \ldots \ldots$ PERLODIDAE, p. 416

Without such gills on submentum, fig. $161 \ldots \ldots \ldots \ldots \ldots \ldots \ldots \ldots$

S. Branched gills always present on sides of thorax near bases of legs and sometimes

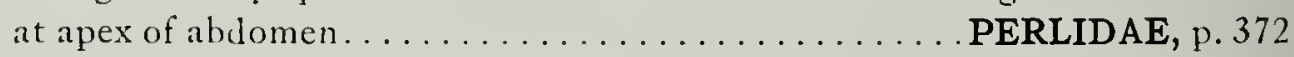

Gills of all kinds entire!y lacking...........CHLOROPERLIDAE, p. 427

\section{PTERONARCIDAE}

'This family consists of two North American genera, Pteronarcys and Pteronarcella, only the first being known to occur in Illinois. Pteronar- 
FRISON: STONEFLIES, OR PLECOPTERA, OF ILLINOIS

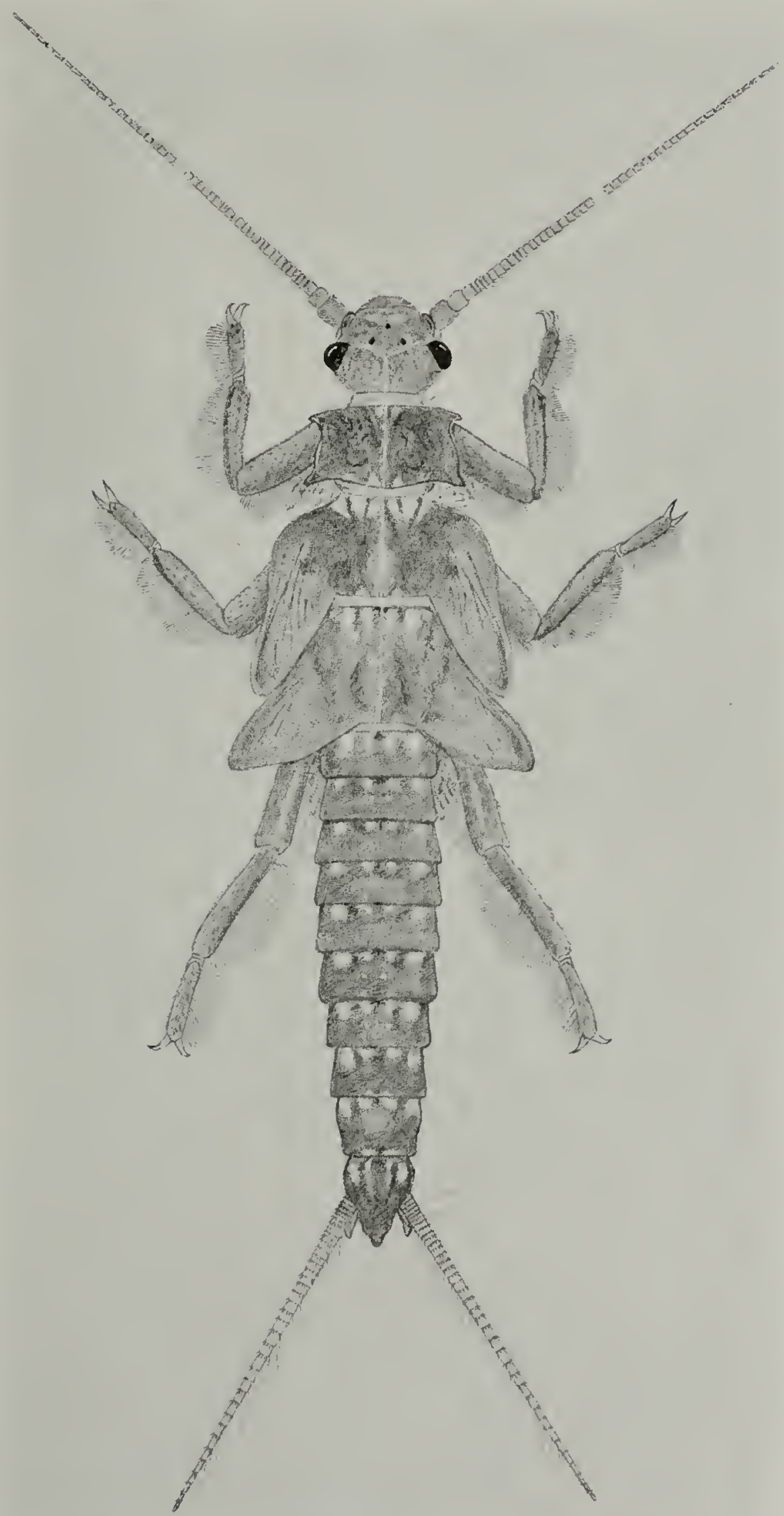

Fig. 268.-Pteronarcys nobilis, nymphal male. 
cella is apparently restricted to the western part of this continent. Presence of gills on the third abdominal segment readily separates the nymphs of Pteronarcella from those of Pteronarcys. The adults differ in venational characters and in number of pairs of vestigial gills on abdominal segments.

\section{Pteronarcys Newman}

Newman (1838) p. 175. Genotype Pteronarcys regalis Newman =Pleronarcys dorsata (Say), subsequent designation of Enderlein (1909).

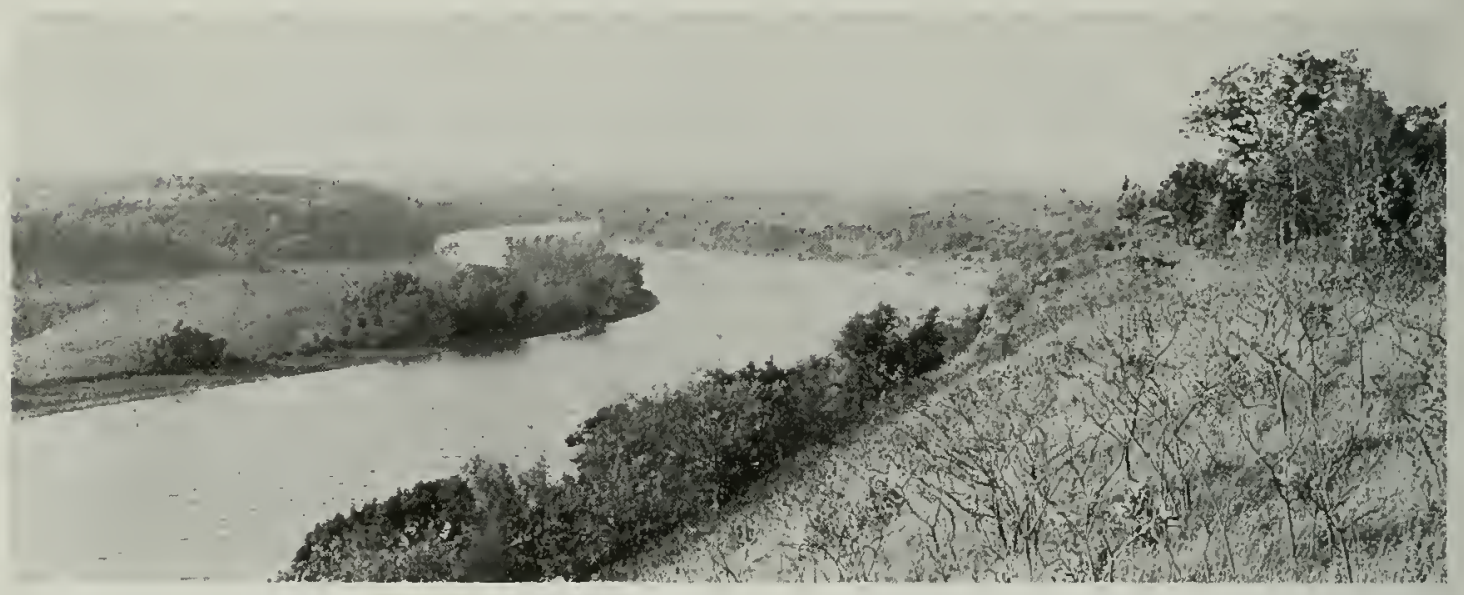

Fig. 269. - TYpical large river habitat of Illinois stoneflies. The Rock river at Oregon and similar streams within or bordering the state are favored by Acroneuria abnormis, A. ruralis and Pteronarcys nobilis.

\section{Pteronarcys nobilis Hagen}

Figs. 19, 28, 54, 84, 114, 160, 170, 259, 267, 268 4 270, 271, 272, 273, 274, 275.

Pteronarcys nobilis Hagen (1861) p. 15. Original description $\left(\sigma^{7}\right)$.

Our studies reveal only one species of this genus, nobilis Hagen, from lllinois. It was first recorded from our state by Walsh (1862) from Rock Island. In the "Table of Distribution by States" of Needham and Claassen (1925) two species of Pteronarcys are indicated without definite records for Illinois, and in the text dorsata (Say) is stated to be "common in small rivers of the central states." The two species thus indicated are undoubtedly dorsata and nobilis. Material in the collection of Cornell university has no actual specimens of dorsata from Illinois.

Adults of these gigantic stoneflies are essentially nocturnal and by day hide under bridges or other objects that offer fair protection from light. They have never been observed to feed and structure of the mouthparts indicates that they never do. Lights along watercourses prove attractive to the adults at night, and most of our specimens have been captured as a result. Interestingly enough, adults of all other Illinois genera (Allocap-

4 Figure numbers in bold face are drawings of the nymph, dorsal view. 
nia, Taeniopteryx, Strophopteryx, Nemoura and Leuctra) whose nymphs have mouthparts of the same general type as nobilis, figs. $28,8+, 11+, 160$, are diurnal and often feed on blue-green algae growing on trees and other objects near the streams where the nymphs develop. In Pteronarcys nobilis the mandibles are flabby and nonfunctional whereas in the above genera these structures keep their rigidity and functional ability.

Remnants of nymphal gills in the adults of the genus Pteronarcys first attracted the attention of Newport (18tt) and have often since then been considered rather extraordinary. The facts are however that all adults that I have studied of species having conspicuous tracheal gills in the nymphs show remnants of these gills, and apparently an adult which did not show them would be an exception to the rule.
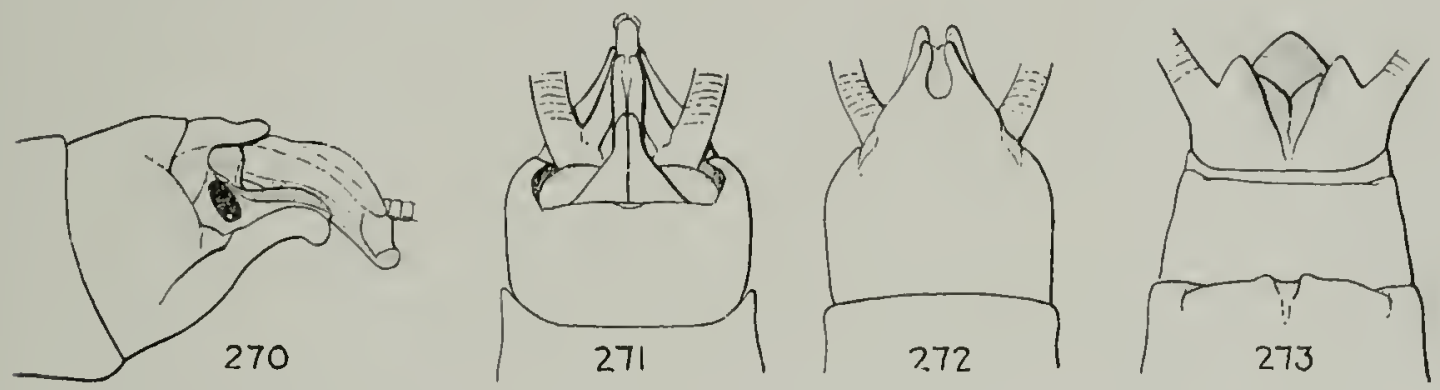

Figs. 270-273. - TERMINAL ABDOMINAL SEGMENTS AND GENITAl.1A of P'fronarcys nobilis. 270.- Iateral view of male. 271.-Dorsal view of male. 272.-Ventral view of male. 273. - Ventral view of female.

The adults begin emerging in Illinois in April and a few are still emerging during the first days of June. A female with eggs has been taken at Rock Island on June 3.

The nymph of nobilis are not found in Illinois in the small creeks and brooks, which are capable of sustaining certain Allocapnia, Nemoura and Leuctra. Instead they are found in the medium sized rivers such as the Embarrass, fig. 13, and the largest rivers such as the Rock, fig. 269, and Mississippi. The nymphs apparently prefer some riffle in the stream where they can cling to submerged decaying objects, such as branches or trunks of trees which tend to lodge in such places, or where they can be covered with a finer debris of twigs and old leaves. Our records for the various sizes of the nymphs are indicative that it requires about two years for development from egg to adult. Examinations of stomach contents show the nymphs to be herbivorous, a type of feeding indicated by their mouthparts.

The adult terminal abdominal segments and genitalia are shown in figs. 270-273. Since the nymph has not been previously recognized, a description of its most important features follows. 
Nymphal male, fig. 268.-General ground color of dorsum dark brown, with yellowish brown marking as follows: area behind epicranial arms, wing pads, median line and lateral margins of pronotum, spots on meso- and metanotum, spots on basal margins of abdominal tergites. Venter in general lighter than dorsum. Most specimens well incrusted with fine debris so that the obscure and rather indefinite color pattern is not evident.

Head with three ocelli forming a triangle, lateral ocelli about on a line with anterior margin of compound eyes and slightly farther apart than distant from median ocellus; a round impunctate spot on each side of head between lateral ocellus and base of antennae. Labrum, fig. 28 , labium, fig.
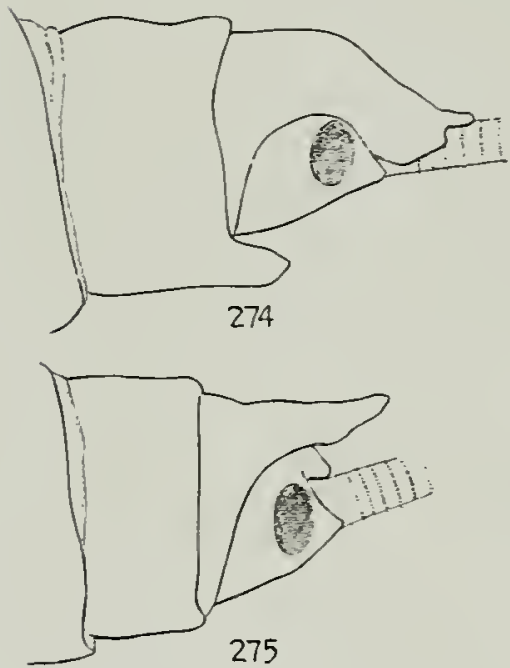

Figs. 274-275.-LATERAL VIEW OF NYMPHAL TERMINAL ABDoMinal SEgMENTS OF Pteronarcys nobilis. 274.Male. 275.-Female. Shaded area indicates cercal attachment. 114, maxilla, fig. 84, mandibles, fig. 54, and submentum, fig. 160 , as illustrated.

Pronotum much broader than long, posterior margin wider than anterior margin, anterior angles conspicuously and laterally produced, posterior angles produced but less so than anterior angles and slightly directed backwards. Mesonotum with wing pads rounded at tip and produced mainly backwards. Metanotum with wing pads rounded at tip and produced more laterally.

Legs with femur, tibia and tarsus fringed with long hairs, fig. 259 ; first and second tarsal segments about of equal length, third tarsal segment much longer than preceding two combined.

Abdominal segments transverse, except modified apical segments. Ninth sternite with posterior margin in middle area produced as a lobe, fig. 27 $\dot{t}$. partially over tenth sternite, the lobe

slightly notched. Tenth tergite much produced posteriorly and downwards, fig. $27 t$, entirely covering tenth tergite, with a small thumblike projection on dorsum near end. Cerci not as long as abdomen, composed of about 40 segments, apical segments longest and narrowest.

Gills present on venter, fig. 267, arranged in pairs anterior and posterior to legs and on first two ventral abdominal segments, pairs on prosternum anterior to forelegs arranged in a transverse row in cervical region. No anal-abdominal or coxal gills.

Mature specimens with a body length, exclusive of appendages, sometimes as much as $38 \mathrm{~mm}$.

Nymphal female.- Similar to male in general color and most morphological details. Tenth abdominal tergite triangularly produced, fig. 275, and ending in a sharp projection. Eighth abdominal sternite not produced and with a slight notch in middle of posterior margin near opening of genital duct. 

as $t+\mathrm{mm}$.

Mature specimens with a body length sometimes as much

It appears from study of literature and specimens that the nymphs of dorsata and nobilis have been confused and that some nymphs recorded as dorsata are nobilis. When Smith (1917) ivrote her treatise on the Pteronarcinae and Perlodini she stated that the nymph of nobilis was unknown. Through the kindness of Professor Claassen I have been permitted to study some of the nymphs determined by Smith (1917). I find that two female nymphs from "White Pigeon river, Michigan" and one from "Otter river, Portage county, Michigan" agree with reared nymphs of nobilis. This indicates that Smith confused the nymphs of nobilis and dorsata or that her description was based solely upon nymphs of nobilis.

The characters of the adults of nobilis and dorsata are such that it is evident that the nymphs will greatly resemble one another, and it is entirely possible that they cannot always be correctly separated. Smith (1917) does not state that she has actually reared dorsata and 1 have failed to locate nymphal material anywhere which has been definitely associated with adult dorsata. Until such material is available it will be impossible, if ever, to separate in a key the nymphs of dorsata and nobilis. The fact that in the adult females of dorsata the posterior margin of the eighth abdominal sternite is supposed to be straight and in nobilis is notched suggests that this difference may be expected to exist in the nymphal females. Certainly the female nymphs of nobilis show such a notch but due to lack of material I am in doubt about this character in dorsata. The structure of the genitalia of the male is such that no guesses can be made regarding probable differences.

Adults.-Arcola: May 7, 1927, 19. Charleston: Apr. 11, 1931, $20^{7}$ reared; Apr. 17, 1931, 1 \% reared. Momence: June 4, 1932, $1 \sigma^{7}$, 19. Oregon: Nay 21-June 15, $1 \sigma^{7}, 4$; ; June 1930, $1 \sigma^{7}$. Rock Island: May 21, 1928, $2 \sigma^{7}, 1$; ; May 28, 1928, 1 o $^{7}$; July 7, 1929, 2o; June 3, 1930, $60^{7}, 7$; ; May 3, 1931, $1 \sigma^{7}$ reared; May 16, 1931, $1 \sigma^{7}$ reared; June 8, 1931, $1 \sigma^{7}$ reared; June 13, 1931, 3o; May 19, 1934, $1 \sigma^{7}$.

Nymphs.-Charleston (Embarrass r.): Dec. 6, 1930; Mar. 22, 1931. Dixon (Rock r.): May 22, 1925. Milan (Rock r.): Sept. 19-29, 1927. Oregon (Rock r.): July 11, 1929. Rock Island (Rock r.): Apr. 2-3, 1928; May 16June 8, 1931; Apr. 27, 1932. Rockford (Rock r.): Apr. 3, 1928. Rockton (Rock r.): July 25, 1926. Sterling -Dixon (Rock r.): July 29, 1925.

\section{TAENIOPTERYGIDAE}

As has been pointed out, the genera Taeniopteryx and Strophopteryx have not previously been set apart by American workers as constituting a separate family but have been considered Nemouridae. The family 
Taeniopterygidae was first proposed by Klapalek (1909b) for European species and has since been accepted by others (Schoenemund 1928). It seems to me to require recognition in any comprehensive classification of the North American Plecoptera.

\section{KEY TO GENERA}

\section{Adults}

Coxae in both sexes with small round membranous areas, fig. $2 \mathrm{a}$, on ventral surfaces (point of articulation of tracheal appendages in nymphs). Male with cerci reduced to a single globose segment, figs. 195, 223, and subgenital plate (prolongation of ninth ventral abdominal segment) with apical portion not abruptly turned upwards at a right angle, fig. 231 . Female with ninth abdominal sternite without a long triangular projection.......... Taeniopteryx, p. 340

Coxae in both sexes without membranous areas on ventral surfaces, fig. $2 b$. Male with cerci with at least three filiform segments, fig. 199, and subgenital plate with apical portion turned abruptly upwards at a right angle, fig. 226. Female with ninth abdominal sternite with a long triangular projection, fig. $280 \ldots \ldots$. $\ldots \ldots \ldots \ldots \ldots \ldots \ldots \ldots \ldots \ldots \ldots$ Strophopteryx, p. 347

\section{Nymphs}

Coxae without tracheal appendiges, fig. 255. Ninth abdominal sternite with posterior portion conspicuously produced backwards in a $\mathrm{V}$ shaped projection, fig. 279 , covering part of tenth segment........... Strophopteryx, p. 347

Coxae with conspicuous tracheal appendages, fig. 256. Ninth abdominal sternite with posterior margin transverse; not produced backward in $\mathrm{V}$ shaped projection covering part of tenth segment.............. Taeniopteryx, p. 340

\section{Taeniopteryx Pictet}

Pictet (1841) p. 345. Genotype Nemoura nebulosa Pictet $=$ Taeniopteryx nebulosa (Pictet), original designation.

The writer has already (1929) given his reasons for considering the genus Taeniopteryx as used by Needham and Claassen (1925) to be a composite of several genera. At the same time this name was restricted among North American stoneflies to the species maura Pictet, nivalis (Fitch) and parvula Banks. Genus and species were then treated in rather exhaustive fashion, so that only modified excerpts from the previous paper have been given place here.

\section{KEY TO SPECIES}

\section{Adults}

Male with a globular appendage, fig. 231, on ninth abdominal sternite (subgenital plate). Female with portion of eighth abdominal sternite, fig. 216, anterior to genital opening darkly sclerotized.................... nivalis, p. 341

\footnotetext{
${ }^{5}$ Keys to genera and species refer only to Illinois forms.
} 


\section{TAENIOPTERYX-KEY TO SPECIES-CONT'D}

Male without a globular appendage, fig. 223 , on ninth abdominal sternite. Female with portion of eighth abdominal sternite, fig. 214 , anterior to genital opening not darkly sclerotized; at most with anterior border of genital opening dark, contrasting with membranous area.................. parvula, p. 345

\section{Nymphs}

Males and females with a conspicuous white mid-dorsal stripe extending from heald to end of abdomen, fig. 276. Apex of male abdomen, side view, with supra-anal lobe protruding considerably above apical segment; not so in female. Mature nymphal male with outline of globular appendage visible near middle of ninth sternite.............................................. p. 341

Males and females without a conspicuous white mid-dorsal stripe extending from head to end of abdomen, fig. 277. Apex of male abdomen, side view, with supratanal lobe protruding considerably above apical segment; not so in female. Mature nymphal male without outline of appendage visible near middle of ninth sternite......................................... parvula, 345

\section{Taeniopteryx nivalis (Fitch)}

Figs. 2a, 55, 85, 115, 156, 171, 195, 216, 231, 256, 276.

Nemoura nivalis Fitch (1847) p. 279. Original description $\left(\sigma^{7}, 9\right)$. $\left(0^{7}, 8\right)$.

Taeniopteryx nivalis Frison (1929) p. 378. Nymphal description

This is one of the two largest as well as one of the three most abundant and widely distributed species of our fall and winter fauna. Our records of both nymphs and adults show it to be a true member of this seasonal group. It has been recorded from the District of Columbia, Maine, Maryland, Massachusetts, New Hampshire, New York, North Carolina and Pennsylvania, as well as from lllinois (Needham and Claassen 1925, Frison 1929). There is a strong probability that maura Pictet and nivalis (Fitch) are the same species (Frison 1929) in which case the former name would have priority.

There is one generation a year. The adults begin to emerge in Illinois about the first of January and reach their maximum abundance between February 15 and March 15. During the warmer parts of the day they may be collected in numbers on bridges, tree trunks or other objects near permanent streams.

Their food under natural conditions appears to consist of blue-green algae (Protococcus), so plentiful on nearly all objects near watercourses, but judging by their cannibalism in captivity they utilize any available food. Ovipositing females fly or crawl into the water, where the matrix holding the numerous eggs-1407 were counted in one such mass-dissolves and the eggs drop separately to the bottom. Proof of the correct 


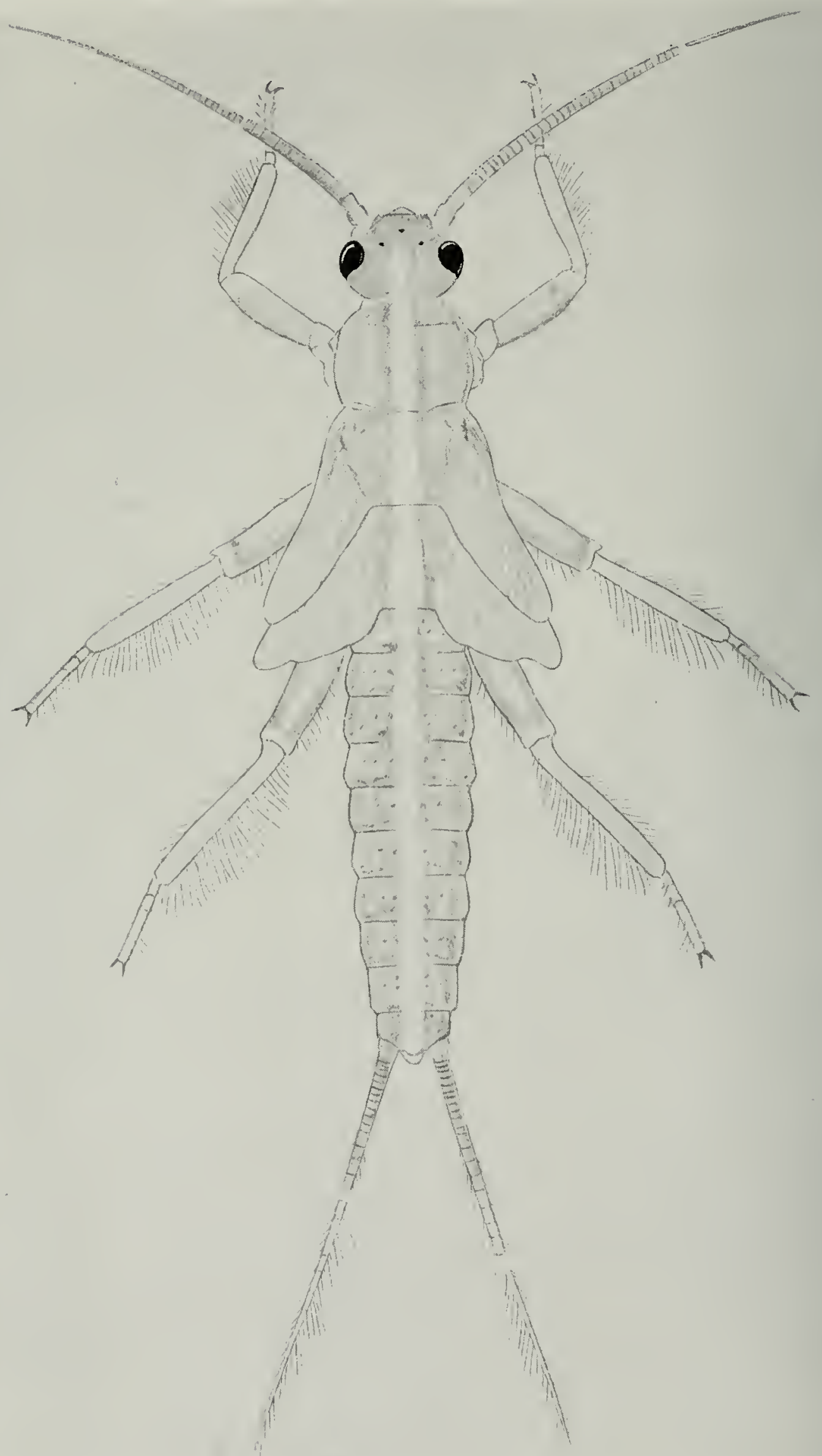

Fig. 276. -Taeniopteryx nivalis, NYMPHAL FEMALE. · 
association of males and fenales has been obtained by rearings and the collection of mating pairs. Features of the apical abdominal segments are shown in figs. 195, 216, 231, and the type of wing venation in fig. 171.

The nymphs are to be found in permanent streams ranging in size from the Salt Fork at Urbana to the Mississippi. Being essentially herbivorous, they live in submerged vegetable debris, particularly old leaves. During the summer months no trace of them can be found by ordinary field collecting. However, I have previously shown facts that indicate that the eggs hatch soon after being laid, but that rapid development is postponed until the temperature of the water drops noticeably, and reaches a peak sometime between November and January. 'The earliest that I have found the small nymphs is October 10, at Oakwood.

Detailed descriptions of male and female nymphs, based upon reared material, were published by the writer (1929). Mouthparts are shown here in figs. $55,85,115$.

Aduits.-Algonquin: 19. Allerton: Mar. 9, 1930, 9甲. Barstow: Apr. 2, 1928, 19. Big Rock: Apr. 1, 1928, 19. Brocton: Mar. 9, 1930, 89. Carmi: Mar. 9, 1928, $3 \sigma^{7}$, 4ㅇ. Castle Rock: Apr. 3, 1928, 19. Charleston: Mar. 9, 1930, $9 \sigma^{7}$, ㅇ; Mar. 22, 1931, 11․ Chicago: Mar. 25, 1910, $1 \sigma^{7}$. Chrisman: Mar. 9, 1928, 19. Como: Mar. 11, 1928, $20^{7}$. Danville: Jan. 11, 1928, 19; Mar. 11, 1928, $3 \sigma^{7}$, 29. Decatur: Mar. 15, 1930, $1 \sigma^{7}, 29$; Mar. 27, 1931, 29. Dixon: Apr. 3, 1928, $2 \sigma^{7}, 29$. East Peoria: Apr. 10, 1912, 3\%. Elizabethtown: Mar. 7, 1928, $0^{7} \sigma^{7}$, 우. Elmwood: Apr. 1, 1928, $10^{7}, 2 \%$. Evansville: Feb. 3, 1934, $\sigma^{7} \sigma^{7}$, ㅇํ. Georgetown: Mar. 9, 1928, $13 \sigma^{7}$, 19ㅇ. Golconda: Mar. 7, 1928, 2o. Grayville: Mar. 8-9, 1928, $11 \sigma^{7}, 10$.. Hamlet: Apr. 2, 1928, $1 \sigma^{7}$, 49. Havana: Apr. 21, 1898, 19. Homer: Mar. 21, 1905, 189;

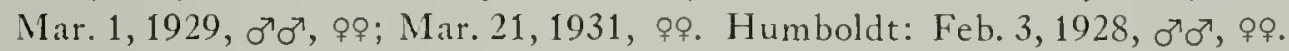
Kampsville: Jan. 29, 1932, 1 \% . Kankakee: Mar. 25, 1928, $2 \sigma^{7}, 12 \sigma^{7}$. Lawrenceville: Mar. 9, 1928, $0^{7} \sigma^{7}$, 9 . Lexington: Mar. 25, 1928, 69. Louisville: Feb. 2, 1928, $1 \sigma^{7}, 1$. Mackinaw: Apr. 1, 1928, $1 \sigma^{7}$. Maquon: Apr. 1, 1928, 7 o $^{7}$, 33ㅇ. Mahomet: Jan. 15, 1928, 4o , 4\%; Apr. 4, 1929, 1 ơ 2 \%. Marengo: Apr. 4, 1928, 1ㅇ. Mascoutah: Mar. 3, 1928, $10^{7}$. Monmouth: Apr. 2, 1928, $1 \sigma^{7}$, 39. Mounds: Feb. 2, 1934, 1 o . Muncie: Mar. 16, 1907, 5o; Mar. 7, 1909, 19; Jan. 2-11, 1928, $0^{7} 0^{7}$, 9 ; ; Feb. 27, 1928, $30^{7}, 159$; Mar. 31, 1928, $1 \sigma^{7}$. New Athens: Mar. 3, 1928, $1 \sigma^{7}$. New Memphis: Mar. 3, 1928, $160^{7}$, 6\%. Norwood: Apr. 2, 1928, $1 \sigma^{7}$. Oakwood: Feb. 24-Mar.

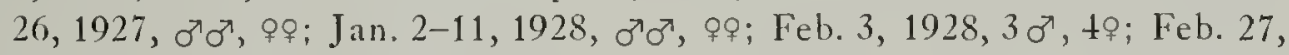
1928, б $\sigma^{\top} \sigma^{7}$, 우; Mar. 31, 1928, 19. Ocoya: Mar. 24, 1928, 1․ Oregon: Apr. 3, 1928, 19. Palos Park: Mar. 15, 1933, $0^{7} 0^{7}$, ㅇํ. Paris-Chrisman: Mar. 9, 1928, $3 \sigma^{7}$, 69. Pekin: Apr. 12, 1912, $1 \sigma^{7}$. Pontiac: Mar. 25, 1928, $3 \sigma^{7}, 139$. Rockford: Apr. 3, 1925, $2 \sigma^{7}$. Seymour: Mar. 20-24, 1928, $10^{7}, 79$. Sparland: Feb. 2, 1932, $1 \sigma^{7}$. Sterling: Apr. 3, 1928, $2 \sigma^{7}, 99$. St. Joseph: Apr. 2, 1905, 19; Feb. 11, 1928, $0^{7} \sigma^{7}$, fq. Towanda: Mar. 24, 1928, 89. Union Hill: Mar. 25, 1928, 49. Urbana: Mar. 11, 1887, 19; Apr. 16, 1899, $1 \sigma^{7}, 1$; ; Mar. 11, 1911, 1q; Mar. 18, 1927, 19; Jan. 14-16, 1928, $\sigma^{7} \sigma^{7}$, 우 ; Feb. 2, 1928, $5 \sigma^{7}$, 4 \% . Walnut Prairie: Mar. 8, 1928, 2q. White Heath-Mahomet: Mar. 25, 1928, $10^{7}, 4$. 


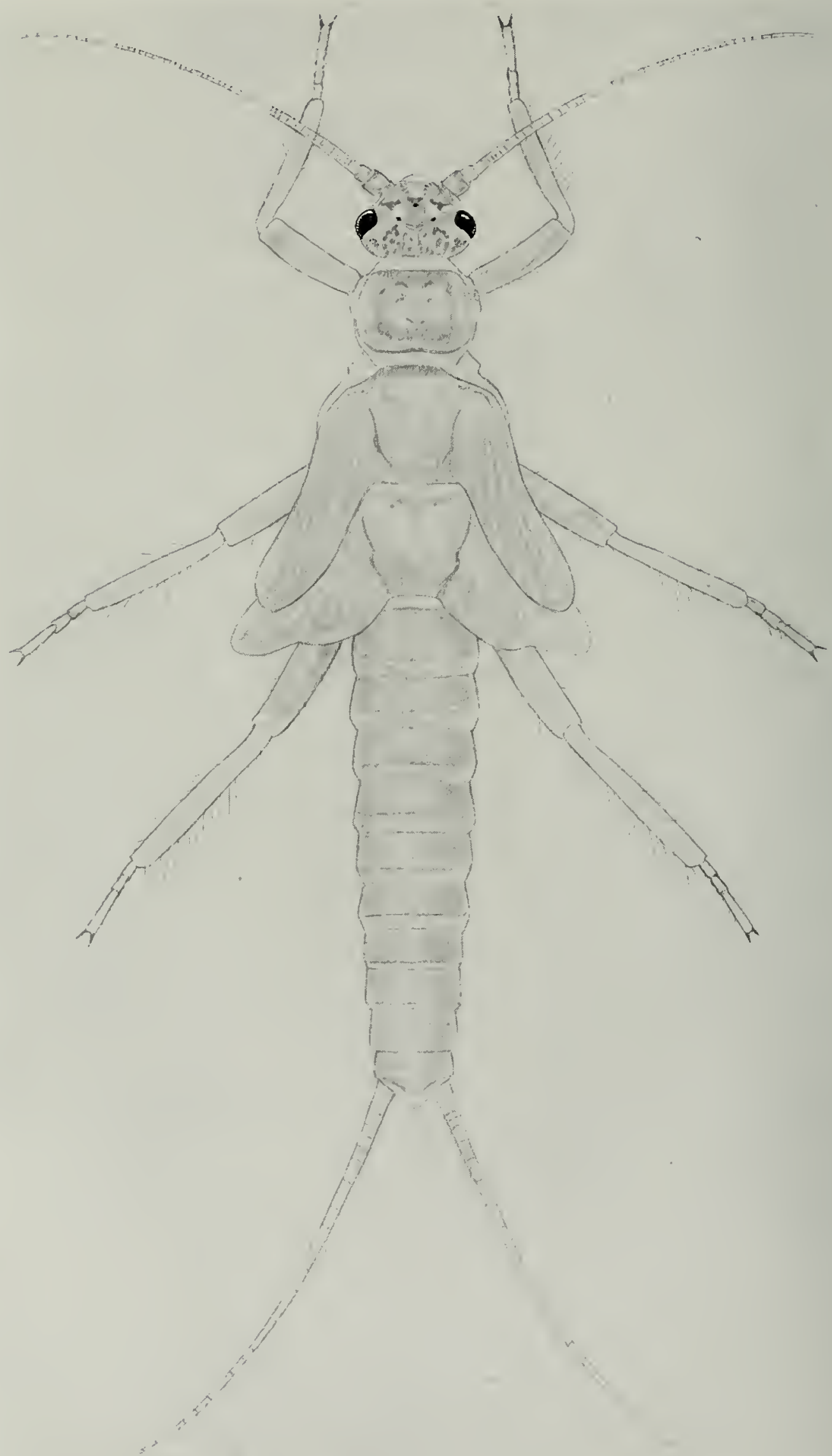

Fig. 277.-Taeniopteryx paroula, NrMPHAL Female. 
Nymphs.-Charleston (Embarrass r.): Dec. 14, 1930. Danville (Salt Fork r.): Jan. 2-11, 1928. Duncan Mills (Spoon r.): Mar. 23, 1932. Elizabethtown (Ohio r.): Mar. 7, 1928. Georgetown (Little Vermilion r.): Mar. 9, 1928. Gray ville (Wabash r.): Mar. 8, 1928. Homer (Salt Fork r.): Mar. 21, 1914; Nov. 5-23, 1927; Mar. 1, 1929. Hutsonville (Wabash r.): Nov. 28, 1928. Mounds (Ohio r.): Feb. 2, 1934. Muncie (Stony cr.): Oct. 25-Nov. 23, 1927; Feb. 3, 1928. New Memphis (Kaskaskia r.): Mar. 3, 1928, exuviae. Oakwood (Salt Fork r.): Feb. 24-Mar. 10, 1927; Oct. 11-Nov. 23, 1927; Jan. 7-Feb. 27, 1928; Nov. 2, 1929; Dec. 27, 1930. Paris-Chrisman (Brouilletts cr.): Mar. 9, 1928, exuviae. Pekin (Illinois r.): Apr. 12, 1912. Peoria (Illinois r.): Apr. 11, 1912. Rock Island (Rock r.): Apr. 2, 1928; Apr. 10, 1931. White Heath (Sangamon r.): Feb. 21, 1928.

Reared from nymphs.-Elizabethtown (Ohio r.): Mar. 7, 1928. Rock Island (Rock r.): May 3, 1931.

Mating pairs.-Oakwood: Feb. 3, 1928; Mar. 21, 1929. Georgetown: Mar. 9, 1928.

\section{Taeniopteryx parvula Banks}

Figs. 190, 214, 223, 277.

Taeniopleryx parvula Banks (1918) p. 7. Original description $\left(\sigma^{7}, 9\right)$.

Taeniopteryx parvula firison (1929) p. 383. Nymphal description $\left(0^{7}\right.$, o) .

Field work since 1929 has corroborated the statement made then, that parrula was "the rarest of the three large species of winter stoneflies occurring in Illinois." Thus far the nymphs have been found in only two of the largest rivers, the Ohio and the Rock, and the adults at locali. ties adjacent to these rivers and the Wabash. The species has also been recorded from the District of Columbia, Maine, Maryland, Massachusetts, Minnesota, New Jersey and Wisconsin.

Our records of parrula indicate that it occupies a later position in the seasonal succession of adults than nivalis, appearing about the first of March and continuing until about the last of April. A mating pair was taken April 3 at Dixon, clinging to the side of a tree where the female was feeding on blue-green algae. Features of the apical abdominal segments are shown in figs. 190, 223.

No detailed description of the nymph of this species was published in 1929, due to lack of material. Main characters of the immature form, however, were indicated, based upon cast skins and the association of one cast skin with its reared adult. Additional nymphal material now substantiates this earlier characterization. Also, the nymph has since been described by Claassen (1931). The mouthparts are practically identical with those of $T$. nivalis.

Adults.-Dixon: Apr. 3, 1928, $2 \sigma^{7}$, 69. Elizabethtown: Mar. 7, 1928, 


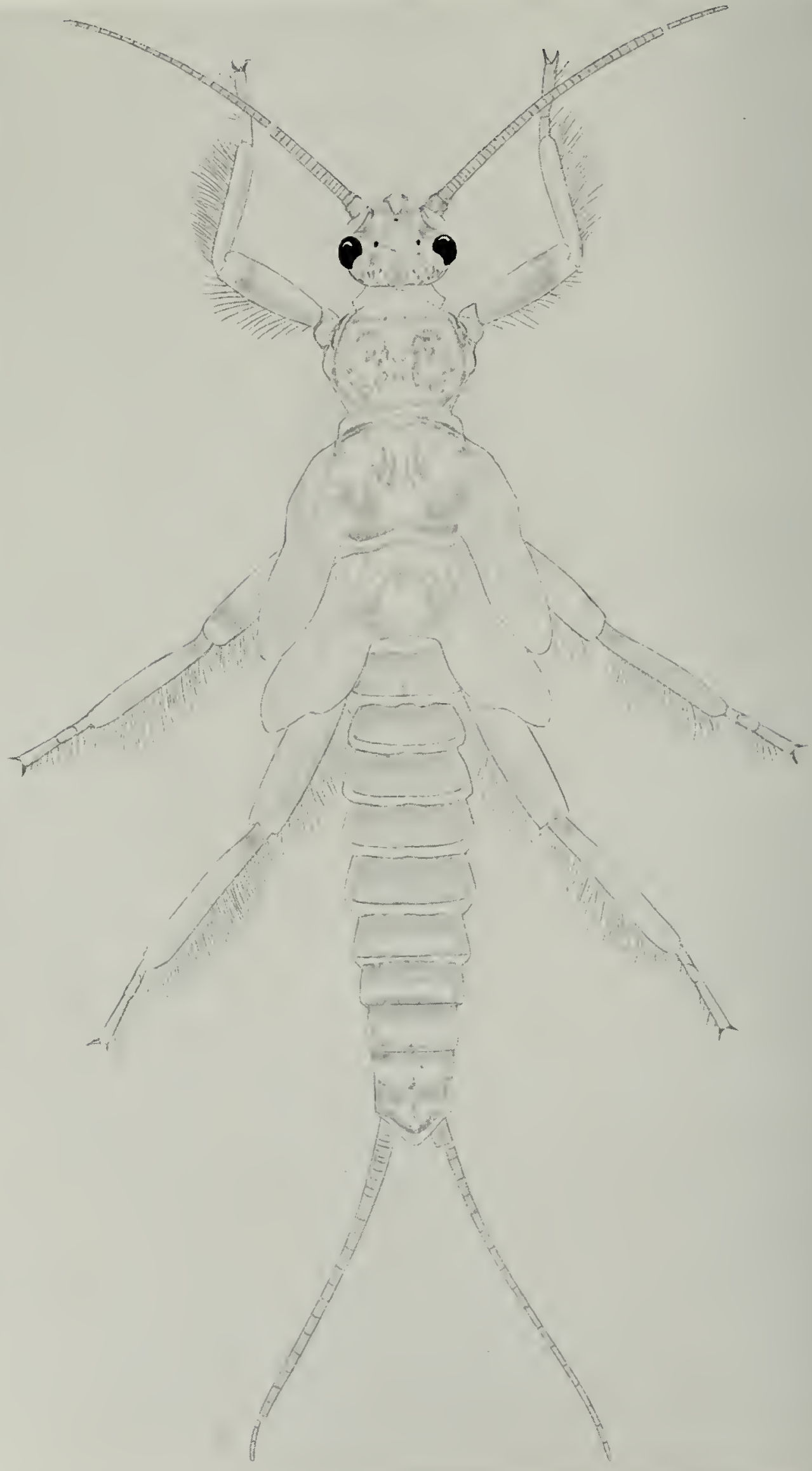

Fig. 278.-Strophopteryx fasciata, NYMPHAL FEMALE. 
$6 \sigma^{7}, 8$. Golconda: Mar. 17, 1932, $1 \sigma^{7}$. Grayville: Mar. 8, 1928, $7 \sigma^{7}, 14$. Oregon: Apr. 3, 1928, $1 \sigma^{7}$, 9 우. Rockford: Apr. 3, 1925, ơ ơ; Apr. 23, 1926, $2 \sigma^{7}$. Sterling: Apr. 3, 1928, 2 \%

Nymphs.-Elizabethtown (Ohio r.): Mar. 7, 1928, exuviae. Oregon (Rock r.): Apr. 3, 1928, exuviae. Rock Island (Rock r.): Apr. 10, 1931. Sterling (Rock r.): Apr. 27, 1932.

Mating pairs.-Dixon: Apr. 3, 1928, 1 pair.

\section{Strophopteryx Frison}

Frison (1929) p. 374. Genotype Semblis fasciata Burmeister = Strophopteryx fasciata (Burmeister), original designation; monotypic.

This genus was originally proposed by the author (1929) in the belief that Taenioptery $x$ as then used by American students was a heterogeneous assemblage of species which formed at least three distinct and easily separable groups equivalent to genera. This conclusion, based upon study of adults and nymphs, is supported by a more comprehensive study of the North American stonefly fauna made since it was drawn. 'To date the genus has but one North American species, as below.

\section{Strophopteryx fasciata (Burmeister)}

Figs. 2b, 56, 86, 116, 148, 172, 199, 226, 255, 278, 279, 280.

Semblis fasciata Burmeister (1839) p. 875 . Original description. $\left(0^{7}\right.$, o).

Strophopteryx fasciata Frison (1929) p. 385. Nymphal description

'This species and T. nivalis (Fitch) are our two largest winter stoneflies, but fasciata is less abundant and has a more localized distribution. It has also been recorded from the District of Columbia, Kansas, Maryland, Massachusetts, Minnesota, Missouri, New York, North Carolina, Pennsylvania, Tennessee, Virginia and West Virginia.

In my paper of 1929 considerable was published on habits of the adults and nymphs, as well as were detailed descriptions of the previously unknown nymphs. Little information can be added now.

The adults reach their maximum abundance in this state during the last half of March and first of April, according to latitude. There is only one generation a year. Consistently this species appears later than $T$. nizalis, but the two are often found together because they frequent the same places and their times of adult emergence overlap. I have observed them in thousands feeding upon elm blossoms near the Rock river, but do not doubt that other vegetation contributes to their diet. 'The females, except for the position of the body while the egg mass is being formed, have egg laying hahits similar to those of Taeniopteryx and Allocapnin (Frison 1929). The sexes have been associated definitely by the collection 
of mating pairs, and adults with nymphs by the rearing of both sexes. Characteristics of the apical abdominal segments are shown in figs. 199, 226, 280, and the type of wing venation by fig. 172 .

The nymphs are essentially herbivorous. Although found in the same rivers and often in close association with $T$. nivalis they prefer the more stony portions of the stream bed near riffles. The small nymphs are not found by ordinary methods of collecting until late fall, and growth proceeds most rapidly during December, January and February. Nymphal mouthparts are shown in figs. $56,86,116$, and the apical abdominal segments of the female in fig. 279.
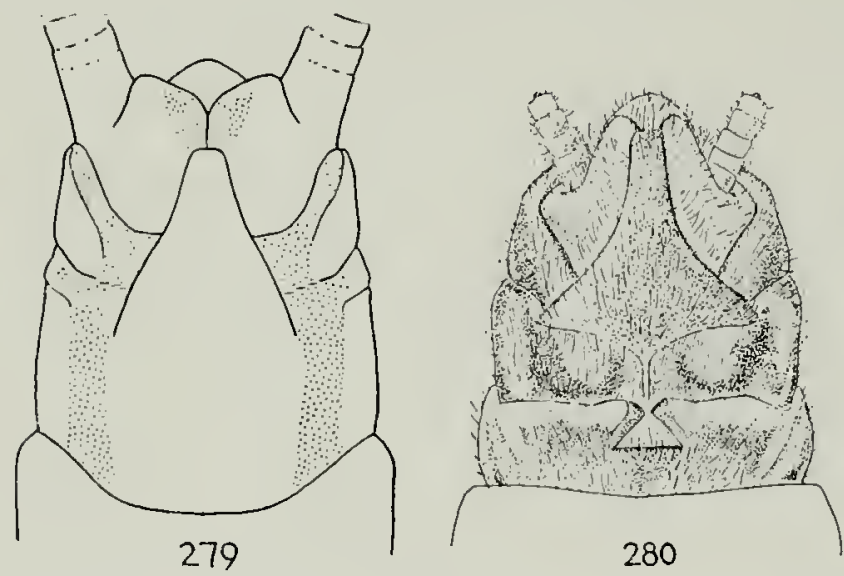

Figs. 279-280.-Ventral View of female terminal. abdominal segments of Strophopteryx fasciata. 279.-Nymph. 280.-Adult. Shape of subgenital plate of adult female is indicated in the nymph.

The Walsh (1862) record of Taeniopteryx fasciata from Rock Island, Ill. certainly refers to this species. Walsh's identification of fasciata was checked by Hagen, whose placement of fasciata has been accepted by Needham and Claassen (1925). The latter authors however overlooked in their monograph the placing in synonymy of the Walsh record. Fasciata is one of the two commonest species of Taeniopteryx (in the broad sense as used at the time of the paper by Walsh) in Illinois, is very common at Rock Island, and markings of wings have always assisted in its correct identification. The record of Walsh was also overlooked in my paper in 1929.

Adults.-Algonquin: Apr. 1, 1907, 19. Barstow: Apr. 2, 1928, $10^{7}$. Carmi: Mar. 8, 1928, $20^{7}, 1$ ㅇ. Charleston: Mar. 9, 1930, $10^{7}$; Mar. 22, 1931,

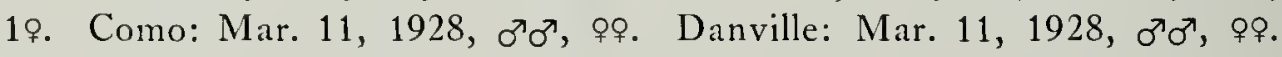
Dixon: Apr. 3, 1928, $\sigma^{7} \sigma^{7}$, कㅇ. Elizabethtown: Mar. 7, 1928, 19. ErieDenrock: Apr. 3, 1928, $2 \sigma^{7}$, 2\%. Grand Detour: Apr. 3, 1928, $0^{7} \sigma^{7}$, Grayville: Mar. 8, 1928, $100^{7}$, 79. Havana: Apr. 21, 1898, 19; Apr. 30, 1912, 2ㅇ. Herod: Mar. 6, 1928, 19. Homer: Mar. 19, 1907, $1 \sigma^{7}$. Kankakee: Mar. 25, 1928, $10^{7}$, 19. Keithsburg: Apr. 4, 1932, o․ Lexington: Mar. 25, 1928, $6 \sigma^{7}$, 59. Mackinaw: Apr. 1, 1928, $2 \sigma^{7}, 109$. Mahomet: Apr. 4, 1929, $10^{7}, 3$ \% . Maquon: Apr. 2, 1928, $0^{7} \sigma^{7}$, 1928, $1 \sigma^{7}$. Muncie: Apr. 4, 1909, 19; Mar. 31, 1928, 4o , 89. Oakwood: Feb. 24-26, 1927, $15 \sigma^{7}, 13$; Mar. 4, 1927, $5 \sigma^{7}, 5$; ; Mar. 17, 26, 1927, o $\sigma^{7}$,

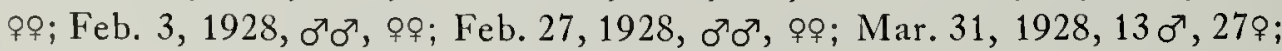
Mar. 21, 1929, $\sigma^{7} \sigma^{7}$, q9. Ocoya: Mar. 25, 1928, $1 \sigma^{7}$. Oregon: Apr. 3, 1928, $3 \sigma^{7}$, 4ㅇ․ Paris-Chrisman: Mar. 9, 1928, $1 \sigma^{7}$. Pontiac: Mar. 25, 1928, 
$3 \sigma^{7}, 3$ 9. Rockford: Apr. 21, 1926, $2 \sigma^{7}, 4$ ㅇ. Rock Island: Apr. 3, 1928, $\sigma^{7} \sigma^{7}$, $¥$; Apr. 10, 1931, $2 \sigma^{7}, 4$; Apr. 3, 1932, $0^{7} \sigma^{7}$. Seymour: Mar. 24, 1928, 1; Mar. 22, 1930, 19. Sterling: Apr. 3, 1928, $0^{7} 0^{7}$, 우. Towandil: Mar. 24, 1928, 607 49. Union Hill: Mar. 25, 1928, $2 \sigma^{7}$. Urbana: Mar. 18-23, 1928, 3ㅇ. White Heath: Feb. 21, 1928, $10^{7}$.

Nymphs.-Charleston (Embarrass r.): Mar. 22, 1931. Dixon (Rock r.): Apr. 3, 1928. Golconda (Big Grand Pierre r.): Mar. 7, 1928. Grayville (Wabash r.): Mar. 8, 1928. Homer (Salt Fork r.): Nov. 23, 1927. Lexington (Mackinaw r.): Mar. 25, 1928, exuviae. Mackinaw (Deep cr.): Apr. 1, 1928, exuviae. Mt. Carmel (Wabash r.): Apr. 2, 1932. Oakwood (Salt Fork r.): Feb. 24-26, Mar. 10, Nov. 23, 1927; Jan. 11, Feb. 27, Mar. 4, 1928. Oregon (Rock r.): Apr. 3, 1928. Pontiac (Vermilion r.): Mar. 25, 1928, exuvia. Rockford (Rock r.): Apr. 3, 1928. Rock Island (Rock r.): Apr. 2, 1928; Apr. 10, 1931; Mar. 2, Apr. 3, 1932. Sterling (Rock r.): Apr. 3, 1928. Towanda (Money cr.): Mar. 24, 1928, exuviae. White Heath (Sangamon r.): Feb. 21, 1928.

Reared from nymphs.-Oakwood (Salt Fork r.): Mar. 10, 1927.

\section{NEMOURIDAE}

Only one species of this family as now defined is known to occur in Illinois-Nemoura renosa Banks. Nemoura (s. lat.) contains a large number of North American species which are distributed chiefly in the western, northern and northeastern parts of this continent. That central Mississippi valley states have a paucity of species is indicated by occurrence of only one species in Illinois and lack of records from most states in this general region.

European students of the stoneflies have separated the genus Nemoura into subgenera hased upon the modifications presented by the apical abdominal segments and appendages, which system has been supplanted by one based on arrangement and type of the nymphal tracheal gills. The Illinois species renosa Banks fits the characterization giren for the subgenus Amphinemura Ris (1902).

\section{Nemoura Latreille}

Latreille (1796) p. 101. Genotype Nemoura (Nemura) variegata Olivier, subsequent designation of Enderlein (1909).

\section{Nemoura [AmphinemurA] venosa Banks}

Figs. 29, 58, 89, 119, 152, 173, 189, 264, 281, 282.

Nemoura venosa Banks (1897) p. 21. Original description (or, $)^{7}$.

Nemoura venosa Claassen (1931) p. 95. Nymphal description.

Except for the various descriptions and records of Banks (1897-1920), 
350

ILLINOIS NATURAL HISTORY SURVEY BULLETIN XXIV

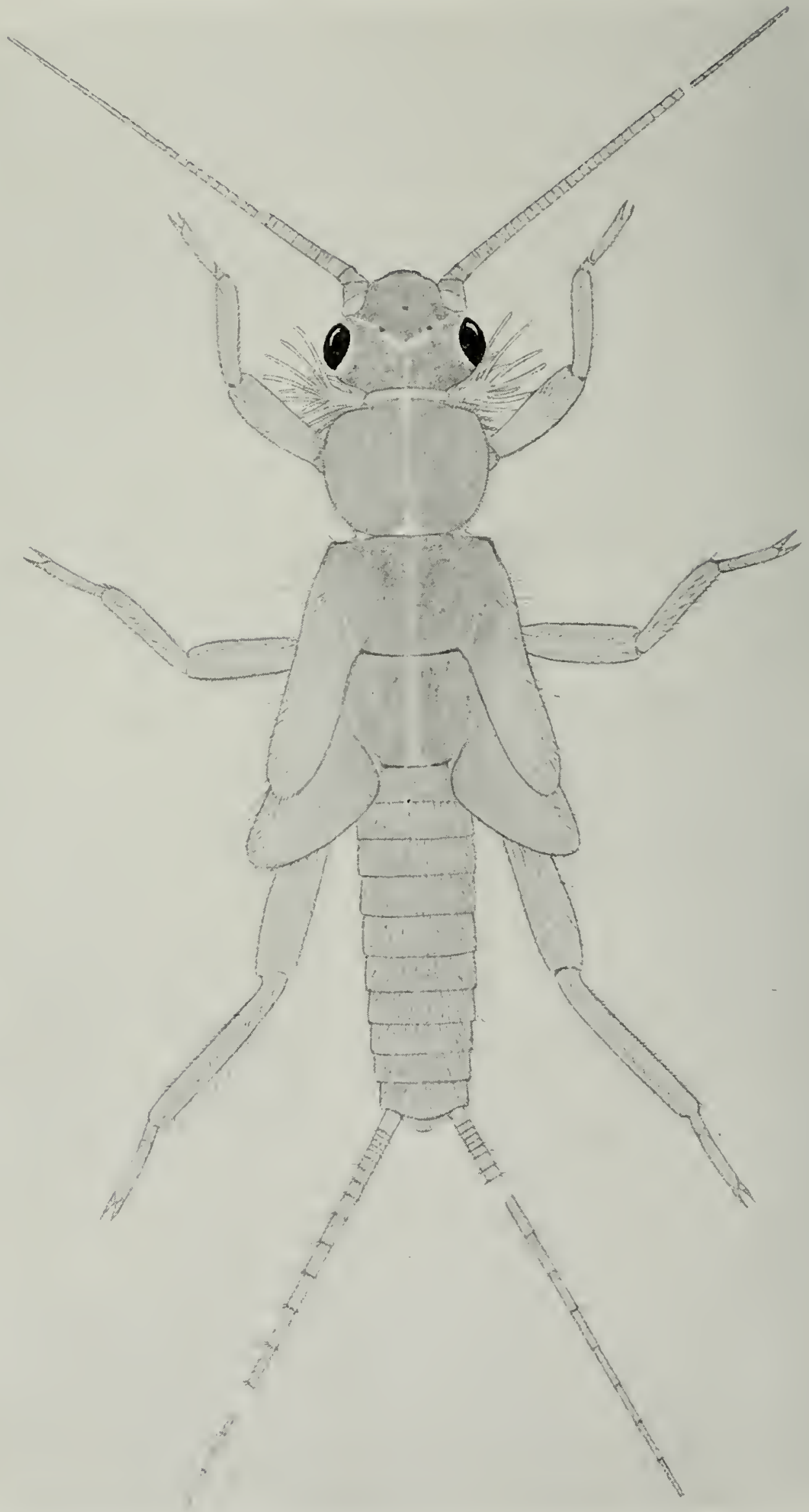

Fig 281.-Nemouta venosa, NYmphal female. 
the records of Walsh $(1862,1863)$ under other names, and the nymphal description by Claassen (1931), nothing has been published concerning this species. Our lllinois records indicate that it is likely to be found in any part of the state but is particularly abundant in the small streans of southern Illinois. The adults begin to appear in April and are found as late as June. I believe that the adults feed on tender vegetation and algae growing near the streams they frequent. Association of the sexes and nymphs with adults is based upon mating pairs and reared specimens. The structural details of the terminal abdominal segments are shown in figs. 189,282 , and the type of wing venation in fig. 173 .

The nymphs, fig. 281, apparently make their greatest and most rapid growth in spring and all our evidence indicates but one generation a year. They are herbivorous and are most frequently encountered in small streams with sandy bottoms where they crawl between submerged leaves and under other decaying vegetation. Their hairy bodies often are the cause of their becoming more or less covered with debris and being mistaken for other aquatic nymphs.

Chief morphological features of the nymph have been described by Claassen (1931). They differ from those of all other Illinois species by the inclusion of

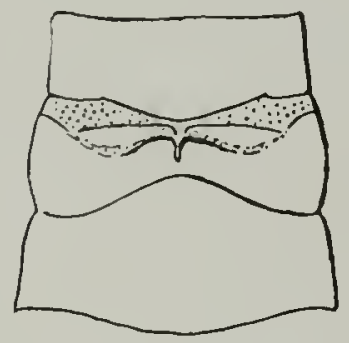

Fig. 282.-VENTRAL VIEW OF TERMINAL ABDOM1NAL SEGMENTS OF Nemoura venosa, ADULT FEMALE. four bunches of gill filaments, with five to nine filaments in a bunch, transversely arranged on the ventral cervical region between head and thorax, fig. 26t, and absence of these filaments elsewhere. Nymphal mouthparts of this species are shown in figs. 29, 58, 89, 119, 152.

In 1862 Walsh published a record of "Nemoura completa Walker" which according to the introduction of his article came from the vicinity of Rock Island, Ill. The presence of Nemoura venosa Banks in this state and its more or less general distribution leads me to conclude that the completa of Walsh should be placed in the synonymy of renosa. Just what the true $N$. completa Walker is could not be determined by Needham and Claassen at the time of their monograph and it may be one of many species of Nemoura.

A year later, in 1863, Walsh again referred to $N$. completa and in addition mentioned five specimens of "Nemoura albidipennis Walker" from Illinois. There is a damaged specimen of Nemoura renosa Banks in the SURveY collection which was determined by Walsh as "Nemoura albidipennis Walker." The remarks by Walsh concerning the difference between the specimens he determined as completa and albidipennis are of 
such a nature as to lead me to believe that his supposedly two species of Nemoura were slightly different colored specimens of the same species. Further evidence that Walsh confused venosa under different names is found in the fact that in the SURveY collection is a male of Nemoura renosa from "Ky." which was originally determined by Walsh as "Nemourn perfecta Walker." I believe that this record has never been published.

Needham and Claassen (1925) have recorded this species from Lake Forest, Ill. and also from Georgia, Massachusetts, New York, North Carolina, Ontario and Pennsylvania.

Adults.-Fountain Bluff: May 14, 1932, $\sigma^{\top} \sigma^{\top}$, 우. Herod: Apr. 20, 1930, $1 \sigma^{7}, 1$ ㅇ. Muncie: May 20, 1909, $1 \sigma^{7}$. New Columbia: Apr. 3, 1932,

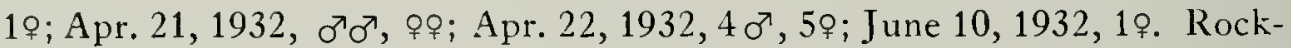
ford: Apr. 23, 1926, 1․ Watson: Apr. 23, 1932, o7 $0^{7}$, ㅇํ. "N. Ill.": $1 \sigma^{7}$.

Nymphs.-Dixon Springs (trib. of Sugar cr.): Apr. 2, 1932. Harrisburg (Blackman cr.): Apr. 2, 1932. Herod (Gibbons cr. and Blackman cr.): Apr. 20, 1932. Marshall (trib. of Big cr.): May 11, 1933. New Columbia (Clifty cr.): Mar. 26, Apr. 3, 21, 22, 1932. Watson (trib. of Little Salt cr.): Apr. 4, 7, 1932.

Reared from nymphs.-Watson (trib. of Little Salt cr.): Apr. 27, May 1, 1932.

Mating pair.-Fountain Bluff: May 15, 1932.

\section{LEUCTRIDAE}

Here is another family represented in Illinois by a single species. The genus Leuctra contains 16 species distinguished primarily by differences in structure of the apical abdominal segments. Distributional records indicate a paucity of species of Leuctra in the central states and a maximum abundance in the mountainous or hilly regions of the United States and Canada.

I consider as belonging to this family the genera Perlomyia Banks, Megaleuctra Neave and Eucapnopsis Okamoto. These three genera are western rarities in collections and with their nymphal stages unknown. Megaleuctra was placed by Neave (1934) in the family Nemouridae; a family used by him in its broadest sense and containing the genus Leuctra. I do not share the view that Megaleuctra presents an obstacle to the recognition of Leuctridae, Nemouridae and Taeniopterygidae as separate families. All these groups possess characters in common, evidence of common line of descent, but are nevertheless distinguishable as separate natural units, which I consider to have been correctly evaluated as of family rank by most recent European students of stoneflies.

Neave has placed Eucapnopsis Okamoto (1922) in the family Capnii- 
Fig. 283.- Leuctra claasseni, NMPHAL FEMALE. 
dae, calling attention at the same time to its nemourid (s. lat.) affinities. In the key to families for this paper Eucapnopsis runs to the Leuctridae. The short cerci of the adult are the strongest warranty for this placement.

\section{Leuctra Stephens}

Stephens (1835) p. 144. Genotype Leuctra geniculata Stephens, subsequent designation of Enderlein (1909).

\section{Leuctra claasseni Frison}

Figs. 59, 88, 118, 153, 178, 194, 230, 258, 283, 284, 285.

Leuctra claasseni Frison (1929) p. 404. Original description (adult $\sigma^{7}$; nymphal $\sigma^{7}$, o).

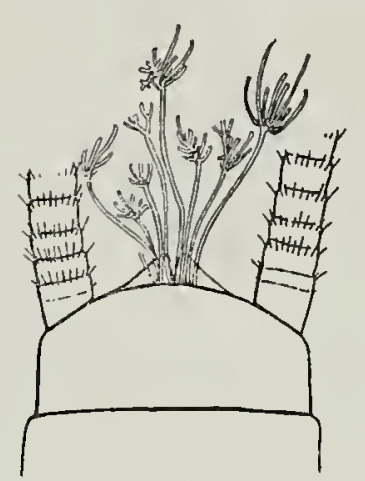

Fig. 284.-DORSAL VIEW OF TERMINAL ABDOMINAL SEGMENTS OF LeUCtra claasseni, NYMPHAL FEMALE, $S H O W I N G$ ANAL GILIS.

species of these genera, the nymphs of Leuctra claasseni prefer to hide singly under stones in swifter water. They are undoubtedly herbivorous.

The adult male and the nymphs have been described in detail (Frison 1929), but at that time the anal gills of the nymph were overlooked due to the fact that they are easily broken off and often are deeply retracted. These gills, fig. 284, consist of five to nine delicate filaments branched at the tips. The characteristic appearance of the nymph, with wing pads paralleling the long axis of the body, is shown in fig. 283, and characters of the mouthparts in figs. 59, 88, 118. The forewing, fig. 178, differs from the related Nemoura by lack of a crossvein in the apical marginal space distad the tip of the subcostal vein. 
Female.-The adult female is much like the male in general appearance and in most structural details. The most distinctive features of the female, those presented by the eighth and ninth abdominal sternites, are shown in fig. 285. No other described species of Leuctra has a similar aspect. The abdomen is mostly. membranous, except that its extreme tip, a series of narrow elongate spots along the sides and the median area of the sternites are heavily sclerotized. The subgenital plate scarcely protrudes over the ninth sternite, fig. 285, and in the middle of the membrane along the posterior margin of the plate there is a knoblike projection, flanked on each side by two heavily sclerotized spots.

Allotype, female.-Herod, Ill. (Hicks Branch): Apr. 22, 1932, collected by H. H. Ross and C. O. Mohr. Deposited in the collection of the Illinois State Natural History Survey.

Adults.-Fountain Bluff: Feb. 22, 1933, 19. Harrisburg: Apr. 2,

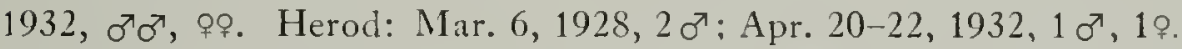

Nymphs.-Harrisburg (Blackman cr.): Mar. 6, 1928; Apr. 2, 1932. Herod (Gibbons cr.): Mar. 6, 1928.

Since the species has not been recorded from other states the following records are given also. Adults.-Cedar, Comanche county, Okla.: Feb. 28, 1932, $110^{7}, 12 \%$. Comanche county, Okla.: Feb. 27-28, 1932, $64 \sigma^{7}, 48$. Honey creek, Murray county, Okla.: Mar. 20, 1932, $10^{x}, 7$, Wichita National Forest, Okla.: Mar. 3, 1929, $60^{7}, 14$. . Nymphs.- -St. Clair-Rolla (Little Bourboise cr.), Mo.: Jan. 30, 1932, 1 nymph. Cedar, Comanche county, Okla.: Feb. 28, 1932. Wichita National Forest, Okla.: Mar. 3, 1929. The specimen from Missouri was collected by Dr. H. H. Ross and Dr. C. O. Mohr of the Survey, and those from Oklahoma by Dr. R. D. Bird and his associates, then of the University of Oklahoma.

\section{CAPNIIDAE}

In North America this family includes three genera, Capnia, Capnura and Allocapnia. Capnura is known only from Washington and contains but a single species. Capnia, a rarity in Illinois, is rich in species but is primarily a genus of the western states and Canada. Allocapnia, containing eight species, takes the place of Capnia in the eastern and central states and is of special interest to the student of Illinois stoneflies because of the abundance of some of the species, peculiarities in their distribution, and the correlation of growth of nymphs and emergence of adults with the coldest months of the year.

\section{KEY TO GENERA}

\section{Adults}

Mesosternum with posterior margin of large, heavily or darkly sclerotized medial area (mesobasisternite) strongly produced backwards, fig. 287. Second trans- 


\section{CAPNIIDAE-KEY TO GENERA-CON'T'D}

verse vein (subcosta) of forewing uniting with margin of forewing (costa) much before the cord (more or less transverse line-up of crossveins and some longitudinal veins beyond middle of wing). Anal field or lobe of hind wing large and nearly as long as front portion.................. Allocapnia, p. 357 Mesosternum with posterior margin of large, heavily or darkly sclerotized medial area (mesobasisternite) nearly transverse, fig. 286. Second transverse vein of forewing extending to or nearly to the cord. Anal field of hind wing reduced and not extending much farther than half the length of front portion....

Capnia, p. 356

\section{Nymphs}

Wing pads present in most species, absent or rudimentary in at least one species. Anal field of hind wing pad, when present, extending far beyond middle of

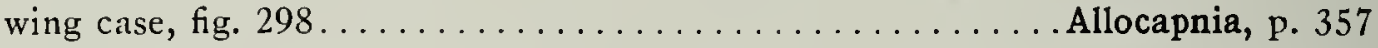

Wing pads always present. Anal field of hind wing pad not extending much beyond the middle of the wing case........................ 356

\section{Capnia Pictet}

Pictet (1841) p. 320. Genotype Capnia nigra Pictet, subsequent designation of Enderlein (1909).

\section{Capnia (vernalis Newport?)}

Figs. 174, 176, 286, 288.

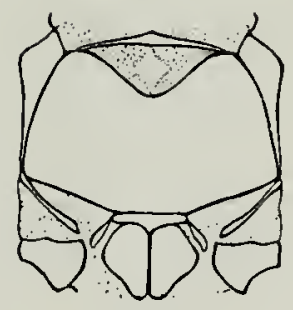

286

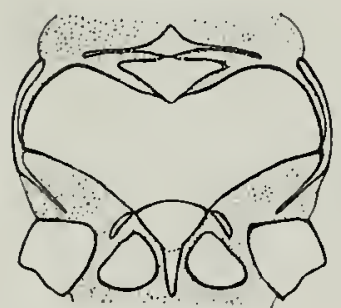

287

Figs. 286-287.MESOSTERNUM. 286. - Capnia sp. 287. - Allocapnia mystica.

No additional specimens of this stonefly have been captured in Illinois since the one recorded by myself in 1929 and I can add nothing further to the statements made at that time, which were as follows:

"A unique female belonging to this genus was collected at Grayville, Ill., March 8, 1928, by T. H. Frison and H. H. Ross. Since no keys exist for the determination of the females of this genus, and males were not found to associate with the female, the Illinois representative of this genus must go unnamed for the present. Only one species, Capnia vernalis Newport, of the 19 known North American members of the genus has been found east of the Rocky mountains. This is suggestive that the Illinois specimen is this species, but it may be an undescribed one or a western form ranging eastward.

"Structurally, the female agrees well with the description of the female of Capnia vernalis Newport

" To date only one species of nymph belouging to this genus has been described from North Imelica and until now no nymphs of this genus have been found in Illinois. The eharacters used to distinguish the nymph in this keg are based upon statements of
Claassen (1931). 
as given by Needham and Claassen (1925), but since the differential or specific characters of the females of the genus have not been defined this cannot be taken as conclusive proof of specific identity. It is included in this paper because its date of capture places it in our Illinois list of winter stoneflies, and in hope that mention of it will lead to interested parties discovering the male. Furthermore, the record is important because the genus Capnia has not heretofore been recorded from any state in the Mississippi basin."

The nymph of Capnia vernalis Newport has been recently described and figured by Claassen (1931). The nymphs are said to be herbivorous and live in leaves and debris in small upland streams. In general they are very suggestive of the genus Allocapnia.

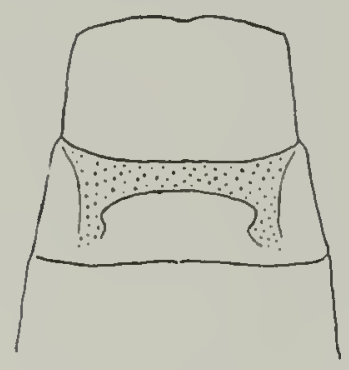

Fig. 288. - $\mathrm{AB}_{\mathrm{B}}$ DOMINAL STERNITES OF Capnia sp., ADUT.T FEMALE.

The "Capnia minima? Nerport" of Walsh (1862) is most certainly an Allocapnia and probably the species viripara.

\section{Allocapnia Claassen}

Capnella Claassen (1924) p. 43. Preoccupied. Genotype Capnella granulata Claassen = Allocapnia granulata $($ Claassen), original designation.

Allocapnia Claassen (1928) p. 667. New name.

A summary of the distributional records of the five species of Allocapria known at the time of the monograph by Needham and Claassen (1925) might have been taken to indicate then that the northeastern part of the United States was the general center of distribution for this genus. In my report of 1929 Illinois records were given for all except one of the known species of Allocapnia and two previously unknown species were described as new based upon Illinois material. The present paper adds another new species from Illinois and extends the range of the genus as far west and south as Oklahoma. It is evident therefore that the genus Allocapnia is quite at home in the streams of the middle Mississippi valley and is to be expected in many states from which it has not been recorded.

It is further evident from study of the distributional maps of the seven species occurring in Illinois that the extreme central eastern part of Illinois and the Ozarkian uplift region in the extreme southern part of the state are especially favorable to the development of a varied Allocapnia fauna. In the central and northern parts of the state, except for the eastern central portion draining into the Wabash river, only two species of this genus have been found. 'This suggests to me that the center of dispersal for Allocapnin is to the south and east of Illinois and that the 
stonefly lists of Georgia, Indiana, Kentucky, North Carolina, Ohio, Pennsylvania, Tennessee, Virginia and West Virginia are due for many additions when their winter fauna is studied.

The males are easy to identify because of the presence of peculiar and varied raised structures on the apical abdominal tergites. At the time of their monograph Needham and Claassen (1925) stated that "in the females

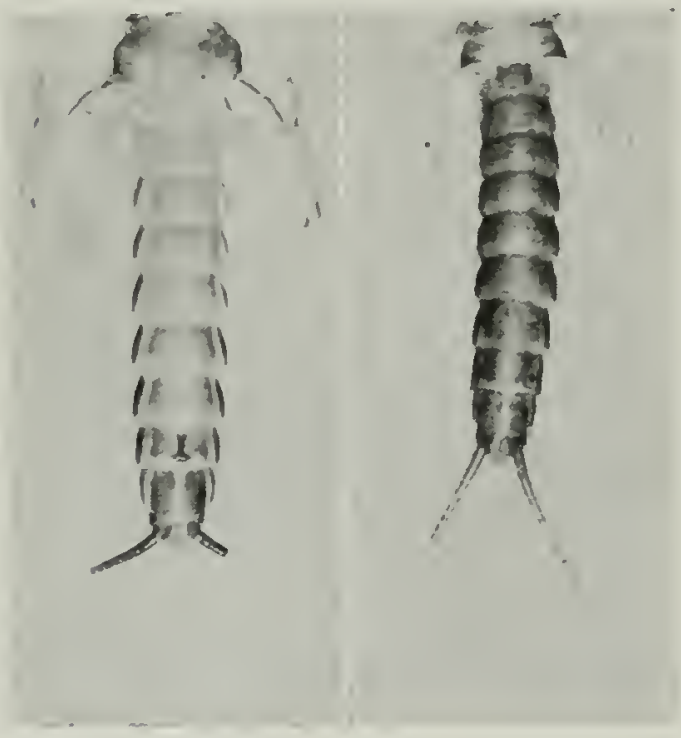

Figs. 289-290.-VENTRAL VIEW OF Allocopnia, XYMPHAL females. 289.(Left), A. granulata, showing indication of characteristic subgenital plate of eighth sternite. 290.-(Right), $A$. recta. the genital structures are of little value as key characters" and no attempt was made to key the females. The capture of males and females in coitu enabled the writer (1929) to associate the males and females of the various species and to point out characters by which these females could be identified.

When the nymphs were first described (Frison 1929) the difficulty in sharply separating or identifying the nymphs of the various species was recognized and stated as follows:

"Such rearings and collections have served to remove all doubts regarding the correct generic association of the nymphs with their adults and, with the exception of the genus Allocapnia, for the species as well. The difficulty with the nymphs of Allocapnia is due to the fact that this genus affords an exceptionally good example of a homogeneous group. Specific differences in the adults of this group are well marked and constant, but they consist for the most part of genital or accessory genital characters which are not developed in the nymphs in a comparable manner. There are however certain characters which permit the ready separation of all nymphs of this genus into males and females and the identification and keying of several of the males. Although it is possible for one well acquainted with the adults and nymphs of Allocapnia from Illinois to name most of the remaining species not included in the key (because of knowledge of the seasonal and geographical distribution of the species in the state, streams where certain species are liable to be found, slight indications of structural characters later apparent in the adults, etc.), it is impossible to formulate a key which would not at times be misleading to others. Therefore, instead of constructing a key based upon exceptional specimens of full grown nymphs, in which structural characters of adults 


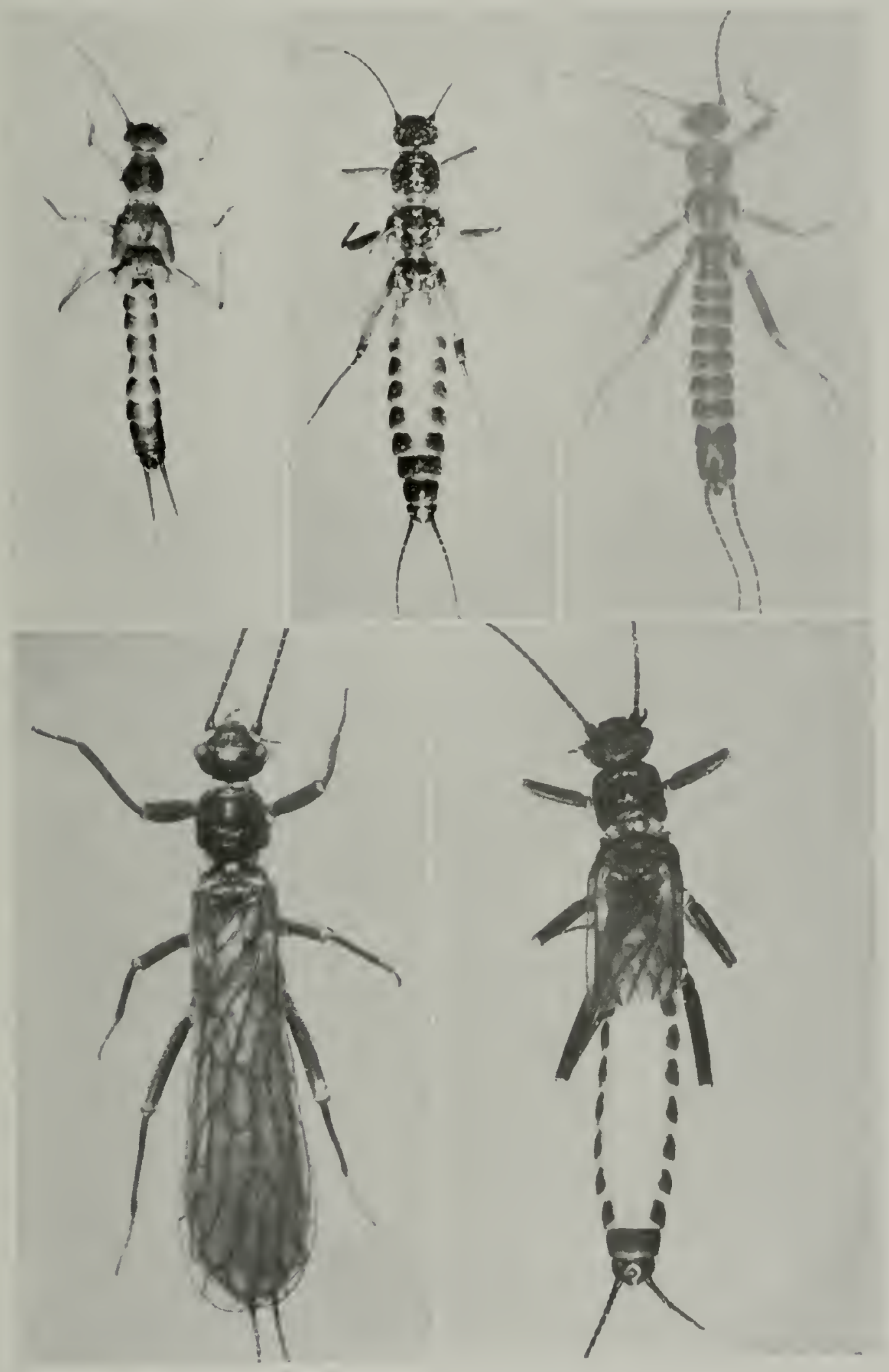

Fig. 291-295.-DORSAL VEWS of Allocapnia, NMMHS AND ADL1.TS. 291.- (TOP) left), A. recta, nymphal male. 292. ('Top center), 1. vicipara, alult female, showing short wings and darkly sclerotized eighth, ninth and tenth abdominal segments. 293.-(Top right), A. vivipara, adult male, showing lack of wings. 294.- Bottom left), A. granulata, adult female, showing long wings. 295.-(Bottom right), A. sranulata, adult female, with wings clipped to show darkly sclerotized ninth and tenth abdominal segments. 
can be plainly deciphered in advance, attention is called to such specimens under each species of Allocapnia. The chances of naming the nymphs of this genus, particularly the females, increase with the age of the specimens, and vice versa. Many of the full grown female nymphs of Allocapnia show in clear outlines what the ventral structure of the eighth abdominal segment of the adult will be, fig. 289 , while others of similar size, due to a lack of contrasting sclerotization at time of capture, show nothing, fig. 290. In the males, also, a heavily sclerotized knoblike structure may frequently be seen beneath the dorsal integument of the ninth abdominal segment, and in exceptional cases it is so well delineated that the species can be recognized by it."

Much additional nymphal material from various parts of the state and of known identity has confirmed our earlier statements regarding the difficulty of keying and identifying the nymphs of Allocapnia because of their rather uniform appearance.

The time of emergence of the adults of the various species presents a good seasonal succession beginning in November and continuing into April. Like other Illinois winter stoneflies, Taeniopteryx and Strophopteryx, the adults feed upon blue-green algae and the nymphs are herbivorous. The nymphs of most species are found in small streams but several of the species likewise live in the larger rivers.

Claassen (1931) has published a record of Allocapnia incisura Claassen from Charleston, Ill., which is not accepted in this paper. Extensive collecting by myself and assistants in the region about Charleston and in all parts of Illinois has failed to disclose the presence of incisura in this state. Correspondence with Dr. Claassen reveals that the material upon which his record was based is now lost. In view of the fact that so many species of Allocapnia are now known from Illinois, the possibility of incisura occurring in this state is not to be denied. However, until actual specimens upon which to base such a state record are available to us, it seems advisable to leave this species off our Illinois list.

\section{KEY TO SPECIES}

\section{Adults}

1. Eighth dorsal abdominal segment with a raised knoblike structure, figs. 221, 224. Wings either absent, abbreviated or extending nearly to apex of ab-

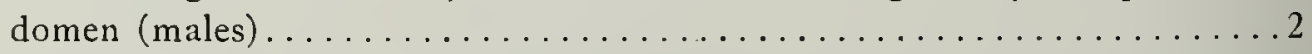
Eighth dorsal abdominal segment without a raised knoblike structure, fig. 292. Wings never absent; either abbreviated or extending to or beyond apex of

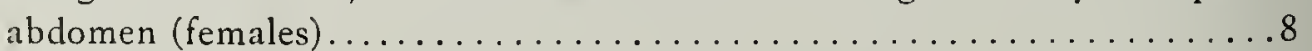

2. Wingless, fig. $293 \ldots \ldots \ldots \ldots \ldots \ldots \ldots \ldots$ vivipara, p. 370 Wings abbreviated or long, figs. $292,294 \ldots \ldots \ldots \ldots \ldots \ldots \ldots \ldots \ldots$ 


\section{ALLOCAPNIA-KEY TO SPECIES-CONT'D}

3. Seventh dorsal abdominal segment with a tubercle or knoblike structure similar to knob on the eighth dorsal abdominal segment............... Seventh dorsal abdominal segment without a raised tubercle or knoblike structure similar to knob on the eighth dorsal abdominal segment . . . . . . .5

4. Knoblike structure, fig. 222, on seventh dorsal abdominal segment large and conical, rising perpendicular to segment. Supra-anal process about as long as seventh and eighth abdominal segments combined. Wings usually extending little beyond third abdominal segment......... forbesi, p. 363

Knoblike structure, fig. 225, on seventh dorsal abdominal segment slightly notched at tip, slightly inclined posteriorly. Supra-anal process only slightly longer than seventh dorsal abdominal segment. Wings extending about to seventh abdominal segment............ illinoensis, p. 365

5. Wings rarely extending backwards beyond fifth dorsal abdominal segment. Mid-dorsal area of abdominal segments darkly sclerotized and mid-dorsal longitudinal light stripe therefore absent. Species rarely found in Illinois in winter prior to January . . . . . . . . . . . . . . . . 6

Wings usually extending backwards beyond fifth dorsal abdominal segment. Mid-dorsal area of abdominal segments pale, contrasting with lateral margins; a mid-dorsal longitudinal light stripe therefore present. Species found in Illinois in fall or winter usually before January . . . . . . . . 7

6. Knob on dorsum of eighth abdominal segment deeply divided along mid-dorsal line into two more or less conical tubercles; situated before posterior margin of ninth dorsal segment. Upper tip of supra-anal process (pronglike process recurved upward and forward over apical segments) with bulbous enlargement. Apical segments of abdomen with hairs not much longer than those

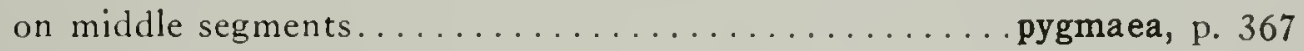

Knob on dorsum of eighth abdominal segment not so deeply divided along mid-dorsal line that two distinct and disconnected tubercles result; situated at apex of upward and backward directed hind margin of ninth dorsal segment, fig. 227. Upper tip of supra-anal process scarcely enlarged. Apical segments of abdomen with hairs much longer than those on middle seg-

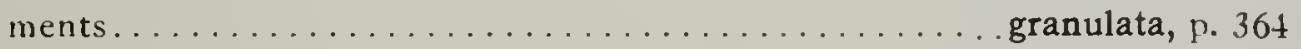

7. Knob arising at anterior margin of eighth abdominal tergite and extending backward and upward at a $45^{\circ}$ angle, fig. 229 ; as high as length of seventh segment, apex of knob forming two small tubercles separated by a small cleft. Supra-anal process large, nearly two times as long when extended as eighth abdominal segment...............mystica, p. 366

Knob arising near middle of eighth abdominal tergite about perpendicular to segment, height much less than length of seventh segment, apex of knob not cleft but forming a single, small, more or less round plateau-like area highest at anterior margin. Supra-anal process small, scarcely longer when extended than eighth abdominal segment............ recta, p. 367

8. Last three dorsal segments $(8,9$ and 10) of abdomen entirely and darkly sclerotized, fig. 292. A wide longitudinal pale memhranous stripe extending on dorsum of abdomen from base to hind mirgin of seventh segment. .9

Last two dorsal apical segments only (9 and 10) of ahdomen entirely and darkly sclerotized, fig. 295. A wide longitudinal pale membranous stripe extending on dorsum of abdomen from base to hind margin of eighth segment . 10 


\section{ALLOCAPNIA-KEY TO SPECIES-CONT'D}

9. Posterior transverse margin of eighth ventral abdominal segment with a small rounded lobelike projection at its middle, fig. 217. A narrow transverse pale membranous strip visible between darkly sclerotized areas of seventh and eighth ventral abdominal segments in extended specimens......

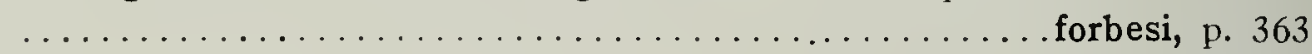

Posterior transverse margin of eighth ventral abdominal segment straight, without a projection at its middle, fig. 218. Darkly sclerotized areas of seventh and eighth ventral abdominal segments fused near middle, without a pale membranous strip between them, fig. 218 . ... vivipara, p. 370

10. Darkly sclerotized areas of seventh and eighth ventral abdominal segments fused near middle, fig. 215; without a pale membranous transverse strip

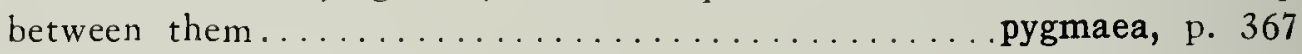

A narrow transverse pale membranous strip visible between darkly sclerotized areas of seventh and eighth ventral abdominal segments in extended speci-

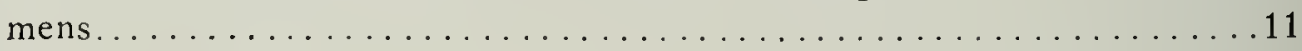

11. Posterior transverse margin of eighth ventral abdominal segment almost straight, fig. 213; at most with a small outward bulge at middle of margin.

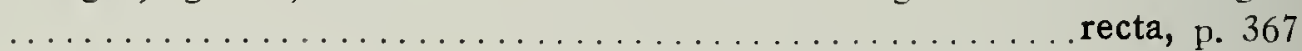

Posterior transverse margin of eighth ventral abdominal segment with a conspicuous but very short, sunken projection a little less than one-third as wide as darkly sclerotized area of same segment.............. 12

12. Antennae stout, moniliform; basal and middle segments much broader than segments of maxillary palpi. Eighth abdominal sternite with posteriomedian process deeply inset or sharply delineated, figs. 212, 220. Larger species (body $7-9 \mathrm{~mm}$.). Not found in Illinois in winter prior to Janu-

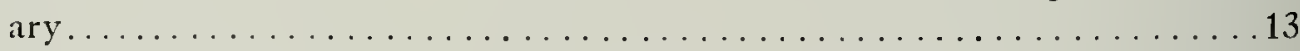

Antennae more slender, filiform; basal and middle segments not much broader than segments of maxillary palpi. Eighth abdominal sternite with posteriomedian process not so deeply inset or sharply delineated, fig. 219. Small species (body $6-8 \mathrm{~mm}$.). Species reaching maximum abundance in Illinois in fall or winter prior to middle of January............ mystica, p. 366

13. Eighth abdominal sternite with base of posteriomedian process fused with basal portion of ninth ventral abdominal segment, fig. 220 .granulata, p. 364

Eighth abdominal sternite with posteriomedian process inset in more membranous area and almost dividing basal part of sternite into two more or less distinct lateral areas, fig. $212 \ldots \ldots \ldots \ldots \ldots \ldots$ illinoensis, p. 365

\section{Nymphs}

1. Nymphs with a conspicuous dorsal lobelike protuberence, fig. 297, at apex

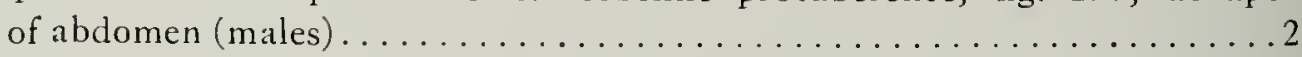

Nymphs without a conspicuous dorsal lobelike protuberence, fig. 298, at apex of abdomen. Apical margin broadly rounded behind.........females ${ }^{7}$

2. Nymphs with wing pads (winged adults), fig. $298 \ldots \ldots \ldots \ldots \ldots \ldots \ldots$

- It is impossible to key to species all nymphs helonging to this genus. Some mature specimens however can be separated with certainty by the chnacters used here. This is true even of some females which are far enough developed to reveal the shape of the eighth rentral abdominal segment. 
ALLOCAPNIA-KEY TO SPECIES-CONCL'D

Nymphs without conspicuous wing pads (wingless adults), fig. 297.

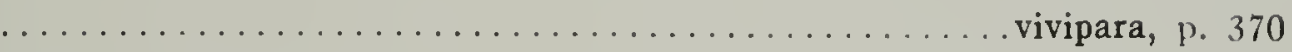

3. Forewing pad overlapping base of hind wing pad in large nymphs.......4 Forewing pad not overlapping base of hind wing pad in large nymphs....

.............pygmaea, p. 367; granulata, p. 364 ; illinoensis, p. 365

4. Dorsal lobelike protuberence at apex of abdomen nearly twice as long from base of cerci to apex as length of ninth dorsal abdominal segment . mystica, p. 366

Dorsal lobelike protuberence at apex of abdomen scarcely longer from base of cerci to apex than length of ninth dorsal abdominal segment, fig. $291 \ldots$

recta, p. 367

\section{Allocapnia forbesi Frison}

Figs. 217, 222, 296.

Allocapnia forbesi Frison (1929) p. 397. Original description $\left(\sigma^{7}, 9\right)$.

Very little information concerning this species can be added to that given in the original description. Field studies since 1929 clearly indicate that forbesi is restricted in its distribution, fig. 8 , to small streams in the Ozarkian uplift region of extreme southern Illinois, that the maximum emergence of the adults occurs during the last of November or first few weeks of December, and that in certain streams the species is abundant. This species has

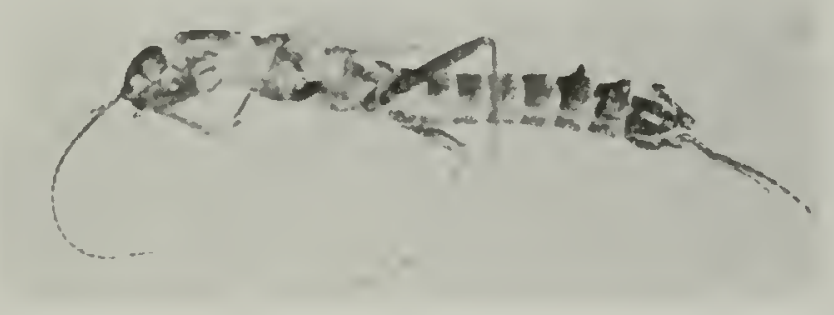

Fig. 296.-Lateral view of Allocapnia forbesi, ADUIT MALE, SHOWING KNOBLIKE PROTUBERANCESON SEVENTH ANDEIGH'TH ABDOMINAL. SEGUENTS. not yet been recorded from any other state.

Adults.-Cobden: Marr. 4, 1928, 1 o $^{7}$. Dixon Springs: Dec. 7, 193.3, $59 \sigma^{7}, 5$. . Golconda: Dec. 7, 1933, $\sigma^{x} \sigma^{x}$, ơ?. Herod: Nov. 30, 1928, $440^{x}$, 11\%; Dec. 21, 1930, $1 \sigma^{7}$; Dec. 7, 1933, $35 \sigma^{7}$, 79. New Columbia: Dec. 26, 1932, o $^{7} \sigma^{7}$. Stonefort: Mar. 7, 1928, $3 \sigma^{7}$.

\section{Allocapnia forbesi var. cornuta - NEW VARIETY}

The most distinctive feature of the male of forbesi is the presence of a large raised tubercle, fig. 222, on the seventh abdominal tergite, abo:1t as large as that on the eighth tergite. Two males of forbesi have been found which possess on the sixth abdominal tergite a raised tubercle similar to that on the seventh tergite. I an certain that these two males are forbesi because of their agreement with all other structural details, association with other forbesi, and similarity in structure of raised tubercles on apical tergites. Evidently we are here dealing with a species which is show- 
ing a tendency towards further evolution of dorsal abdominal tubercles, something rather characteristic of the Allocapnia series. Since this variant. might be considered a new species if collected elsewhere as a unique, I am proposing the name of forbesi variety cornuta for this most interesting form.

Holotype, male.-Dixon Springs, Ill. (Hills Branch cr.): Dec. 7, 1933, collected by T. H. Frison and C. O. Mohr.

Paratype, male.--Herod, Ill. (N. Hicks Branch): Nov. 30, 1928, collected by T. H. Frison and H. H. Ross. Holotype and paratype deposited in the collection of the SURveY.

\section{Allocapnia granulata (Claassen)}

Figs. 220, 227, 289, 294, 295. $\left(\sigma^{\top}\right.$, o).

Capnella granulata Claassen (1924) p. 44. Original description

Allocapnia granulata Frison (1929) p. 394. Nymphal description $\left(\sigma^{7}\right.$, \&).

Except for further distributional records I can add very little to the information concerning this species which I published in 1929. A. granulata occurs in all parts of the state but is particularly abundant in the central and northern portions. Contrary to such species as recta, forbesi and pygmaea, the nymphs are found in large rivers as well as in medium sized streams. The adults begin to emerge during the first of January and reach their maximum abundance the latter part of February or in early March. The terminal abdominal segments, not illustrated hitherto, are shown in figs. $220,227$.

This species was first recorded from Illinois (Coles county) by Needham and Claassen (1925). It is also known from the District of Columbia, Maryland and New York. I have compared Illinois specimens with the typic specimens in the collection of Cornell university.

Adults.-Castle Rock: Apr. 3, 1928, $10^{7}, 2$. . Charleston: Mar. 9, 1930, $25 \sigma^{7}, 80$; Mar. 22, 1931, $\sigma^{7} \sigma^{7}$, ợ. Danville: Jan. 11, 1928, $16 \sigma^{7}$; Mar. 11, 1928, $4 \sigma^{7}$; Feb. 21, 1931, $1 \sigma^{7}, 1$ ㅇ․ Elizabethtown: Mar. 7, 1928, 1․ Georgetown: Mar. 9, 1928, $\sigma^{7} \sigma^{7}$, 9 . Mahomet: Jan. 15, 1928, 140 Muncie:

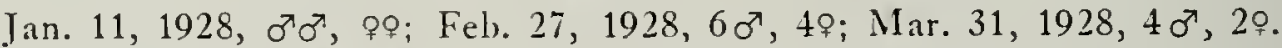

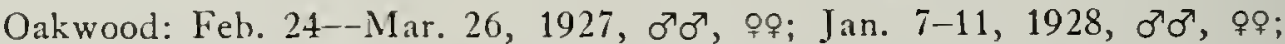

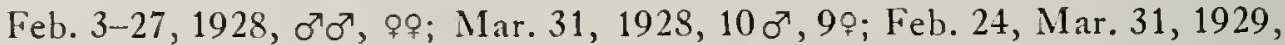

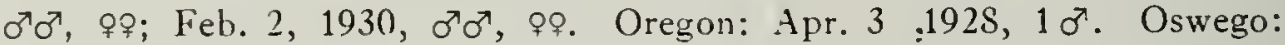
Feb. 11, 1928, 607. Paris-Chrisman: Mar. 9, 1928, 4․ Pontiac: Mar. 7, 1916, 2o; Mar. 24, 1928, $10^{7}$, 79. Rock Island: Apr. 2, 1928, 3ㅇ. Rocky Branch: Jan. 14, 1932, $2 \sigma^{7}$. Towanda: Mar. 24, 1928, $1 \sigma^{7}, 2$. . Union Hill: Mar. 24, 1928, $10^{7}$. Urbana: Apr. 3, 1898, 1\%; Jan. 16, 1928, 19. White Heath: Feb. 10, 1929, $10^{7}$, 3우. White Heath-Mahomet: Mar. 25, 1928, 6 \%.

Nymphs.-Oakwood (Salt Fork r.): Jan. 11-12, Feb. 24-26, Mar. 4-10, 1927. 
Mating pairs.--Georgetown: Mar. 9, 1928. Oakwood: Feb. 24-20, Mar. 4-10, 1927; Jan. 7-11, Feb. 3, 11, 27, 1928; leb. 24, Mar. 31, 1929.

\section{Allocapnia illinoensis - NEW SPECIES}

Figs. 212, 225.

Male.-Length to apex of wings $3-4 \mathrm{~mm}$. ; length to apex of abdomen 6-8 mm. General color dark brown or blackish.

Head slightly wider than thorax. Ocelli arranged to form an isosceles triangle; the anterior ocellus situated well forward on the front, the hind ocelli almost three times as far apart as distance from one ocellus to compound eye. Antennae with 34 segments or thereabouts; basal segment twice as wide as second, succeeding segments gradually becoming less moniliform and more filiform towards apex; length of segments greatest in middle of antennae.

Darkly sclerotized area of pronotum quadrangular, slightly widened at base; angles somewhat rounded, surface with raised rugosities.

Legs almost uniformly dark brown or black; second tarsal joint short, about one-fifth as long as first tarsal segment.

Wings abbreviated, usually extending to sixth or seventh abdominal tergite; hyaline, with veins dark and contrasting.

Abdomen with tergites seven and beyond darker and more heavily sclerotized than those preceding; first five or six tergites with a narrow median pale longitudinal membranous-like stripe. Cerci brown with 16-18 segments; basal segments somewhat moniliform, succeeding segments more filiform. Seventh and eighth dorsal segments with raised knoblike structures, fig. 225. Tubercle on the seventh segment located on the posterior third of the segment, and although rising essentially perpendicular it is slightly inclined posteriorly, and the tip is very slightly notched, fig. 225. Tubercle on eighth segment rising from posterior third of segment and inclined posteriorly at an angle of about $30^{\circ}$; tip deeply notched, fig. 225. Dorsal segments nine and 10 with a median membranous depression or area for reception of the recurved supraanal process. Ninth ventral segment rounded behind with apical margin slightly knobbed. Upper part of recurved supra-anal process forming a heavily sclerotized shaft, enlarged at tip, about as long as eighth segment ; lower part of process less sclerotized, forming a sheath for reception of dorsal shaft, shaped as in fig. 225.

Female. - Length to apex of wings $6-7 \mathrm{~mm}$; ; length to apex of abdomen $6-8 \mathrm{~mm}$.

Head, thorax, abdomen and appendages in general similar to those of the male. Differs from male as follows: wings not abbreviated and extending almost to or beyond tip of abdomen. A wide median dorsal longitudinal strip extending from base of abdomen to hind margin of eighth tergite. Last two abdominal tergites entirely and darkly sclerotized. Apical tergite rounded 
behind. Posterior transverse margin of eighth abdominal sternite with a conspicuous sunken or inlaid and somewhat triangularly shaped projection, fig. 212 ; this inset posteriomedian process in a somewhat membranous area which almost divides the basal part of the sternite into two more or less distinct lateral areas.

Holotype, male.-Dolson (Clarksville), Ill. (fence post near Rocky Branch): Jan. 14, 1932, collected by T. H. Frison and H. H. Ross.

Allotype, female.-Same data as for holotype.

Paratypes. - Same data as for holotype: $7 \sigma^{7}, 2 \%$. Dolson (Clarksville) (Rocky Branch): Mar. 1, 1931, $10^{7}$; Jan. 14, 1932, pair in coitu. Dolson (Clarksville) (trib. of Rocky Branch): Jan. 5, 1933, 43 o , 2q. Dolson (Clarksville) (Big. cr.): Jan. 5, 1933, $20^{7}$. Oliver (trib. of Big cr.): Jan. 14, 1932, $4 \sigma^{7}$. All collected by T. H. Frison and H. H. Ross.

This species was discovered in March 1931, not far from Charleston in a local "pocket" of considerable ecological interest. Each year since then when this particular area has been visited the species has again been found; thereby substantiating from another point of view the conclusion that the morphological differences observed in the adults are true criteria of a distinct species and in this instance a new species.

Nymphs certainly belonging to this species were collected in association with the adults but as in other species of Allocapnia possessing well developed wing pads in both sexes, it is impossible to enumerate characters which will invariably serve to identify these nymphs to species. In other words, the nymphs are practically identical with those of mystica, granulata and most other species of Allocapnia.

\section{Allocapnia mystica Frison}

Figs. 175, 177, 219, 229, 287.

Allocapnia mystica Frison (1929) p. 399. Original description (adult $\sigma^{x}$, o; nymphal $\sigma^{x}$, o).

Collecting since 1929 has added new locality records for this species but has not fundamentally changed the general picture of its range in the state. It is a species of the Ozarkian uplift and more locally of some streams in the upper Wabash watershed. The adults start emerging in November and their maximum abundance is over before February.

Adults.-Carrier Mills: Dec. 1, 1928, $8 \sigma^{7}$. Dixon Springs: Dec. 7, 1933, $2 \sigma^{7}$. Eichorn: Nov. 30, 1928, $2 \sigma^{7}$; Mar. 6, 1928, $1 \sigma^{7}$, 19; Dec. 21, 1930, $\sigma^{7} \sigma^{7}$, 우. Fountain Bluff: Feb. 22, 1933, $\sigma^{7} \sigma^{7}$, 웅․ Golconda: Mar. 7,

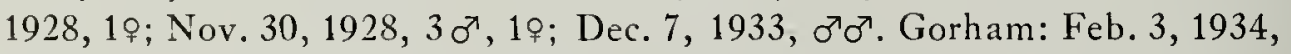
$12 \sigma^{7}, 2$. . Grand Detour: Feb. 3, 1934, $\sigma^{7} \sigma^{7}, 4$ \% . Harrisburg: Mar. 6, 1928,

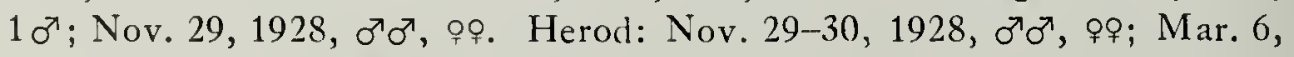

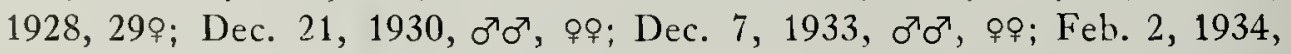
$\sigma^{7} \sigma^{7}$, 우. Marshall: Jan. 3, 1933, $\sigma^{7} \sigma^{7}$, 우. Murphysboro: Feb. 22, 1933, $0^{7} \sigma^{7}$, 우. New Columbia: Dec. 25-28, 1932, $\sigma^{7} \sigma^{7}$, 우. Oakwood: Nov. 


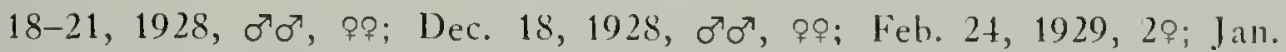
24, 1931, $1 \sigma^{7}$. Rosiclare: Nov. 30, 1928, $30 \sigma^{7}, 39$. Thebes: Feb. 3, 19.34, 20 , 2 ㅇ․

Nymphs.- Harrishurg (Blackman cr.): Nov. 29, 1928. Herod (N. Hicks Branch and Gibbons cr.): Nov. 20, 30, 1928. Marshall (tril, of Big cr.): Jan. 3, 1933. Oakwood (trib. of Salt Fork r.): Nov. 18-21, 1928.

Reared from nymphs.-Grand Tower: Fel. 3, 1934, $1 \sigma^{7}$. Oakwood: Nov. 21, 1928, $2 \sigma^{7}, 3$ \%.

Mating pairs.-Golcondat: Dec. 8, 1933. Herod: Dec. 7, 1933; Feb. 2, 1934. Oakwood: Nov. 18, 21, Dec. 18, 1928.

Since this species has not heen recorded from other states, Surver collections by H. H. Ross and C. O. Mohr from Missouri are given as follows: Carthilge: Nov. 3, 1933, $1 \sigma^{7}$. Niangua (Webster county): Dec. 4, 1933, $40 \sigma^{\pi}, 40$. St. Clair-Rolla (1.ittle Bourbois cr.): Jan. 30, 1932,

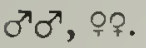

\section{Allocapnia pygmaea (Burmeister)}

Figs. $215,224$.

Semblis pygmaea Burmeister (1839) p. 874. Original description (ब). $\left(\sigma^{7}\right.$, q).

Allocapnia pygmaea Irison (1929) p. 396. Nymphal description

Except for additional locality records, I have almost nothing to add to my account of 1929. This species is a true member of the winter fauna of the Ozarkian uplift of southern Illinois. Characteristic structures of the terminal abdominal segments of the male, not figured in 1929 , are shown here in fig. 215. The species has been recorded previously from lllinois (Frison 1929), the District of Columbia, Maine, Maryland. Massachusetts, New Hampshire, New York and Virginia.

Adults.-Bloomfield: Mar. 7, 1928, $13 \sigma^{7}, 2$. Dixon Springs: Fel. 2, 1934, $\sigma^{7} \sigma^{7}, 2$. Eichorn: Mar. 6, 1928, $\sigma^{7} \sigma^{7}$, ㅇ․ Golcondal: Mar. 7, 1928, $\sigma^{7} \sigma^{7}$, ‡․ Gorham: Feb. 3, 1934, $1 \sigma^{7}, 19$. Herod: Mar. 6, 1928, $\sigma^{7} \sigma^{7}$, 우. Herod-Elizabethtown: Mar. 6, 1928, $3 \sigma^{7}$. New Columbia: Dec. 26, 1932, $\sigma^{7} \sigma^{7}$. Thebes: Fel. 3, 1934, $4 \sigma^{7}$. Vienna: Mar. 7, 1928, $1 \sigma^{7}$.

Nymphs.-Golconda (Big Grand Pierre r.): Mar. 7, 1928.

Mating pairs.-Dixon Springs: Feb. 2, 1934. Herod: Mar. 6, 1928. Golconda: Mar. 7, 1928.

\section{Allocapnia recta (Claassen)}

Figs. 213, 221, 290, 291.

Capnella recta Claassen (1924) p. 44. Original description $\left(\sigma^{7}, \%\right)$. Allocapnia recta Frison (1929) p. 395. Nymphal description (o , of).

In my paper of 1929 this species was recorded only from Oakwood in 


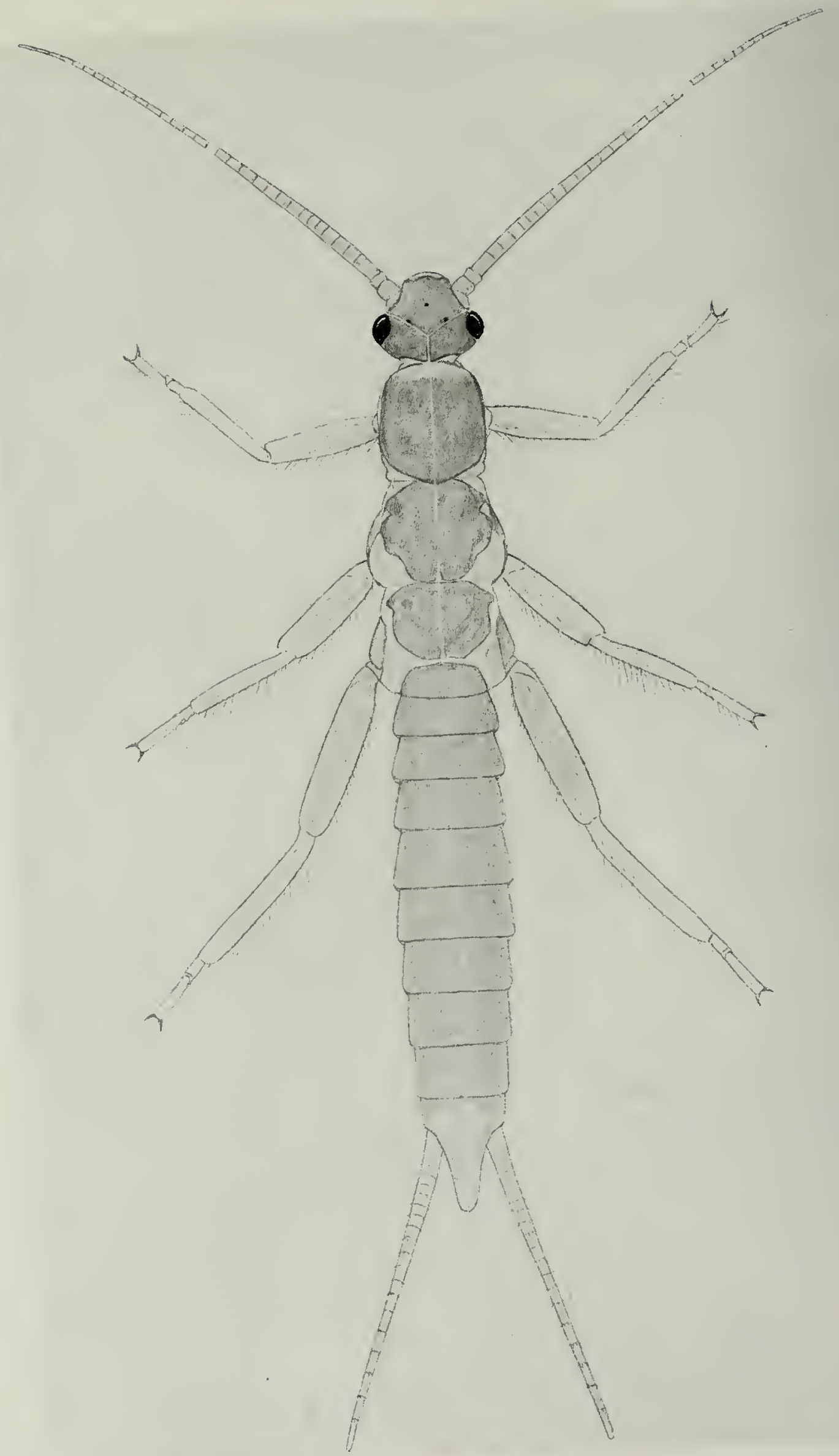

Fig. 297.-Allocapnia vivipara, NYMPHAL MALE. 


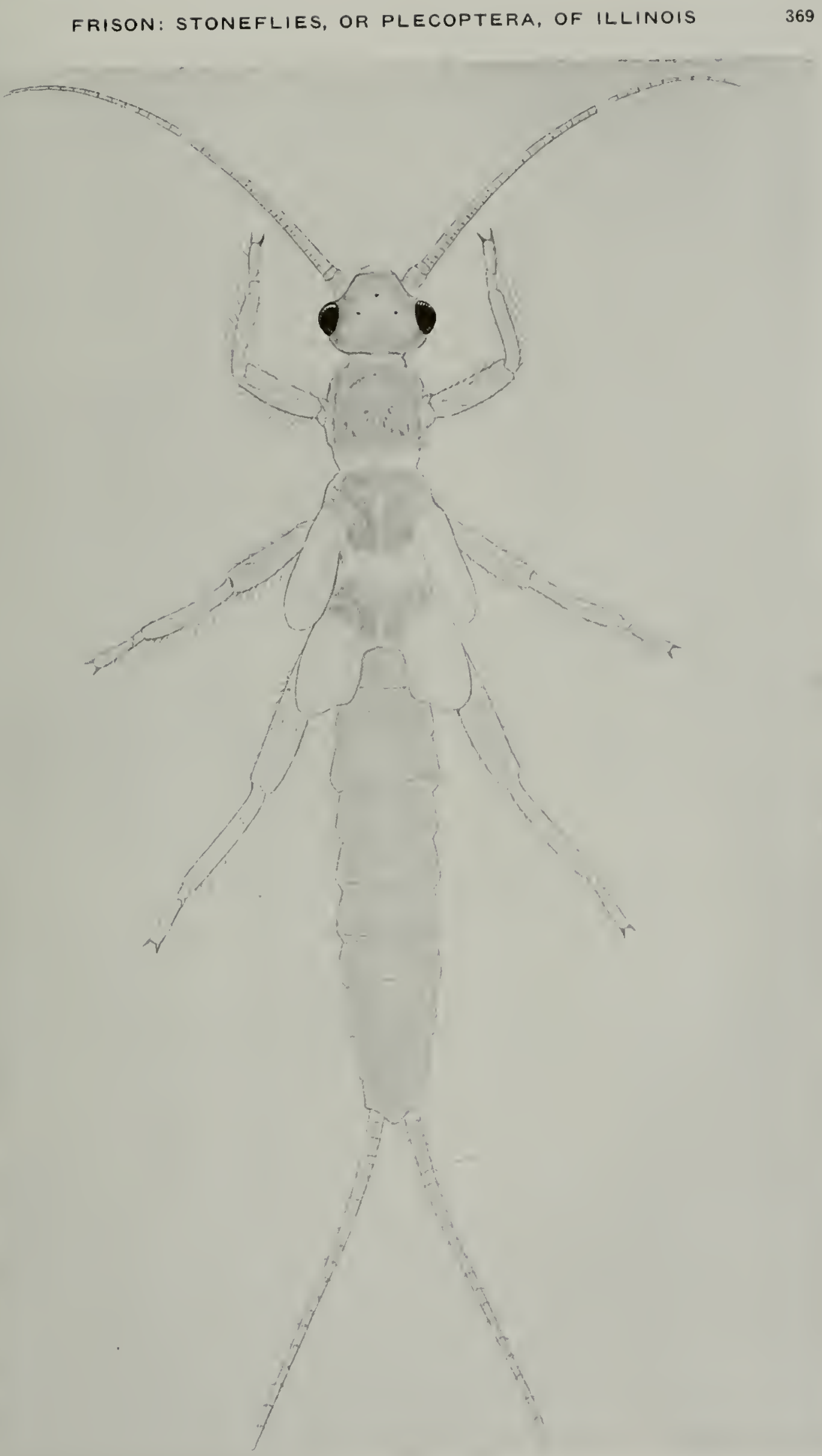

Fig. 298. - Allocapnia vivipara, NYMHHAL FEMALE. 
Illinois and was said to share "with forbesi the distinction of being our rarest members of this genus." Additional collecting has revealed this species in another locality not far from Oakwood but it remains extremely localized. Adults begin to emerge in late November and reach a maximum of abundance in December and the early part of January. This species has been recorded to date only from Illinois (Frison 1929), Massachusetts and New York.

Terminal abdominal segments of the male, not illustrated in the previous Illinois report, are shown here in fig. 221. Illinois specimens have been compared with the types of this species in the collection of Cornell university.

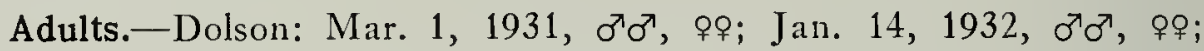

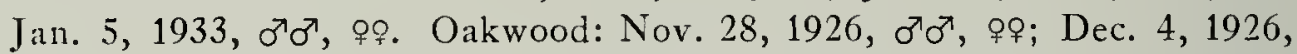

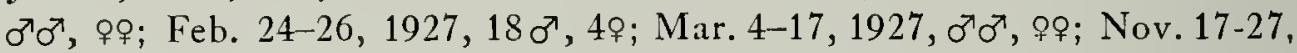

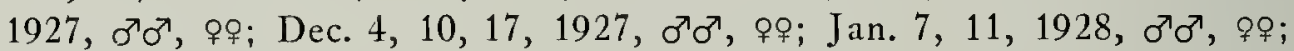
Feb. 3-27, Mar. 11, 1928, 7 ơ $^{7}$ 23; Nov. 18-21, 1928, $24 \sigma^{7}$, 2क; Dec. 18, 1928, $33 \sigma^{7}, 15$; ; Mar. 21, 1929, 1 \% .

Nymphs.-Oakwood (trib. of Salt Fork r.): Nov. 28, Dec. 4, 1926; Feb. 24, Mar. 10-17, Nov. 20-23, Dec. 17, 1927; Feb. 11, Nov. 4, 18-21, Dec. 18, 1928.

\section{Allocapnia vivipara (Claassen)}

Figs. 57, 87, 117, 144, 218, 228, 257, 292, 293, 297, 298.

Capnella vivipara Claassen (1924) p. 46. Original description (o', ᄋ). Allocapnia vivipara Frison (1929) p. 392. Nymphal description $\left(\sigma^{\top}\right.$, o).

A. vivipara is one of the commonest as well as academically one of the most interesting members of our stonefly fauna. It is generally distributed throughout the state and thrives in small streams as well as along the edges of our largest rivers. Although the adults may be found from December to April, their maximum abundance in most parts of the state is reached during March. Of special interest to the student of stoneflies is the fact that the wings of the male adult are reduced to mere rudiments and in the female wing length varies from brachypterous to macropterous forms. In Illinois the commonest form of the female in the northern counties is brachypterous, and in the southern counties macropterous.

No observations concerning the biology of this species can yet be added to those published by the writer (1929). Terminal abdominal structures of the male are shown in fig. 228.

The original description of vivipara was based upon specimens from Lake Forest, I1l. This species has also been recorded from Missouri, New York and Ohio. Walsh in 1862 recorded "Capnia minima? Newport" 
from the vicinity of Rock Island, Ill. Capnia at the time of Walsh was used in a broad sense and included those species now placed in Allocapnia. Based upon the fact that Allocapnia viripara Claassen is the most abundant of the Illinois species, is very common at Rock Island, and that the true Capnia in its present restricted sense is a rarity and known only from southern Illinois, I feel that the record of Walsh had best be placed in the synonymy of this species. Further support may be in the fact that the descriptions of Capnia minima? available to Walsh referred to a male with rudimentary wings while in the male of rivipara the wings are actually represented by the merest rudiments. Needham and Claassen (1925) did not mention this record of Walsh (1862).

Adults.--Barstow: Apr. 2, 1928, $0^{7} 0^{7}$, ㅇ․ Beltrees: lieb. 4, 19.3t, $5 \sigma^{7}$. Bloomfield: Mar. $7,1928,31 \sigma^{7}, 3$ o. Bloomington: Mar. 25, 1928, 19. Brocton: Mar. 9, 1930, $10^{7}$. Carbondale: Jan. 22, 1928, $30^{7}$; Mar. 4 ,

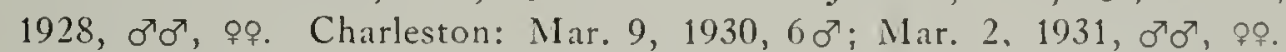
Choat: Mar. 8, 1928, $1 \sigma^{7}$. Chrisman: Mar. 9, 1928, $5 \sigma^{7}$, 9․ Danville: Jan. 11, 1928, $2 \sigma^{7}$; Feb. 21, 1931, $1 \sigma^{7}$, 19. Decatur: Mar. 1.5, 1930, $1 \sigma^{7}$. Detroit: Jan. 29, 1932, $1 \sigma^{x}, 1$. Dolson: Mar. 1, 1931, $5 \sigma^{7}$ : Jan. 5-6, 1933, $\sigma^{7} \sigma^{7}$, 우. Eichorn: Mar. 6, 1928, $0^{7} \sigma^{7}$, oㅇ. Elizabethtown: Mar. 7, 1928, 2ㅇ. Evansville: Feb. 3, 1934, $2 \sigma^{7}, 1$ ㅇ․ Farmer City: Mar. 25, 1928, 1 . Fountain Bluff: Feb. 22, 1933, $10^{7}, 1$ ㅇ․ Ft. Sheridan: Dec. 23, 1927, $70^{7}$, 1ㅇ. Gays: Dec. 30, 1928, $1 \sigma^{7}, 2$. 0 . Georgetown: Mar. 9, 1928, $2 \sigma^{7}, 1$. Glenview: Dec. 27, 1927, $2 \sigma^{7}$. Golconda: Mar. 7, 1928, $12 \sigma^{7}, 109$. Gorham: Feb. 3, 1934, $0^{7} \sigma^{7}$, 우․ Gossett: Mar. 8, 1928, $90^{7}$, 4․ Grape Creek: Jan. 17, 1931, 19. Grayville: Mar. 8, 1928, $\sigma^{7} \sigma^{7}$, 6ㅇ. Harrisburg: Mar. 6, 1928, 19. Harrisburg-Stonefort: Mar. 7, 1928, $6 \sigma^{7}$, 5o. Herod: Mar. 6, 1928, $\sigma^{7} \sigma^{7}$, 우; Dec. 7, 1933, $\sigma^{7} \sigma^{7}$, 우. Herod-Elizabethtown: Milr. 6, 1928, $2 \sigma^{7}$. Hillsboro: Dec. 30, 1928, $6 \sigma^{7}$. Humboldt: Mar. 11, 1928, $\sigma^{7} \sigma^{7}$, 우. Jonesboro: Feb. 3, 1934, $0^{7} \sigma^{7}$, 우. Kampsville: Jan. 29, 1932, $1 \sigma^{7}$. Lexington: Mar. 25, 1928, 19. Litchfield: Jan. 3, 1929, $4 \sigma^{7}$, 2क. Louisville: Feb. 3, 1928, $0^{7} \sigma^{7}$, 우. Mahomet: Jan. 15, 1928, $0^{7} \sigma^{7}$, 72. Mascoutah: Mar. 3, 1928, 2o. Mermet: Mar. 7, 1928, $9 \sigma^{7}$, 39. Michael: Jan. 29, 1932, $1 \sigma^{7}$. Muncie: Mar. 7, 1909, 1우 ; Jan. 11, 1928, $10^{7}$, 1우 F Feb. 27, 1928, $10^{7}$, 3o; Mar. 31, 1928, $10^{7}, 2$. . Nurphysboro: Feb. 22, 1933, $\sigma^{7} \sigma^{7}$, ㅇ․ New Columbia: Dec. 25-28, 1932, $\sigma^{7} \sigma^{7}$, कㅇ. Oakwood: Fel. 24, 1927, $15 \sigma^{7}$,

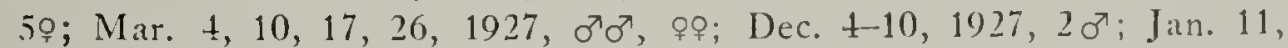
1928, $10^{7}$; Feb. 3, 27, 1928, $10^{7}$, 2क; Dec. 18, 1928, o o $^{7}$, 우; Fel. 24, 1929, $\sigma^{7} \sigma^{x}$, of; Jan. 24, 1931, $2 \sigma^{7}$. Ocoya: Mar. 25, 1928, 1 . Oliver: Jan. 14, 1932, $4 \sigma^{7}$. Olmstead: Feb. 2, 1934, $\sigma^{7} \sigma^{7}$, 우. Oswego: Feb. 11, 1928, $1 \sigma^{7} ; \mathrm{Apr}$. 1, 1928, $1 \sigma^{7}$. Palos Park: Mar. 15, 1933, ơ $\sigma^{7}$, 우. Pana: Dec. 30, 1928, $13 \sigma^{7}, 5$ \%. Paris: Mar. 9, 1928, $10^{7}$; Jan. 14, 1932, $0^{7} \sigma^{7}$, ơ. Paris-Chrisman: Mar. 9, 1928, $1 \sigma^{7}, 5$ o. Plainview: Jan. 29, 1932, $1 \sigma^{7}$. Pontiac: Mar. 25, 1928, $1 \sigma^{7}$. Quincy: Jan, 29, 1932, $0^{7} \sigma^{7}$, 99. Reeders: fiel. 3, 1934, $7 \sigma^{7}, 2$. Rock Island: Apr. 2, 1928, 19. Rocky Branch: Jan. 14, 1932, ठ $\sigma^{7}$, क․ Salem: Feb. 21, 1933, $2 \sigma^{7}$. Shelbyville: Dec. 30, 1928, $1 \sigma^{7}, 1$ \% . Thebes: Feb. 3, 1934, $2 \sigma^{7}$. Texas City: Mar. 8, 1928, $0^{7} \sigma^{7}, 99$. Towanda: Mar. 25, 1928, 50. Urbana: Jan. 16, 1928, $\sigma^{7} \sigma^{7}$, 90 . Vienna: Mar. 7, 1928, $\sigma^{7} \sigma^{7}$, 97. Vienna-Mermet: Mar. \&, 1928, $30^{7}, 17$. Walnut Prairie: Mar. 8, 1928, 19, 19. Watson: Apr. 7, 1932, 1; Jan. 8, 1933, ơ $0^{7}$, 우. Westfield: fiel). 
14, 1932, $0^{7} \sigma^{7}$, 웅. Winchester: Jan. 29, 1932, $1 \sigma^{7}, 1$ 우. Winthrop Harbor: Mar. 16, 1933, $0^{7} 0^{7}$, 우. White Heath-Mahomet: Mar. 25, 1928, $10^{7}$. W. York: Mar. 8, 1928, 13 ơ 13 ㅇ.

Nymphs.-Barstow (trib. of Rock r.): Apr. 2, 1928. Carbondale (trib. of Crab Orchard cr.): Mar. 4, 1928, exuviae. Cobden (Clay Lick cr.): Dec. 1, 1928. Cora: Dec. 8, 1933; Feb. 3, 1934. Danville (North Fork): Jan. 11, Nov. 22, 1928. Detroit (Duff cr.): Jan. 29, 1932. Dolson (Big cr.): Jan. 5, 1933. Effingham (Little Wabash r.): Mar. 25, 1932. Ft. Sheridan: Dec. 23, 1927. Funkhouser: Dec. 2, 1928. Glenview: Dec. 27, 1927. Grand Tower: Feb. 3, 1934. Harrisburg (Blackman cr.): Nov. 29, 1928. Herod (N. Hicks cr.): Nov. 30, 1928. Mahomet (Sangamon r.): Jan. 15, Nov. 22, Dec. 9, 1928. Marseilles (N. Kickapoo cr., Walbridge cr.): Nov. 23, 1928. Michael: Jan. 29, 1932. Muncie (Stony cr.): Dec. 4, 1926; Feb. 27, Mar. 31, Dec. 23, 1928. Oakwood (Salt Fork r. and tribs.): Nov. 28, Dec. 4, 1926; Mar. 4-10, Nov. 23, 1927; Feb. 11, Mar. 31, Nov. 18-22, Dec. 18, 1928. Oliver (trib. of Big cr.): Jan. 14, 1932. Pana: Dec. 30, 1928. Paris: Jan. 14, 1932. Payson (Burton cr.): Jan. 29, 1932. Quincy (Mill cr.): Jan. 29, 1932. Shelbyville (Kaskaskia r.): Dec. 30, 1928. Starved Rock (trib. of Illinois r.): Nov. 23, 1928.

Mating pairs.-Carbondale: Mar. 4, 1928. Grayville: Mar. 8, 1927. Mahomet: Jan. 15, 1928. Oakwood: Mar. 4, 10, 1927; Dec. 18, 1928. Paris: Jan. 14, 1932. W. York: Mar. 8, 1928.

\section{PERLIDAE}

The family Perlidae, as here used, differs from the Perlidae of previous American writers (Needham and Claassen 1925) by the transfer of several genera to the families Chloroperlidae and Perlodidae. My reasons for restricting the number of genera in this family have been given in speaking of the classification proposed by this paper, p. 308 .

In Illinois we find seven groups or assemblages of morphologically distinct species, constituting the genera Atoperla, Perlinella, Neoperla, Perlesta, Acroneuria, Neophasganophora and Togoperla, which I consider as belonging to the family Perlidae in its strictest sense.

Two of these genera, Neophasganophora and Togoperla, were included in the genus Perla by Needham and Claassen (1925) together with other species which I recognize as genera and place in the families of Chloroperlidae and Perlodidae. The genus Perla as used by Needham and Claassen (1925) is, as these authors have frankly stated, "a somewhat heterogeneous group of mostly rather large stoneflies having little else in common than the dorsally cleft tenth segment of the male abdomen."

When writing of the nymphs Claassen (1931) refers again to the unnaturalness of Perla as used by Needham and Claassen (1925), when he states "it is evident that some changes will have to be made as soon as the immature stages of the various species are better known, especially 
in the genus Perla, in order to arrange the species in more natural groups." It is incompatible with the varied knowledge now available concerning the adults and nymphs of our Illinois stoneflies and defeats one of the purposes of taxonomy longer to accept as a generic unit such a heterogeneous assemblage of unrelated species as have been placed in Perla by American authors. Although Needham and Claassen (1925) have placed several species of Perla (in the broad sense as used by them) in the subgenus Perla Geoffroy (s. str.) it is even doubtful whether the true Perla in the restricted sense as used by Klapalek (1923) occurs in North America.
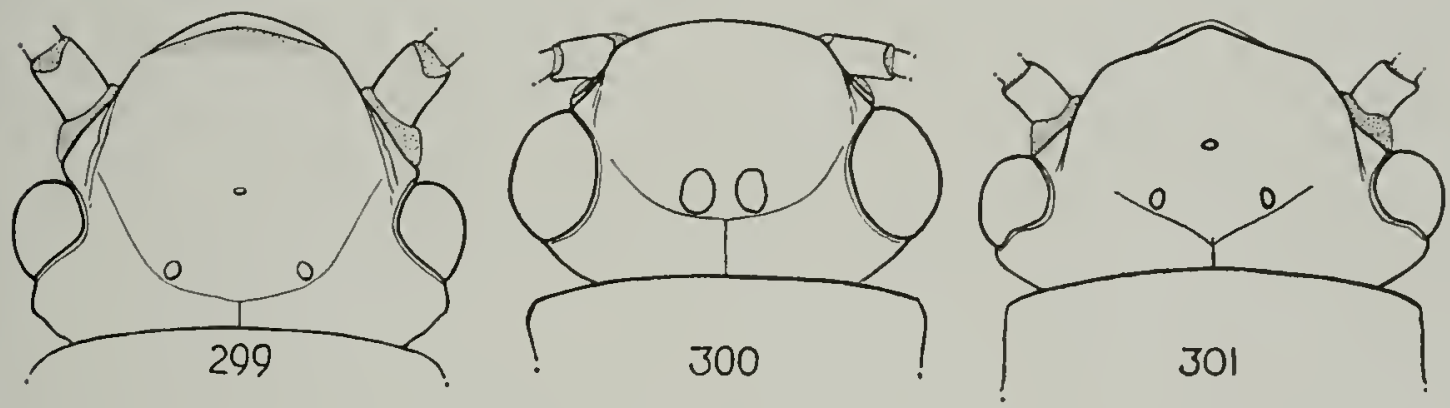

Figs. 299-301.--DORSAL VIEW OF HEAD OF PERLID ADULTS, SHOWING DIFFERENCE in NUMBERS AND ARRANGement of OCElli. 299.--Perlinella drymo, female. 300.-Neoperla clymene, female. 301.-Acroncuria abnormis, female.

The genera composing the family Perlidae, with the exception of Acroneuria which may eventually be shown to be a composite of several related groups, are essentially genera of the states east of the Rocky mountains. The adults range from medium to large and are more frequently collected by the general entomologist than are those of other families. The adults of this family are very definitely associated with the late spring and summer fauna, in marked contrast with the Taeniopterygidae and Capniidae which appear during the colder months. The nymphs are essentially carnivorous and the adults take little or no food.

\section{KEY TO GENERA}

\section{Adults}

1. Ninth ventral abdominal segment much produced posteriorly and recurved upward so that tenth ventral ahdominal segment is mostly or entirely concealed, fig. 302. Some species with a disklike structure in middle of posterior portion of ninth ventral abdominal segment, fig. 302. Eighth ventral abdominal segment never notched in middle of posterior margin or produced over ninth ventral abdominal segment, fig. 302, (males)...2

Ninth ventral abdominal segment poorly or not at all produced posteriorly, fig. 247 ; tenth ventral abdominal segment always visible. Fighth ventral abdominal segment notched in middle of posterior margin, figs. 243,254 , or with a subgenital plate, fig. 248, partly projecting over ninth segment

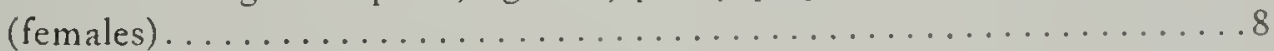


PERLIDAE-KEY TO GENERA-CONT'D

2. Median ocellus lacking or so poorly developed that only lateral ocelli are clearly visible, fig. 300 ; head therefore appearing to have but two ocelli..3

Median ocellus well developed, fig. 301; head therefore clearly with three ocelli....................................

3. Lateral ocelli close together, much closer to one another than each lateral ocellus is removed from compound eye. Forewing without crossveins in anal field and with many crossveins before subcosta, fig. 181. Ninth ventral abdominal segment without a disklike structure in middle of posterior portion......................... Neoperla, p. 381

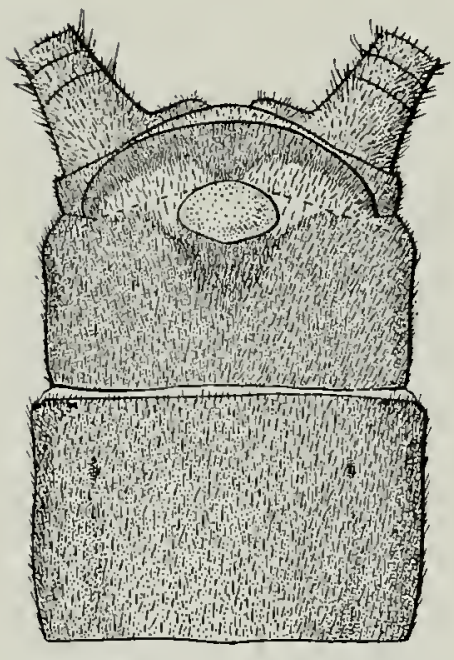

Fig. 302. - Ventral. VIEW OF TERMINA1, ABDOMINAL SEgMENTS OF Acroneuria ruralis, ADULT MAIE, SHOWING PADLIKE DISK ON NINTH STERNITE.

Lateral ocelli far apart, at least as far removed from one another as each lateral ocellus is removed from compound eye. Forewing with crossveins in anal ficld and few if any crossveins before subcosta, fig. 179 . Ninth ventral abdominal segment with a disklike structure in middle of posterior portion...Atoperla, p. 377

4. Ninth ventral abdominal segment with a disklike structure in middle of posterior portion, fig. $302 \ldots \ldots \ldots \ldots \ldots \ldots \ldots \ldots \ldots \ldots \ldots \ldots \ldots \ldots$

Ninth ventral abdominal segment without a disklike structure in middle of posterior portion....5

5. Fifth dorsal abdominal segment much different from preceding segments, enlarged and prolonged backwards, figs. 206, 207. Tenth dorsal abdominal segment divided in middle and with a pair of genital hooks directed forward, figs. $206,207 \ldots \ldots \ldots \ldots \ldots \ldots \ldots \ldots$

lifth dorsal abdominal segment similar to preceding segments. Tenth dorsal abdominal segment undivided and without genital hooks, fig. $202 \ldots \ldots \ldots \ldots \ldots \ldots$. . . . . . . . . 384

6. Genital hooks on tenth dorsal abdominal segment short, fig. $206 \ldots \ldots \ldots$

.......................................... 412

Genital hooks on tenth dorsal abdominal segment very long, fig. 207.... $\ldots \ldots \ldots \ldots \ldots \ldots \ldots \ldots \ldots \ldots \ldots \ldots \ldots \ldots \ldots \ldots$ Neophasganophora, p. 407

7. Forewings with few or no crossveins in costal cell and several crossveins between first and second anal veins, fig. 180. Compound eyes set forward on side of head about their diameter distant from hind margin of head, fig. 299. Prothorax with sides and a median longitudinal stripe of black or brown; area between yellow................. Perlinella, p. 380

Forewings with crossveins numerous in costal cell and usually no crossveins (rarely one) between anal veins of forewing, fig. 182. Compound eyes set back on side of head near hind margin, fig. 301. Prothorax essentially brown with scattered interrupted lighter markings..... Acroneuria, p. 388

8. Median ocellus lacking or so poorly developed that only lateral ocelli are visible, fig. 300; head therefore appearing to have only two ocelli......9

Median ocellus well developed, fig. 301; head therefore clearly with three ocelli.................................. 10 


\section{PERILIDAE-KEY TO GENERA-CONT'D}

9. I.ateral ocelli close together, much closer to one another than each lateral ocellus is removed from compound eye. Forewing without crossveins in anal field and with many crossveins in costal cell, fig. 181. Eighth ventral abdominal segment as in fig. $245 \ldots \ldots \ldots \ldots$. . . . . . . . . . 381

I.ateral ocelli far apart, at least as far removed from one another as each lateral ocellus is removed from compound eye. Forewing with crossveins in inal field and with few if any crossveins in costal cell, fig. 179. Eighth ventral abdominal segment as in fig. 240 .

Atoperla, p. 377

10. Forewing with few or no crossveins in costal cell and several crossveins between first and second anal veins, fig. $180 \ldots \ldots \ldots \ldots \ldots$ Perlinella, p. 380

Forewing with numerous crossveins in costal cell and usually no crossveins (rarely one) between first and second anal veins, fig. $182 \ldots \ldots \ldots \ldots 11$

11. Costal margin of forewing and base of $\mathrm{Rs}$ and $\mathrm{M}$ yellowish, contrasting with brownish veins. . . . . . . . . . . . . . . . . 12

Costal margin of forewing dark and almost unicolorous with rest of wing . . 13

12. Fighth ventral abdominal segment with a well developed subgenital plate and shaped as in fig. $252 \ldots \ldots \ldots \ldots \ldots \ldots$. . . . . . . . . . . . . 407

Fighth ventral abdominal segment without a well developed subgenital plate and shaped as in fig. $241 \ldots \ldots \ldots \ldots \ldots$ Perlesta, p. 384

13. Forewing with at least one crossvein, usually more, beyond the cord in apical portion of wing in addition to those in subcostal cell, fig. 182. Fighth ventral abdominal segment in some species with a well developed subgenital plate, figs. 243, 247, and in others with the subgenital plate less developed, figs. $244,248 \ldots \ldots \ldots \ldots \ldots \ldots$ Acroneuria, p. 388

Forewing usually with no crossvein (rarely one) beyond the cort in apical portion of wing in addition to those in subcostal cell. Eighth ventral abdominal segment without a well developed subgenital plate, fig. 254.

Togoperla, p. 412

\section{Nymphs}

1. Compound eyes situated far forward on side of head and considerably removed from posterior margin, figs. $303,304 \ldots \ldots \ldots \ldots \ldots \ldots \ldots \ldots \ldots \ldots \ldots \ldots \ldots \ldots$

Compound eyes situated well back on side of head and close to posterior margin,

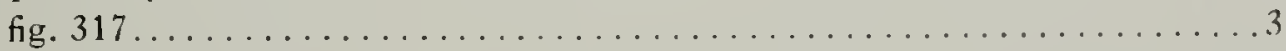

2. Anterior ocellus absent, fig. 303. Nymphs small, not exceeding $12 \mathrm{~mm}$. when full grown. Almost uniform light brown.............. Atoperla, p. 377

Anterior ocellus present in half grown to full grown adults, fig. 304 , but inconspicuous in small nymphs. Nymphs of medium size, up to $20 \mathrm{~mm}$. or more when full grown. Dorsum of head, thorax and alodomen with a discernible pattern of contrasting areas of light and dark brown........

$\ldots \ldots \ldots \ldots \ldots \ldots \ldots \ldots \ldots \ldots \ldots \ldots \ldots$. . . . . . . . . . . . . . . 380

3. Anterior ocellus absent, fig. 305. Distinct transverse occipital ridge back of

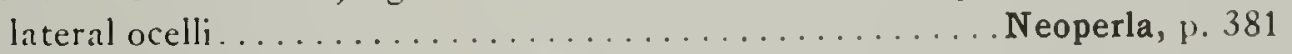

Anterior ocellus present, fig. 307. With or without distinct trinsverse occipital

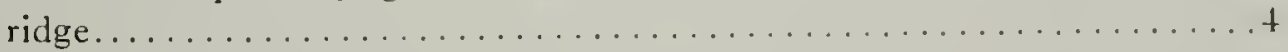

t. Dorsum of abdomen with conspicuous freckle-like spots on a uniform lark background, fig. 307. Transverse occipital ridge present. Anal gills present.

Perlesta, p. 384 


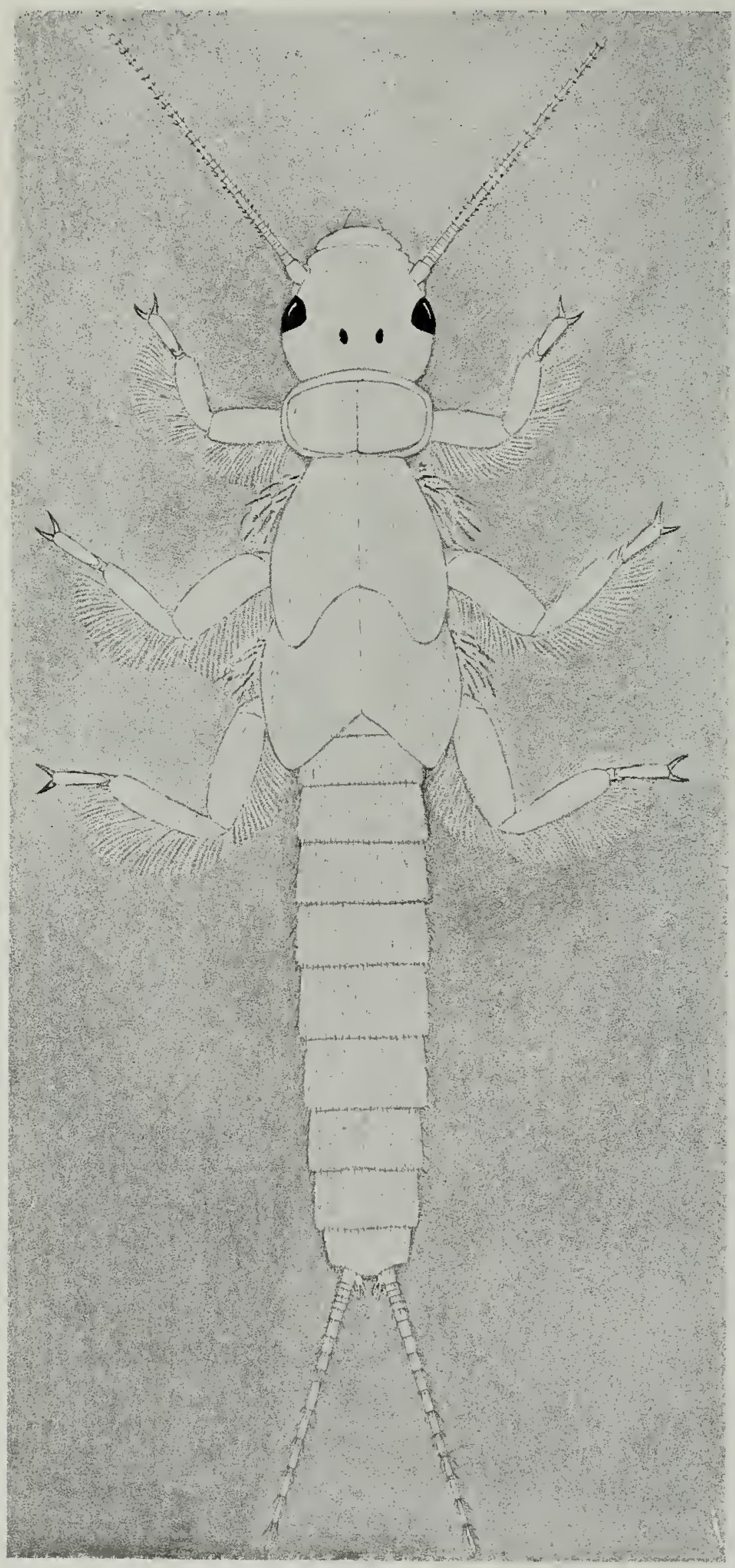

Fig. 303.-Atoperla ephyre, NYMPHAL FEMALE. 
Dorsum of abdomen without freckle-like spots, figs. 316, 318. With of without transverse occipital ridge. With or without anal gills ..........

5. Transverse occipital ridge present, fig. $318 \ldots \ldots \ldots \ldots \ldots \ldots \ldots \ldots$

'Transverse occipital ridge absent, fig. $314 \ldots \ldots \ldots$ Acroneuria in part, p. 388

6. Anal gills present, fig. 318. Dorsum of abdomen with conspicuous alternating light and dark transverse areas or bands........ Neophasganophora, p. 407

Anal gills absent, fig. 314. Dorsum of abdomen without conspicuous alternating light and dark transverse areas or bands.............

7. Dorsum of head, thorax and abdomen nearly uniform light brown. Lateral ocelli ahead of the transverse occipital ridge a distance about equal to the distance between them, fig. $315 \ldots \ldots \ldots \ldots$ Acroneuria in part, p. 388

Dorsum of head and thorax with some light areas distinct from brown background. Lateral ocelli ahead of the transverse occipital ridge a distance about or less than one-half the distance between them, fig. $321 \ldots$...

$\ldots \ldots \ldots \ldots \ldots \ldots \ldots$ Togoperla, p. 412

Atoperla Banks

Banks (1905) p. 56. Genotype Perla producta Walsh= Aloperla ephyre (Newman), original designation; monotypic.

'This genus contains but one small species which shows many characters in common with Perlimella. Claassen (1931) states that "In general appearance Atoperla is similar to Perlinella but is smaller in size and has no anal gilis." This statement about absence of anal gills is probably due to the "old and shriveled specimens" upon which description of the nympli was hased, for fresh specimens show traces of these anal gills.

\section{Atoperla ephyre (Newman)}

Figs. 30, 60, 90, 120, 146, 179, 200, 240, 303.

Perla ephyre Newman (18.39) p. 87. Original description.

Atoperla ephyre Claassen (1931) p. 78. Nymphal description.

'This species was first recorded from Illinois by IValsh (1862) under two names, Perla producta IValsh and Perla fumipenmis IValsh, and later by Claassen (1931) as Atoperla ephyre. The material of IValsh was collected at Rock Island and Chicago and the nymphs recorded by Claassen came from the Fox river, Ottawa, IH. Other references to this species in Illinois are based upon the records of $W$ alsh and add nothing new. In addition to the Illinois records ephyre has been recorded from Arkansas, Kansas, Massachusetts, New York, North Carolina and Pennsylvania, records which indicate that this species is to be expected in most states east of the Rocky mountains.

Types of producta Walsh exist in the collection of the Museum of Comparative Zoology, Cambridge, Mass. The types of fumipennis are 
apparently no longer in existence. I accept the placing by Needham and Claassen (1925) of this latter name in the synonymy of ephyre upon the basis of comparisons of Illinois material with the original description and our intimate knowledge of the Illinois fauna which does not indicate the existence of another species closely allied to ephyre. The characters mentioned by Walsh in his original description fall within the range of the color variation of this species. The Natural History Survey collection contains one female specimen of ephyre from "N. Ill." which was determined as Perla producta Walsh by Walsh.

Judging from records in literature and our field observations this species is never exceedingly abundant. Our Illinois material comes mostly from the Rock river valley and specimens have never been collected in the southern part of the state. It is further evident from our field work that the nymphs frequent medium to large sized, clean streams where the bottom is rocky or gravelly and the current rather fast. The nymphs, judging by their mouthparts and the habits of other genera in this family, are carnivorous. Specimens of the nymphs have not been dissected to establish this point because of the scarcity of our nymphal material. The adults are nocturnal and may be collected at lights, or during the day while they are resting upon structures near the places at which the nymphs leave the water to emerge at night. The seasonal appearance of the adults is such as to place this species as a member of the late spring and early summer fauna.

The nymph has already been adequately described by Claassen (1931) and the adults of both sexes by previous students of this group. The description of the nymph by Claassen (1931), however, is erroneous in regard to the statement about the absence of anal gills. 'The anal gills, although feebly developed, are present and discernible in fresh material. The specimens available to Claassen at the time of his paper were "old and shriveled" and undoubtedly had the anal gills broken off or so withdrawn within the anal segment that they were not visible. Characters developed in the preceding key to the genera bring out the most typical features of this species and genus, and the general appearance is shown by fig. 303 .

Adults.-Galena: June 1, 1933, 1ㅇ. Oakwood: July 6, 1927, $10^{7}, 1 \%$; June 17, 1928, 19; May 24, 1931, $1 \sigma^{7}$. Oregon: July 18, 1921, 2q. Rockford: June 13, 1931, 29. Rock Island: June 3, 1930, $10^{7}$; June 5, 8, 13, 1931, $1 \sigma^{7}, 5 \%$. The adults from Oakwood were collected along the shore of the Salt Fork river where the bed is rocky and the current fast.

Nymphs.-Byron: May 23, 1927. Grand Detour: May 29, 1927. Rockford: June 13, 1931, exuviae. Rock Island: July 7, 1929, exuvia. Sterling-Dixon: June 8, 1927. All nymphal material from the Rock river. 
FRISON: STONEFLIES, OR PLECOPTERA, OF ILLINOIS

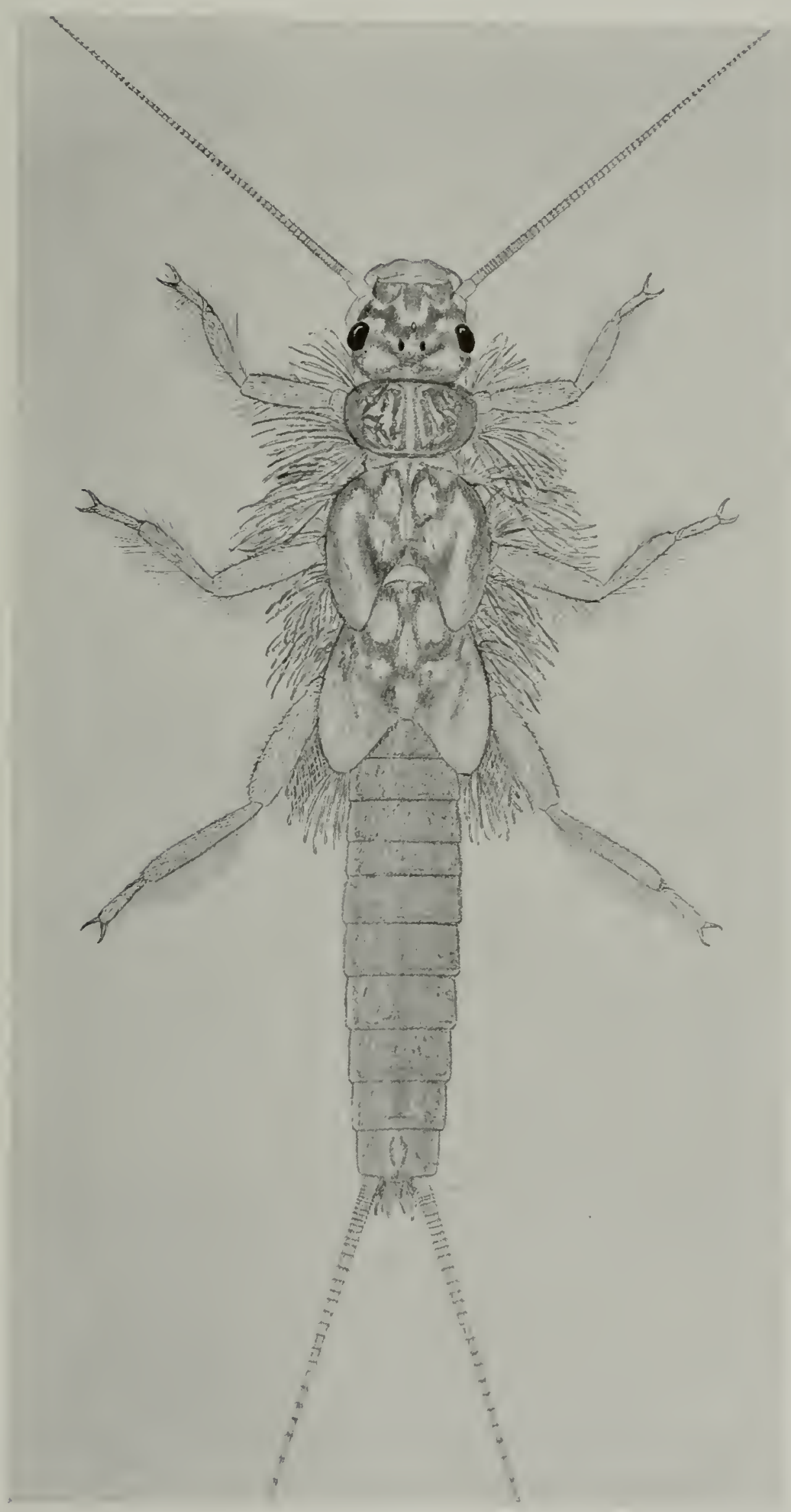

Fig. 304.-Perlinella drymo, XYMPHAL FEMALE. 


\section{Perlinella Banks}

Banks (1900) p. 242. Genotype Perla trivittata Banks = Perlinella drymo (Newman), original designation; monotypic.

Like the closely related genus Atoperla, this genus contains but one known species, drymo (Newman).

\section{Perlinella drymo (Newman)}

Figs. $31,61,91,121,154,180,201,253,265,299,304$.

Perla drymo Newman (1839) p. 86. Original description.

Perlinella drymo Claassen (1931) p. 79. Nymphal description.

Perlinella drymo was first recorded from Rock Island, Ill. by Walsh (1862), under the name of Perla elongata Walsh. It was next recorded from Lake Forest, 11l. by Claassen (1931).

Our field observations and records in literature are rather indicative that this species, although widely distributed, is never very abundant. Needham and Claassen (1925) state that it is distributed "east of the Mississippi river" and records in literature in addition to this state are for Georgia (typic locality), Indiana, Maine, Massachusetts, New Hampshire, New Jersey, New York, North Carolina, Nova Scotia and Tennessee. Our Illinois records are so generally scattered over the state it is safe to predict that future collecting in many other states in the Mississippi drainage area will reveal the presence of this stonefly.

The adults are diurnal and are most frequently caught while resting on bridges, trees or other objects situated near streams which harbor the nymphs. Our records for the adults indicate that they begin to emerge the latter part of March and reach their maximum abundance in April. Thus, on the basis of the seasonal appearance of the adults this species may be classified as a spring form.

Although no types of elongata are known to exist I do not question the placement of elongat $a$ in the synonymy of $d r y m o$ as is done by Needham and Claassen (1925). The description of elongata by Walsh states "Differs from the preceding ( $P$. fumipemis $=A$. ephyre) only in the ocelli being three in number." This statement, together with his other descriptive remarks, clearly indicates the relationship of elongata with eplyyre. which is a condition already noted. Furthermore, $P$. drymo occurs at Rock Island as proved by our collection there of the immature forms.

The nymphs of this species are quite conspicuous because of their long, branched, copious gills, fig. 265. The only place I have found them common was in the Big Grand Pierre river near Golconda on March 7 , 1928. Upon this occasion the nymphs were collected in numbers on a 
gravelly sand bar but slightly covered with water. They were lodged under and between small stones where the current was swift and debris had accumulated. The dissection of one of these nymphs has revealed many head capsules of chironomid nymphs, thus proving that they are carnivorous.

The nymph has been described by Claassen (1931); however the most important morphological features of adults and nymphs are given here in figs. 31, 61, 91, 121, 15t, 201, 253.

Adults.-Alto Pass: Apr. 8, 1928, $10^{7}$. Havana: Apr. 21-23, 1898, $3 \sigma^{7}, 3$ ㅇ. Homer: Apr. 28, 1929, 19. Mahomet: Apr. 23, 1925, $1 \sigma^{7}$. Metropolis: Mar. 28, 1932, 1 ㅇ․

Nymphs.-Golconda (Big Grand Pierre r.): Mar. 7, 1928. Havanal (Illinois r.): Apr. 23, 1898, cxuvine. Herod (trib. of N. Hicks Branch): Dec. 21, 1930. Homer (Salt Fork r.): Apr. 20, 1928. Hutsonville (W'abash r.): Nov. 29, 1928. Rock Island (Rock r.): Apr. 2, 1928. Sterling (Rock r.): May 13, 1925.

\section{Neoperla Needham}

Pseudoperla MacGillivray, in Banks (1892) p. 372. Preoccupied. No genotype given.

Neoperla Needham (1905) p. 108. New name. Genotype Perla occipitalis Pictet $=$ Neoperla clymene $($ Newman), original designation.

According to Klapalek (1923) members of this genus occur in Africa, Asia, the East Indies and North America. 'The same author lists three species, clymene (Newman), occipitalis (Pictet) and fumipemis (Walsh), as belonging to this genus in North America. I agree with Needham and Claassen (1925) in considering occipitalis and clymene to be the same and that fumipennis, as stated elsewhere, belongs in the synonymy of Atoperla ephyre. Therefore, Neoperla in North America is represented by a single species, clymene (N'ewman).

\section{Neoperla clymene (Newman)}

Figs. 32, 62, 92, 122, 164, 181, 203, 245, 261, 300, 305, 306.

Chloroperla clymene Newman (1839) p. 87. Original description.

Neoperla clymene Claassen (1931) p.67. Nymphal description.

Walsh (1862) under the name of "Perla occiptalis? Pict.," first recorded this species from near Rock 1sland, 111 . 'The next 1 llinois records for this species are those of Needham and Claassen (1925). Our 1llinois records are from widely scattered localities and sufficient to indicate that it is liable to be found in every county. 'To date clymeme has been recorded from many of the states east of the Rocky mountains. It enjoys with Perlesta placida (Hagen) the distinction of having its distribution the best known of the North American stoneflies. 


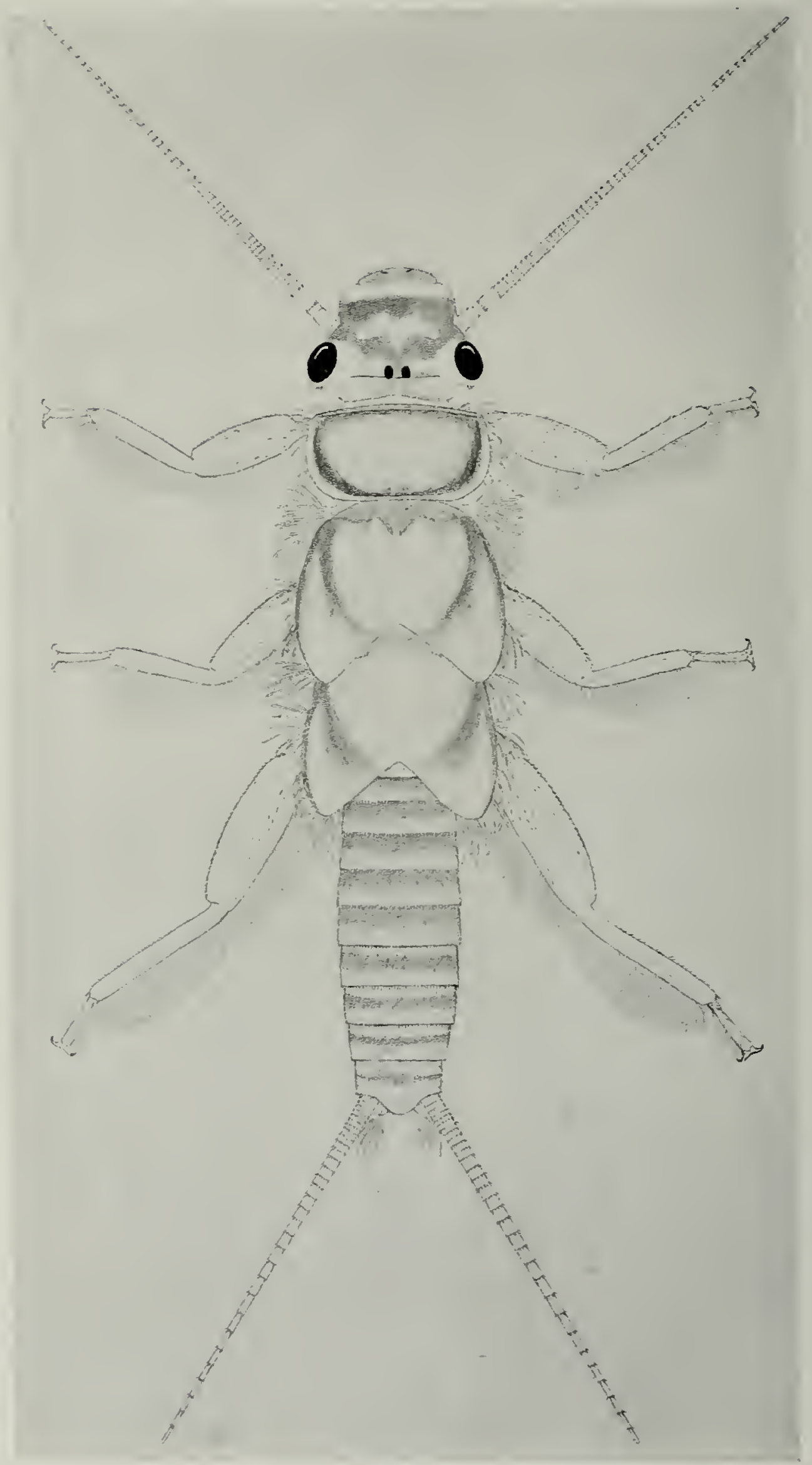

Fig. 305.-Neoperla clymene, NYMPHAL FEMALE, LIGHT FORM. 
FRISON: STONEFLIES, OR PLECOPTERA, OF ILLINOIS

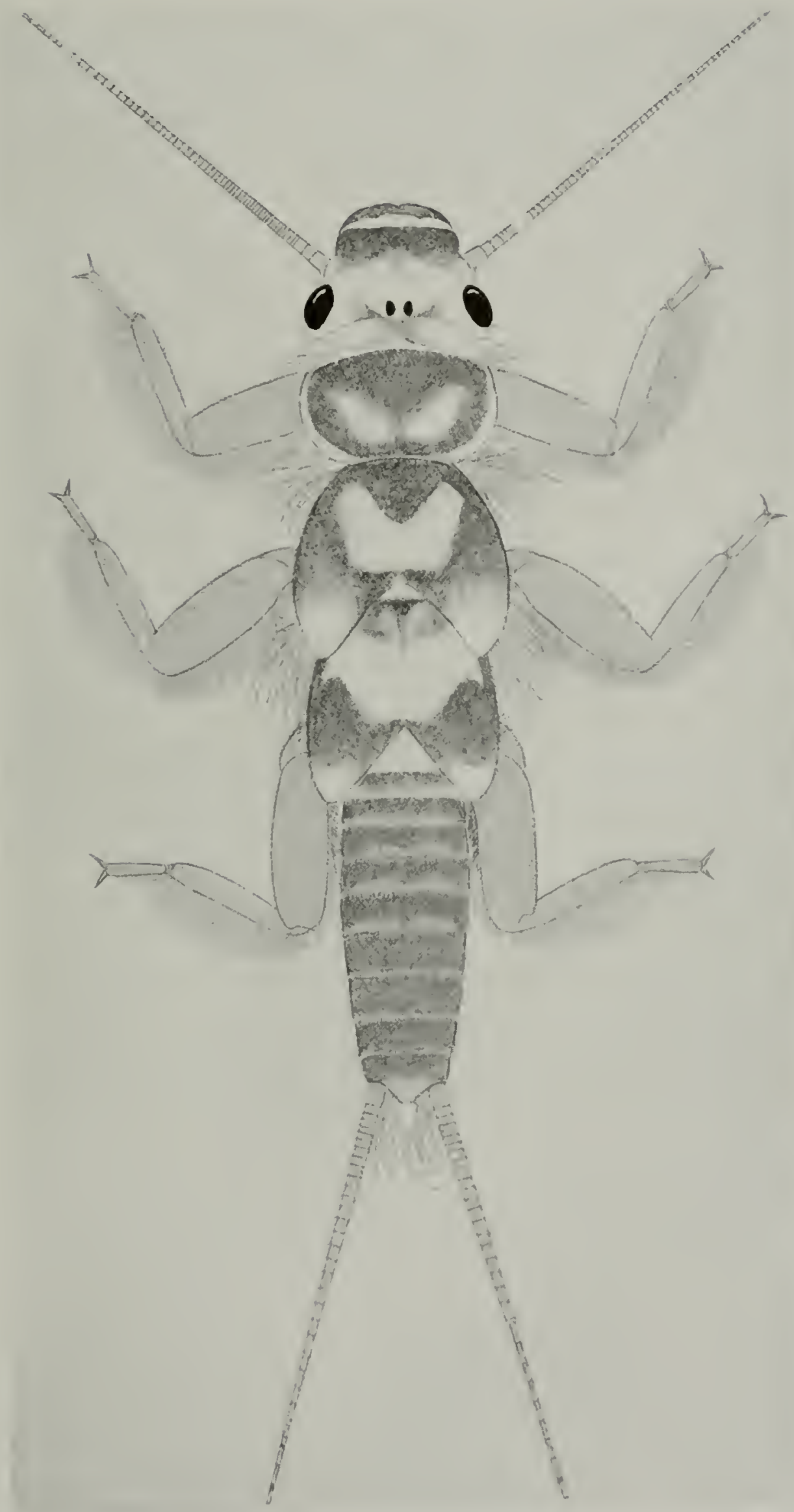

Fig. 306.-Neoperla clymene, NMMPHAL FEMALE, DARK FORM. 
The nymphs, described by Claassen (1931), are readily separated from most species because they possess only two ocelli. Important morphological features of adults are shown in figs. 203, 245, and of the nymphs in figs. $32,62,92,122,164,181,300$.

The alimentary tract of a dissected nymph was found to be full of insect remains, particularly the head capsules of chironomid larvae. This confirms the statement of Claassen (1931) that the nymphs are carnivorous. They live in small as well as large streams and are often found associated with Perlesta placida in vegetative growth on small stones or other objects submerged in rapid parts of the stream.

The adults are nocturnal and may be collected at lights or during the day by sweeping vegetation near streams. They begin to emerge in Illinois about the middle of June, reach their maximum abundance in early July and a few can still be collected in late August-making them a true summer species.

Adults.-Cairo: June 29, 1909, 10 . [Champaign: July 31, 1889, $1 \sigma^{7}$. Elizabethtown: June 20, 1929, 19; June 25, 1932, $1 \sigma^{\circ}$. Herod: June 21, 1929, 19. Homer (park): June 30, 1927, $15 \sigma^{7}, 33$; ; July 11, 1927, $2 \sigma^{7}, 69$. Mt. Carmel: June 10, 11, 1890, $2 \sigma^{7}$; June 30, 1906, $1 \sigma^{7}$, 3ㅇ. Muncie: July 6, 1907, 1\%; July 27, 1927, $1 \sigma^{7}$, 1\%; Aug. 21, 1927, 2क. Oakwood: July 6, 1925, 29; June 18, 1926, $1 \sigma^{\pi}$, 3\%; July 6, 1927, $14 \sigma^{7}$, 22웅 July 8, 1928, 19; June 14, 1930, $2 \sigma^{7}, 19$. Pike: June 25, 1906, 19. Rock Island: June 13, 1931, $1 \sigma^{7}$. Savanna: July 20, 1927, 19. Urbana: 1\%; Aug. 11, 17, 1892, $1 \sigma^{7}, 1$; ; June 17, 1929, $2 \sigma^{7}$.

Nymphs.-Como (Elkhorn cr.): June 18, 1925. Como-Lyndon (Rock r.): Aug. 5, 1924. Goodfield (Mackinaw r.): June 16, 1931, exuviae. Golconda (Ohio r.): Apr. 17, 1930. Herod (N. Hicks Branch): June 21, 1929. Keithsburg (Mississippi r.): June 9, 1932. Lyndon (Rock r.): July 8, 1925. Mt. Carmel (Wabash r.): Apr. 2, 1932. Rock Island (Rock r.): July 6-7, 1929; June 8, 1931.

Reared from nymphs.-Oakwood (Salt Fork r.): June 29, 1929.

Mating pair.-Oakwood: June 22, 1930.

\section{Perlesta Banks}

Banks (1906b) p. 222. Genotype Perla placida Hagen=Perlesta placida (Hagen), original designation.

This genus is now considered as having only one species, placida (Hagen). When originally proposed it was thought to contain more species (cinctipes Banks and virginica Banks) but Needham and Claassen (1925) have concluded that these forms represent a single species. Our observations in Illinois and several adjacent states tend to confirm the conclusion that but one species of Perlesta exists or has been described to date. 
FRISON: STONEFLIES, OR PLECOPTERA, OF ILLINOIS

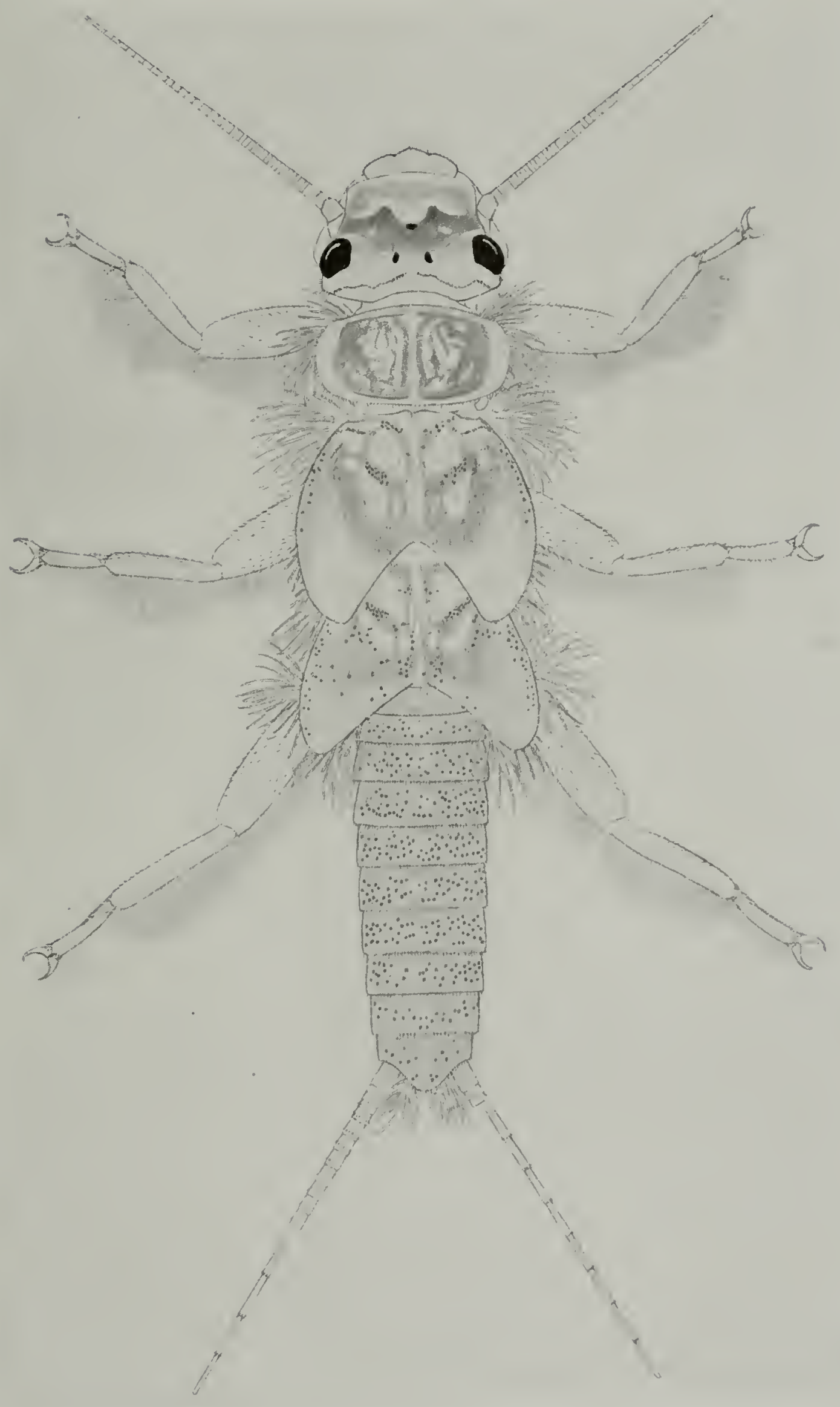

Fig. 307.-Perlesta placida, NIMPHAL MALE. 


\section{Perlesta placida (Hagen)}

Figs. 22, 33, 63, 93, 123, 149, 202, 241, 307, 308.

Perla placida Hagen (1861) p. 28. Original description.

Perlesta placida Claassen (1931) p. 76. Nymphal description.

This species, like Neoperla clymene (Newman), has been recorded from many of the states east of the Rocky mountains and is likely to be found in most of the others. It was first recorded from Illinois, near Rock Island, by Walsh (1862) under the name "Perla decipiens, n. sp." and also as "Chloroperla brunnipennis, n. sp." According to Needham and Claassen (1925), decipiens Walsh and brun-

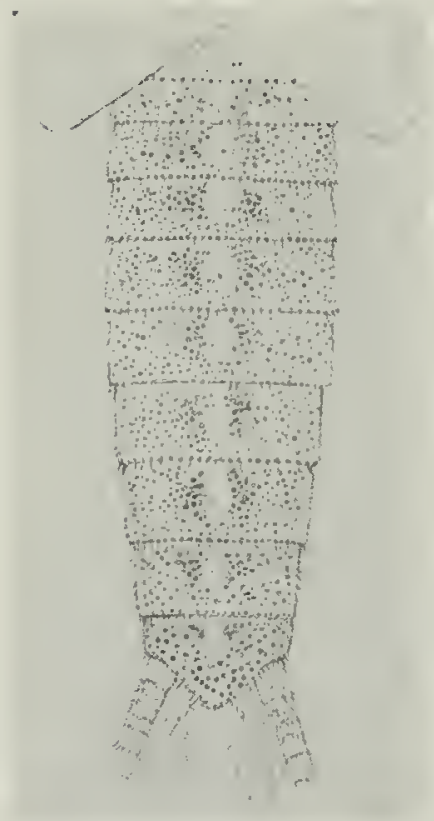

Fig. 308. -DORSALABDOMINAL SEGMENTS OF Perlesta placida, NYMPHAL MALE, EXTREME SPECKLED FORM. nipennis Walsh are synonyms of placida (Hagen) and I am accepting this synonymy. Typic specimens of decipiens and brunnipennis are in the Muscum of Comparative Zoology, Cambridge, Mass. In our collection there is one specimen of placida (Hagen) which has been named as decipiens by Walsh. In addition to the record by $W$ alsh, this species has been recorded from Lake Forest and W. Ottawa, Ill. by Claassen (1931).

The adults are nocturnal and swarm to lights near rivers. During the day the adults rest upon regetation or other objects near streams and may be captured in numbers by sweeping the vegetation with a net. They begin to emerge the latter part of May, reach their maximum abundance during the first weeks of July, and have practically disappeared by the end of August. Their seasonal range is such that they are a true nember of the summer fauna. We have collected the nymphs or adults of placida in most of the counties of Illinois, fig. 6, and they are so abundant in all parts as to be exceeded here only by a few of the winter stoneflies such as Allocapnia rizipara and Taeniopteryx nivalis.

As Claassen (1931) has stated, the nymphs are carnivorous. Upon several occasions 1 have collected nymphs which were then engaged in making a meal of a chironomid nymph. The alimentary tract of a specimen collected at Oregon, I1l. on July 11, 1929 was full of insect remains, particularly of chironomid larvae. The adults have not been observed feeding.

Nymphs may be obtained in numbers from the vegetation growing on small stones in the rapid parts of streams, under stones, or where debris 
lodges. Clean streams and those carrying a heavy load of silt are equally productive. Apparently little preference for stream size is shown either, except that the nymphs do not occur in many small streams that are productive of Allocapnia. This is probably due to the fact that Perlestn nymphs develop at a time of year when many small streams which are inhabited by Allocapnia are very largely dry.

Although records of birds using adult stoneflies as food are rare I feel certain that these insects as a food supply are not altogether overlooked. Upon one occasion near Oregon. Ill. when placida was exceedingly abundant, I saw a robin catch and eat an adult of this stonefly.

The nymphs are easily recognized because of their freckled or spotted appearance, fig. 308. Claassen (1931) has described the nymph, based upon association of nymphs and adults, and my rearings prove this correlation to be correct. The important morphological features of the adults and nymphs are given here in figs. 33, 63, 93, 123,1+9, 202, 241.

Adults.-Algonquin: June 25, 1905, $1 \sigma^{7}$; July 17-24, 1905, 49; July 4, 16, 1906, $1 \sigma^{7}, 1$ \%; July 4, 1907, 1\%; July 21, 1908, 1o; July 9, 1909, 3\%; July 1, 1910, $1 \sigma^{7}$; July 23, 1927, $5 \sigma^{7}, 1$. A . Alton: July 21, 1932, 19. Aurora: July 9, 1925, 99; June 15, 1910, $1 \sigma^{7}, 10$; July 17, 1927, $2 \sigma^{7}, 103$ ㅇ. Beardstown: June 25, 1931, 10. Blue Island: June 6, 1912, $10^{7}, 19$. Byron: July 11, 1927, 19. Champaign: June 9, 14, 1888, $1 \sigma^{7}$, 19; July 2, 1892, 1 q. Charleston: June 7-19, 1931, $1.3 \sigma^{7} .59$. Clay City: June 24, 1909, $3 \sigma^{7}$. Dubois: July 2, 1909, 19. Duncan Mills: July 10, 1896, 19. E. Duhuque: July 21, 1927, $1 \sigma^{7}, 3$ \%. Fffingham: June 20, 1927, 2\%; June 17, 1929, $\sigma^{7} \sigma^{7}$,

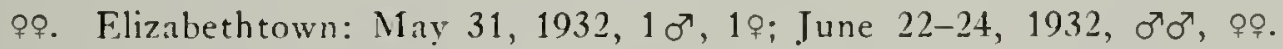
Florence: June 7, 1928, $8 \sigma^{7}, 59$. Fountain Bluff: July 25, 1905, $1 \sigma^{7}$. Frankfort: June 8, 1933, $10^{7}, 1$. . Fulton: July 20, 1927, 29. Grand Tower: Aug. 8, 1891, 1 ơ ; June 30, 1909, 1\%; July 12, 1909, 19; July 2, 1932, 19. Hardin: June 25, 1931, $1 \sigma^{7}$. Havana: May 31, 1894, 1\%; June 21-25, 1898, $2 \sigma^{7}, 2 \%$; June 19, 1909, 1; Aug. 22, 1910, 19. Homer: June 17, 1917, $1 \sigma^{\text {st }}$; July 19,

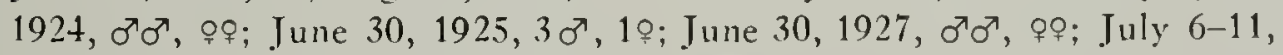
1927, $\sigma^{7} \sigma^{7}$, July 25, 1931, 19. Kampsville: June 25, 19.31, $2 \sigma^{7}, 1$. . Kankakee: June 29,1928, $1 \sigma^{7}, 1$; ; June 12, 1931, $1 \sigma^{7}$; June 5, 1932, $1 \sigma^{7}$. Makanda: May 21, 1932, $10^{7}, 1$ \%. McHenry: June 30, 1931, $2 \sigma^{7}, 3$ 9. Momence: June 4,

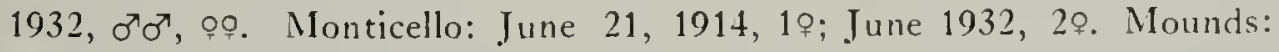
May 25, 1932, 1․ Muncie: June 13, 1905, 19; June 23, 1912, 29; June 10, 1919, 19; June 8, 1927, o7 $\sigma^{7}$, fo ; July 27, 1927, 49; Aug. 21, 1927, $10^{7}$; July 9, 1931, 19. New Milford: July 21, 1931, $1 \sigma^{7}, 19$. Oakwood: June 6, 1925, $1 \sigma^{7}, 29$; Nay 30, 1926, 19: June 9, 18, 1926, $19 \sigma^{7}, 139$ : June 2, $1927,1 \sigma^{7}, 10 ;$ July $6,10,1927,156 \sigma^{7}, 126$; June 17, 1928, $11 \sigma^{7}, 23$; July 28, 1929, 2क; May 24, 1930, $1 \sigma^{7}$ : June 14, 1930, $3 \sigma^{7}, 8$. Odin: June 2, 1909, $10^{7}$. Oregon: July 9, 1925, $2 \sigma^{7}, 10$; July 18, 1927, o o or $^{7}$ 우; July 18-19, 1927, $900^{7}$, 105\%; May 21-June 15, 1928, $3 \sigma^{7}$, 69; June 27-28, 1928, $40^{7}$, 29: July 11, 1929, $0^{7} \sigma^{7}$, ㅇ; June 1930, $60^{7}, 169$; June 13, 1931, 19; July 3, 19.32, 19. Ottawa: June 12, 1901, 3 o $^{7}, 1$. Ozark: May 18, 1932, ㅇํ. Pike: June 25, 1906, 1 ㄱ. Prophetstown: July 19, 1927, 
$4 \sigma^{7}, 1$ 19. Pulaski: June 10, 1907, 19; May 11, 1932, $\sigma^{7} \sigma^{7}$, 우. Putnam: July 12, 1933, $1 \sigma^{7}$. Rockford: July 18, 1927, $72 \sigma^{7}, 87$; ; June 13, 1931, $40^{7}, 4$ 우. Rock Island: June 23, 1928, 3; July 7, 1929, 1우 June 24, 1931, 2ㅇ. Rockton: July 2, 1931, $\sigma^{7} \sigma^{7}$, 우요. Savanna: June 22, 1892, $2 \sigma^{7}$, 4; July 19-26, 1892, $17 \sigma^{7}$, 15우 J July 20, 1927, ơ o7, 웅. S. Beloit: July 1, 1931, 1ㅇ. Sheldon: June 4, 1932, $1 \sigma^{\top}$. Springfield: June 2, 1885, 2o; June 23-24, 1885, 1․ St. Joseph: May 26, 1912, $1 \sigma^{7}$; June 25, 1927, $1 \sigma^{7}$. Thebes: June 29, 1909,1 . Ur Urana: June 25, 1889, $2 \sigma^{7}$; June 24, 1891, $1 \sigma^{7}$; June 27, 1892, $2 \sigma^{7}$; July 3, 9, 18, 1892, $2 \sigma^{7}$, 2o; Aug. 3, 1892, 1; May 24, 1899, 1\%; July 5, 1907, $1 \sigma^{7}, 1$ 우; June 17, 1929, $1 \sigma^{7}, 1$; ; June 9, 1933, б7 $\sigma^{7}$, 우. Warsaw: June 10, 1932, $1 \sigma^{7}$. White Heath: June 18, 1906, 2क; June 24, 1916, $1 \sigma^{7}$. Wilmington: June 12, 1931, o $\sigma^{7} \sigma^{7}$, 우. Zeigler: June 15, 1929, $1 \sigma^{7}, 1$ ㅇ.

Nymphs.-Allerton (trib. of Salt Fork r.): June 17, 1929. Altamont (Second cr.): Apr. 11, 1932. Brockton (Catfish cr.): Mar. 28, 1932. Byron (Rock r.): May 23, July 8, 12, 1927. Castle Rock (Rock r.): May 26, 1929. Dixon (Rock r.): May 2, 12, 22, 1925; June 17, 21-23, 1927. Elgin (Fox r.): June 18, 1931, exuviae. Golconda (Ohio r.): May 13, 1932. Goodfield (Mackinaw r.): June 16, 1931. Grafton (Mississippi r.): May 20, 1932. Grand Detour (Rock r.): July 27, 1927. Hill (trib. of Bishop cr.): Apr. 4, 1932. Homer (Salt Fork r.): May 12, 1928; June 17, 1930. Kankakee (Kankakee r.): June 12, 1931. Keithsburg (Mississippi r.): June 15, 1931, exuviae; 1932. Loch Haven (Piaso cr.): Apr. 10, 1932. Muncie (Stony cr.): June 8, 1927. Oakwood (Middle Fork of Vermillion r., Salt Fork r.): June 6, 1925; June 2, 1927; May 21, 1928; June 29, 1929; May 1, 1932; Apr. 12, 1933. Oliver (trib. of Big cr.): May 11, 1933. Oregon (Rock r.): June 29, July 3-6, 1927; July 11, 1929; May 15, 1930; June 18, 1931. Ottawa (Illinois r.): June 21, 1901, exuviae. Rockford (Rock r.): July 15, 1927. Rock Island (Rock r.): July 7, 1929; June 3, 1930; June 8, 13, 24, 1931. Shelbyville (Kaskaskia r.): Apr. 9, 1932. Starved Rock (Illinois r.): June 13, 1901, exuviae. Sterling (Rock r.): May 4, 15, June 15, 1925; June 13, 1927. Sterling-Dixon (Rock r.): May 21, 1925. St. Elmo (S. Fork cr.): Apr. 11, 1932. Vandalia (Kaskaskia r.): Apr. 10, 1932. Vienna (Rocky Branch): Mar. 27, 1932. Watson (trib. of Little Salt cr.): Apr. 7, 23, 1932. White Heath (Sangamon r.): May 13, 1928. Wilmington (Kankakee r.): June 12, 1931. Yorkville (Fox r.): June 18, 1931.

Reared from nymphs.--Oaḱwood: June 29, 1929.

Mating pairs.--Homer (park): June 30, July 11, 1927. Momence: June 4, 1932. Rockford: July 18, 1927.

\section{Acroneuria Pictet}

Pictet (1841) p. 144. Genotype Perla arenosa Pictet=Acroneuria arenosa (Pictet), or'ginal designation.

The genus Acronouria was originally proposed by Pictet as a subgenus of Perla, and aremsa from North America cited as its type. Abnormis (Newman) was included in the subgenus Acroneuria at the time of its erection but it is evident from the statements of Pictet that he knew abnormis only from Newman's description and not from actual specimens.

Although the adults of Acroneuria are very large for stoneflies and 
a few specimens are found in most general collections, the various species have been badly confused due to lack of proper association of males and females, and actual scarcity of good series of specimens. Klapalek's (1909a) revision of Acroneuria is helpful but quite inadequate due to these limitations. Needham and Classen (1925) have contributed the best analysis of our Acroneuria fauna and I an following their nomenclature, synonyny and specific concepts except as noted under the various species discussed.

Since A. arenosa (Pictet) in the sense of Needham and Claassen las not been found in Illinois it may be well to say a word here concerning this species. Needham and Claassen (1922, 1925) have associated the name of arenosa with an eastern species which is peculiar in having the "second anal vein of the hind wing many (about 12) branched." The original description of arenosa mentions no such peculiarity and Pictet's fig. 2 on plate 10 of his justly celebrated work does not show such venation-at least I cannot interpret these drawings as showing a many branched second anal vein comparable to that found in the species we are now calling arenosa. A future study of the types, if they are in existence, may show that the North American species going by the name of arenosa does so improperly, and that arenosa should replace the name now in use for some other eastern species of Acroneuria.

Needham and Classen recognize 17 species of Acroneuria from North America, five of which are known only from the western parts of the United States or provinces of Canada. Our studies of the Illinois fauna indicate that one of these, erolufa Klapalek, is a synonym of arida (Hagen), leaving a total of 16 species. Of these we have reared and definitely associated the sexes of four species, arida, internata, abnormis and ruralis, and located the cast skins of possibly two others. The questionable species ( $s p . a$ and $s p . b$ in key to nymphs, p. 391) are represented by cast skins only, one form $(s p . b)$ by one cast skin and the other form (sp. a) by four cast skins. Lack of material of the forms just mentioned is a good indication of their extreme rarity in Illinois, in view of our very thorough collecting, both in season and area.

The adults of all the Illinois species are nocturnal and are attracted to lights near the rivers where the nymphs develop. During the day the adults rest in any place where they can find shelter, particularly from direct sunlight. They have not been observed to feed and their mouthparts indicate they are incapable of utilizing solid food. All of the species are true members of the early summer fauna.

The nymphs as a result of their large size, often conspicuous markings and long developmental period are collected more frequently by the general student of aquatic life than most other genera of stonefly nymphs. 
Unlike Allocapnia the nymphs are readily separated to species and even the cast skins are usually sufficient for specific identification. Examination of the alimentary tracts of nymphs of all the reared Illinois species reveals that they are carnivorous. Like many other species the nymphs are not so partial to the association or a cover of stones as the literature or their name might indicate and at times certain species can be obtained most easily in accumulations of leafy debris lodged in or near the edges of the streams they inhabit. The long life cycle of the nymphs, two or perhaps in some cases three years, necessitates the restriction of the nymphs to medium or large rivers which are not likely to go dry in the summer months. An abundant and more or less constant invertebrate animal food supply is undoubtedly another factor eliminating large Acroneuria nymphs from the very small streams which are suitable for development of Allocapnia, Leuctra, Nemoura, Capnia, certain species of Isoperla and others.

\section{KEY TO SPECIES}

\section{Adults}

1. Ninth ventral abdominal segment greatly produced posteriorly and recurved upward so that tenth segment is mostly or entirely concealed; with a raised disk in middle of posterior portion, fig. 302. Eighth ventral segment about similar to preceding segments and never produced over ninth. Subanal lobes well developed and recurved over dorsal surface of tenth dorsal

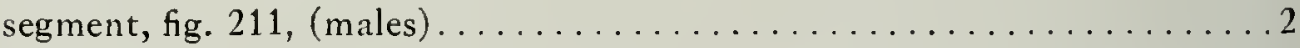

Ninth ventral abdominal segment not greatly enlarged and not covering tenth segment; without a raised disk, fig. 247. Eighth ventral segment often with posterior margin produced over ninth segment, fig. 250, or with a hump anterior to posterior margin, fig. 244. Subanal lobes not well developed and not recurved over dorsal surface of tenth dorsal segment

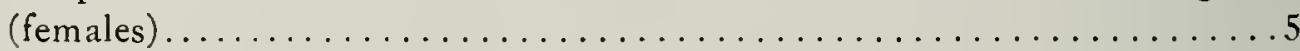

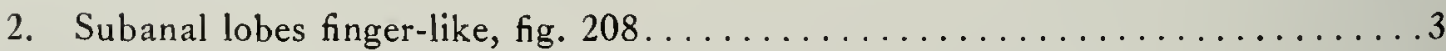

Subanal lobes broad and somewhat triangular, fig. $211 \ldots \ldots \ldots \ldots \ldots$

3. Disk on ninth ventral abdominal segment small, much smaller than diameter of compound eye..................................... p. 397

Disk on ninth ventral abdominal segment larger, but slightly smaller than diameter of compound eye.................... internata, p. 401

4. Numerous short spinelike setae on ninth and tenth dorsal abdominal segments, fig. $210 \ldots \ldots \ldots \ldots \ldots \ldots \ldots \ldots \ldots \ldots \ldots$. . . . . . . . . . . . . 391

No short spinelike setae on ninth or tenth dorsal abdominal segments, fig. 211. A declivitous basin-like area on middle posterior part of tenth segment, fig. $211 \ldots \ldots \ldots \ldots \ldots \ldots \ldots \ldots \ldots \ldots \ldots \ldots \ldots \ldots \ldots \ldots$ ruralis, p. 403

5. Eighth ventral abdominal segment (subgenital plate) but little produced over ninth segment, fig. $248 \ldots \ldots \ldots \ldots \ldots \ldots \ldots \ldots \ldots$. . . . . . . . . . . . . . . 391

Eighth ventral abdominal segment (subgenital plate) considerably produced

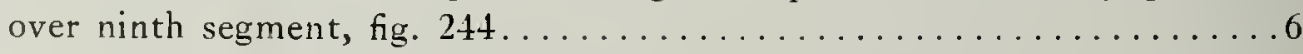

6. With a raised disk or hump on posterior portion of eighth ventral abdominal segment, fig. $244 \ldots \ldots \ldots \ldots \ldots \ldots \ldots \ldots \ldots \ldots \ldots$ ruralis, p. 403 


\section{ACRONEURIA-KEY TO SPECIES-CONT'D}

Without a raised disk or hump on eighth ventral abdominal segment, figs. 246,247 .

7. Eighth ventral abdominal segment much produced over ninth segment, figs.

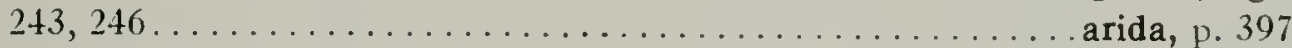

Fighth ventral abdominal segment less produced over ninth segment and with a thaplike process at each lateral posterior corner, fig. 247 . . internata, p. 401

\section{Nymphs}

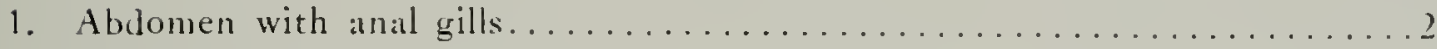

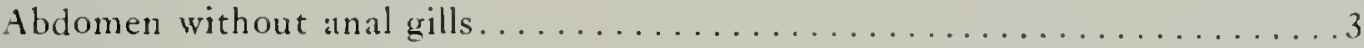

2. Dorsal segments of abdomen with alternating light and dark transverse bands. Head with a continuous light, often IV shaped, transverse band anterior to median ocellus, fig. $313 \ldots \ldots \ldots \ldots \ldots \ldots \ldots \ldots \ldots \ldots \ldots \ldots \ldots \ldots \ldots \ldots$ rida, p. 397

Dorsal segments of abdomen entirely dark. Head with five light spots on a dark background anterior to epicranial arms, fig. $316 \ldots \ldots$. sp. a, p. 405

3. Head unicolorous, brown. An occipital ridge present on posterior margin of

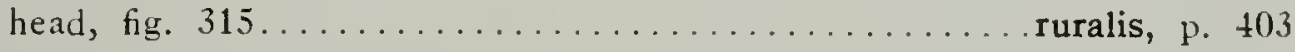

Head with light spots or an irregular, sometimes W shaped, band contrasting with dark background. No occipital ridge present.............t

4. Dorsal segments of abdomen entirely dark, fig. 309 . . . . . . . . abnormis, p. 391

Dorsal segments of abdomen with transverse light bands or areas alternating

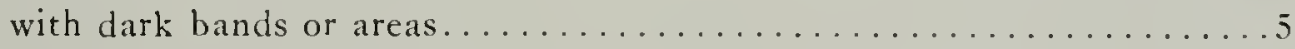

5. Head anterior to epicranial arms with five light spots contrasting with dark background. Light areas on dorsum of abdominal segments transverse, bandlike and parallel with dark bands, fig. $314 \ldots \ldots \ldots$. . . . .

Head anterior to anterior ocellus with a light transverse, more or less W shaped, band. Light area on dorsum of abdominal segments tending to divide dark bands along meson into right and left detached dark areas, fig.

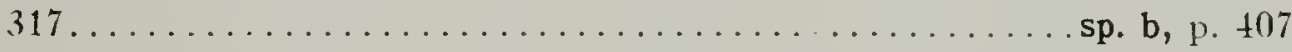

\section{Acroneuria abnormis (Newman)}

Figs. 3, 23, 34, 64, 94, 124, 151, 182, 210, 248, 301, 309, 310, 311, 312.

\section{Perla abnormis Newman (1838) p. 177. Original description.}

Acronewia abnormis Clatassen (1931) p. 82. Nymphal description.

I am convinced from a study of an extensive series of adults and nymphs of Acroneuria from various localities in Illinois that if pemmsyiranica (Rambur) is a valid species it does not occur in Illinois, and that our commonest species shouid be associated with the name aburmis (Newman). Our state material has also led me to believe that abnormis and pemmsylanica are synonymous, the former name having priority."

\footnotetext{
" Examination of eastorn stonefles in the collections uf the Fuitul status National

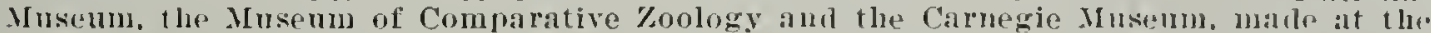
tinn this bajer was in final proof, demonstrated the existence of an wistepu silucies of Ironfurie, which in part, corleetly or incoreretly from the nomenclaturial stand-

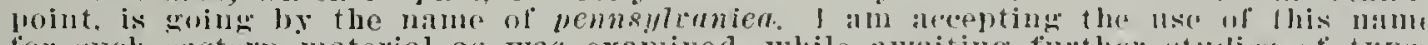

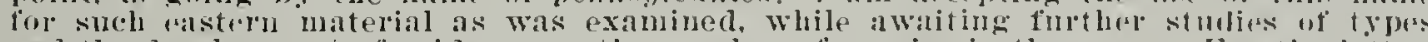
ind the drvelopment of evidence on the number of specios in the gonls. Fur lhe latiol. a derision as to the number of distinctive nymuls is rssential.
} 


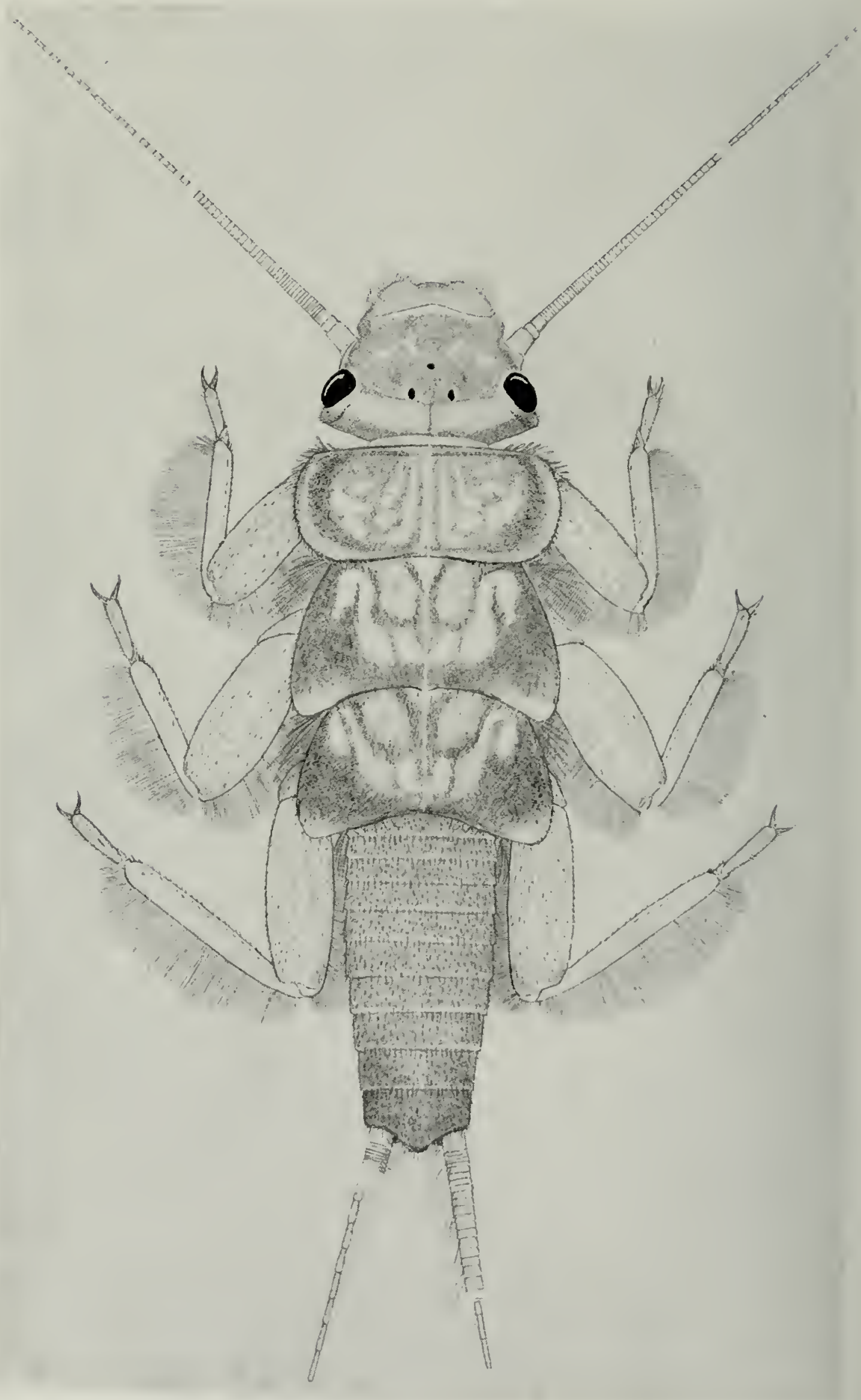

Fig. 309.--Acroneuria abnormis, NYMPHAL FEMALE. 
My reasons for this belief are as follows: 1.-Existing distributional records assigned to these two names indicate they have the same genera! range. This parallelism in range is not in itself proof of likeness, but coupled with other facts it tends to show the existence of only a single species. 2.-The number of crossveins in the area beyond the cord in the forewing is subject to great variation. At present this character is practically the basis on which abnormis and pennsylzanica are separated in the keys in literature. Reared adults, mating pairs and other material, which I am certain represent but one species, can be keyed to both of thes: names in the keys of Needham and Claassen (1922, 1925). In figs. 310, 311 are shown the forewings of a male and female collected while in coitu; this female will key to abnormis and the male to penusyli'anica. A tabulation made of the crossveins beyond the cord in the forewings of numerous males and females from Illinois shows that the crossveins are rarely the same number in the right or left wings of the same individual, the range in variation runs from two to $1 t$, and the males and females are equally variable. 3.- The nymphs in Illinois producing adults of the abnormis or the pennsyl-

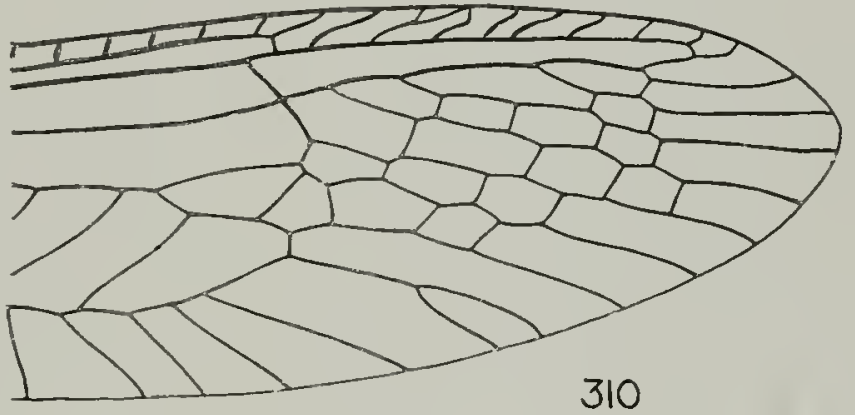

310

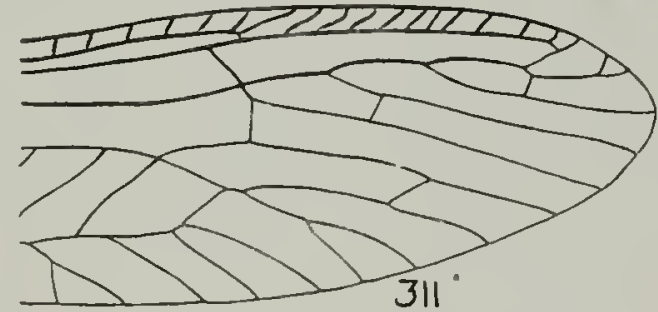

Figs. 310-311. - TIPS OF RIGHT FOREWINGS OF Acroneuria abnormis. Note variation in number of crossveins in wings of same species. 310.Female. 311.--Male. Drawn from the wings of a mating pair.

zanica type are similar, agree

with nymphs determined by Claassen as abnormis, fit very well the essential characters of his excellent description of it and run in his key of nympls to this species. Studies of nymphs to date have failed to reveal a distinctive nymph which can be definitely assigned to pennsylranica. t.-I believe that too much emphasis or the wrong inference has been placed unon Klapalek's (1909a) recognition of abnormis and pennsylzanica as separate species. Although Klapalek calls his 1909 a paper a revisional study it is hased upon a serious paucity of material and it has many limitations. According to Klapalek the penusylzanica Rambur is a different species and his poor illustration of the type female attempts to portray in part this difference. Hagen (1861) placed penusylzanica in the synonymy of alnormis and his use of an exclamation point behind the author's name 
of each species indicates, as stated in his introductory remarks, that he studied the types of both. In addition Hagen described a new species ruralis and pointed out the most essential recognition characters for the female of this species - the produced subgenital plate and a hump or raised callosity (transverse tubercle) on this plate before its apex. If the type of pennsylanica Rambur had such a structure it seems queer that it would be overlooked by Hagen. Klapalek did not redescribe or place in synonymy iuralis (Hagen) or its synonym rupinsulensis, states that he did not know these species, and therefore might have found the type of pennsylvanica to have a produced subgenital plate, and recognized it as a valid species equivalent to what we are calling ruralis. Failure to mention the peculiar hump on the subgenital plate however tends to indicate pennsylianica Rambur is not the same as ruralis, in keeping with Hagen's view.

What, then, is pennsylianica Rambur? It is my belief that it is a female of abnormis which has so dried that the prolongation and shape of the subgenital plate is not normal. It should be stated too that there is some variation in the degree of prolongation of the subgenital plate of the females of what I an calling abnormis and which $I$ am sure are one species. Klapalek even states that the subgenital plate of the type is damaged, which might not have been the case when Hagen examined it. If the type is ever found to show a transverse callosity or tubercle before the apex of the subgenital plate, the name pennsylvanica would have priority over ruralis. Regardless of the status of pennsylvanica, all our Illinois material of the species under discussion must be associated with the oldest name-abnormis.

Hagen (1861) first recorded abnormis from "South Illinois (Robt. Kennicott)," followed by Walsh (1862, 1863) from near Rock Island, Ill. Garman (1888) mentions the nymph as "Plecoptera, nymph" from Willow slough near Quincy, Ill. The existence of Garman's nymphal specimens in our collection makes possible this placement of his reference. In spite of its abundance I know of no other records for its occurrence in this state. Our collecting of the past few years shows abnormis to be the most common of our Acroneuria fauna and present in all parts of the state. According to the literature it also occurs in Canada, the District of Columbia, Maryland, New York, North Carolina, Pennsylvania, Tennessee and West Virginia. Future collecting will undoubtedly reveal its presence in most states east of the Rocky mountains.

All of our adults have been collected or reared during May and June and the maximum abundance of the adults is about the middle of the latter month. They are therefore members of the late spring and early summer fauna. Like the other Illinois Acroneuria, the adults are nocturnal and are attracted to lights near large rivers. 
The nymphs are restricted to the medium or large rivers. 'They are carnivorous, as evidenced by insect remains in the alimentary tract of a nymph collected in the Rock river at Rock Island, IH., April 2, 1928. Our association of nymphs with adults is based upon many rearings of both sexes.

Distinctive features of the adults are shown in figs. 210,248, 310, 311. The nymph has been well characterized by Claassen (1931). Its important morphological features are given in figs. $3 t, 6+, 9 t$, $12+, 151$; the color pattern as shown in fig. 309 is subject to variation in the relative amounts of light or dark areas, fig. 312.

Adults.-Dixon: May 31, 1914, 1o. Elizalhethtown: May 28-30, 1928, $3 \sigma^{7}$. Grand Tower: June 2, 1913, 10'. Homer (park): June 30, 1927, 19. Kankakee: June 12, 1931, $3 \sigma^{7}, 29$. Metropolis: June 1, $4,1928,3 \sigma^{7}, 1$ ㅇ. Oregon: June 20, 1917, 18 ; May 2I-June 15, 1928, $10^{7}, 2$; May 1929, 1; June 1930, 3ㅇ․ Pike: May 26, 1906, $9 \sigma^{7}, 11$ \%. Rockford: June 1.3, 1931: 10. Rock Island: May 21, 1928, 3o; June 3, 1930, $2 \sigma^{7}, 12 \%$; June 8, 13, 24, 1931, $1 \sigma^{7}$, 79. Savanna: June 11, 1917, I $0^{7}$. Shawneetown: June 21, 1927, 19. Sterling: May 21, 1925, 1 .. Urbana: June 8, 1905, $10^{7}$.

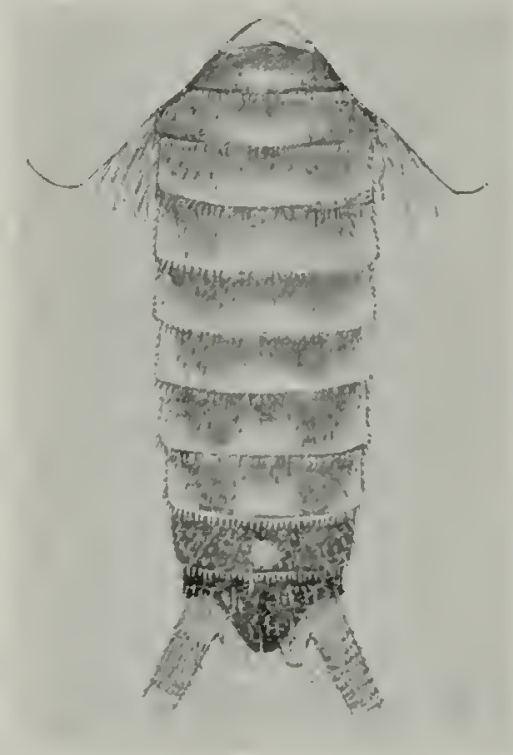

Fig. 312.-DORSAL ABDOMINAL SEgMeNTS OF Acroneuria abnormis, NYMPH, LIGHT FORM.

Nymphs.-Byron (Rock r.): July 8, 11, 1927. Charleston (Embarrass r.): June 8, 1931, exuviae. Dixon (Rock r.): Apr. 3, 1928. Dixon-Oregon (Rock r.): July 27, 1927. Duncan Mills (Spoon r.): Sept. 2, 1910. Fulton (Mississippi r.): Sept. 11, 1932. Grafton (Illinois r.): Aug. 30, 1913; Sept. 8, 1932. Kampsville (Illinois r.): Aug. 22, 1913. Kankakee (Kankakee r.): June 12, 1931. Keithsburg (Mississippi r.): June 15, 1931; June 8, 1932, exuviae. Meredosia (Illinois r.): Sept. 5, 1913. Oregon (Rock r.): Apr. 3, 1928; July 11, 1929. Pike (Illinois r.): May 26, 1906, exuviae. Prophetstown (Rock r.): July 29, 1925. Quincy (Willow slough, Mississippi r.): Aug. 7, 1888. Rockford (Rock r.): May 4, 1926; June 13, 1931. Rock Island (Rock r.): Apr. 2, 1928; Apr. 10, 1931; Apr. 27, May 9, 1932; May 11, 1934. Savanna (Mississippi r.): Sept. 11, 1932. Wilmington (Kankakee r.): Apr. 28, 1931.

Reared from nymphs.-Rockford (Rock r.): June 12, 13, 1931. Rock Island (Rock r.): June 3, 1930; June 8, 13, 1931.

Mating pairs.-Rock ford: June 13, 1931. Rock Island: June 3, 1930; June 13, 1931.

\section{Acroneuria arida (Hagen)}

Figs. 35, 65, 95, 125, 155, 208, 242, 243, 246, 250, 313.

Perla arida Hagen (186I) p. 18. Original description.

Acroneuria evoluta Klapalek (1909a) P. 245. New synonymy (o). 


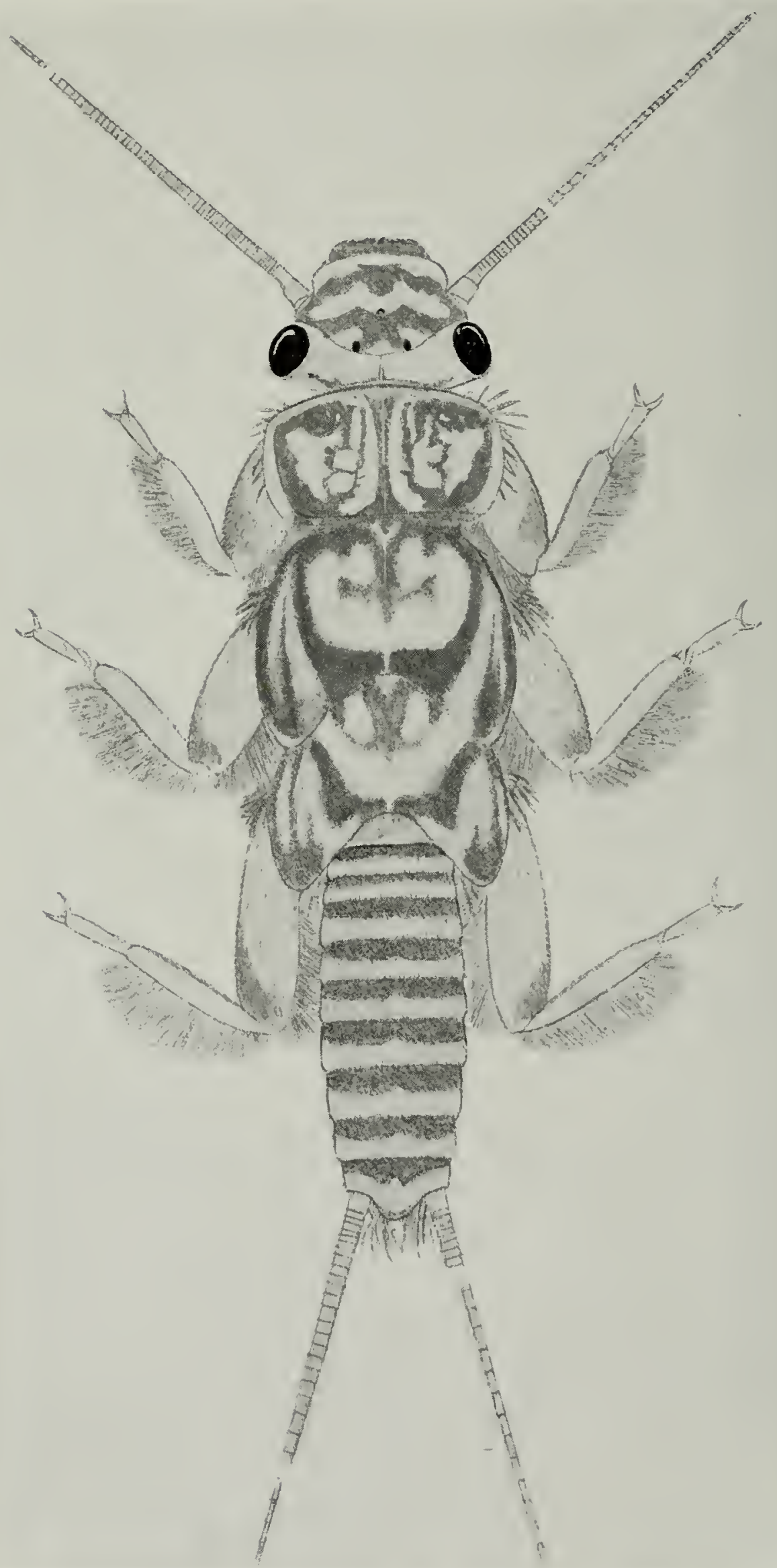

Fig. 313.-Acroneuria aridn, NYMPHAL FEMALE. 
This species has been previously recorded from Galena, 11l. by Needham and Claassen (1925). Arida is also listed as occurring in Arkansas, the District of Columbia, Indiana, Kansas, Missouri, New York, Ohio, Tennessee and Texas. This scattering indicates that it is likely to be found in most of the states east of the Rocky mountains.

Study of a large series of specimens from Illinois, specinens from other states which are unnamed or were previously named as eioluta, and the original descriptions have convinced me that arida (Hagen) and evoluta Klapalek are identical and not distinct species as considered by Needham and Claassen (1925). The shape of the eighth ventral abdominal segment is quite distinctive although subject to some variation, figs. $2+2,243,246,250$. I am certain that my extensive Illinois material named as arida and showing in some instances variations in the shape of the subgenital plate constitutes a single species because of reared material, mating pairs, similar nymphs and numerous bits of biological evidence. When Klapalek (1909a) described evoluta he was not aware of the essential characters of arida as is proved by his placing of arida as a synonym of arenosa, the subgenital plate of which according to his own illustration (fig. 7) is different from that he gives for ezoluta (fig. 9-typical of what is here called arida).

Recently there has appeared an article by Clark (1934) which describes in considerable detail the adult of this species under the name of eroluta. I have studied a specimen from Put-in-Bay, Ohio, kindly sent to me by Professor C. H. Kennedy, which is similar to the adults studied by Clark. The study of this specimen confirms my previous belief based upon the article itself that Clark failed to record the presence of the remnant or vestigial thoracic gills in his description and omitted them in his drawings. 'Their omission would indicate that the specimens studied by Clark did not belong to the Perlidae as I now limit this family. This is not the case.

As suggested above with reference to the genus I doubt whether the name arenosa Pictet has been correctly associated with the proper species. Irenosa might have been the species here called arida (ez'oluta) or one or two other species from eastern North America. The nomenclature of Needham and Claassen however will he followed except for the synonymy indicated, until there is evidence to the contrary based upon typic material.

Specimens of arida have been collected in most sections of Illinois except from the northwestern counties. It also happens that most of our material comes from the eastern side of the state. I an inclined to believe that the difference in number of records from the eastern and western sides of the state is mostly the result of unbalanced collecting, but the com- 
plete absence to date of specimens from northwestern Illinois cannot be thus dismissed. The Rock river is located in northwestern Illinois and our collecting in this stream has over a period of years been qualitatively and quantitatively as thorough as in most other parts of the state.

The adults begin to emerge around the first of June and in central llinois reach their maximum abundance about the last of this month. 'They must therefore be considered a member of the early summer fauna. Although the nocturnal adults are usually not abundant, I have collected more than 100 in one evening at lights near a dam on the Salt Fork river near Homer. Mating takes place at night and often while the adults are concentrated near lights.

Heretofore the nymph of arida has not been definitely associated with its adult. Claassen (1931) mentions in the introduction of his book that Garman's (1912) fig. 47 "represents Acroneuria, probably arida Hag." In his key to nymphs of Acroneuria Claassen includes arida and also presents one drawing and one photograph which he labels as arida. A description such as is given for other species of Acroneuria is not given and localities are not associated with his figures. A comparison of his two illustrations reveals a possibility of their representing one, possibly two, species neither of which corresponds to the nymphs which I have reared and hence definitely associated with arida (eroluta). I believe however that the figure given by Garman based upon material from Kentucky is identical with arida. Garman's figure indicates transverse strips on the abdominal tergites whereas Claassen's figures and statements show he was dealing with a species with uniformly dark abdominal tergites.

That the nymphs are carnivorous is proved by the dissection of a specimen collected in the Kankakee river, Kankakee county, Ill., June 1, 1901, which contained numerous insect remains in the alimentary tract.

The most distinctive features of the adults, which have been described by others as noted above, have been given here in the key to species, p. 390 , and are shown in figs. 208, 2+2,2+3,2+6, 250 .

Most important characters of the previously undescribed nymph are as follows.

Nymphal female, fig. 313.-General ground color yellowish with brownish markings on dorsum as follows: labrum except for extreme anterior tip; two transverse sinuate bands on head connected by narrow line on side of head adjacent to antennae-one of these bands crosses the head just anterior to articulation of antennae and the second is located on a line with anterior portion of compound eyes with its greatest width in middle of head where it fills the ocellar space; extreme posterior edge of head; a series of 
dark markings on pro-, meso- and metanotum as shown in fig. 313; transverse bands on anterior margins of abdominal tergites, these bands being widest on middle tergites; bands at base and apex of femur.

Head with three ocelli forming an equilateral triangle; lateral ocelli larger than anterior ocellus and situated about on a line with the middle of compound eyes; anterior ocellus placed anterior to a line connecting anterior points of compound eyes. No occipital ridge. Posterior margin of compound eye with a row of short stout prominent setae. Labrum, fig. 35, labium, fig. 125, maxilla, fig. 95, mandibles, fig. 65, and submentum, fig. 155, as illustrated.

Pronotum much broader than long; angles or corners well rounded, especially hind angles; anterior margin slightly bulging forward and hind margin slightly indented in middle; marginal groove well defined and completely extending around pronotum; flange widest on sides. Meso- and metanotum with wing pads well developed; lateral margins broadly rounded, particularly mesonotal wing pads.

Legs flattened; femora much broader than tibiae and well covered with short stout setae; hind margin of femora and tibine with a fringe of long dense setae.

Abdomen shaped and marked as in fig. 313. Cerci much shorter than body, with 40 or more segments; basal segments much broader than long, middle and apical segments much longer than broad. Tenth abdominal sternite but slightly produced backwards on posterior margin. Eighth abdominal sternite with posterior margin straight; posterior setal fringe interrupted in middle.

Gills present; two pairs of large, many branched clumps on the side of each thoracic segment near articulation of legs; one pair at apex of abdomen.

Mature specimens with a body length, exclusive of appendages, sometimes as much as $23 \mathrm{~mm}$.

Nymphal male.-Similar to female in general color and most morphological details. Eighth abdominal sternite with row of setae on posterior margin not interrupted in middle. Mature specimens smaller than females with a body length up to $17 \mathrm{~mm}$.

Adults.-Anna: June 8, 1907, $1 \sigma^{7}$. Aurora: July 17, 1927, 1?. Cairo: June 27, 1905, 19. Champaign: June 17, 1886, 19.; June 12, 15, 1888, $2 \sigma^{7}$. Charleston: June 8, 11,1931, $3 \sigma^{7}, 1$. E. Effingham: June 20, 1927, $1 \sigma^{7}$. Elizabethtown: June 22, 1927, $10^{7}$; June 24, 1932, $10^{7}$. Homer: July 19, 1924, 1\%; June 30, 1927, 42 $\sigma^{7}, 73$; ; July 6-11, 1927, $1 \sigma^{7}$, 8\%; June 14-17, 1930 , $4 \sigma^{7}$, 1\%; June 11, 1931, $8 \sigma^{7}, 2 \%$. Kankakee: June 13, 1931, $1 \sigma^{7}$. Metropolis: June 4-6, 1928, $4 \sigma^{7}$. Momence: June 4, 1932, $\sigma^{7} \sigma^{7}$, 19. Muncie: July 27, 1927, 1; July 3, 1929, $1 \sigma^{7}$. Oakwood: June 9, 1926, 1\%; July 6, 1927, $1 \sigma^{7}$, 4\%. Ogden: June 14, 1930, $1 \sigma^{7}$; June 17, 1933, 19. Petersburg: June 9, 1914, $1 \sigma^{7}$. Shawneetown: June 21, 1927, $3 \sigma^{7}$. Urbana: June 24-25, 1889, $1 \sigma^{7}$, 19; July 5, 1907, 2o; June 17, 1929, $1 \sigma^{7}$. Wilmington: June 12, 1931, $10^{7}$.

Nymphs.-Charleston (Embarrass r.): Dec. 6, 1930; Mar. 22, Apr. 


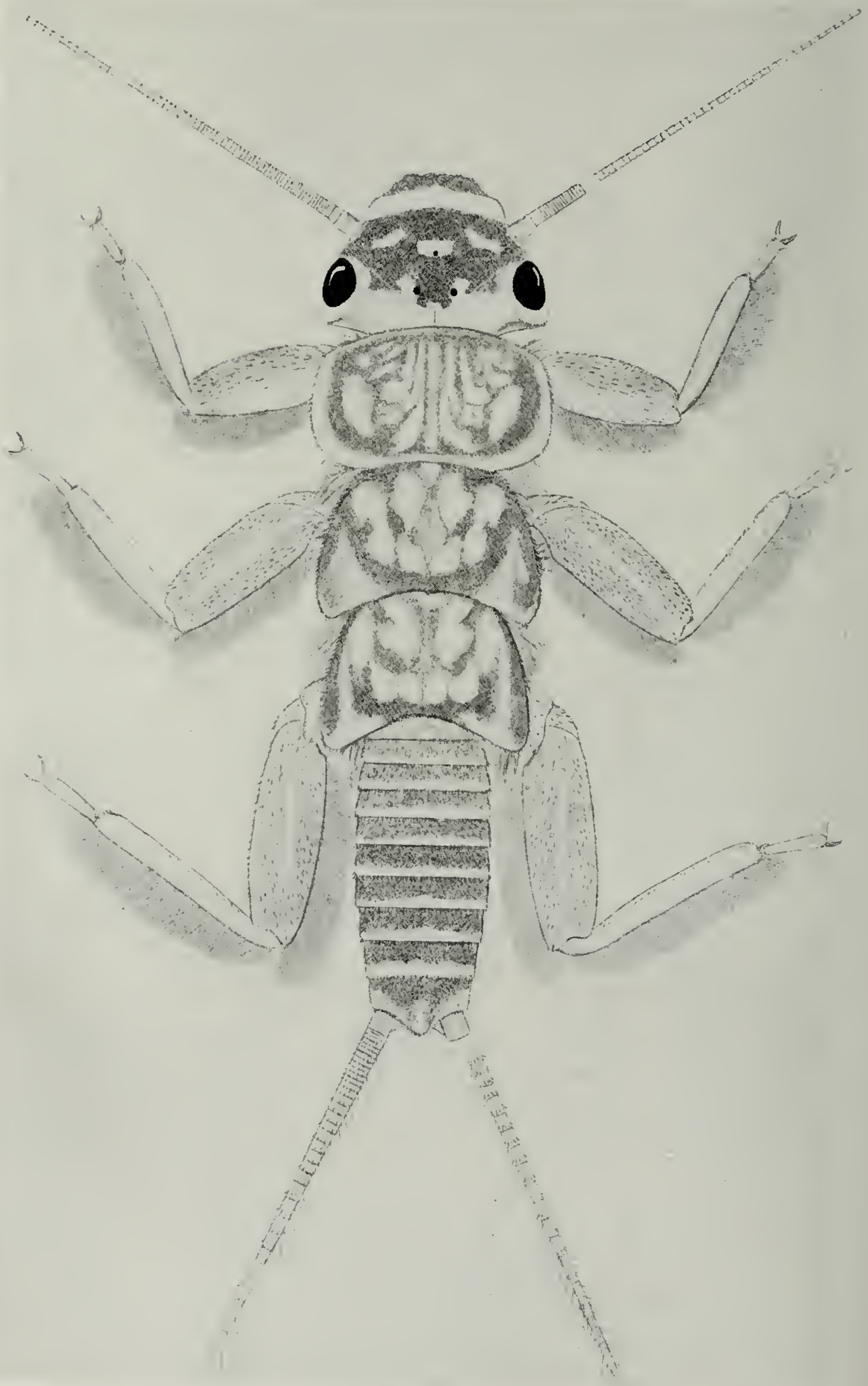

Fig. 314.-Acroneuria internata, NYMPHAL FEMALE. 
2, 17, June 7, 1931; Mar. 28, 1932. Golconda (Ohio r.): May 13, 1932. Homer (Salt Fork r.): Apr. 20, 1921; June 3, 1925; June 14, 1930; Apr. 18, 1931. Kankakee (Kankakee r.): June 1, 1901, Apr. 28, 1931. Mahomet (Sangamon r.): Sept. 1, 1928. Muncie (Stony cr.): May 27, 1905; June 8, 1927. Oakwood (Salt Fork r.): June 6, 1925; Sept. 1, 1927; Nov. 2, 1929; Sept. 8, 1932; Apr. 12, 1933. Ottawa (Illinois r.): June 12, 1901, exuviae.

Reared from nymphs.-Charleston (Embarrass r.): June \&, 11, 19, 1931. Homer (Salt Fork r.): June 14, 1930.

Mating pairs.-Homer (park): June 30, 1927.

\section{Acroneuria internata (Walker)}

Figs. 36, 66, 96, 126, 159, 209, 247, 266, 314

Perla internata IValker (1852) p. 152. Original description.

Acroneuria internata (Walker), or the species now going under this name in North America, has remained almost unknown to workers on Plecoptera. Practically all authors until Needham and Claassen (1922) have placed internata in the synonymy of one or more species or dismissed it as unrecognizable. Needham and Claassen (1925) first recorded it from Illinois (Bloomington, June 21, 189t, C. C. Adams) and also list it from Colorado, Indiana, Michigan, Missouri and West Virginia. These records indicate it is to be expected in most of the states in the Mississippi watershed.

Our picture of its distribution in lllinois parallels that of 1 arida (Hagen), which see.

Field studies indicate that this stonetly is the least abundant of the Illinois species of Acroneuria that are known in the adult stage. Most of our adults have been collected at night at lights and not before the first week in June. Our latest date for the collection of an adult is July 28. Rearings of adults from nymphs indicate their maximum abundance to occur about the end of June. The adult is to be considered therefore as a member of the late spring and early summer fauna.

The adults have been well described by Needham and Claassen (1925). Their distinctive features for identification purposes are given in the key to species and in figs. 209, 247.

The nymph of internata has not been previously described or recorded. Our association of nymph with adult is based upon rearings of both sexes and our association of sexes upon emergence of opposite sexes from similar nymphs. That the nymphs are carnirorous and afford no exception to the rule among Acronenria is evident by the finding of numerous insect remains in the alimentary tract of a nymph collected in the Embarrass river, Charleston, Ill., March 22, 1931.

Description of the previously unrecognized nymph follows: 
Nymphal female, fig. 31t.-General ground color yellowish with brownish markings on dorsum as follows: labrum; most of central area of head except for five more or less definite light spots, three of which are adjacent to ocelli and one on each side of head between anterior ocellus and base of antenna; small area on posterior margin of head feebly connected at sides with posterior margin of compound eye; a series of markings on pro-, meso- and metanotum as shown in the figure; abdominal tergites except for narrow yellow posterior margins; and large portion of femur.

Head with three ocelli forming a triangle, lateral ocelli slightly closer to one another than to anterior ocellus; lateral ocelli much larger than anterior ocellus and placed about on a line with middle point of compound eyes; anterior ocellus placed anterior to a line connecting anterior points of compound eyes. No occipital ridge. Posterior margin of compound eyes with a row of short stout prominent setae. Labrum, fig. 36, labium, fig. 126, maxilla, fig. 96, mandibles, fig. 66, and submentum, fig. 159, as illustrated.

Pronotum much broader than long; hind angles much rounded, front angles sharper; anterior margin slightly bulging forward and hind margin slightly indented towards middle; marginal groove well defined and extending completely around pronotum; flange widest on sides. Meso- and metanotum with wing pads indicated; lateral margins rounded.

Legs flattened; femora much broader than tibiae and well covered with short stout setae except for a bare median longitudinal stripe; hind margins of femora and tibiae with a fringe of long dense setae.

Abdomen shaped and marked as in fig. 314. Cerci much shorter than body, with 50 or more segments; basal segments much broader than long, middle segments slightly longer than broad, apical segments much longer than broad. Tenth sternite but slightly produced backwards on posterior margin. Eighth sternite with posterior margin straight; posterior setal fringe interrupted in middle.

Gills present, fig. 266; two pairs of large, many branched clumps on the sides of each thoracic segment near articulation of legs; anal gills absent.

Mature specimens with a body length, exclusive of appendages, sometimes as much as $27 \mathrm{~mm}$.

Nymphal male. - Similar to female in general color and most morphological details. Eighth abdominal sternite with row of setae on posterior margin not interrupted in middle. Mature specimens smaller than females, with a body length up to $15 \mathrm{~mm}$.

Adults.-Charleston: June 8, 1931, 19. Kankakee: July 10, 1925, $2 \sigma^{7}, 29$. Metropolis: June 6, 1928, $1 \sigma^{7}$. Muncie: July 6, 1907, $1 \sigma^{7}$. Oakwood: June 6, 1925, $1 \sigma^{7}$; July 6, 1927, 19; July 28, 1929, 19; June 14, 22, 1930, $5 \sigma^{7}$. Shawneetown: June 21, 1927, $10^{7}$. 
Nymphs.-Charleston (Embarrass r.): Nov. 14, Dec. 14, 1930; Mar. 22, Apr. 2, 17, 1931. Kankakee (Kankakee r.): June 1, 1901. Oakwood (Salt Fork r., Middle Fork of Vermilion r.): June 16, 1925; Sept. 1, 1927 ; Nov. 18, 1928; May 3, 1931; May 1, 1932; Apr. 12, 1933. Ottawa: June 12, 1901, exuviae. 1931.

Reared from nymphs.-Charleston: May 31, June 7, 8, 11, 14, 19,

\section{Acroneuria ruralis (Hagen)}

Figs. 37, 67, 97, 127, 147, 211, 244, 302, 315.

().

Perla (Acroneuria) ruralis Hagen (1861) p. 18. Original description

Acroneuria ruralis Claassen (1931) p. 89. Nymphal description.

Acroneuria ruralis, the largest of the Illinois species of this genus, wals first recorded from near Rock lsland, Ill. by Walsh (1862) and again in 1863, both times under the name of rupinsulensis Walsh. The description of the produced subgenital plate of the female and "a distinct transverse linear tubercle upon it" leaves no doubt that rupinsulensis is a synonym of ruralis. This synonymy was first indicated by Needham (1920). Types of rupinsulensis Walsh are now in the collection of the Museum of Comparative Zoology, Cambridge, Mass. The next records from Illinois (Bloomington, Moline and Savanna) are those by Needham and Claassen (1925). To date this species has been recorded east of the Rocky mountains from Canada and 11 states and is to be expected in most of the remainder, particularly those in the Mississippi watershed. The adults in our collection come from all sections of Illinois traversed by large or medium sized rivers.

Our records show that the adults begin emerging during the last of May, reach their maximum abundance about the middle of June, and a few are still about during the first of July; therefore the species is a member of the late spring and early summer fauna. The adults are nocturnal, attracted to lights and though not rare are seldom found in numbers.

The nymphs are restricted to medium or large rivers like other nembers of this genus. Our association of nymph with adult and males with females is based upon rearings. Like the other Acroneuria this species is carnivorous. The alimentary tract of a nymph collected in the Rock river, Rock Island, Ill., April 2, 1928, was found to he full of the remains of larvae of chironomids, caddice flies and other aquatic insects. The nymph has a developmental period certainly of two years and possibly three.

Distinctive features of the adults are given in figs. 211, 24t, 302. The nymph has been adequately characterized by Claassen (1931) and 


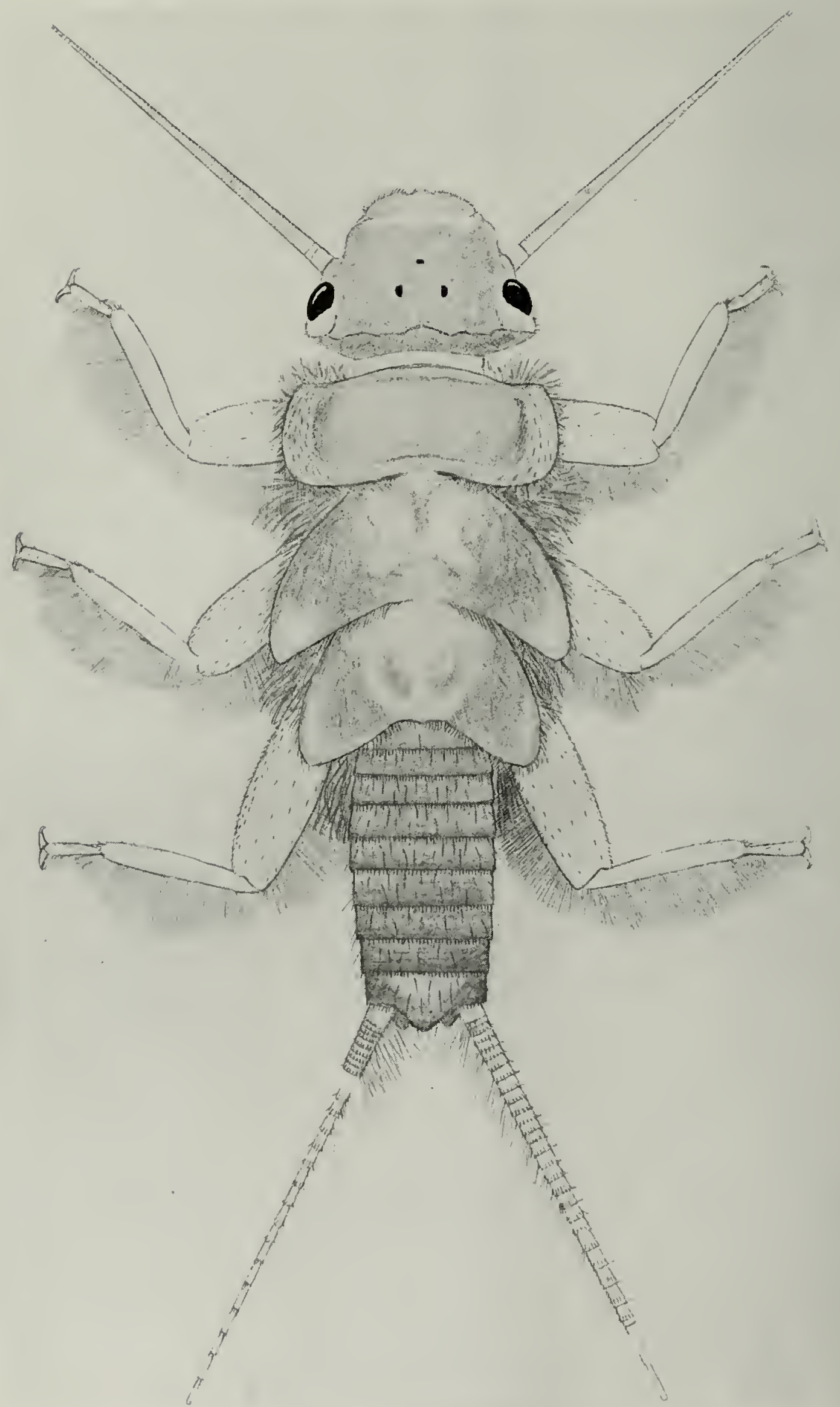

Fig. 315.-Acroneuria ruralis, NYMPHAL FEMALE. 
its most important morphological characters are shown in figs. 37,67 . $97,127,147$.

Adults.-Algonquin: June 29, 1906, $1 \sigma^{7}$. Bloomington: 19. Citiro: May 23, 1907, $10^{7}$. Elizabeth town: June 22, 1927, 19. Galesburg: June 24, 1907, 29. Grand Tower: June 1, 1913, 19. Havana: June 28, 1907, $1 \sigma^{7}$; June 29, 1913, $1 \sigma^{x}$. Keithsburg: June 9, 14, 1932, $10^{x}$, 3o. Leroy: July 1 , 1928, $10^{x}$. Metropolis: June 4, 5, 9, 1928, $5 \sigma^{x}, 2$. . Oregon: May 1929, $10^{x}$, 2\%; June 1930, $1 \sigma^{7}$. Rock Island: June 3, 1930, $2 \sigma^{7}, 1$; ; June 13, 24, 1931, $3 \sigma^{7}, 8$. Shawneetown: June 21, 1927, $1 \sigma^{7}$. Urbanal: June 5, 1907, 19; July $5,1907,1$ ㅇ.

Nymphs.-Alton (Mississippi r.): Aug. 29, 1913. Geneseo (Green r.): Aug. 4, 1925. Grafton (Mississippi r.): Aug. 30, 1913; Sept. 8, 1932. Hillsdale (Canoe cr.): July 30, 1925. Keithsburg (Mississippi r.): June 9, 1932. Lyndon (Rock r.): July 8, 1925. Milan (Rock r.): Sept. 29, 1927. Oregon (Rock r.): Apr. 3, 1928. Prophetstown (Rock r.): July 20, 29, 1925. Rock Island (Rock r.): Apr. 2, 1928; June 3, 1930; May 16, 1931; Apr. 27, 1932; May 11, 1934. Salvanna (Mississippi r.): Sept. 11, 1932. Sterling (Rock r.): Aug. 5, 12, 1924.

Reared from nymphs.-Rock 1stand (Rock r.): June 8, 13, 24, 1931.

\section{Acroneuria sp. a}

Figs. $38,68,98,128,166,316$.

Near Keithsburg, Ill. on the Mississippi river we have found clinging to the piling of a railroad bridge four cast skins of a species of Acroneuria which we cannot place to species. We are tentatively calling this Acroneuria "sp. a" until the adult is known. Considerable effort has been made to capture the live nymph or adult but so far to no avail. This species is certainly a rarity in Illinois. Judging by the location of Keithsburg (southwest of Rock Island) this is a northern species which has penetrated down the Mississippi river or its tributaries and in Illinois is at the southern edge of its distribution.

In general the nymph is suggestive of the nymph figured by Claassen (1931, Pl. 33, fig. 227) under the name of arida. The true arida, however, has a quite different nymph as described and illustrated in the present paper. In fig. 316 is shown our idea of the appearance of the nymph based upon cast skins. Although a detailed description of the nymph might be presented based upon the cast skin, such a description is left until the actual nymph and adults are known. The most important characters in addition to the color pattern are the presence of small anal gills in addition to thoracic gills and the absence of a prominent occipital ridge. The mouthparts are as follows: labrum, fig. 38, mandibles, fig. 68, maxilla. fig. 98, labium, fig. 128, and submentum, fig. 166 .

Exuviae.-Keithshurg (Mississippi r.): June 14, 1931, 2 \%; June 9, $1932,1 \sigma^{7}, 1$ \%. 


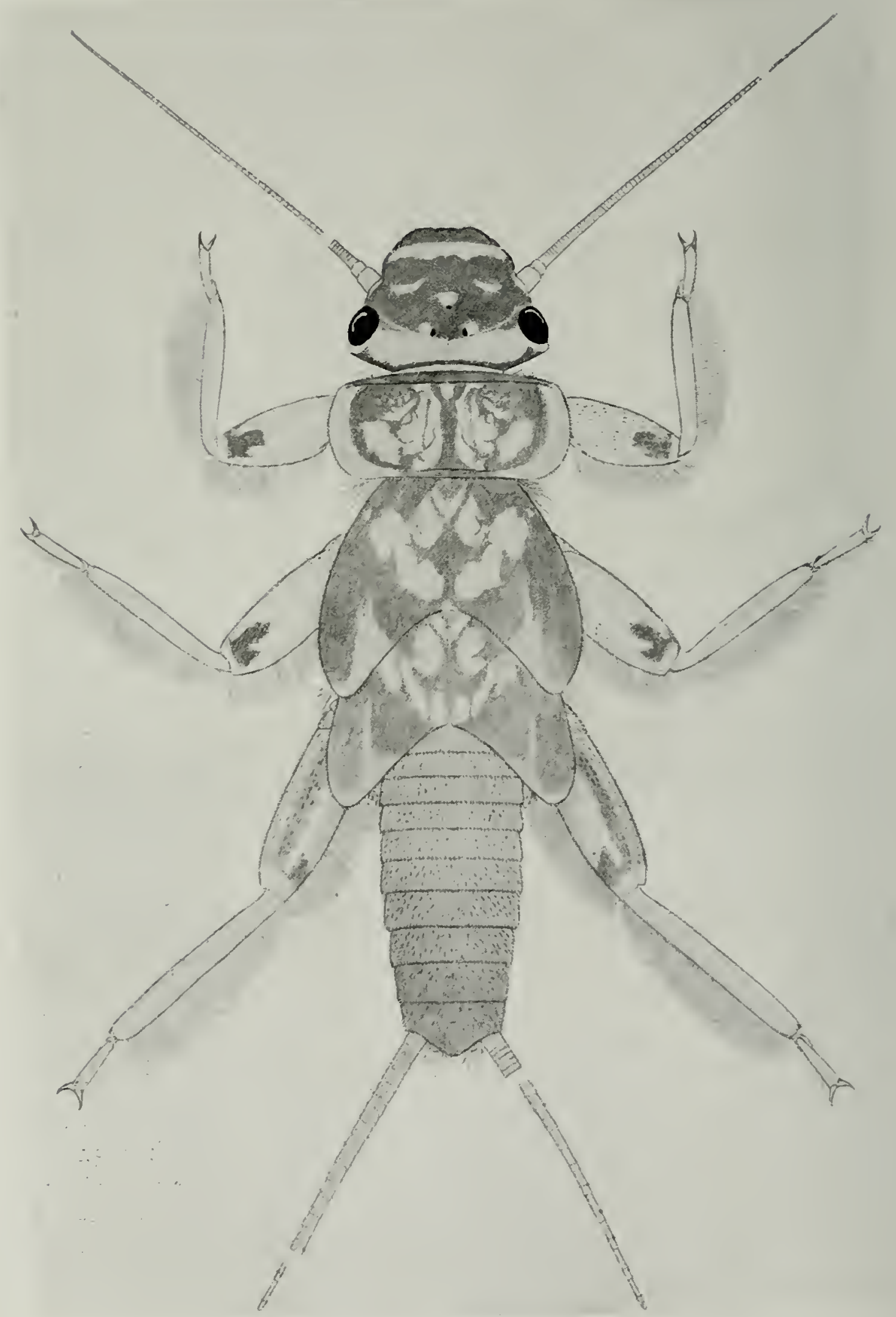

Fig. 316.-Acroneuria sp. a, NMPHAI. FEMALE. AS INDICATED BY EXUVIA. 


\section{Acroneuria sp. b}

Figs. 39, 69, 99, 129, 169, 317.

One cast skin was collected on a tree near the bank of the Ohio river, near Cave-in-Rock, 11l., May 30, 1928, which cannot be placed definitely to species and therefore in this paper has been referred to ats Acroneuria "sp. b." 'This may be the nymphal skin of a very light colored specimen of $A$. aburormis" but it seems best to consider it as different until the North American Acroneuria fauna is better known. Since Cave-in-Rock is in extreme southeastern Illinois on the Ohio river, and similar nymphs have not been found in central or northern Illinois, it seems that the watershed of the Ohio holds the key to establishing the identity of this form.

In general structure the nymph is suggestive of abnormis as described in this paper. In fig. 317 is shown our idea of the appearance of the nymph based upon a cast skin. Detailed description of the nymph is left until its true status is known. The most important characters, in addition to the color pattern, fig. 317 , are the absence of anal gills and occipital ridge. The mouthparts are as follows: labrum, fig. 39, mandibles, fig. 69, maxilla, fig. 99, labium, fig. 129, and submentum, fig. 169.

Exuvia.-Cave-in-Rock (Ohio r.): Mny 30, 1928, $10^{7}$.

\section{Neophasganophora Lestage}

Lestage (1922) p. 101. New name for Phasganophora Klapalek. Genotype Neophasganophora capitata (Pictet) $=$ Perla capitata Pictet, original designation.

The genus was first recognized by Klapalek (1921) and renamed Neophasganophora by Lestage (1922) because Phasganophora was preoccupied. The single North American species belonging here, and type of the genus, has been placed in the genus Perla by American writers on this group of insects. The genus Perla, as pointed out elsewhere in this paper, has been a sort of dumping ground for various and often not closely related species. It is even doubtful whether Perla in its strictest sense occurs in North America.

According to Klapalek (1923), species belonging to this genus are found in northern Asia and North America. This latter author erred however in recognizing as separate species on the basis of poor color characters such forms as amuulipes Hagen, illustris Banks and flnz'escens Walsh, which are synonyms of capitata Pictet or at least but color varieties of it. He also included media Walker and fumosa Banks. Needham and 


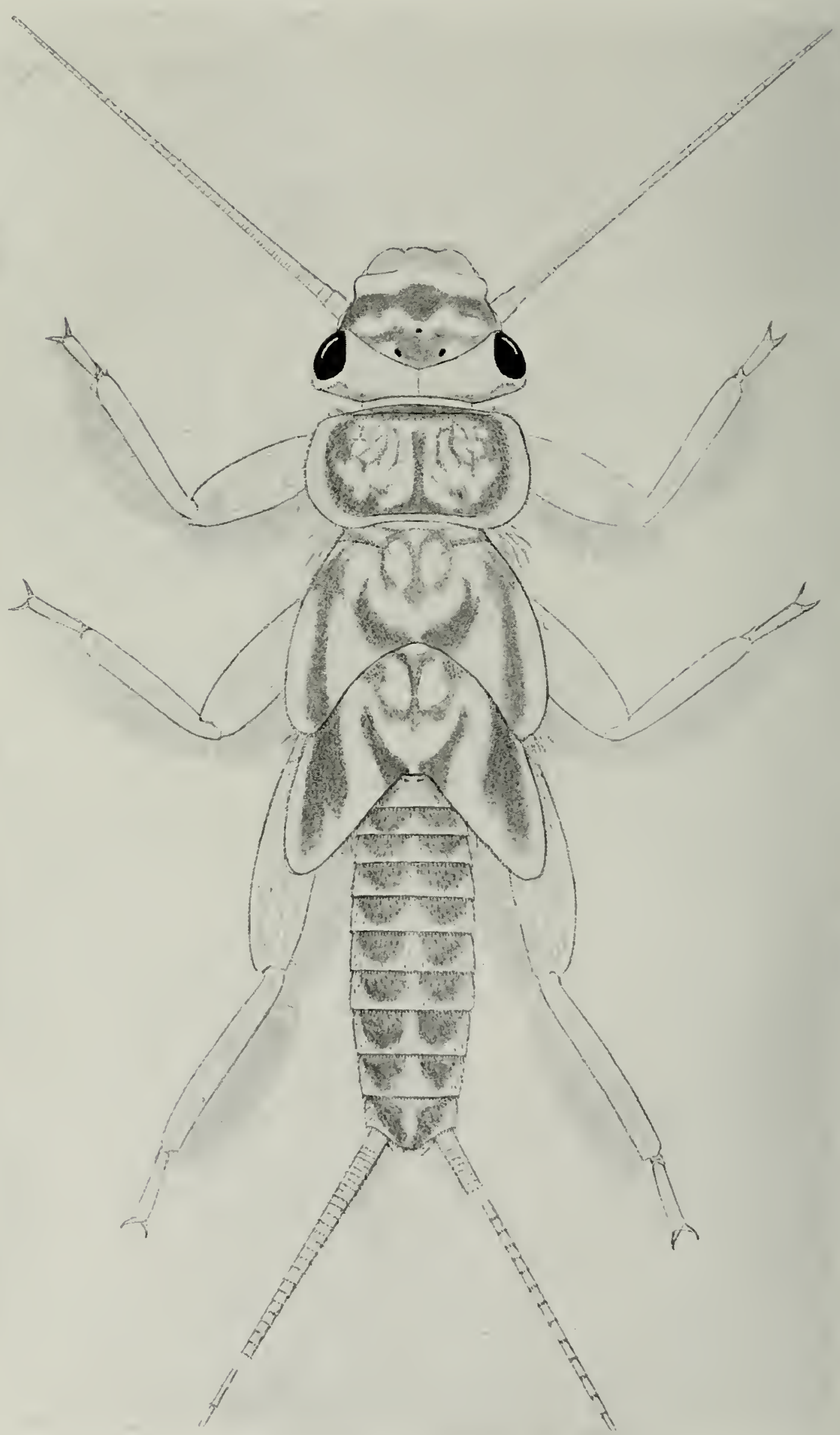

Fig. 317.-Acroneuria sp. $b$, NYMPHAL MALE AS INDICATED BY EXU.VIA. 
Claassen (1925) show that the latter is a synonym of immarginata Say. Media and immarginata both belong in the genus Togoperla. Needham and Claassen (1925) recognize Neophasganophora and Togoperla as subgenera of Perla but as stated earlier I consider them genera.

My studies of extensive series of specimens, observations in the field and rearings have convinced me that the synonymy of capitata Pictet as given by Needham and Clatassen (1925) is essentially correct and thit this genus contains but a single described North American species.

\section{Neophasganophora capitata (Pictet)}

Figs. $10,70,100,130,150,207,252,318,319,320$.

Perla capitata Pictet (1841) p. 214. Original description ( $\left.\sigma^{7}\right)$.

Perla capitata Claissen (1931) p. 47. Nymphal description.

'This large and common stonefly has been recorded from Canada and many states east of the Rocky mountains and is likely to be found in most of the others. It was first recorded from Illinois, near Rock Island, by Walsh (1862) under the name "flaz'escens, n. sp.," the type of which i.s now in the Museum of Comparative Zoology, Cambridge, Mass. The next record is that of Needham and Claassen (1925): "Illinois, Ottawa, July 2 (W. E. Howard)."

The adults are diurnal and thereby differ from the other Perlidae thus far discussed. On bright days they are active and congregate on vegetation near rivers in which the nymphs live. Mating takes place under such circumstances and a freshly emerged adult female frequently attracts many males. At evening I have observed fenuales with attached egg masses flying over rapids below dams, obviously for the purpose of dropping the egg masses into the water. Occasional specimens are found at lights but according to my experience they are not attracted to lights at night in the same manner as Acroneuria and other genera and their presence there is apt to be accidental. The adults emerge at night from mature nymphs which crawl out of the water when ready to produce adults. They begin to emerge the last part of May and reach their maximum abundance during the first part of July, a seasonal range which makes them a member of the late spring and summer fauna. Our association of males and females is attested by rearings, mating pairs and field data.

Our specimens of both adults and nymphs come from the central and northern parts of the state. Absence of specimens from the southern end indicates that this species is uncommon or absent from the smaller, less permanent streams, although it should and probably does occur here and there along the IVabash, Ohio and Mississippi rivers. In localities of northern and central Illinois where capitata is abundant, the rivers have 


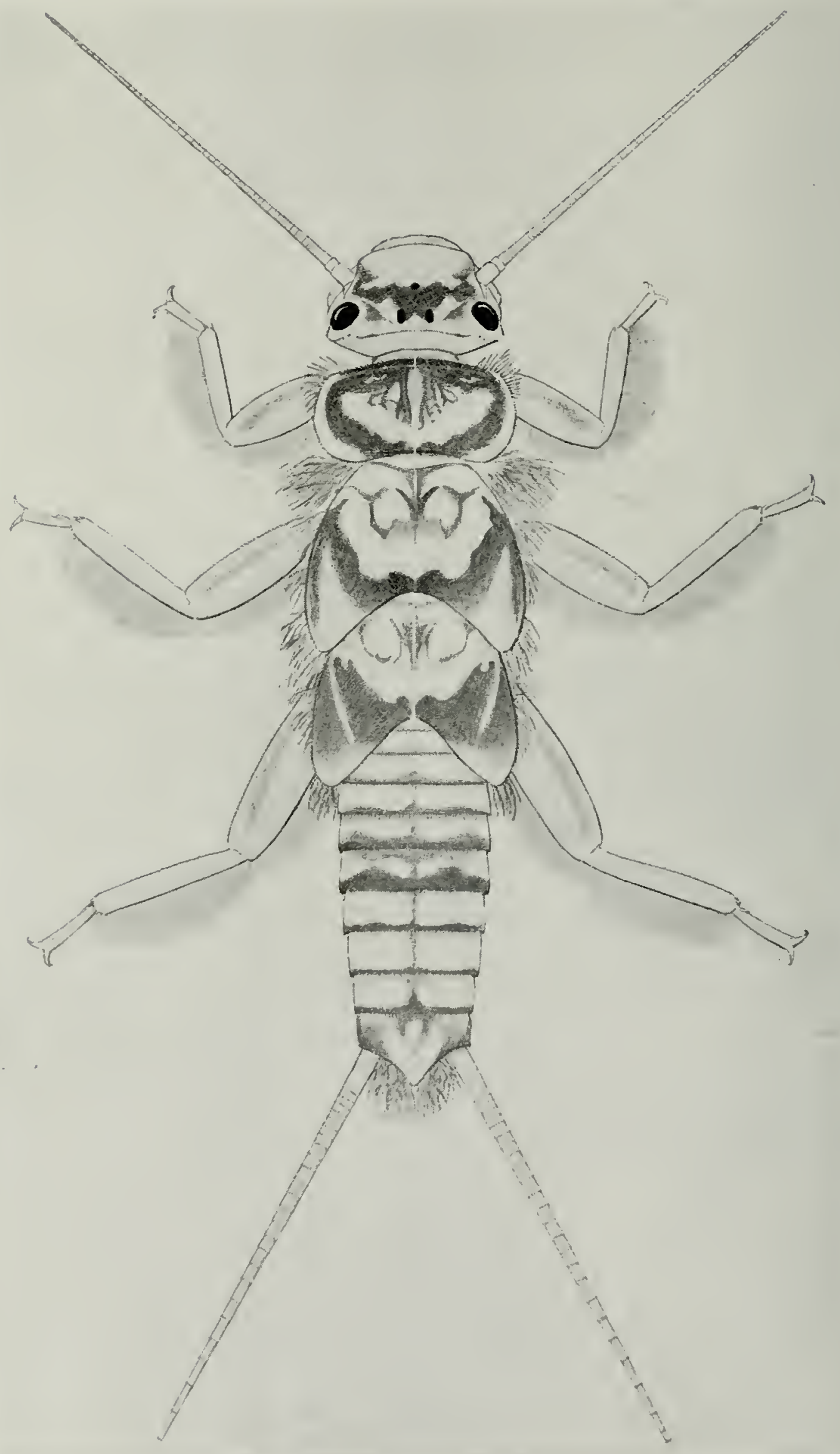

Fig. 318. - Neophasganophora capitata, NYMPHAL FEMALE. 
a rocky bed, the water is usually fairly clear and the current is swift. Rapids below dams are favorite haunts of the nymphs of this species and it is at such places in Illinois that they are most abundant.

The nymphs are carnivorous.

Dissection of one capitata nymph collected in the Rock river, Rock Island, Ill., June 27, 1932, revealed an ingested, nearly full grown stoneHy nymph so well preserved that it: identification as Isoperla bilineatn was possible. The life cycle of capitata undoubtedly takes two and possibly three years for completion.

The nymphs, fig. 318 , are easily recognized by the structural characters utilized in the key to species and by their conspicuous color pattern.

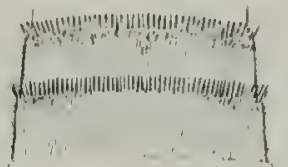

319

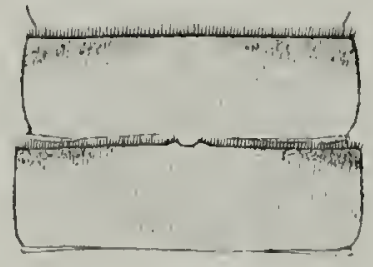

320

Figs. 319-320.-EIGHTH AND N1NTH A boOMinal SEgments of Neophasganophora capilata, NruPHs. This ubiquitous species illustrates the means of separating male and female nymphs by means of the continuous or interrupted posterior setal margins of eighth sternites. 319.-Male. 320.-Female.

They have been described in detail by Claassen (1931). 'That author's association of nymph with adult is proved to be correct by our rearings.

Adults.-Homer (park): June 30, 1927, $2 \sigma^{7}$; June 1, 1931, $4 \sigma^{7}$. Kankakee: July 10, 1925, $1 \sigma^{\top}, 5 \%$. Keithsburg: June 9, 1932, $2 \sigma^{7}, 59$. Momence: July 17, 1914, 19. Oakwood: June 9, 1926, 39; July 6, 10, 1927, ठ7రా, \&o; June 14, 1930, $3 \sigma^{7}$. Oregon: June 19-21, 1917, 49; July 9, 1925, 29; July 13, 1926, 19; July 18-19, 1927, ơ $\sigma^{7}$, ㅇ; May 21-June 28, 1928, 1 ơ , 우; June 1929, 4o; July 11, 1929, o7 $\sigma^{7}$, 우; June 1930, 69; June 13, 1931, 7 б. Ottawa: June 12, 1901, $1 \sigma^{7}$. Pike: May 26, 1906, $4 \sigma^{7}$. Rockford: July 18, 1927, $10^{7}, 1$; J June 13, 1931, 36 o $^{7}, 14$. Rock Island: June 3, 30, 1930, 우; June $8,13,24,1931,6 \sigma^{7}, 2$ ㅇ․ Springfield: June 23-2t, 1885, 1 ㅇ. Sterling: May 21, 1926, $10^{7}$.

Nymphs.-Byron (Rock r.): May 17, 19, 23, 1927. Dixon (Rock r.): July 29, 1924; May 12, 22, 1925; Apr. 3, 1928. Dixon-Oregon (Rock r.): July 27, 1927. Grand Detour (Rock r.): May 25-29, 1927; July 2, 1932. Hillsdale (Rock cr.): July 21, 1925. Homer (Salt Fork r.): Nov. 5, 23, 1927; Apr. 18, 1931. Kankakee (Kankakee-r.): June 12, 1931. Keithsburg (Mississippi r.): June 15, 1931; June 9, 1932, exuviae. Jyndon (Rock r.): July 8, 1925. Muncie (Stony cr.): Oct. 19, 1929. New Milford (Kishwankee cr.): May 7, 1926. Oakwood (Middle Fork of Vermilion r., Salt Fork r.): Mar. 11, Oct. 11, 20, 27, Nov. 23, 1927; Nov. 2, 1929; May 3, 1931; May 11, 1932; Apr. 12, 1933. Oregon (Rock r.): Maly 25-26, July 5, 1927 ; Apr. 3, 1928; July 11, 1929; May 15, 1930; July 3, 1932. Ottawa (Illinois r.): July 21, 1901, exuviae. Paris-Chrisman: Mar. 9, 1928, exuvia. Pike: May 26, 1906, exuvia. Prophetstown (Rock r.): July 20, 1925. Rockford (Rock r.): Apr. 26, 1927. Rock Island (Rock r.): Apr. 2, 1928; June 3, 1930; Apr. 10, June 13, 1931; Apr. 27, May 9, 1932. Starved Rock (Illinois r.): June 13, 1901, exuvia. Sterling (Rock r.): Aug. 12, 1924; May 15, June 1.5-19, July 6, 1925; Apr. 3, 1928; Apr. 27, 1932. White Heati (Sin- 
gamon r.): May 13, 1928. Wilmington (Kankakee r.): Apr. 28, June 12, 1931.

Reared from nymphs.-Rockford (Rock r.): June 13, 1931. Rock Island (Rock r.): June 3, 1930; June 13, 1931.

Mating pair.-Oregon: June 27, 1928.

\section{Togoperla Klapalek}

Klapalek (1907) p. 19. Genotype Perla limbata Pictet = Togoperla limbata (Pictet), original designation.

Togoperla was proposed as a subgenus by Klapalek (1907) for certain Asiatic species of stoneflies and then given generic status by the same author (1923). It has been recognized as a subgenus containing North American representatives by Needham and Claassen (1925). Although differing from Neophasganophora in certain essential points it is most closely related to this genus, but is sufficiently distinct to entitle it to true generic status. Two species were placed by Needham and Claassen in the subgenus Togoperla,-media (Walker) and immarginata (Say).

One of these, media, has been found in Illinois and we have located a few specimens of a nymph of another species, not immarginata, apparently belonging in this genus which is not as yet associated with its adult.

\section{KEY TO SPECIES}

\section{Nymphs}

Anterior and posterior margins of dorsum of head light and distinctly contrasting with dark areas, fig. 323. Light dorsal areas or spots in general distinctly contrasting with brown background. A few light spots on apical dorsal abdominal segments.................................... $414^{10}$

Anterior and posterior margins of dorsum of head not distinctly contrasting with brown background, fig. 321. Light dorsal areas poorly defined. Apical dorsal abdominal segments uniformly dark brown..............media, p. 412

\section{Togoperla media (Walker)}

Figs. 41, 71, 101, 131, 206, 254, 321, 322.

Perla media Walker (1852) p. 145. Original description.

Perla media Claassen (1931) p. 48. Nymphal description.

This species is a rarity in Illinois and our record is based upon the finding of a single nymph in the Mississippi river in extreme northwestern Illinois. Field studies made by the author in Wisconsin prove that media is a northern element in our stonefly fauna and that northwestern Illinois probably represents the extreme southern edge of its distribution in the central states.

10 The adult of $s p$. $a$ is still nuknown $n$ r at present not associated with the nymph and therefore no key can be given for the mature forms. 
FRISON: STONEFLIES, OR PLECOPTERA, OF ILLINOIS

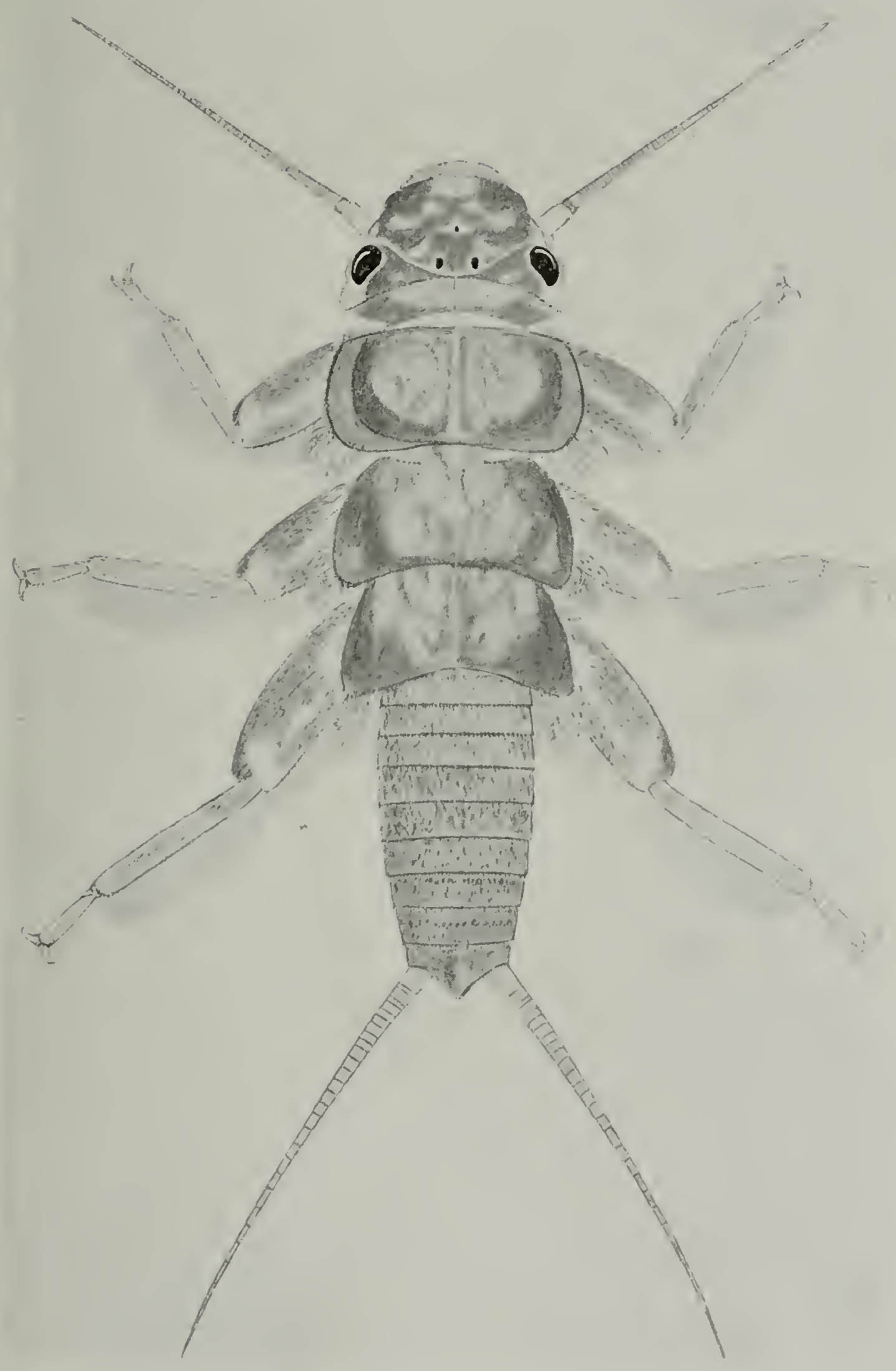

Fig. 321.-Togoperln medin, NYMHAL FEMALE. 
Nymphal specimens collected by myself near Mercer, Wis., August 9, 1932, were found when dissected to contain remains of various insects. This confirms the statement of Claassen (1931) that the nymph is a carnivore. Size ranges of nymphal material from $W$ isconsin indicate certainly a two and possibly a three year life cycle. This means that only large or at least permanent streams can support this species. I have found the nymphs of media abundant in most northern streams of Wisconsin.

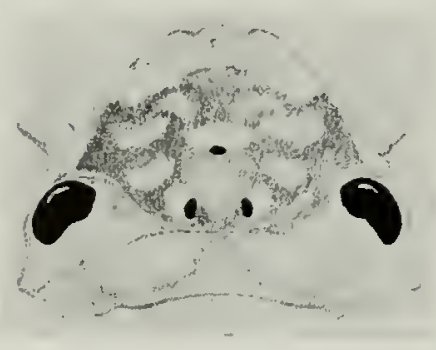

Fig. 322. - Togoperla media, DORSAL VIEW OF NYMPHAL HEAD SHOWING LIGHT FORII.

The nymphs taken in streams with clear water such as Trout river near Boulder Junction, $W$ is. have a lighter color than those from streams such as Teal creek, near Hayward, Wis. where the water is brownish.

The adults of Togoperla media are diurnal and like those of Neophasganophora capitata congregate on vegetation near rivers in which the nymphs live. Mating takes place during the day. The adults emerge from nymphs which leave the water at night. In $W$ isconsin the adults begin to appear during June, reach a maximum abundance in the northern counties during the first week in July, and by August have practically disappeared. The same general sequence may be expected in Illinois except that the species is rare and may appear earlier.

The nymphs, fig. 321, can be easily identified by the characters used in the key and have been described in detail by Claassen (1931). Our association of nymph and adults is based upon reared specimens and our association of the sexes upon similar nymphs, mating pairs and miscellaneous biological information. The most important morphological features of the adults and nymphs are shown in figs. 41, 71, 101, 131, 206, 254.

Nymph.- Savanna (beneath stones on a wing dam in the Mississippi r.): Sept. 10, 1932. Collected by T. H. Frison Jr.

\section{Togoperla sp. a}

Figs. 42, 72, 102, 132, 157, 323.

On wing dams in the Mississippi river near Alton and Grafton occurs a perlid nymph which probably belongs to this genus. This nymph was first collected during general biological work by Mr. R. E. Richardson in 1913 and a single specimen was again found in 1932 after diligent search by H. H. Ross and Carl O. Mohr. Several trips to this area to secure enough material for our rearing cages resulted only in the capture of this latter nymph. It is evident that this stonefly is a rarity in Illinois and the area from which it comes suggests it may be a more western species 
FRISON: STONEFLIES, OR PLECOPTERA, OF ILLINOIS

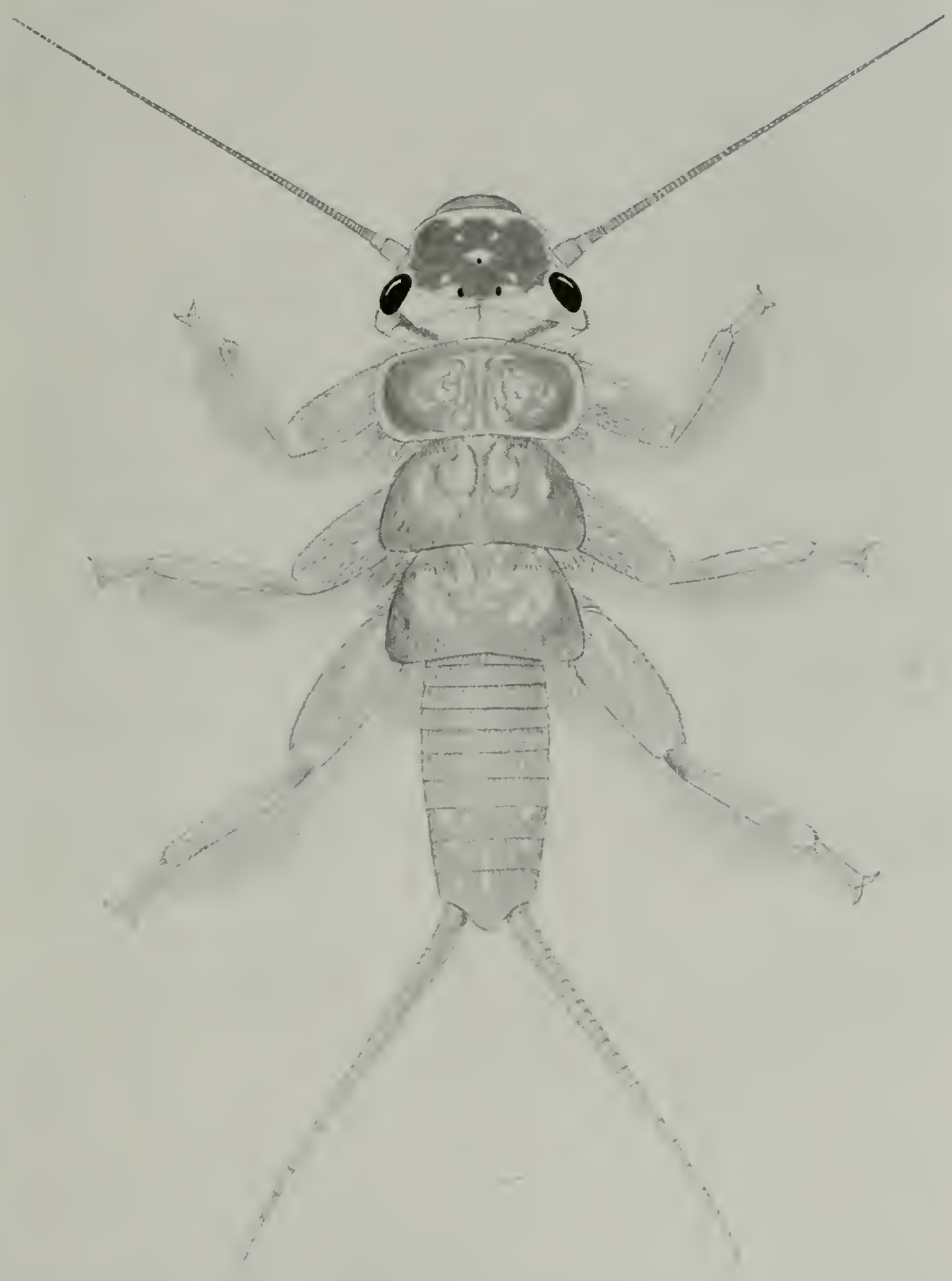

Fig. 323.-Togoperla sp. a, XYMPHL MALE.

which is to be expected in the upper part of the Missouri river system. It may be that this is the nymph of Perla kansensis Banks which is known from Kansas. 
The general appearance and color pattern of the nymph is shown in fig. 323. Its most important characters, aside from color pattern, are the placement of compound eyes on the side of the head near posterior margin, as in most Perlidae; three ocelli; presence of an occipital ridge; presence of thoracic gills; and the absence of anal gills. The mouthparts are as illustrated : labrum, fig. +2 , mandibles, fig. 72, maxilla, fig. 102, labium, fig. 132, and submentum, fig. 157.

Nymphs.-Alton (Mississippi r.): Aug. 29, 1913. Grafton (Mississippi r.): Aug. 30, 1913; Sept. 8, 1932.

\section{PERLODIDAE}

This family is represented in Illinois by a single group of closely related species for which I am proposing the new generic name Hydroperla. Two other North American genera belonging to this family, Perlodes Banks and Isogenus Newman, are western or more northern in their distribution. These genera and certain others not found in North America constitute in my opinion a natural group of family rank which has been recognized in European literature by the name of Perlodidae. Needham aid Claassen (1925) have included in the family Perlidae, along with many other genera, Perlodes, Isogemus and the species here assigned to my proposed new genus $H y d r o p e r l a$. The general characters of the adults and nymphs of the Perlodidae are essentially those given in the key to families, p. 333. Although Perlodidae and Chloroperlidae are closely related they may always be definitely separated by the presence or absence of a peculiar finger-like gill on the submentum of the nymphs, figs. 167, 168, or its remnant in the adults. This character requires at times some effort to see, but nevertheless is definite and of much value.

Needham and Claassen (1925) have also placed the species recorded here by the names of Hydroperla crosbyi (Needham and Claassen), Hydroperla zarians (Walsh) and certain others under the subgeneric name of Hemimelaena Klapalek. The fact that Klapalek has placed Heminelaena in Perlidae (s. str.) while recognizing the family Perlodidae leads me to believe that such North American species as zarians are not comparable with the small flarizentris Pictet known from Portugal as a sole member of the genus Hemimelaena known to Klapalek. Furthermore, Klapalek (1912) has indicated by the placement of postica Walker in the genus Isogemus and subgenus Isogenoides (type frontalis Newman) that the true postica from North America, based upon the type, belongs in the family Perlodidae. It seems to me that the Illinois species rarians, crosbyi and the one named harti in this paper, as well as some others not found in Illinois, constitute a natural group of generic status. None of the 
generic or subgeneric names of Klapalek seem to embrace or include this group when it is properly understood or segregated and hence a new generic name is proposed.

\section{Hydroperla- NEW GENUS}

Type Perla crosbyi Needham and Claassen $=$ Hydroperla crostyi (Needham and Claassen).

The genus Hydroperla is apparently most closely related to Isogenus. In the adults it is characterized by the following: three ocelli; forewing; without crossveins in anal area and with a series of median and cubital crossveins, fig. 183; first tarsal segment much shorter than third tarsal segment; cerci long and many segmented; prothoras about as wide as head; withoutt nymphal gill remnants on sides or venter of thorax and $a b$ domen; remnant of finger-like gills located near each side of outer basal corner of submentum; species dominantly black; of medium size with a body length usually more than 13 mm; males with tenth tergite deeply cleft; and females with a subgenital plate which usually

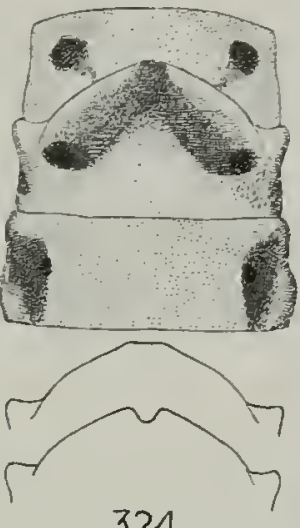

324

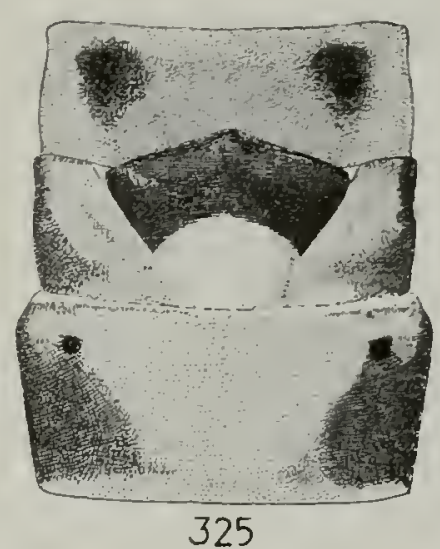

Figs. 324-325. SEVENTH, EIGHTH AND NINTH ABDOMINAL STERNITES OF ADUL'T FEMALE, SHOWING SUBGENITAL PLATES. 324. Hydroperla harti, t!pical form; variations of subgenital plate in outline. 325 . - H. crosbyi. is without any trace of a median notch, figs. $32+, 325$.

Adults of Hydroperla may be separated from the other closely related grenera belonging in Perlodidae as follows: 1.-From Perlodes by the absence of the network of irregular crossveins, figs. 183, 18t, beyond the radial sector of the fore- and hind wings. 2.-From Isogenus in the females usually by the absence of a deep median notch on the posterior margin of the subgenital plate, figs. $32+, 325$, and in the males by the absence of dorsal humps on the apical abdominal tergites.

The genus is characterized in the nymphs by the following: three ocelli; labium with paraglossae extending forward much farther than the glossae, the glossae deeply inset below and between the paraglossae so as to appear almost as basal segments of them, figs. 133, 134; venter of thorax without distinct, large, overlapping, shieldlike plates; with small finger-like gills located near each side of outer basal angle of submentum. figs. 167, 168; absence of thoracic or abdominal gills; labrum as in figs. 
$+3,+4$, mandibles as in figs. $73,7+$, and maxillae as in figs. 103, 104 .

Claassen (1931) does not separate the nymphs of Isogenus from his so-called "gill-less Perla" but differentiates them from Perlodes by their lack of gills on the submentum. His placement of the nymph of Isogenus is apparently based upon a questionable identification or very poor specimens, as indicated by "Isogenus colubrimus (?) Hagen" and his statement

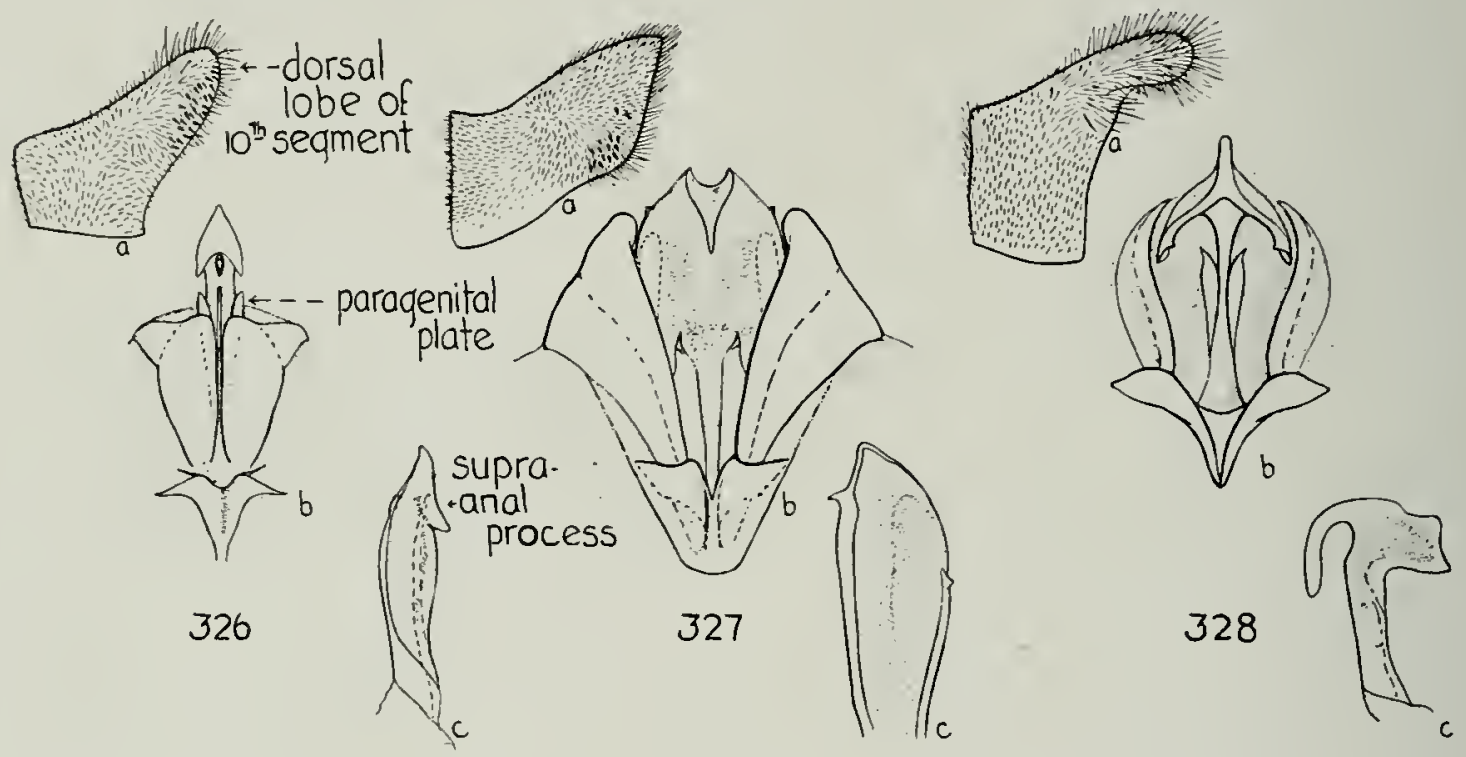

Figs. 326-328. - Male genttal structures of three species of Hydroperla. 326. - - H. harti. 327. - H. varians. 328. - H. crosbyi.

that "the nymphs have been in alcohol so long that the bodies are rather badly shriveled." My adult specimens of Isogenus colubrinus Hagen and Isogenus frontalis Newman all show remnants of the finger-like nymphal gill near each side of the outer basal angle of the submentum and therefore I am positive that such gills are present in the nymphs and were overlooked by Claassen.

Lack of nymphal material of Perlodes and Isogenus prevents a full statement here of how they differ from $H_{y}$ droperla. Presence of fingerlike gills on the sides of at least some nymphs of Perlodes suggests this as one very valuable differential character. Until the nymphs of Perlodes and Isogenus are better known and have been reared no absolute characters for separation of these genera can be given.

\section{KEY TO SPECIES}

\section{Adults}

1. Tenth dorsal abdominal segment cleft for reception of supra-anal process; eighth ventral abdominal segment with posterior margin straight (males)..2 Tenth dorsal abdominal segment not cleft; eighth ventral abdominal segment 
HYDROPERLA-KEY TO SPECIES-CONT'I)

with posterior margin somewhat projecting over ninth segment, figs.

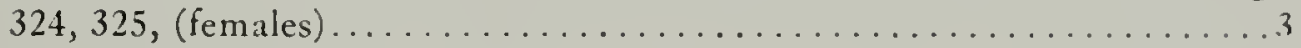

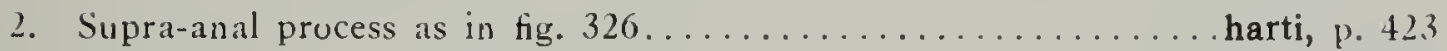
Supra-anal process as in fig. $327 \ldots \ldots \ldots \ldots \ldots \ldots$. . . . . . . . . . . . . . . $426^{11}$ Supra-anal process as in fig. $328 \ldots \ldots \ldots \ldots \ldots \ldots \ldots \ldots$. . . . . . . . . . . .

3. Dark, somewhat triangular markings on sides of ventral abdominal segments. Subgenital plate on eighth sternite as in fig. $325 \ldots \ldots \ldots \ldots$ crosbyi, p. 419)

1) ark markings on sides of ventral abdominal segments not triangular. Subgenital plate on eighth sternite as in fig. $324 \ldots \ldots \ldots \ldots$........ p. 42.3

\section{Nymphs ${ }^{12}$}

General coloration dark, with dark areas on head and thorax very distinct. Dorsal segments of abdomen with basal portions dark and apical portions light so that abdomen appears banded transversely, fig. $329 \ldots \ldots \ldots \ldots$ crosbyi, p. 419

Pale nymphs with brownish areas on head and thorax not very distinct. Dorsal segments of abdomen with some brownish spots but no distinct dark bands on basal portions, fig. $330 \ldots \ldots \ldots \ldots \ldots \ldots \ldots \ldots \ldots \ldots \ldots \ldots \ldots \ldots \ldots \ldots \ldots \ldots$ harti, p. 423

\section{Hydroperla crosbyi (Needham and Claassen)}

Figs. $43,73,103,133,168,183,325,328,329$. tion $\left(\sigma^{\top}\right)$.

Perla crosbyi Needham and Claassen (1925) p. 79. Original descrip-

The male holotype of this species, in the collection of Cornell university, has been studied by the writer through the courtesy of Professor Claassen. The peculiar bell shaped tip of the supra-anal process, fig. 328, of the male is quite distinctive and enables ready identification of this species. The typic specimens came from Missouri and our Illinois material presents the first records of this species since its description. I believe that it will eventually be found in many of the states in the Mississippi drainage.

We have collected this species only in central Illinois, but I believe that it will be found in medium or large streams in other sections. The adults are rarely found by the general collector. This is because of their seasonal timing, actual limitation in number and diurnal habits which eliminate their concentration at lights during the night. All but a few of our specimens have been secured by rearing the nymphs. During the day the adults, when not flying, rest or crawl about in places exposed to the warmth of the sun. So few individuals are produced per linear mile of stream and so many situations are suitable for resting places that

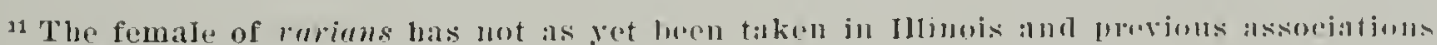
in literature may be in reror.

12 Nympls of rarians not kuowu. 


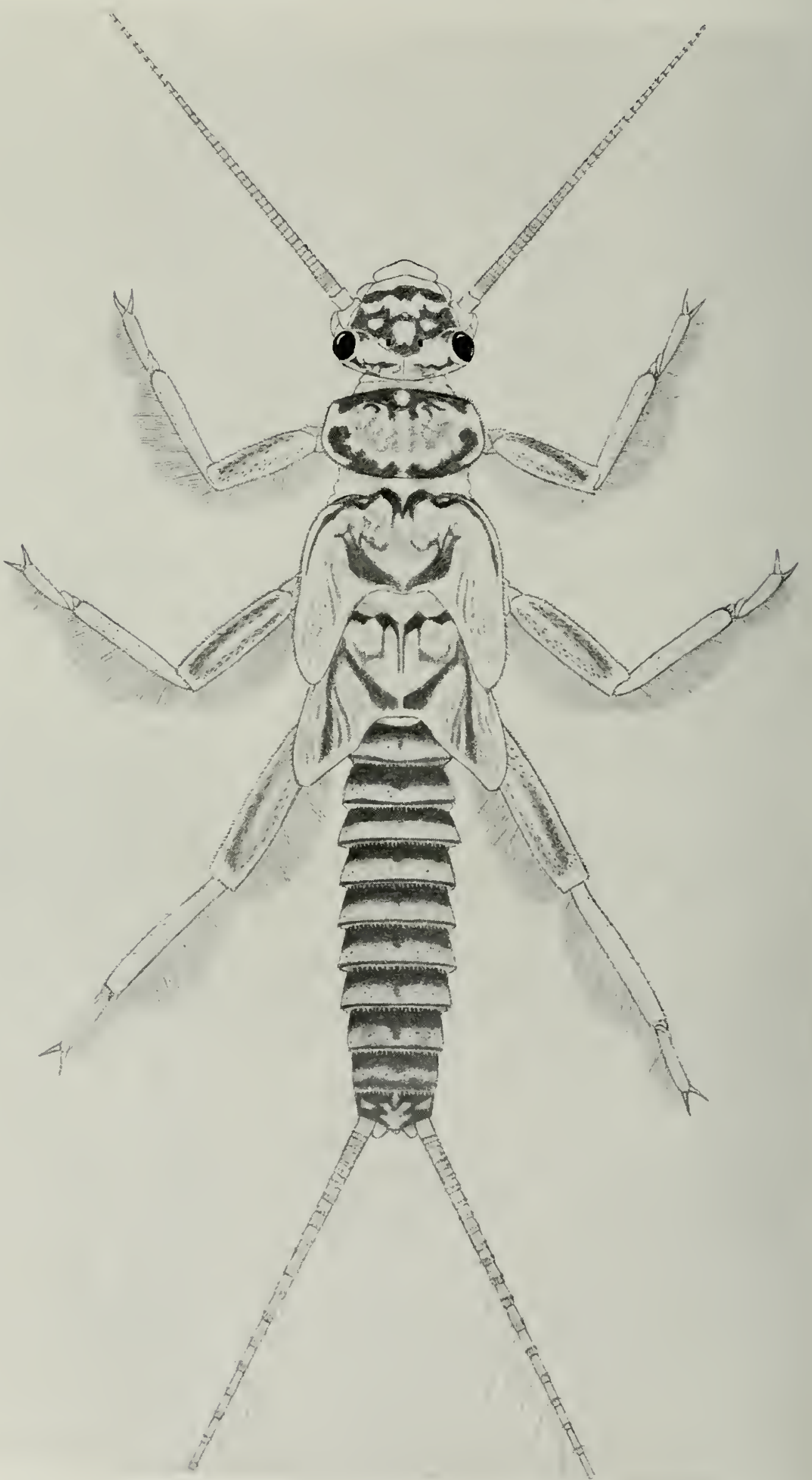

Fig. 329.--Hydroperla crosbyi, NYMPHAL MALE. 
their collection is mostly a matter of chance. The nymphs however, even though never abundant, concentrate in clumps of decaying leaves which are lodged in the water against stones or branches of trees, fig. 14, and examination of such places in late March or early April in central Illinois will certainly reveal some specimens. The nymphs are not partial to rapid water and are often found in slow, heavily silted streams in rich soil areas.

Our rearings and collections of adults in April and not later than the first of May prove crosbyi to be a true member of the early spring fauna. Our association of nymphs and adults is based upon rearings, and association of the sexes upon mating pairs.

Dissection of one crosbyi nymph collected in Catfish creek, near Brocton, Ill., March 28, 1932, revealed numerous chironomid nymphs and other insects in the alimentary tract, so that these nymphs are to be classed as carnivorous. Our collection of nymphs indicates that it takes about one year for the life cycle to be completed and that the most rapid growth of the nymphs occurs in Fehruary and March.

The following characterizes the previously undescribed nymph.

Nymphal male, fig. 329.--General ground color yellowish with conspicuous dark brown or black markings on dorsum as follows: most of central area of the head anterior to epicranial arms except for three yellowish spots and a more or less $W$ shaped transverse band; transverse markings on posterior margin of head; posterior, anterior and part of lateral margins of prothorax; a series of markings on meso- and metanotum; a wide transverse band on anterior margin and a more slender transverse band or line on posterior margin of each abdominal tergite; and longitudinal stripes on femur.

Head with three ocelli forming a nearly equilateral triangle, lateral ocelli about on a line with anterior point of compound eyes and median ocellus about on line with middle of point of articulation with antennae. No occipital ridge. Posterior margin of compound eye with a row of short setae. Labrum, fig. +3, labium, fig. 133, maxilla, fig. 103, mandibles, fig. 73, and submentum, fig. 168 , as illustrated.

Pronotum much broader than long; hind angles much rounded, front angles sharper; marginal groove rather weakly defined, particularly on lateral margins. Meso- and metanotum with wing pads well developed, those on mesonotum extending almost straight backward, and those on metanotum extending slightly outward as well.

Legs but slightly flattened; femora about twice as broad as tibiae and covered with numerous short stout setae except for a bare median longitudinal stripe; hind margins of femora, tibiac and tarsi with a fringe of long fine setae. 


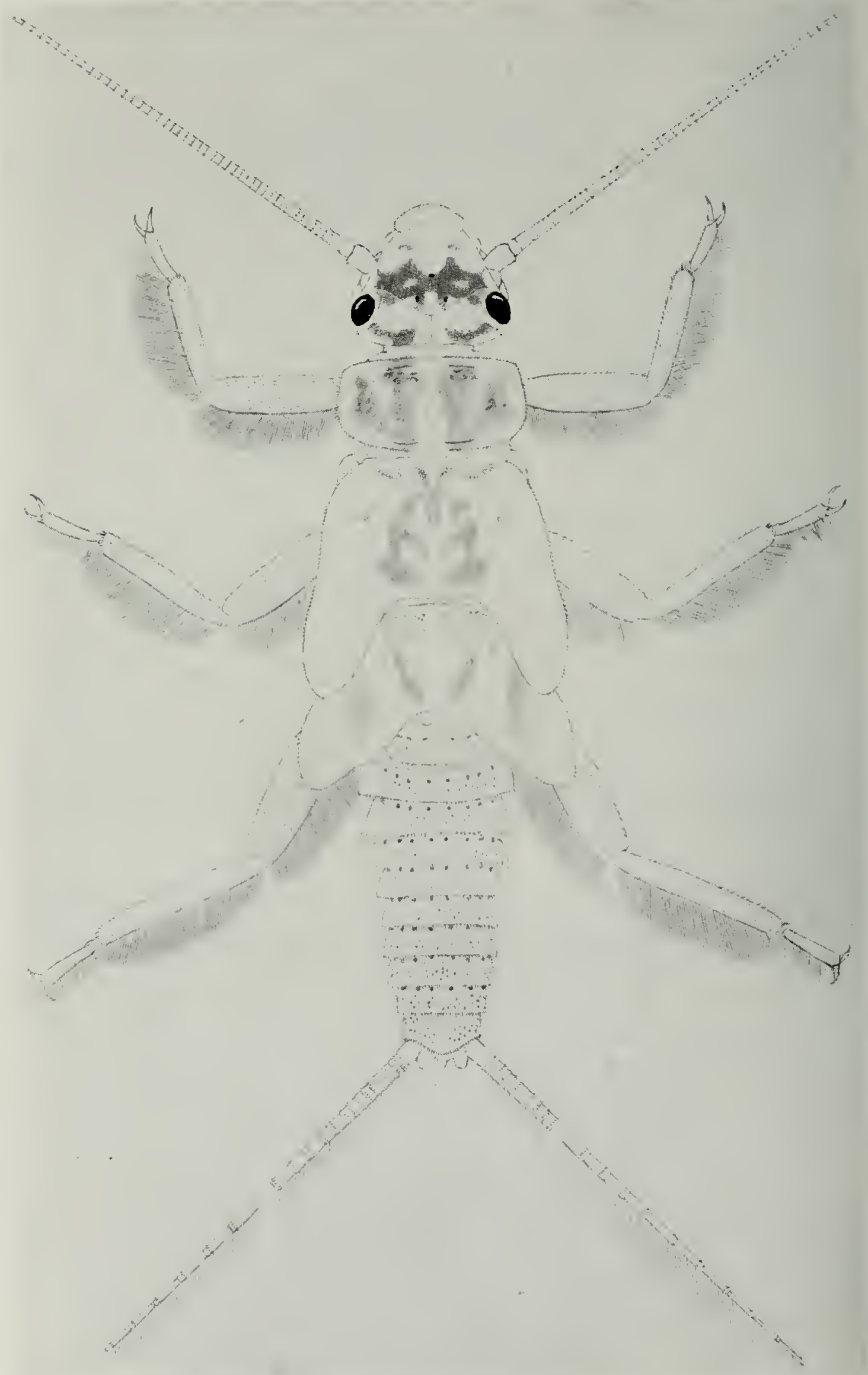

Fig. 330.-Hydroperla harti, NYMPHAL MALE. 
Abdomen shaped and marked as in fig. 329. Cerci about as long as abdomen, with 30 or more segments, segments progressively longer apically. Tenth tergite but slightly produced backwards on posterior margin. Eighth sternite with posterior margin almost straight and transverse setal fringe not interrupted.

Thoracic and abdominal gills absent. A small finger-like gill, fig. 168, at each outer posterior corner of submentum.

Mature specimens with a body length, exclusive of appendages, sometimes as much as $20 \mathrm{~mm}$.

Nymphal female. - Similar to male in general color and most morphological details. Eighth abdominal sternite with row of setae on posterior margin interrupted in middle. Mature specimens average larger than males, with a body length up to $27 \mathrm{~mm}$.

Adults.-Charleston: Apr. 11, 1931, $1 \sigma^{7}$. Havana: Apr. 21-24, 1898, 29. Urbana: May 1, 1927, $10^{7}$; Apr. 11, 1928, $1 \sigma^{7}$.

Nymphs.-Brockton (Catfish cr.): Mar. 28, 1932. Charleston (Embarrass r.): Mar. 22, Apr. 2, 17, 1931; Mar. 28, 1932. Decatur (Stephens cr.): Mar. 27, 1931. Marshall (Big cr.): Feb. 27, 1932. Oakwood (Salt Fork r.): Mar. 4, 1927. Shelbyville (Kaskaskia r.): Apr. 10, 1932. W. Union (Mill cr.): Feb. 27, 1932.

Reared from nymphs.-Charleston: Apr. 11, 17, 24, 1931, $12 \sigma^{7}, 60$.

Mating pair--Charleston: Apr. 17, 1931.

\section{Hydroperla harti - NEW SPECIES}

Figs. 24, 44, 74, 104, 134, 167, 324, 326, 330.

The distribution in Illinois of this new species is peculiar in that all our adults, nymphs and nymphal cast skins have come from the Mississippi river or from the Rock river near its confluence with the Mississippi. Our collecting in central eastern Illinois is sufficiently quantitative and qualitative to indicate that harti is either a great rarity in that part of the state or is absent. Its distribution suggests that there is probably some idiosyncracy in the life history of this species which restricts it to very large rivers. Along the Mississippi in southern Illinois it is as common as is crosbyi in central Illinois.

Our collections of adults and rearings show that harti is a true member of the spring fauna. The adults, like crosbyi, are diurnal and a favorite resting place during the day is pier, wing dam or bridge piling in the Mississippi river or vegetation near the shore. It is on such structures in the river also that the cast skins of the nymphs are found in numbers. Mating takes place during the day. The largest number of adults taken at one place and time was near Ivy Landing, Ill., May 17. 1932, where these stoneflies were active on vegetation near the river. Perla fugitans Needham and Claassen may be closely related to this species. 
Due to scarcity of material I have not dissected a nymph but judging from the mouthparts I am confident that it is carnivorous like its close relative crosbyi.

Male. - Length to apex of wings $15 \mathrm{~mm}$. ; length to apex of abdomen $12 \mathrm{~mm}$. General dorsal color dark brown or black. Yellowish dorsal areas as follows: a band on extreme posterior margin of head, narrow area around compound eyes, and an arm extending forward from posterior band into ocellar area; a median longitudinal stripe, broad on anterior pronotal flange and on posterior half of pronotum, narrow between these two areas; a median longitudinal stripe on mesonotum; apical abdominal tergite and extreme base of cerci. General ventral color yellow with median and lateral dark areas on thoracic segments and with broad dark bands on abdominal sternites except first which has spots, and last sternite which is entirely yellow but for small dark spots near base of cerci. Antennae, legs and cerci except extreme base are essentially dark brown or black.

Head but slightly wider through compound eyes than pronotum; ocelli nearly forming an equilateral triangle, lateral ocelli about on a line with middle of compound eyes, median ocellus about on a line with posterior point of articulation of antennae. Submentum with remnants of the finger-like nymphal gills at outer posterior angle. Antennae with 40 or more segments, basal segments wider than long, middle and apical segments longer than wide.

Pronotum approximately quadrangular, much broader than long, slightly wider at posterior margin than on anterior margin; front angles rather sharp, rear angles slightly rounded; pronotal flange well developed on anterior margin but weakly so on sides and on posterior margin; a rather indistinct pattern of raised rugosities on surface.

Legs almost uniformly dark brown or black; second tarsal segment much shorter than first, the first much shorter than third.

Wings long, extending beyond tip of abdomen, up to $14 \mathrm{~mm}$. in length; membrane dull hyaline, veins very dark and contrasting; venation slightly variable but essentially as for crosbyi, fig. 183.

Abdomen with dorsal segments one to nine without special structures; tenth tergite cleft, with paragenital plates, supra-anal process and apical lobes as in fig. 326. Cerci with 30 or more segments, basal segments broader than long, middle and apical segments much longer than broad.

Female. - Length to apex of wings $21 \mathrm{~mm}$; length to apex of abdomen $15 \mathrm{~mm}$. Head, thorax, abdomen and appendages in general similar to those of male. Differs from male as follows: basal abdominal segments often slightly lighter than those of middle area, ninth abdominal tergite largely yellow; tenth abdominal 
tergite not cleft but slightly rounded behind; abdominal sternites one to eight mostly yellowish, with more or less quadrate spots on lateral margins; eighth abdominal sternite with a posteriorly protruding and somewhat triangular subgenital plate overlapping basal portion of ninth sternite, fig. 32t; subgenital plate dark brown or black; a more or less rounded spot on each lateral portion of ninth sternite.

Nymphal male, fig. 330.-General ground color pale whitish yellow. Dorsum with some brownish, often suffused markings on head and thorax; longitudinal rows of small distinct brownish spots on abdomen; the area anterior of epicranial arms on the head is the darkest of the brown areas, followed in intensity by markings on pronotum.

Head with three ocelli nearly forming an equilateral triangle; lateral ocelli about on a line with anterior point of compound eyes and median ocellus about on line with middle of point of articulation with antennae. No occipital ridge. Posterior margin of compound eye with a row of some short setae. Labrum, fig. $+t$, labium, fig. 134, maxilla, fig. 104, mandibles, fig. 74, and submentum, fig. 167 , as illustrated.

Pronotum much broader than long; hind angles much rounded, front angles sharper; marginal groove rather weakly defined, particularly on lateral margins. Meso- and metanotum with wing pads well developed, those on mesonotum extending almost straight backward, and those on metanotum extending slightly outward is well.

Legs but slightly flattened; femora about twice as broad as tibiae and with only a few short stout setae; hind margins of femora, tibiae and tarsi with a fringe of long fine setae.

Abdomen marked as in fig. 330. Cerci longer than abdomen, with over 30 segments; segments progressively longer apically. Tenth tergite slightly produced backwards on posterior margin. Eighth sternite with posterior margin almost straight and transverse setal fringe not interrupted.

Thoracic and abdominal gills absent. A small finger-like gill, fig. 167, at each outer posterior corner of submentum.

Mature specimens with a body length, exclusive of apperdages, of $13 \mathrm{~mm}$.

Nymphal female.-Known to me only from cast skins which average larger than the males and have the row of setae on the posterior margin of the eighth abdominal sternite interrupted in the middle. Color pattern and other features are as in the male.

Holotype, male.-Ivy Landing, 11l. (near Mississippi r.): Mily 17, 1932. Collected by H. H. Ross and C. O. Mohr.

Allotype, female. Collected in coitu with holotype.

Paratypes.-Chester: May 11, 16, 1932, $1 \sigma^{7}$, 49. Fountain Bluff: Apr. 21, 1914, $2 \sigma^{7}$; May 12-15, 1932, 49. Grafton: May 10, 1932, $10^{7}$. Ivy Landing: May 17, 1932, $30^{7}, 9$ ㅇ. Rock Island: May 3, 19.31, $20^{7}, 1$ ․ 
Tiptonville, Tenn. (Reelfoot lake): Mar. 28, 1932, $1 \sigma^{7}$; Apr. 2, 1934, $50^{7}, 8$ ?.

Nymphs.-Alton (Mississippi r.): May 18, 1932, exuvia. Chester (Mississippi r.): May 11, 16, 1932, exuviae. Fountain Bluff (Mississippi r.): May 12-15, 1932, exuviae. Grafton: May 19, 1932, exuviae. Keithsburg: June 14, 1932, exuviae. Rock Island (Rock r.): Apr. 10, 1931; Mar. 2, 1932.

Reared from nymphs.-Rock Island: May 3, 1931.

\section{Hydroperla varians (Walsh)}

Fig. 327.

Perla varians Walsh (1863) p. 364 . Original description $\left(\sigma^{x}\right.$, o).

This species was described by Walsh from specimens taken near Rock Island, Ill., and Dr. Banks has stated to me in a letter that the type is now in the collection of the Museum of Comparative Zoology, Cambridge, Mass. An autotypic male specimen, obtained from the institution just mentioned, is now in the Survey collection and bears the data "Perla varians, Rock Island, 1863." I am basing my concept of varians upon the characters of this specimen. The only other specimen we have of this species, also a male, comes from far to the south on the Ohio river at Golconda, Ill., April 19, 1914.

Study of the male in our collection, named by Walsh, shows that r'arians differs from both crosbyi and harti in the shape of the supra-anal process and in certain other structures, fig. 327. The Illinois males of Hydroperla are easy to separate on the basis of the genital structures but other characters are unreliable or nearly nonexistent. Walsh described the female as well as the male but $I$ am not certain whether his association was correct because harti also occurs at Rock Island and might have been inixed with his varians. His description of the female, that "the seventh abdominal segment is prolonged laterally much beyond the other abdominal segments, so as to partially cover the base of the antepenultimate ventral" is suggestive of harti.

It is also possible that $W$ alsh's series of varians contained males of varians as here used and also of harti. The drawing of Needham and Claassen (1925) of the male of varians does not bring out clearly the details of the supra-anal process, but in general it is very suggestive of what I am calling harti.

Evidently varians is uncommon in Illinois and I have not located a nymph which might be this species. Our specimen from Golconda was collected April 19, a good indication that varians is a true member of the spring fauna as are the other Hydroperla. No doubt its habits are very similar to those of crosbyi and harti.

It should be stated here that Needham and Claassen (1925) have 
recorded varians from Illinois (based upon Walsh's record), Indiana, Kansas, Michigan, Minnesota and Wisconsin. I have studied some of these specimens and the ones studied do not agree with what I am calling rarians based upon the autotypic male in our collection. Further, I believe that some of these specimens which have been recorded as zarians are the same species as specimens recorded under the name of postica Walker. Certain specimens named and recorded by Needham and Claassen both as varians and postica have a much more slender supra-anal process than harti and it is possible that their plate 17, fig. 12, is an illustration of this species, for which I an holding the name of postica. Needham and Claassen do not figure a male of postica.

Apparently, then, there is a species of Hydroperla not as yet found in Illinois which can be associated with the name postica, although just what Walker had when he described postica is somewhat doubtful. The type of zarians at Cambridge, or the specimen selected as a lectotype in the Cambridge series, needs to be restudied in the light of present knowledge to settle the use of the name rarians, and 1 regret not having had such in opportunity.

My rearings and mating pairs have definitely linked the males and females of two species of Hydroperla, crosbyi and harti. Heretofore no reliable basis has existed for the assignment of females belonging to this complex of species to any male. This alone is sufficient to explain wrong associations of sexes or misidentifications in the past.

\section{CHIOROPERLIDAE}

Although this family has been recognized by many European student: of stoneflies, it has not been accepted in American systems of classification. I consider that Chloroperla Newman, Alloperla Banks, Isoperla Banks (s. lat.), Paraperla Banks and Kathroperla Banks are the North American genera comprising this family.

Here probably belong, also, certain species which Needham and Claassen (1925) have placed under the subgenus Hemimelnena. As mentioned before, I am doubtful about the occurrence of the true Hemimelaena in this country and have placed in Perlodidae, under the genus Hydroperla. several species which have been assigned to Hemimelaenn and which I feel certain belong to another line of descent. Future studies of both adults and nymphs are needed before the status of several of the species placed in Hemimelaena by Needham and Claassen can be determined satisfactorily. Perla duplicata Banks, one of two species placed by Needhan 
and Claassen under their new subgeneric name Diploperla, I am placing in Isoperla (s. lat.).

That Diploperla, as represented by the species duplicata in this report, is not a true Isoperla is evident from a study of either adults or nymphs. From the standpoint of identification however it can best be treated at the present time as a member of Isoperla (s. lat.).

The genus Isoperla as used in this paper includes certain species for which Needham and Claassen (1925) have proposed the generic name of Clioperla. In my studies of the adults and nymphs of Illinois species and of other material I have found it impossible to make a clear or absolute distinction between Isoperla and Clioperla. Isoperla is supposedly characterized from the standpoint of wing venation by the absence of intercubital crossveins, and Clioperla by their presence. This is an exceedingly variable character in some of the species concerned. Even in Isoperla bilineata, the type of the genus Isoperla, my tabulations show that about one-third of the Illinois specimens are likely to have an intercubital crossvein in one or both wings.

Since Claassen (1931) has noted a difference in the shape of the lacinia in the nymphs of the species he placed as Isoperla and Clioperla, I would be tempted to hold Clioperla as a valid genus if it were not for two reasons. In the first place I can find no constant distinctive and workable characters except size and color by which to separate the adults of these two groups as at present defined. Secondly, within the group of species placed by Needham and Claassen in Isoperla and those described in this paper we find nymphs with such diversified lacinia that they are as well entitled to generic status on this basis as are the nymphs which have been placed in Clioperla. In other words, if Clioperla is to be recognized as a genus it would be equally proper to establish several additional genera, easily differentiated as nymphs but very hard to define as adults. The characters shown by the lacinia of some of the nymphs unfortunately do not carry over.

Whether the apical segments of the maxillary and labial palpi are slender or not has also been used for separating nymphs of Clioperla and Isoperla. Some of the isoperlid species do have more slender palpi than others but I have been unable to separate the Illinois isoperlids into groups on this basis so that the resulting groups would be in harmony with other evidences of relationships.

In view of the present status of our knowledge of the North American Isoperla (s. lat.) in general it has seemed hest to follow a conservative course in the present study based upon the Illinois fauna and to recognize the smaller complexes (Clioperla, Diploperla, Isoperla s. str., etc.) of 
natural aggregates of species within Isoperla (s. lat.) as subgenera. Perhaps future studies covering all the North American Isoperla (s. lat.) will shed such new light upon this group that it will be found necessary as well as practical to elevate these subgenera to generic status or else to sink them entirely. It seems to me that my difficulty in not being able to formulate a generic classification upon the basis of the adults which will hold for the nymphs, or zice rersa--in spite of the heterogeneous appearance, size and color of the species lumped in Isoperla (s. lat.)-is indicative that the species of Chloroperlidae, particularly isoperlid forms, exhibit a group in a state of active evolution.

'The adults are characterized by the absence of crossveins in the anal area of the forewings, the presence of a series of median and cubital crossveins in the forewing, presence of long and many segmented cerci, short first tarsal segment in comparison with third tarsal segment, and the absence of any remnants of nymphal gills. The combination of the complete absence of all types of gills with possession of mouthparts in which the paraglossae of the labium extends forward much farther than the glossae, fig. 135, especially separates the nymphs of Chloroperlidae from other families.

Of the genera which 1 consider as belonging to Chloroperlidae, only Isoperla (s. lat.) and Chloroperla have heen found in Illinois.

\section{KEY TO GENERA}

\section{Adults}

Hind wing without it folked anal area, fig. $187 \ldots \ldots \ldots \ldots$ Chloroperla, p. 429) Hind wing with a folded anal area, fig. $188 \ldots \ldots \ldots \ldots$. Isoperla (s. Iat.), 1) 4.31

\section{Nymphs}

Wing pads with lateral margins broadly rounded, fig. $331 \ldots$ Chloroperla, p. 429 Wing pads with lateral margins more straight, figs. 339, 344. Isoperla (s.lat.), p. 431

\section{Ghloroperla Newman}

Newman (1836) p. 501. Genotype Chloroperla apicalis Newman, sul)sequent designation of Enderlein (1909).

In Europe the name of Isopteryx is still used for this genus but Banks (1906a) has clearly shown that Chloroperln is the generic name to be used for those species possessing the characteristics of cydippe. Absence of a folded anal field in the hind wing is a reliable character for recognition of the group.

According to Needham and Clakssen (1925) this genus contains hus one North American species. 
430

ILLINOIS NATURAL HISTORY SURVEY BULLETIN $X X: I V$

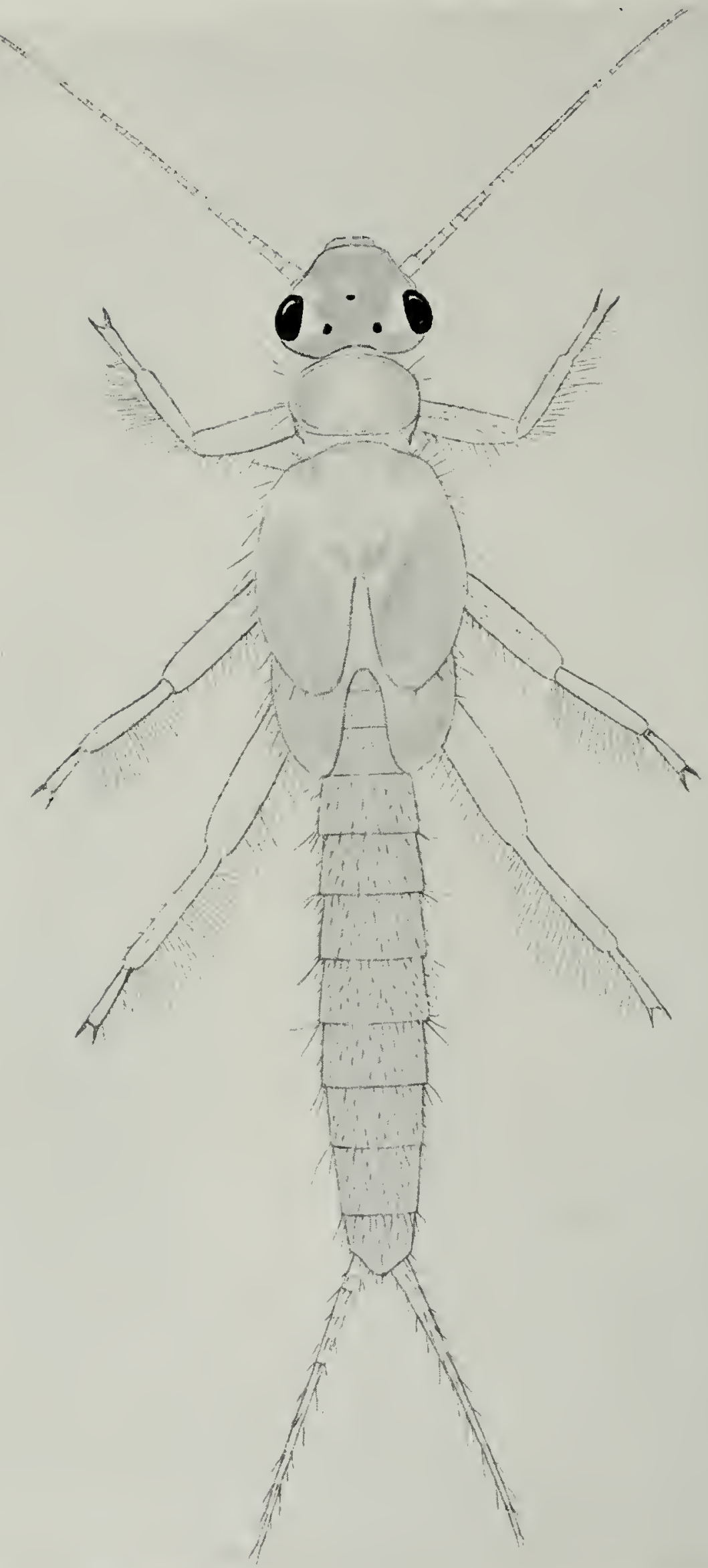

Fig. 331.-Chloroperla cydippe, NYMPHAL FEMALE. 


\section{Chloroperla cydippe Newman}

Figs. $45,75,105,135,185,187,191,232,331$.

Chloroperla cydippe Newman (1839) p. 88. Original description.

Chloroperla cydippe Claassen (1931) p. 63. Nymphal description.

This species has been recorded from near Rock Istand by Walsh (1862) under the name of Isopteryx cydippe. Strangely, it has not been encountered again in this state during our eight years of field work on stoneflies. Since Walsh's identification of this species was checked by Hagen, as indicated by the exclamation point after the name in his report, and since Hagen unquestionably knew cydippe, this record must be accepted. However, we have found this species in abundance in the Wabash watershed of Indiana, near the Illinois border. No doubt it will sometime again be found in this state.

The records given in literature for this species are mostly from states east of the Mississippi river. No doubt it will eventually be found in many states east of the Rocky mountains. Our observations concerning this species at Turkey Run state park, Ind. indicate that the adult maximum abundance comes about the middle of May. The nymphs ate herbisorous and occur in masses of leaves lodged in the water of small streams. We have reared the adults at our Charleston, Ill. station from nymphs taken in Indiana.

The adults have been well described by previous writers. Their distinctive features from the standpoint of identification are given in the key to adults of Chloroperlidae and in figs. 191, 232. The nymph, fig. 331, has been described by Claassen (1931). Its most important morphological features, aside from general appearance and absence of gills, are the broadly rounded lateral margins of the wing pads and the shape of the mouthparts, figs. 45, 75, 105, 135.

\section{Isoperla Banks}

Banks (1906a) p. 175. Genotype Perla bilineata Say = Isoperla bilineata (Say), original designation.

The generic name of Isoperla was proposed by Banks (1906a) for part of the aggregate of species left without a name when Isopteryx of European authors was shown to be equivalent to Chloroperla, the latter having priority. The other part of this aggregate was named by Banks at the same time as Alloperla.

I am using Isoperla in a broad sense, as previously indicated, because of the impossibility of making definite separations at this time of those small natural aggregates which have been proposed as general or subgenera 
and still others which have not been named but exist as shown by my studies. I am referring here to such groups as Clioperla, Diploperla and others unnamed. A thorough study of the North American Chloroperlidae, both adult and nymphs, will reed to be made before these divisions can be properly evaluated as to genera or subgenera. As here used in its broad sense, Isoperla is quite generally distributed over North America.

The Isoperla of this state evidently require one year for completion of their life cycle. Of the nine species included here I have had opportunity to study seven in the field. Most of these are diurnal and may be collected upon vegetation or other objects near the streams inhabited by the nymphs. Isoperla bilineata and probably richardsoni are more nocturnal and come to lights in large numbers. The fact that some species are diurnal and others nocturnal is good evidence that Isoperla as used here is composed of two or more rather separate elements.

Further evidence that the Isoperla of this paper include diverse forms are the feeding habits and mandibles of the adults. I have observed adults of minuta, a diurnal species, feeding upon pollen, and examination of its mouthparts reveals well developed and sclerotized mandibles. Another diurnal species, decepta, likewise has such mandibles but I have not observed the adults feeding. The mandibles of the adults of bilineata, confusa, conspicua, duplicata, mohri and richardsoni, on the contrary, are more flabby and do not impress me as being functional. Some of these are diurnal and others are nocturnal.

The nymphs also show cause for believing that the genus is at present an aggregate. Variation in their choice of stream is prominent. Bilineata and richardsoni apparently prefer the largest rivers, confusa streams of medium size, and decepta, duplicata, minuta and mohri very small streams or brooks.

The food habits of the nymphs, which I suspect are variable but which need further investigation, are another indication. Claassen (1931) states that the structure of mouthparts of the nymphs of Clioperla (Isoperla as used here) "indicates that they are carnivorous," and that nymphs of Isoperla "are carnivorous, but in their younger stages one sometimes finds plant remains, such as diatoms and algae, in their digestive tract." I have examined quite a few nymphs of Isoperla bilineata and minuta without finding any insect remains but have found such remains in the nymphs of duplicata, mohri and confusa. In addition our field notes record the collection of a nymph of Isoperla decepta, and at another time a nymph of richardsoni, with a half eaten chironomid larva in its mouth.

Variations in feeding habits are likewise indicated by differences in structure of the nymphal lacinia. Probably those species like bilineata 
which at times are very abundant lean toward the herbivorous habit, whereas the larger and less abundant species like confusa and duplicata are more pronounced carnivores.

There is a possibility that one or more of the new species placed in this genus have been previously described. These relationships cannot be definitely determined from literature at this time and need to await rearings of adults from nymphs and correct associations of males and females in other parts of the country.

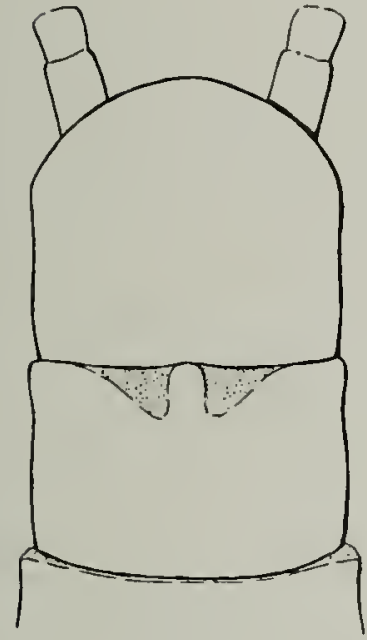

332

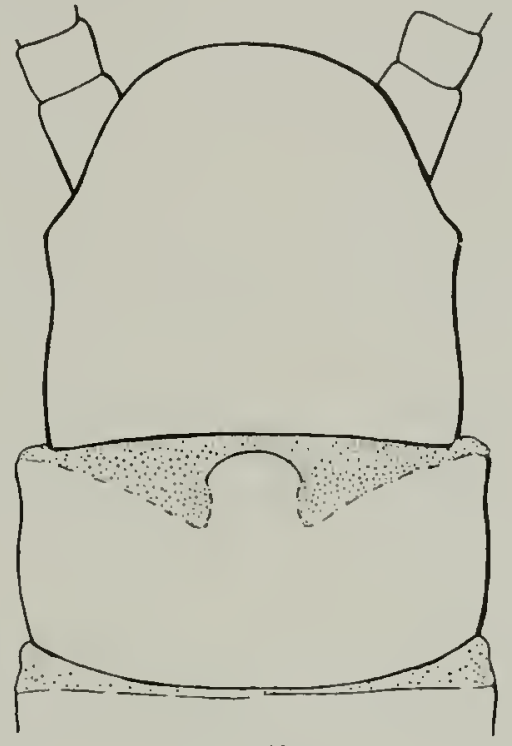

333

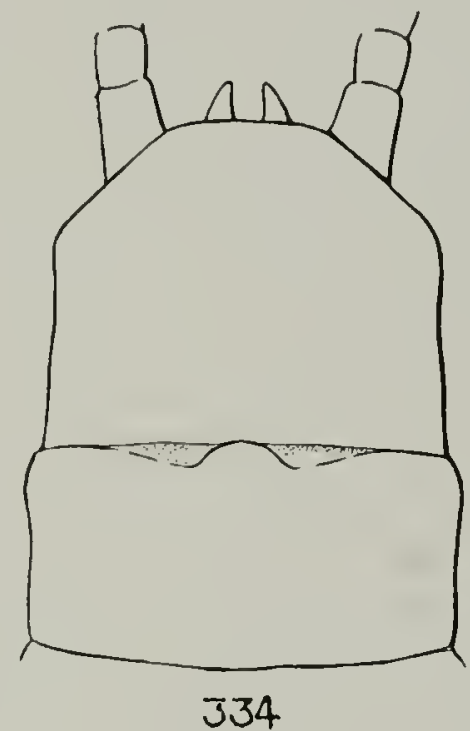

Figs. 332-334. - VENTRAL VIEW OF TERMINAL ABDOMINAL SEGMENTS OF ADUL' MALE OF Isoperla. Note differences in shape of median lobe on posterior margin of eighth sternite. 332.-I. decepia. 333.-I. mohri. 334.-I. bilineata.

Walsh (1862) has described a "female (?) specimen" from near Rock Island under the name of "Chloroperla nana, n. sp." This species has never been satisfactorily placed. It was accidentally omitted from consideration by Needham and Claassen (1925) but subsequently listed as unrecognizable by Claassen (1928). Our studies of the Illinois stoneflies have failed to clear the mystery concerning this species. The description indicates a very small dark species, which might be Isoperla minuta Banks. It does not however have the hyaline streaks on the wings entirely absent as stated in the original description and it seems strange that Walsh would overlook the distinctive shape of the subgenital plate of his specimen if it were a female. Furthermore, we have not as yet found minuta in the vicinity of Rock Island although it is very common in central Illinois. Walsh's uncertainty about the sex of nana indicates that his type was a male if it is the same species as minuta. Perhaps after the Isoperla fauna of the central states is better known it will be advisahle to sink minuta as a synonym of nana. Unfortunately the type of the latter is not in existence. 
KEY TO SPECIES

\section{Adults $^{13}$}

1. Ninth ventral abdominal segment much produced posteriorly and recurved upward so that tenth ventral abdominal segment is mostly or entirely concealed, fig. 334. Eighth ventral abdominal segment slightly produced or with a small lobe in middle of posterior margin, figs. 332-334, (males).2 Ninth ventral abdominal segment poorly or not at all produced posteriorly, and tenth ventral abdominal segment always visible. Eighth ventral abdominal segment without a small lobe in middle of posterior margin; posterior margin either broadly transverse, fig. 251, or strongly produced as a subgenital plate, fig. 237 , (females) ..................

2. Seventh ventral abdominal segment with middle of posterior margin distinctly produced, fig. $341 \ldots \ldots \ldots \ldots \ldots \ldots \ldots \ldots \ldots$. . . . . . . . . . . . 449 Seventh ventral abdominal segment with posterior margin of segment straight. 3

3. Dorsal, ventral and lateral surfaces of abdominal segments uniformly dark brown. A smal! species usually shorter than $7 \mathrm{~mm}$...... minuta, p. 453

Dorsum and venter of abdomen mostly yellow, yellowish brown or whitish green. In some species with dark lateral marking strongly contrasting with remainder of abdomen. Small to medium sized species ranging from

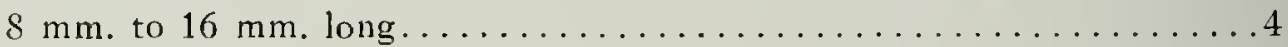

4. Species with contrasting body colors of yellow and black or brown. Veins of wings all dark and strongly contrasting with membrane of interspaces.

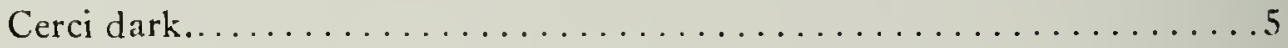

Species yellowish or whitish green. Veins of wings lighter and less contrasting.

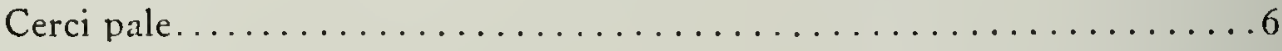

5. Area between ocelli completely dark. Patch of small spines on posterior portion of ninth dorsal abdominal segment, fig. 205. Lobe in middle of posterior portion of eighth ventral abdominal segment broad, similar to fig. 334 . Medium sized species, at least $13 \mathrm{~mm}$. in body length.... confusa, p. 441

Area between ocelli not completely dark. Without a patch of small spines on posterior portion of ninth dorsal abdominal segment, fig. 193. Lobe in middle of posterior portion of eighth ventral abdominal segment narrower and more sharply defined, fig. 333. Small species, less than $10 \mathrm{~mm}$. in body length.................................... p. 455

6. Median and lateral ocelli connected by a dark line making a $\mathrm{V}$ shaped outline.................... bilineata, p. 437 ; richardsoni, p. $459^{14}$ Median and lateral ocelli not connected by a dark line.........decepta, p. 447

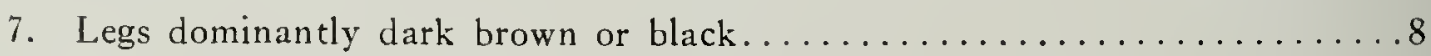

Legs dominantly pale yellow or whitish green..................

8. Dorsal, ventral and lateral surfaces of abdominal segments uniformly dark brown. Crossveins in costal margin of forewing between humeral crossvein and end of subcostal usually entirely lacking, rarely one. Costal margin of forewing pale and contrasting with remaining fuscate portion

${ }_{13}$ The male of conspicua is not known and clio is not included in the adult key under vither sex because of lack of spceimens.

14 I have been unable to separate the males of these two suecies satisfactorily in the key. See disemssion under richardsoni. 


\section{KEY TO SPECIES-ISOPERLA-CONT'D}

of wing. Small species, usually shorter than $8 \mathrm{~mm}$. in body length; subgenital plate as in fig. $234 \ldots \ldots \ldots \ldots \ldots$ minuta, p. 453

Dorsum and venter of abdomen mosty yellow or yellowish brown; in most species with dark lateral markings contrasting with remainder of abdomen. Small to medium sized species ranging from $8 \mathrm{~mm}$. to $17 \mathrm{~mm}$. in body

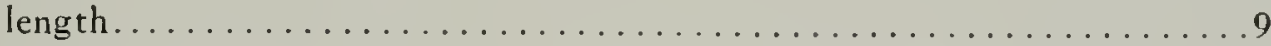

9. Subgenital plate extending entirely across ninth sternite, fig. $249 \ldots . .$.

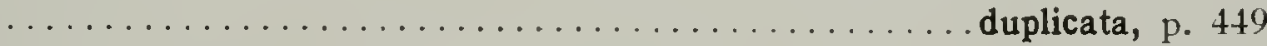

Subgenital plate not extending so far posteriorly $\ldots \ldots \ldots \ldots \ldots \ldots \ldots 10$

10. Subgenital plate deeply notched in middle of posterior margin, fig. 239 ... .

Subgenital plate not deeply notched in middle of posterior

11. Subgenital plate weakly rounded on posterior margin and but slightly produced over ninth sternite, fig. 251. Area between ocelli entirely dark. Medium sized species with a body length exceeding $13 \mathrm{~mm}$. . confusa, p. 441

Subgenital plate well rounded on posterior margin and considerably produced over ninth sternite, fig. 238. Area between ocelli not entirely dark. Small species with a body length less than $10 \mathrm{~mm} \ldots \ldots \ldots \ldots$ mohri, p. 455

12. Median and lateral ocelli connected by a dark line making a $\mathrm{V}$ shaped out-

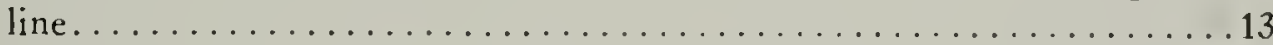

Median and lateral ocelli not connected by a dark line........decepta, p. 447

13. Subgenital plate somewhat triangular and much produced over ninth sternite, figs. $236,237 \ldots \ldots \ldots \ldots \ldots \ldots \ldots \ldots \ldots \ldots \ldots \ldots \ldots \ldots \ldots \ldots$ bilineata, p. 437

Subgenital plate more rounded and but slightly produced over ninth sternite, fig. $235 \ldots \ldots \ldots \ldots \ldots \ldots \ldots$. . . . . . . . . . . . . . . .

\section{Nymphs}

1. Dorsal abdominal segments uniform, brownish except for a few small light

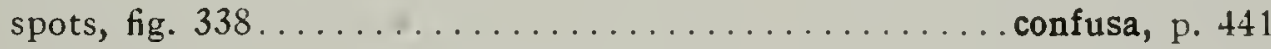

Dorsal abdominal segments with alternating transverse or longitudinal light and dark stripes or bands. . . . . . . . . . . . . . .

2. Dorsal abdominal segments with transverse markings, figs. 337,340 . Full grown nymphs medium to large, 13 to $20 \mathrm{~mm}$. body length..........

Dorsal abdominal segments with longitudinal markings, figs. 335,342 . Full grown nymphs of small to medium size, 6 to $13 \mathrm{~mm}$. body length.....4

3. Anterior margins of dorsal abdominal segments dark, posterior margins light, fig. 340. Lacinia of maxilla much narrower where teeth begin than at base, which is much swollen, fig. $110 \ldots \ldots \ldots \ldots \ldots$ duplicata, p. 449

Anterior and posterior margins of dorsal abdominal segments dark, middle portion light, fig. 337. Lacinia of maxilla almost as wide where teeth begin as at base, fig. $107 \ldots \ldots \ldots \ldots \ldots \ldots \ldots \ldots \ldots \ldots \ldots \ldots \ldots \ldots \ldots$. p. 439

4. Head with dark area extending back from median to lateral ocelli not cuudrate; light area in center of ocellar triangle large, figs. 335,344. I acinia with two long conspicuous teeth at tip, figs. 106, 113.

Head with dark area extending back from median to lateral ocelli almost quadrate; light area in its center or center of ocellar triangle small, figs. 339, 


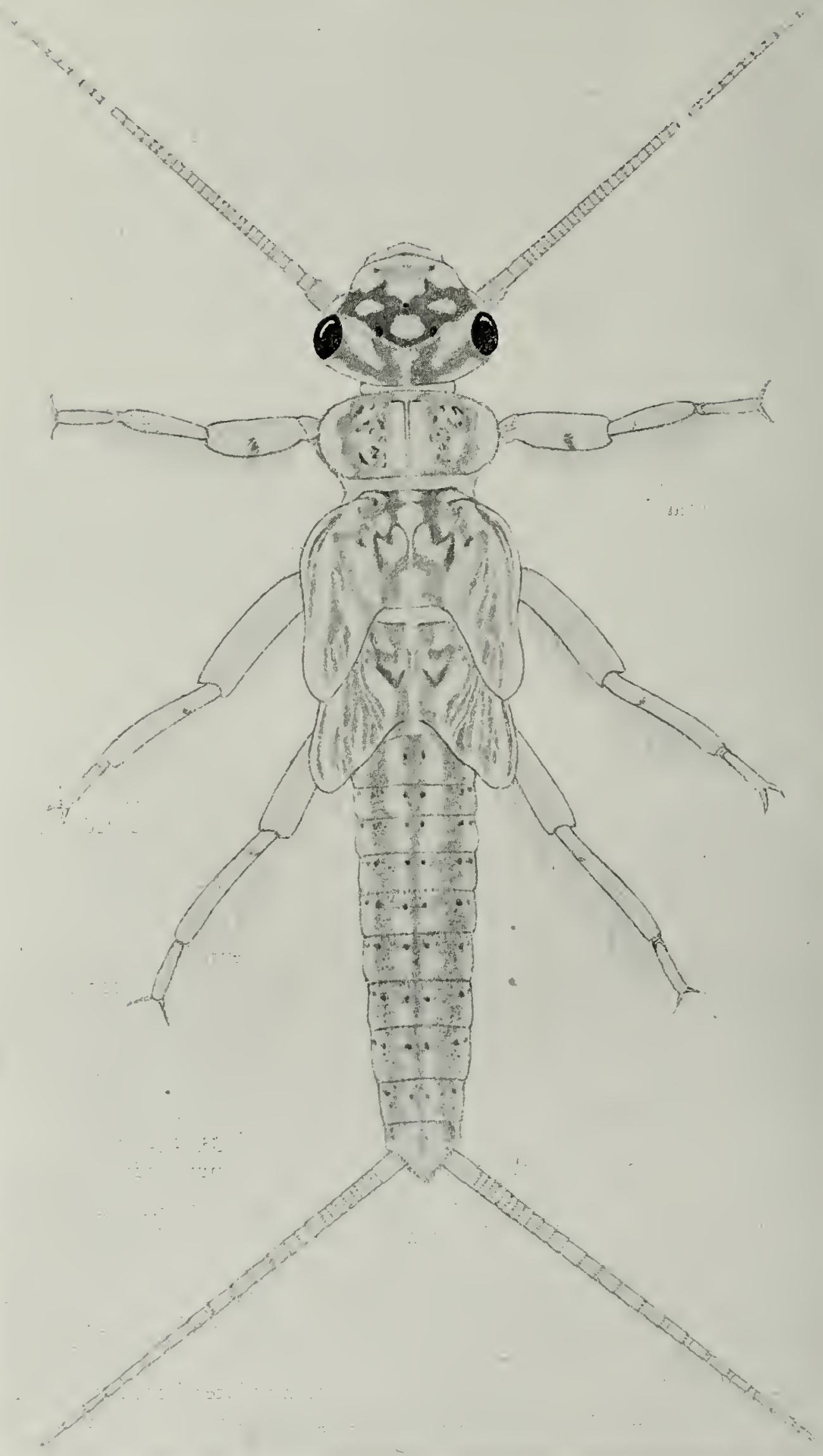

Fig. 335.-I Isoperla bilineata, NYMPHAL FEMALE. 
ISOPERI,A-KFY TO SPECIES-CONCI,'D

342, 343. Lacinia with one, figs. 111, 112, or no, fig. 109, long conspicuous

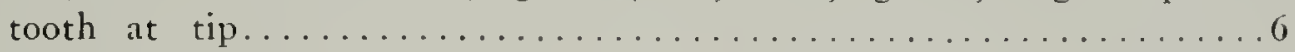

5. Head with light areas between compound eyes and adjacent to ocelli usually forming large detached spots, fig. 335. Three longitudinal dark stripes on dorsum of abdomen indistinct, fig. 335. Lacinial with inner margin lined with a row of long stiff setae, fig. $106 \ldots \ldots \ldots \ldots \ldots$ bilineata, p. 437

Head with light areas between compound eyes and adjacent to ocelli more confluent, fig. 344. Three longitudinal dark stripes on dorsum of abdomen more distinct, fig. 344. Lacinia with a tuft of long setae grouped just below smaller tooth and without a conspicuous row of long stiff setae on inner margin, fig. $113 \ldots \ldots \ldots \ldots \ldots \ldots \ldots \ldots$. richardsoni, p. 459

6. Dorsum of abdomen with two distinct dark longitudinal stripes upon an almost uniformly light background, fig. 343. Laciniat with one long conspicuous tooth at apex, fig. 112. Mandibles deeply notched at tips, fig. $82 \ldots$

mohri, p. 455

Dorsum of abdomen with two dark longitudinal stripes upon a somewhat suffused background which is dotted with numerous freckle-like spots, figs. 339,342 . Lacinia with one, fig. 111, or no, fig. 109, conspicuous tooth at apex. Mandibles less deeply notched at tips, figs. $79,81 \ldots \ldots \ldots \ldots 7$

7. Lacinia with one long tooth at apex, fig. $111 \ldots \ldots \ldots \ldots \ldots$ minuta, p. 453 Lacinia without a long tooth at apex; instead with several short, blunt scraperlike processes at apex, fig. $109 \ldots \ldots \ldots \ldots \ldots \ldots \ldots$ decepta, p. $4+7$

\section{Isoperla bilineata (Say)}

Figs. 46, 76, 106, 136, 161 186, 188, 198, 236, 237, 260, 263, 334, 335, 336.

Sialis bilineata Say (1823) p. 165. Original description.

Isoperla bilineata Claassen (1931) r. 73. Nymphal description.

This species was first recorded from near Rock Island by Walsh (1862). There is a typical female specimen of bilineata without locality label in the Survey collection which was named by Walsh as "Perla bilineata Say," which strengthens the conclusion that Walsh's record was correct. Although there are no additional records in literature for bilineata from Illinois it is our most common species of Isoperla. We have numerous records of it from every part of the state, and it is particularly abundant in localities adjacent to the largest rivers.

Adults begin emerging in southern lllinois by the end of March. but their maximum abundance in most of the state is not reached until about the middle of May. Very few specimens are encountered after the end of June. Bilimeata is therefore a true member of the spring fauna. It is essentially nocturnal and adults are often found in numbers at lights. During the day they may be beaten with a net from vegetation bordering rivers or captured while resting in protected places. The adults emerge from nymphs chiefly at night. 
'The nymphs make their most rapid growth from January to April. 'Their size groups as well as seasonal adjustments indicate a life cycle of one vear. I have been unable to find the remains of insects in the digestive tract of the many nymphs examined and I believe these nymphs are essentially herbivores. Very large and medium sized rivers are apparently ideally suited to the nymphs, but they are uncommon

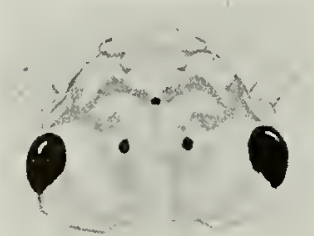

Fig. 336.-HEAD of Isoperla bilineata, N Y M P H A L MALE, EXTREME LIGHT FORM. or absent in many small streams which support such species as decepta, minuta and mohri.

As mentioned beforehand Clioperla and Isoperla in restricted senses have been separated in the adults upon the basis of the absence or presence of intercubital crossveins. This character is very unstable and of very little key value. In bilineata, the type of the genus Isoperla, about one-third of the specimens examined possessed intercubital crossveins, sometimes in both wings and sometimes in but one wing.

Bilineata has a very close ally in the new species which I am naming richardsoni in this paper. In the females these two species are easily separated upon the basis of the shape of the subgenital plates, figs. 235 , 236,237 , but in the males 1 have been unable to locate good differential characters. The characters of the apical abdominal segments of the male, so useful in making determinations in many other genera of closely related species, are in general less well developed in Isoperla than in most other groups.

The nymphs, fig. 335, described by Claassen (1931), are easily recognized because of their distinctive color pattern. The characters presented by the mouthparts are given in figs. 46, 76, 106, 136. The color pattern, particularly on the head, is subject to some variation in the proportions of light to dark areas and fig. 336 shows the head of an extremely light form: The most important structural features of the adults are shown in figs. 198, 236, 237.

Adults.-Algonquin: July 4, 1907, 1; June 28, 1909, $3 \sigma^{7}$. Alton: May 18, 1932, $1 \sigma^{7}, 1$. . Alto Pass: Apr. 17, 1927, $4 \sigma^{7}, 1$ 19. Assumption: Apr. 16, 1927, 1ㅇ. Brookport: Mar. 28, 1932, $1 \sigma^{7}$. Byron: May 19, 1927,

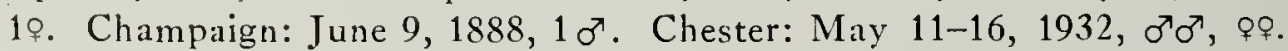
Dixon: May 31, 1914, $1 \sigma^{7}$. Dixon-Oregon: June 27, 1927, $1 \sigma^{7}$. E. Dubuque: July 21, 1927, 1 ; ; June 26, 1928, $2 \sigma^{7}$; June 15-24, 1932, $2 \sigma^{7}, 1 \%$; June 1, 1933, $\sigma^{7} \sigma^{7}$, 우. Elizabethtown: June 22, 1927, $12 \sigma^{7}, 5$; ; May 30, 1928, $4 \sigma^{7}$, 3ㅇ. Florence: June 7, 1928, 19. Fountain Bluff: May 15, 1932, $1 \sigma^{7}$, 1․ Golconda: May 13, 1932, $1 \sigma^{\top}, 1$ ㅇ․ Grafton: May 10, 20, 1932, $\sigma^{7} \sigma^{7}$,

कㅇ. Grand Detour: May 15, 1930, 2ᄋ. Grand Tower: Apr. 21, 1914, $1 \sigma^{\circ}$; May 12-15, 1932, $\sigma^{7} \sigma^{7}$, 우우. Hamilton: June 22, 1928, $2 \sigma^{7}$; June 3, 1930, $2 \sigma^{7}$. Hardin: June 25, 1931, 1ㅇ. Havana: May 3, 4, 6, 1894, $30^{7}$; May 6, 
1895, $1 \sigma^{7}$; Apr. 1896, 19; June 9, 1905, $5 \sigma^{7}, 99 ;$ May 23, 1911, 1; Apr. 30, 1914, 2क; June 22, 1928, $1 \sigma^{7}, 1$; ; May 21, 1932, 1 o , 3 f; May 31, 1933, ơ $\sigma^{7}$, 우; May 9, 1934, $1 \sigma^{7}$. Henry: June 3, 1933, 1․ Kampsville: June 25, 1931, $1 \sigma^{7}, 3$ ㅇ. Keithsburg: June 9, 1932, $0^{7} \sigma^{7}$, 우. Lodit: Apr. 24, 1929, $1 \sigma^{7}$. Mattoon: May 16, 1933, 19. Meredosia: May 29, 1917, 1o; May 31, 1928, $\sigma^{7} \sigma^{7}, 5 \%$; May 20, 1932, $1 \sigma^{\top}$. Merrimac: May 11, 1932, $\sigma^{\top} \sigma^{\top}$, Metropolis: Mar. 28, 1932, $1 \sigma^{7}, 1$ ㅇ․ Momence: June 4, 1932, $\sigma^{7} \sigma^{7}$, ㅇํ. Mit. Carmel: Apr. 14, 1930, 4o, 1 ; ; Apr. 19, 1932, $1 \sigma^{7}, 1$ 19. New Boston: June 14, 1931, 3ㅇ. Oakwood: Mity 8, 1927, 19. Oregon: July 18, 19, 1927, to; June 27, 28, 1928, $1 \sigma^{7}$, 29. Prairie du Rocher: May 17, 1932, $1 \sigma^{7}, 1$ ㅇ. Rockford: May 12, 1927, $\sigma^{7} \sigma^{7}$, 우; June 13, 1931, $2 \sigma^{7}$. Rock Island: June

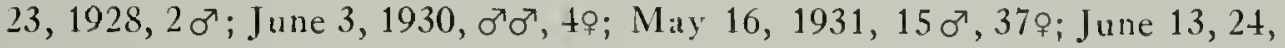
1931, $1 \sigma^{7}, 3 \%$; May 9, 10, 1932, $\sigma^{7} \sigma^{7}$, town: June 21, 1927, 29; May 26-28, 1928, $80^{7}, 1$. . Sparland: June 3, 1933, $\sigma^{7} \sigma^{7}$, ㅇํ. Sterling: May 4, 5, 21, 22, 1925, $60^{7}, 10$ ㅇ․ Urbana: May 19, 20, 1887, $4 \sigma^{7}$; May 25, 1892, $1 \sigma^{7}, 1$ 1 ; May 1927, 1; Apr. 30, 1929, 1o; Maly $17,1931,1 \sigma^{7}$; May 11, 1933, 1 \%; June 8, 1933, 29. Warsaw: June 10, 1932, $0^{7} \sigma^{7}$, 우. White Heath: Apr. 30, 1927, 1․ Zeigler: Apr. 20, 1929, 1 ㅇ.

Nymphs.-Alton (Mississippi r.): May 1932, exuviale. Brookport (Ohio r.): Mar. 28, 1932. Byron (Rock r.): May 19, 1927. Charleston (Embarrass r.): Mar. 28, 1932. Chester (Mississippi r.): May 11, 1932. Dixon (Rock r.): May 12, 22, 1925; Apr. 3, 1928. Fountain Bluff (Mississippi r.): May 15, 1932, exuviae. Golconda (Ohio r.): May 13, 1932. Grafton (Mississippi r.): May 20, 1932. Grand Tower (Mississippi r.): May 12-15, 1932. Joppa (Ohio r.): Mar. 28, 1932. Kankakee (Kankakee r.): Apr. 30, 1931. Keithsburg (Mississippi r.): Apr. 4, 1932. Merrimalc (Mississippi r.): May 11, 1932, exuviae. Mt. Carmel (Wabash r.): Apr. 2, 19, 1932. Oregon (Rock r.): Apr. 3, 1928; May 15, 1930; Apr. 19, 1931. Prairie du Rocher (Mississippi r.): May 17, 1932, exuviae. Rockford (Rock r.): Apr. 29, May 4, 1926; Apr. 26, May 12, 1927; Apr. 3, 1928. Rock Island (Mississippi r.): Apr. 2, 1928; Apr. 10, 18, M1:1y 16, 1931; Mar. 2, Apr. 3, 27, May 9, 1932; Apr. 26, 1933. Shelbyville (Kaskaskiar r.): Apr. 9, 1932. Sterling (Rock r.): May 4, 5, 13, 19, 1925; Apr. 3, 1928; Apr. 27, 1932.

Reared from nymphs.-Rock Island: Apr. 3, May 3, 1931.

\section{Isoperla clio (Newman)}

Figs. $47,77,107,137,145,337$.

Isogenus clio Newman (1839) p. 86. Original description.

Clioperla clio Claassen (1931) p. 69. Nymphal description.

We have obtained very little information concerning this species. It was first recorded from Illinois by Claassen (1931) on the basis of nymphs and reared specimens from Work's brook, Ottawa, April 3, 1902. During the course of our field work we have collected only two nymphs, one nymphal cast skin and no adults.

Our identification as clin is based upon the similarity of the nymph with the drawing given by Claassen (1931). Descriptions and drawings 


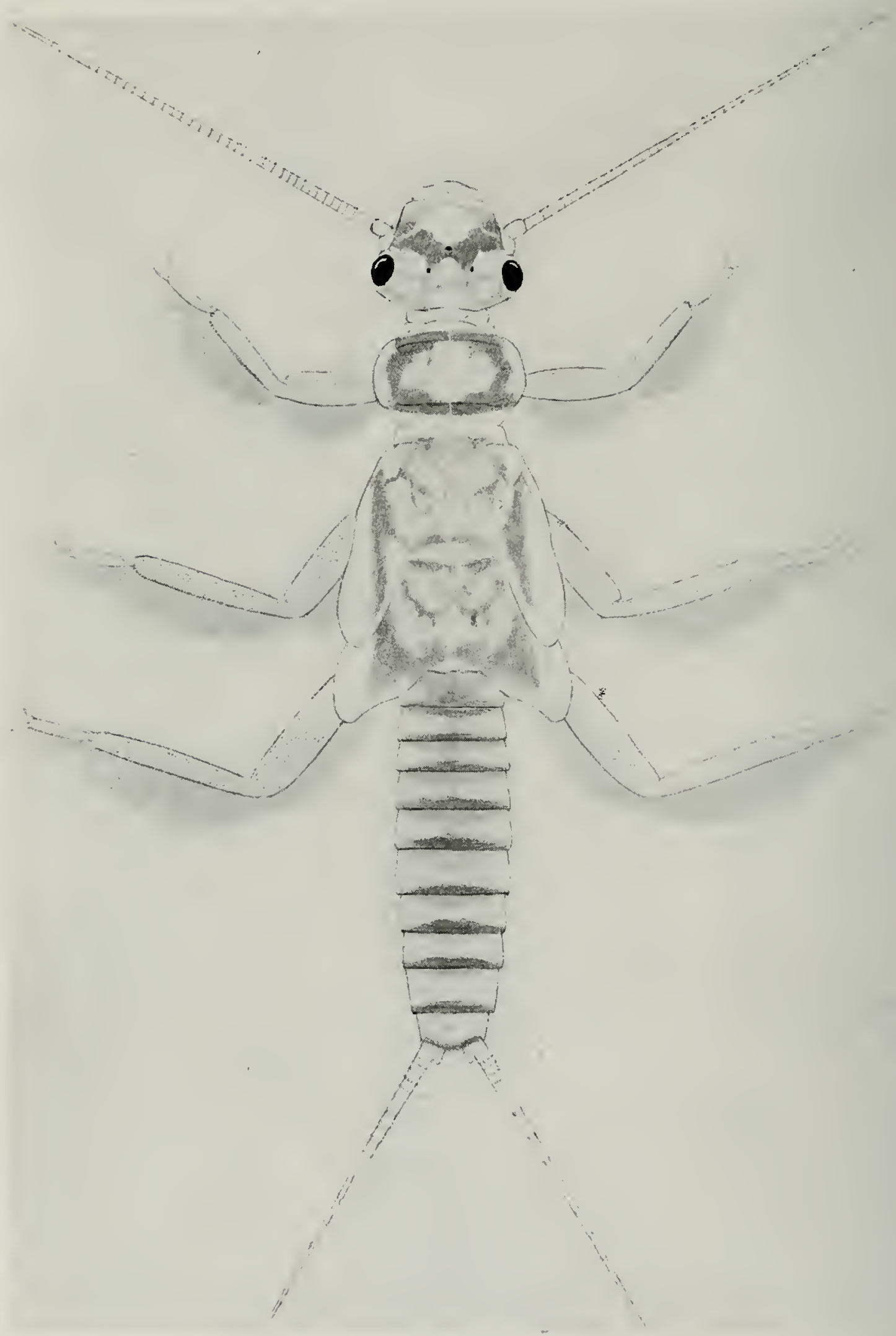

Fig. 337.-Isoperla clio, Nymphal female.

of the adults of clio as presented by Needham and Claassen (1925) indicate that this species is structurally very close to what I am calling Iso- 
perla confusa. There is a possibility that the true clio Newman is the species I am naming confusa and that the species under discussion here is without a name. It may be, too, that the nymph figured by Claassen (1931) has been wrongly associated with its adult but his statement concerning "reared specimens" seems to prohihit such a supposition. My repeated efforts to secure adults of the nymph here called clio, for comparison with confusa, have failed. If previous associations of nymphs and adults under the name clio are in error, even the species conspicun must be considered becaluse its nympl is not definitely known and it comes from the same area as our nymphs at present named ats clio. Accepting the adult and nymph of clio as correctly associated, we have in confusa a species with a very differently colored nymph but an adult of many similarities.

The cast nymphal skin collected in the early part of April, as well as Claassen's record from Ottawa, proves that this species is a member of the early spring fauna. 'The structure of the mouthparts indicates that the nymph is essentially carnivorous.

Nymphs. - Rock ford (Rock r.): Apr. 3, 1928, 1 \% . Rock Island (Rock r., Mississippi r.): Apr. 2, 1928, 1\%; Apr. 27, 1932, exuvia.

\section{Isoperla confusa- NEW SPECIF:S}

Figs. 1, 48, 78, 108, 138, 165, 205, 251, 338.

Our records for this new species indicate that it is particularly common in the Wabash watershed, on the Indiana side as well, but apt to be found anywhere in lllinois. If this picture of its distribution in the state means anything concerning its range in general, we may infer that the center of its distribution lies to the south and east of Illinois.

Our field observations and rearings of adults prove that confusa is a member of the early spring fauna. In our rearing cages at Charleston the first adults were found on March 28 and adults continued to emerge until April 11. The adults are diurnal and have habits in general suggestive of Hydroperla. Very few adult specimens are secured without rearing from nymphs because they are never abundant in comparison with such species as bilineata, and at times minuta and decepta.

The nymphs, like those of Hydroperla crosbyi, are most often found in clumps of decaying leaves, fig. 14 , which are lodged in the water against stones, branches or logs. They seem to be partial to small or medium sized streans with sandy or rocky bottoms. Remains of insects in the digestive tract testify to their carnivorous habits. The size classes of nymphs indicate that one year is required for the completion of the life cycle. 


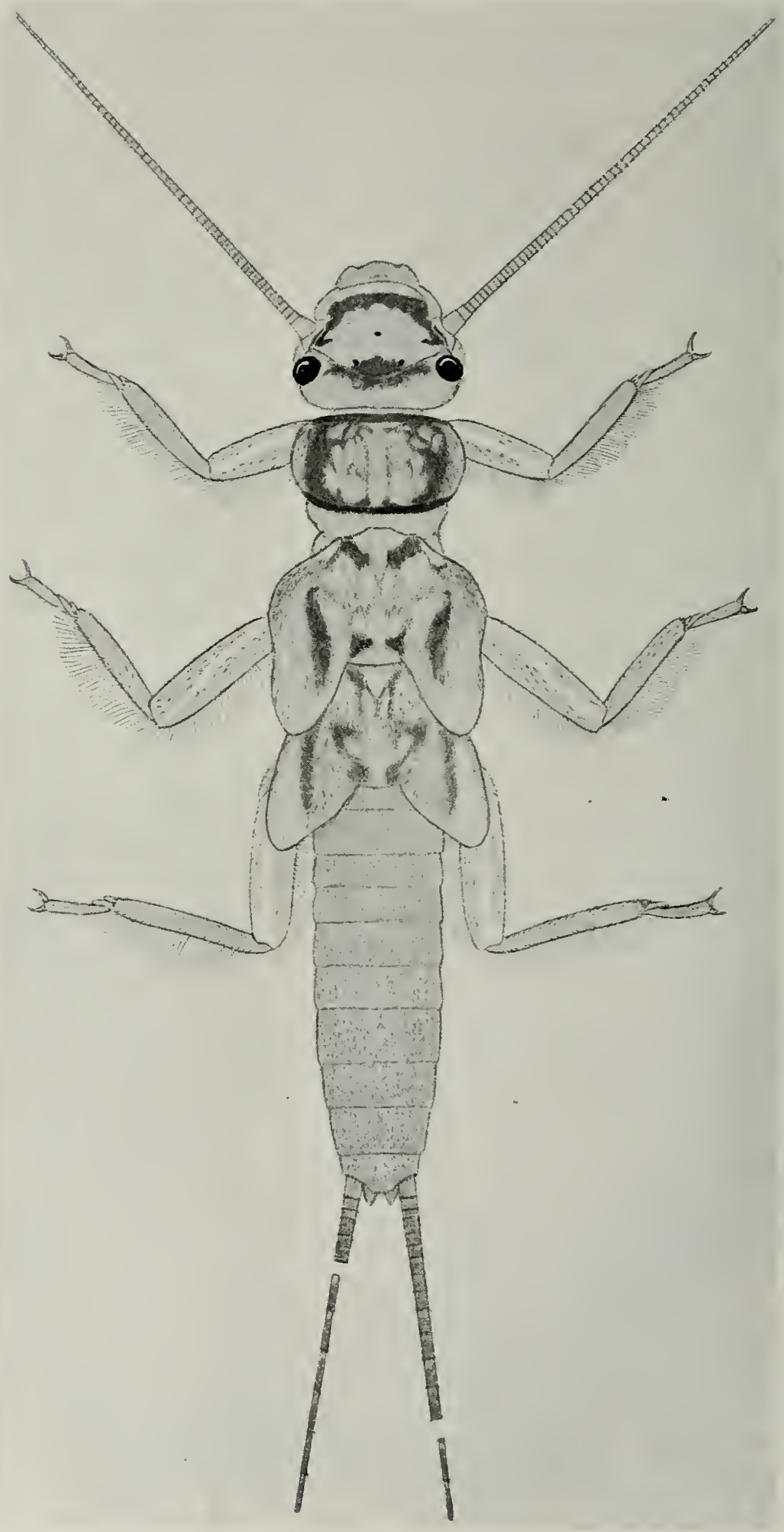

Fig. 338.-Isoperla confusa, NYMPHAL MALE. 
The comment under $I$. clio concerning the present possible misuse of specific names, p. +41 , should be noted.

Male. - Length to apex of wings $16 \mathrm{~mm}$; length to apex of abdomen $14 \mathrm{~mm}$. General color in life black contrasting with orange-yellow. Orange-yellow dorsal areas are as follows: a spot anterior to median ocellus; area around compound eyes; spot on posterior margin of head running forward into ocellar space; longitudinal median stripe on pronotum; most of meso- and metilnotum; and all abdominal tergites. Venter mostly orange-yellow with dark brown or black lateral spots on thoracic segments and along lateral margins of abdomen. Antennae, cerci and legs except for extreme yellowish apical part of femora are chiefly black or dark brown.

Head much wider through compound eyes than width of pronotum; three ocelli nearly forming an equilateral triangle, lateral ocelli placed about on a line with middle of compound eyes, about as far removed from one another as from compound eyes. Antennae with about 50 segments; basal segments wider than long, middle and apical segments longer than wide.

Pronotum approximately quadrangular, much broader than long, angles rather sharp; pronotal Hange well developed on anterior margin but weakly developed on sides and on posterior margin; a rather distinct pattern of raised rugosities on surface; and with a longitudinal median depressed stripe about as wide as distance between lateral ocelli.

Legs with first and second tarsal segments very short, first slightly longer than second, third long.

Wings long, extending beyond tip of abdomen, up to $1+$ mm. in length; membrane dull hyaline, veins very dark and contrasting; venation essentially as in type of genus.

Abdomen with dorsal segments without special apical structures, fig. 205. Nintl tergite with two patches of small sharp spinules on posterior portion. 'Tenth tergite not cleft, fig. 205. Eighth sternite with a small lobe in middle of posterior margin. Ninth sternite strongly produced and turned upward around tenth segment so that it is not visible from below, and without a distinct disklike pad near middle of apical portion. Cerci long, many segmented. No gill remnants on any body area.

Female. - Length to apex of wings $20 \mathrm{~mm}$; length to apex of abdomen $15 \mathrm{~mm}$. Head, thorax, abdomen and appendages in general similar to those of male. Differs from male as follows: eighth abdominal sternite with posterior margin or subgenital plate rounded and slightly extended posteriorly, fig. 251.

Holotype, male--Oliver, 11l. (Big cr.): Apr. 7, 1932, reared from nymph collected by T. H. Firison and H. H. Ross.

Allotype, female.-Same data as for holotype.

Paratypes.-Marshall: Apr. 1, 1932, $10^{7}$; Apr. 9, 1933, 1 o $^{7}$. Oakwood: Apr. 12, 1933, $1 \sigma^{7}$. Oliver: Mar. 28, Apr. 1, 4, 7, 11, 1932, 21 o , 189, reared 
from nymphs taken in Big creek. Turkey Run state park, Ind. (Sugar cr.): Apr. 19, 1933, $1 \sigma^{7}$; May 7, 1933, 19 resting on tree; (Newby gulch): May 11, 1933, 1 우 reared. Montezuma, Ind.: Apr. 13, 1933, $10^{x}$. Collected by T. H. Frison, H. H. Ross, C. O. Mohr.

Nymphal male, fig. 338.- General color of head, thorax and legs a whitish yellow; general color of dorsum of abdomen brown and venter paler. Dorsum with dark markings as follows: a band anterior to articulation of antennae and continuing part way along side of head; a transverse stripe connecting compound eyes and lateral ocelli; narrow band on anterior and posterior margins of pronotum and a wider band on lateral margins except that extreme lateral edge is pale; various suffused areas on thorax as in fig. 338. Some paired whitish spots on abdominal tergites.

Head with three ocelli nearly forming an equilateral triangle, lateral and median ocelli occupying the same relative position as in adult. Antennae yellowish at base and gradually becoming darker towards apex, with more than 50 segments. No occipital ridge. No pronounced row of stout setae associated with posterior margin of compound eye. Labrum, fig. 48, labium, fig. 138, maxilla, fig. 108 , mandibles, fig. 78 , and submentum, fig. 165, as shown.

Pronotum about twice as wide as long, all angles well rounded; marginal groove present on anterior and posterior margins but absent on lateral margins. Mesonotum with wing pads extending almost straight backwards, those on metanotum extending slightly outward as well.

Legs very little flattened; hind margins of femora, tibiae and tarsi with a fringe of long fine setae; femora on outer surface with a longitudinal strip in center which is bare of short setae.

Abdomen with color pattern as in fig. 338. Cerci long, with segments progressively longer apically. Tenth tergite produced backwards and rounded on posterior margin. Eighth sternite with posterior margin almost straight and setal fringe not interrupted in the middle.

Submental, thoracic and abdominal gills entirely lacking.

Mature specimens with a body length, exclusive of appendages, of about $16 \mathrm{~mm}$.

Nymphal female.- In color and most structural details similar to nymphal male. Eighth abdominal sternite has the setal fringe on posterior margin interrupted in the middle.

Nymphs.-Dixon Springs: Feb. 2, 1934. Golconda (Big Grand Pierre r.): Mar. 7, 1928. Harrisburg (Blackman cr.): Mar. 6, Nov. 29, 1928; Apr. 2, 1932. Herod (Gibbons cr.): May 6, 1928; Apr. 20, 1932; Feb. 2, 1934. Marshall (Big cr.): Apr. 9, 1931; Feb. 27, 1932. Oakwood (Salt Fork r.): Nov. 7, 1929; Apr. 12, 1933. Oliver (Big cr.): Jan. 14, Mar. 16, Apr. 11, 1932. Peru (Nigger cr.): Apr. 25, 1933. W. Union (Mill cr.): Feb. 27, 1932. Montezuma, Ind. (I.eatherwood cr.): Apr. 13, 1933. The Shades, Ind.: Nov. 12, 1927. Turkey Run state park, Ind. (Newby gulch): Apr. 13, 1933; (Sugar cr.): Apr. 19, 1933. Veedersburg (Coal cr.): Mar. 18, 1933. 
Reared from nymphs.-Oliver (Big cr.): Mar. 28, Apr. 1, 4, 7, 11, 1932. Collected by T. H. Frison, H. H. Ross, C. O. Mlohr.

\section{Isoperla conspicua-NF.W SPECIF.S}

Fig. 239.

This new species is described upon the basis of a single female discovered in one of our rearing cages at Rock Island, Ill. 'This particular cage wats known to us to contain nymphs of $I$. bilineata and Hydroperla harti, adults of which were reared, but we were not aware of the existence of a third species. No cast nymphal skin was discovered which could be associated with this new species. Therefore the nymph is unknown. There is a slight possibility, in case there is a $\mathrm{w}$ rong association of adults and nymphs under the name clio, that conspicua may be the adult of the nympl now recorded from Illinois as clio, which see.

The date of rearing of conspicua indicates that it is a member of the spring fauna. Our collecting in the state has been sufficiently thorough to show that it is one of our rarer species. 'The shape of the subgenital plate, fig. 239, is very suggestive of the figure given for 1 . sobria (Hagen), known only from Colorado, by Needham and Claassen (1925). It differs from the description of sobria of these authors in several points and until the isoperlid species are better known I believe that it would be a mistake to consider them as the same.

Female.-Length to apex of wings, $12 \mathrm{~mm}$; length to apex of abdomen, $9 \mathrm{~mm}$. General body color brown with yellowish brown markings. Head and thorax with yellowish markings as follows; an irregular area adjacent to sides of head and extending back to posterior margin of head; a large spot in ocellar space; a small part anterior to median ocellus; a longitudinal median stripe on pronotum slightly narrower than distance between lateral ocelli; outer lateral portions of pronotum; and median spots on meso- and metanotum. Abdomen much lighter than thorax, posterior margins of tergites slightly darker than anterior portions, traces on first five tergites of longitudinal alternating light and dark stripes and some small paired spots. Antennae and legs essentially brown, cerci with basal portions of segments yellowish and apical portions more brown and contrasting. Venter of head and thorax yellowish brown with large lateral dark areas on thorax; abdomen essentially pale brown, lighter surrounding subgenital plate. Wings hyaline with veins dark brown and contrasting. No gill remnants on any body area.

Head slightly wider than prothorax; three ocelli forming a triangle, lateral ocelli slightly more removed from one another than from median ocellus; lateral ocelli situated about on a line with middle of compound eyes. Antennae many segmented, from base to apex the seginents becoming progressively longer. 


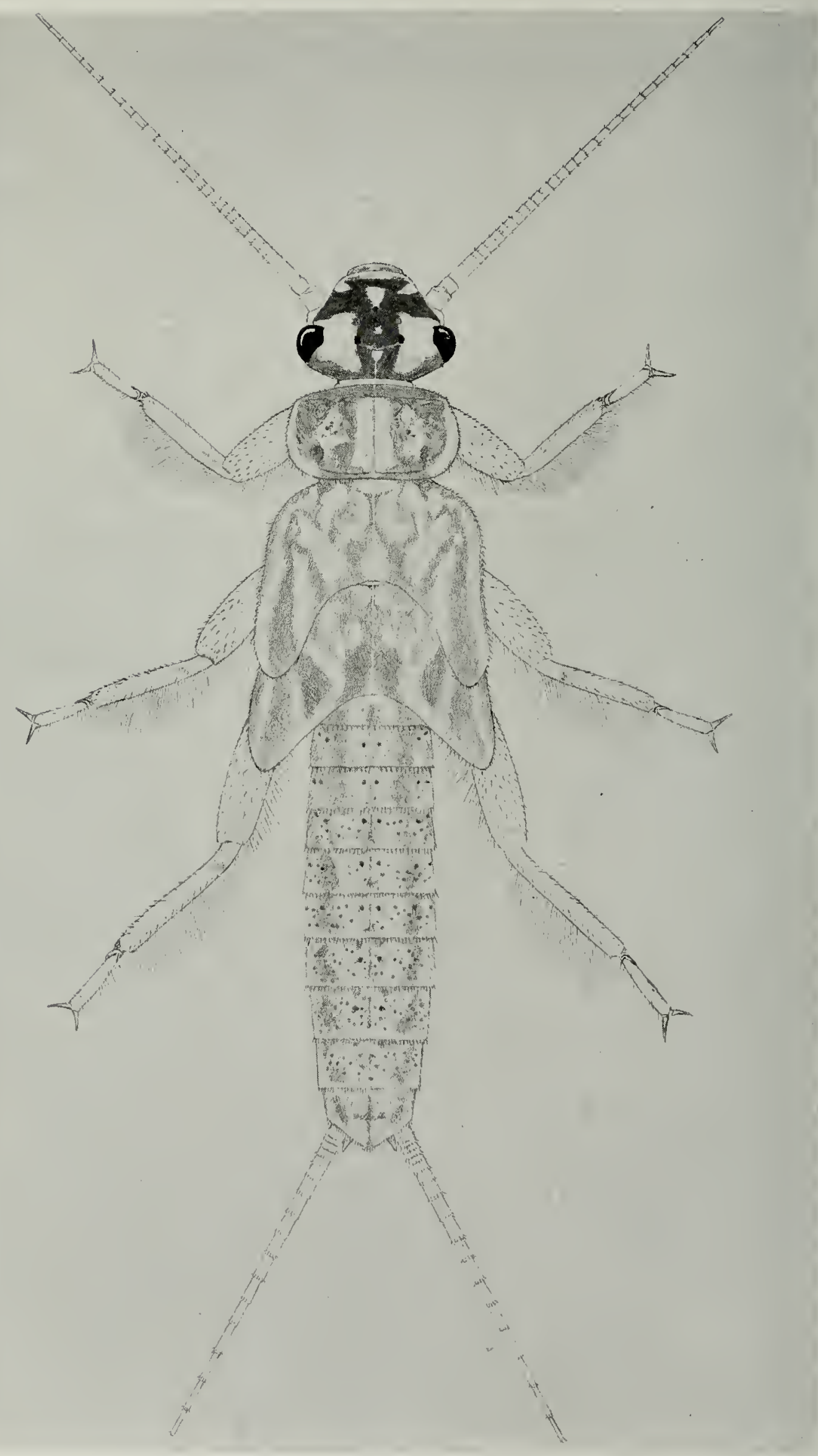

Fig. 339.-Isoperla decepta, NYMPHAL. FEMALE. 
Pronotum approximately quadrangular, much broader than long, angles sharp; anterior margin rounded; pronotal groove well developed on anterior margin but elsewhere indistinct; a distinct pattern of raised brownish rugosities between depressed median area and lateral margins; longitudinal median area slightly narrower than distance between lateral ocelli.

Tarsal segments as in other isoperlids.

Wings extending beyond abdomen and with renation essentially as in type of genus.

Abdomen without special structures on tergites. Eighth stemite with a well developed subgenital plate, deeply notched in middle of posterior margin and slightly overlapping base of nintl sternite, fig. 239. Cerci long and many segmented.

Holotype, female.-Rock Island, IIl. (Rock r.): May 16, 1931, reared from nymph collected by T. H. Frison, H. H. Ross and C. O. Mohr.

\section{Isoperla decepta-NEW SPECIES}

Figs. 49, 79, 109, 139, 163, 192, 233, 332, 339.

Superficially this species in the adult greatly resembles $I$. bilineat $n$. Its existence was first brought to our attention because of the distinctive nymphs, fig. 339. The adults helong to that group of small isoperlids which are dominantly whitish or lemon yellow with contrasting black ocelli and compound eyes and some subdued brownish markings. In Illinois this group comprises the species bilineata, richardsoni and decepta.

Our records are all from extreme southern Illinois and it may be considered as a species associated with the Ozarkian uplift region in our state. It is a true member of the spring fauna.

The adults are diurnal and emerge from nymphs during the day. Dr. Ross has observed them emerging from nymphs and noted that they were able to fly almost immediately after leaving the nymphal skins. During the day the adults congregate upon the vegetation near the streams inhabited by the nymphs and at times fly off over the surrounding fields. These diurnal habits are in marked contrast to bilineata which is nocturnal and attracted by lights.

The nymphs are found in small rapid streams which have a sand and gravel bottom. One of the nymphs when collected had a half eaten chironomid larva in its mouth. This indicates a carnivorous habit but the digestive tracts of other nymphs when examined have not contained insect remains and the nymph may be mostly herbivorous.

Male.-Length to apex of wings $10 \mathrm{~mm}$; length to apex of abdomen $7 \mathrm{~mm}$. In life the species is essentially lemon yellow with some dark or brownish areas and strongly contrasting black ocelli and compound eyes. The dark or brownish areas are as 
follows: apical antennal segments; two longitudinal stripes on pronotum separated by wide light median stripe and bordered by narrow yellow lateral margin; a few fuscous areas on meso- and metanotum and along prominent sutures; and faint suggestions of fuscous spots on basal abdominal tergites. The cerci are slightly fuscous apically but not as dark as antennae. Legs essentially yellowish but with tarsi somewhat fuscous and with a narrow fuscous ring about the length of longest tarsal segment, at base of tibia. Venter uniformly whitish vellow. Median and lateral ocelli not connected by a dark iine. No gill remnants on any body region.

Head much wider than pronotum; ocelli nearly forming an equilateral triangle; lateral ocelli closer to compound eyes than to each other and situated about on a line with middle of compound eyes. Antennae long, many segmented, segments progressively longer from base to apex.

Pronotum quadrangular, much broader than long; marginal groove indistinct except on anterior margin; angles not noticeably rounded.

Legs with first and second tarsal segments very short, second shorter than first and third much longer than either.

Wings with veins arranged essentially as in $I$. bilineata (Say) ; intercubital crossveins lacking. Veins colored in fresh material as follows: medius and second to fifth branches of radius of forewing brown and contrasting with the remainder of light veins of fore- and hind wings.

Abdomen with dorsal segments without special structures and tenth tergite not cleft. Ninth sternite prolonged backwards and upwards, concealing tenth sternite. Eighth sternite with a very small knob in middle of posterior margin, fig. 332.

Female.-Slightly larger than male and like it in general color and most morphological details. Differs in having eighth abdominal sternite with slightly protruding and rounded subgenital plate, fig. 233.

Holotype, male.-New Columoia, Ill. (Clifty cr.): Apr. 22, 1932, collected by H. H. Ross and C. O. Mohr.

Allotype, female.-Same data as for holotype.

Paratypes. - Same data as for holotype, $850^{7}, 86{ }^{\circ}$. Same data as for holotype but specimens reared, $3 \sigma^{7}, 149$. Herod (Gibbons cr.): Apr. 20, 1932, 40 , 3o; (Blackman cr.): Apr. 20, 1932, $21 \sigma^{\top}, 16 \circ$, reared. McClure: May 5, 1932, $4 \sigma^{7}, 2$. . Ozark: May 18, 1932, $2 \sigma^{\top}$. Vienna: Apr. 21, 1932, $5 \sigma^{7}, 5$ o . Collected by T. H. Frison, H. H, Ross, C. O. Mohr, H. L. Dozier.

Nymphal male, fig. 339.-General color pattern with brownish and whitish yellow areas as in the illustration. Numerous freckle-like spots scattered over abdominal tergites in addition to some larger paired spots. Venter with head and thorax light yellowish, abdominal sternites more brownish and with numerous freckle-like spots. Legs, antennae and cerci whitish yellow. 
Head with three ocelli nearly forming an equilateral triangle; lateral ocelli about as far removed from one another as from compound eyes and situated about on a line with middle of compound eyes. No occipital ridge. No conspicuous row of stout setae bordering posterior margin of compound eye. Lahrum, fig. 49, labium, fig. 139, maxilla, fig. 109, mandibles, fig. 79, and submentum, fig. 163, as illustrated.

Pronotum much broader than long; angles rounded, particularly posterior angles. Marginal groove absent on side margins but present on anterior and posterior margins. Wing pads on mesonotum extending almost straight backwards, those on metanotum extending slightly outward.

Legs but slightly flattened; with a posterior fringe of long fine setae; femora with numerous short setae.

Abdomen marked as in fig. 339. Cerci long, many segmented, segments progressively longer apically. Tenth tergite produced backwards on posterior margin. Eighth sternite with posterior margin straight and transverse setal fringe not interrupted in middle.

Submental, thoracic and abdominal gills absent.

Nymphal female.-Similar to male in general color and most morphological details. Eighth abdominal sternite with transverse row of setae on posterior margin interrupted in the midd!e.

Nymphs.-Herod (Blackman cr., Gibhons cr.): Apr. 2, 20, 1932, nymphs and exuviae. New Columbia (Clifty cr.): Apr. 3, 20, 22, 1932, nymphs and exuviae. Viennal (creek east of town): Apr. 21, 1932, nymphs and exuviae. Rocky Branch: Mar. 27, 1932. Collected by T. H. Lirison, H. H. Ross, C. O. Mohr, B. Harper.

\section{Isoperla duplicata (Banks)}

Figs. 50, 80, 110, 140, 204, 249, 340, 341 .

Perla duplicata Banks (1920) p. 316. Original description.

Although we have not actually taken this species in lllinois, we have taken it in the Wabash watershed of Indiana and so close to our state borders that its inclusion seems desirable. It is certainly aberrant in many respects for a typical Isoperla, but as stated elsewhere I am using Isoperla in a broad sense until more information is available.

Needham and Claassen (1925) have placed duplicata in the genus Perla and in their new subgenus Diploperla. According to the classification proposed in this paper, duplicata belongs in the family Chloroperlidae and to one of the natural aggregates or groups of species under Isoperla (s. lat.). The two species placed in the subgenus Diploperla,-Iuplicata and bilobata-have in the adult males knoblike lobes on the median posterior margin of both the seventh and eighth abdominal sternites, fig. $3+1$. In typical Isoperla, such as bilineata, there is but one such lobe on the 


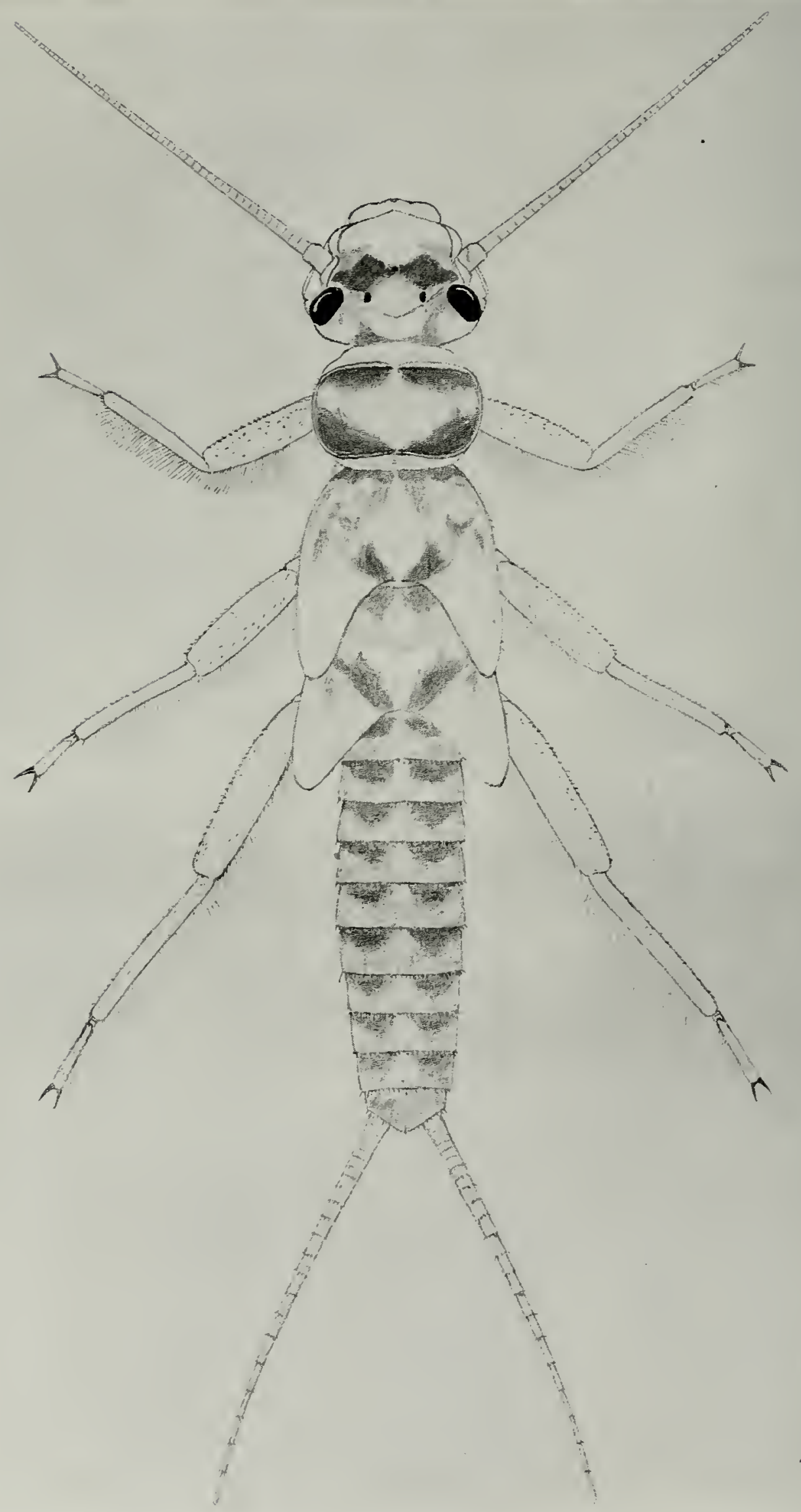

Fig. 340.-Isoperla duplicata, NYMPHAL FEMALE. 
eighth sternite. A vastly more important difference is the cleft of the tenth abdominal tergite and type of genital structures of the male, fig. $20 \mathrm{t}$, which are quite unlike typical Isoperla or certain species which might be considered as belonging to the subgenus Clioperla. 'The lack of a workable character for separating the nymphs of duplicata from those of other Isoperla is my only reason for not recognizing at this time Diploperla as a valid genus. 'The lacinia, fig. 110, which is different, does not lielp because the Iacinia of most all isoperlids apparently differs.

Our rearings of adults (May 11, 12) at our Charleston station from nymphs collected in Turkey Run state park (Newby gulch), Indiana, indicate that this species is a true member of the spring fauna. It is apparently diurnal in habit. Previously the adults have been recorded only from New Jersey, North Carolina and Virginia. Our Indiana records therefore extend its known distribution considerably.

The nymphs were taken in masses of leaves lodged against stones or other objects in a very small stream. Like other large isoperlids, for example $I$. confusa, this species is not abundant and is outnumbered 10 to 1

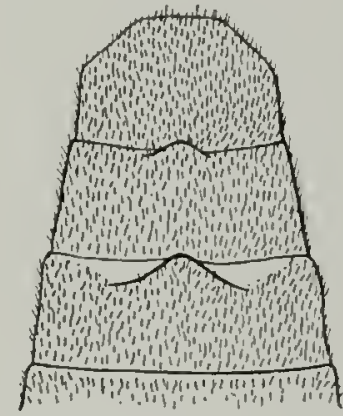

Fig. 341.- VENTRAL VIEW OF TERMINAL ABDOMTNAI. STERNITES OF Isoperla duplicala, ADL'T MALE. by a smaller stonefly, Chloroperla cydippe, present in the same strean and reaching maturity about the same time. 'The life cycle apparently recuire: one year. The nymph is carnivorous as indicated by the numerous insect remains found in the digestive tract of the one specimen dissected.

The adults have been described by other writers. Distinctive features for identification purposes are given in the keys to adults and nymphs, and in the figures enumerated there.

Description of the heretofore undiscovered nymph follows.

Nymphal male, fig. 3+0.-General ground color pale yellow or whitish vellow with dark brown or black markings as in the illustration. Most prominent of the dark markings are the transverse band on head anterior to compound eyes and constricted in middle near median ocellus, and the dark areas on the pronotinn. Ventral aspect almost uniformly yellow.

Head wider than pronotum, with three ocelli forming a triangle; lateral ocelli slightly more removed from one another than from median ocellus. No occipital ridge. No prominent row of short stout setae surrounding posterior portion of compound ere. Labrum, fig. 50, labium, fig. 1 t0, maxilla, fig. 110, and mandibles. fig. 80 , as illustrated.

Pronotum broader than long, but not as broad as head; angles all rounded. Marginal groove distinct on anterior and posterior 


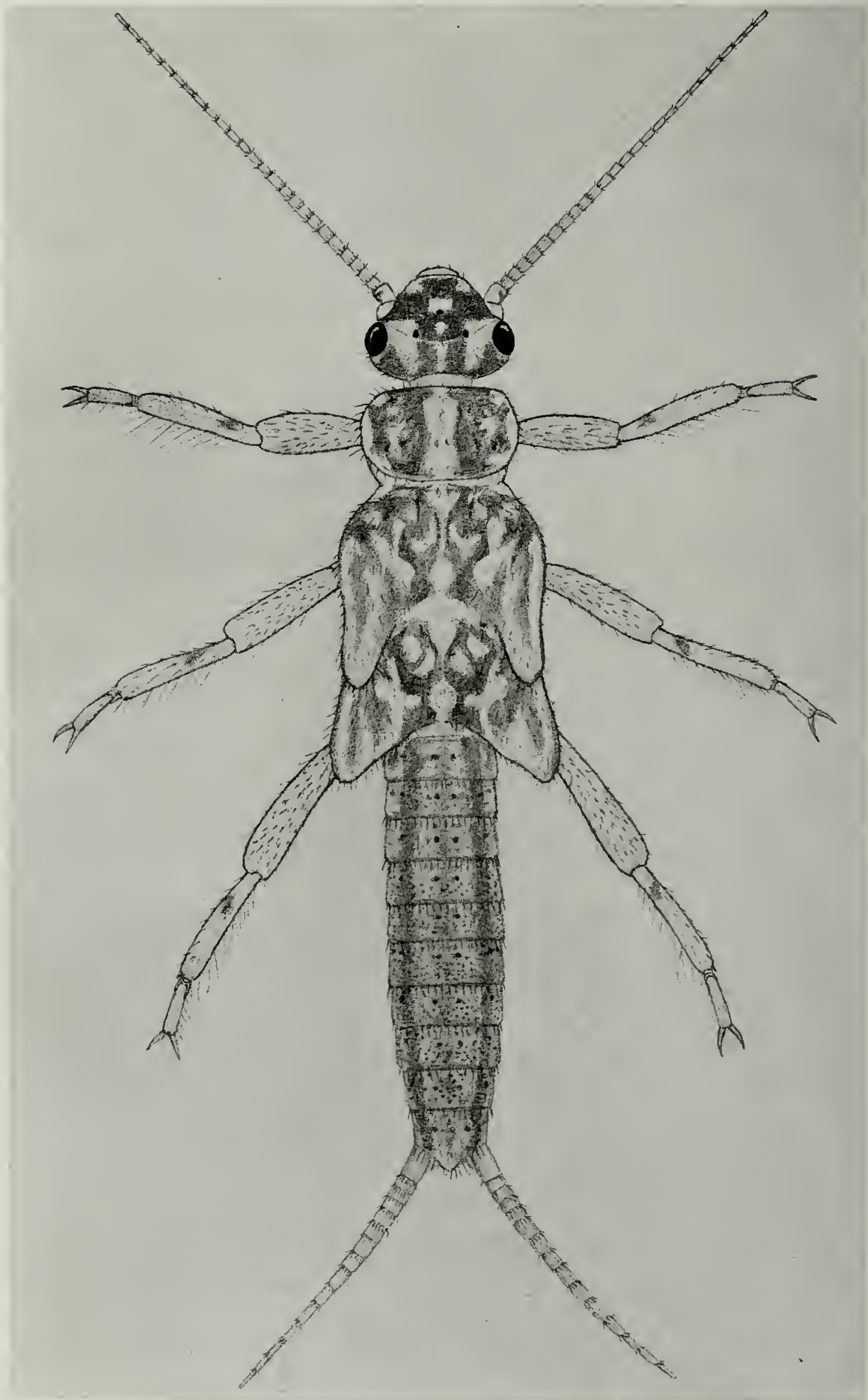

Fig. 342.-Isoperla minuta, NYMPHAL FEMALE. 
margins but weak on lateral margins. Mesonotal wing pads extending chiefly backwards, metanotal wing pads extending slightly outward as well.

Legs essentially as described for other isoperlids.

Abdomen with markings as in fig. 3+0. Cerci about as long as abdomen, many segmented, segments progressively longer apically. Setae on posterior margin of eighth sternite interrupted in middle.

Submental, thoracic and abdominal gills all absent. Mature specimens with a body length, exclusive of appendages, of $19 \mathrm{~mm}$.

Nymphal female.-Like male, even to setae on posterior margin of eighth sternite interrupted in middle. Sexes therefore difficult to separate until specimens are mature enough to show indications of sexual structures.

Adults.- Reared from nymphs from locality as given below, $4 \sigma^{x}, 1$.

Nymphs.-All from small stream in Turkey Run state park, Ind. (Newby gulch): May 6, 1928; May 4, 1929; Apr. 13, May 6, 11, 1933.

\section{Isoperla minuta (Banks)}

Figs. 51, 81, 111, 141, 158, 196, 234, 342.

Chloroperla minuta Banks (1900) p. 244. Original description.

The adult of $I$. minuta is the smallest of the Illinois species of Isoperla. It is this fact which has suggested to me that the "Chloroperla "ana" of Walsh (1862) might be this species.

'The maximum abundance of the adults is reached in central Illinois about the last of May, a seasonal timing somewhat later than for most lllinois isoperlids. All of our records for minuta are from the central and eastern part of the state. This distribution corresponds essentially with that Illinois area which was once upland prairie, and there may be some correlation between the two. The environment and abundance of minuta near Seymour is certainly suggestive of this correlation. Needham and Claassen (1925) list this species from Ohio and Illinois, the types coming from the former state.

I. minuta was found to be exceedingly abundant near Seymour, Ill., May 27, 1929. About noon on the clear warm day of this date, thousands of the adults were observed climbing about on the vegetation bordering a very small tributary of Camp creek. Some of these adults were engaged in mating whereas others were feeding upon the pollen of dock (Rumex) and wild grape (Vitis).

The nymphs were found in the creek clinging to decaying vegetable matter or on the sides of submerged boards or branches of trees. This particular stream is very small, Hows through a rich soil area which was 
once prairie, and is so full of vegetative growth that it seems almost stagnant. I have failed to find insect remains in the digestive tracts of nymphs, and believe that they are herbivorous.

Genital structures of the adults, which have been described elsewhere, are shown in figs. 196, 23+. Following is a description of the previously unrecognized nymphs.

Nymphal female, fig. 3+2. - Dorsum with a definite color pattern of contrasting brown and yellowish brown areas. Particularly important is that the dark area on forepart of head from median to lateral ocelli is almost quadrate, and with a small light area in its center. Also, the dorsum of the abdomen has two dark longitudinal stripes and a few rows of distinct paired spots upon a somewhat suffused background dotted with numerous small freckle-like spots. Venter of head and thorax whitish yellow, abdomen more brownish.

Ocelli three, nearly forming an equilateral triangle; lateral ocelli slightly more removed from one another than from median ocellus. Antennae yellowish, many segmented. No occipital ridge. No pronounced row of stout setae associated with posterior margin of compound eye. Labrum, fig. 51, labium, fig. 141, maxilla, fig. 111, mandibles, fig. 81, and submentum fig. 158, as shown.

Pronotum more than twice as broad as long; all angles well rounded. Marginal groove weakly developed. Mesonotum with wing pads extending slightly outward, those on metanotum extending more outward.

Legs very little flattened, with short stout setae and more slender hairlike setae mixed; fringe of long fine hairlike setae on posterior margin of legs poorly developed.

Abdomen with color pattern as in fig. 342. Cerci brown, short and stout in comparison with most other isoperlids. Eighth sternite with transverse row of setae on posterior margin interrupted in the middle.

Nymphal male. - Similar in almost all respects to fema'e. Eighth sternite with setae on posterior margin not interrupted in the middle.

Adults.-Allerton: June 17, 1929, $1 \sigma^{7}, 19$. Charleston: May 30, 1929, $2 \sigma^{7}$. Clinton: May 31, 1933, $1 \sigma^{7}$. Homer: June 5, 1924, $8 \sigma^{7}, 12 \%$; June 5, 1925, $2 \sigma^{7}, 3$; J June 1, 1931, 1 ․ Kankakee: June 5, 1932, 19. Ludlow: June 9, 1929, $1 \sigma^{7}, 1$ ㅇ. Muncie: May 16, 20, 1909, $12 \sigma^{7}, 5$; ; June 10, 1919, 2\%; May 12, 21, 1928, $6 \sigma^{7}, 3$. . Oakwood: June 14, 1930, $1 \sigma^{7}$. Rantoul: June 9, 1929, 19. Seymour: May 25-27, 1929, 430 , 75\%; June 13, 1929, $10 \sigma^{7}, 12$; May 13, 1933, $\sigma^{7} \sigma^{7}$, ; $ๆ$. Sheldon: June 4, 1932, $\sigma^{7} \sigma^{7}$, ㅇํ. Sherman: May 22, 1930, $1 \sigma^{7}$. Springfield: July 4, 1885, $3 \sigma^{7}$. St. Joseph: May 7, 1905, $1 \sigma^{7}$; May 25, 1913, $1 \sigma^{7}$; May 17, 1914, $6 \sigma^{7}, 60$. Urbana: May 31, 1889, 1ㅇ; May 13-15, 1898, $3 \sigma^{7}, 3$; ; May 29, 1928, $1 \sigma^{7}, 1$; ; May 31, 1929 ,

$10^{7}$. White Heath: May 19, 1933, $10^{\pi}, 1$ 우.

Nymphs.-Dolson (Big cr.): May 12, 1933. Oakwood (trib. of Salt 
Fork r.): Apr. 12, 1933. Oliver (trib. of Big cr.): May 11, 1933. Seymour (Camp cr.): May 27, 1929; Apr. 13, 28, 1932. St. Fimo (S. Fork cr.): Apr. 1, 1932.

Mating pair.-Oakwood: June 1, 1930.

\section{Isoperla mohri-NEW SPECIES}

Figs. 52, 82, 112, 142, 162, 193, 238, 333, 343.

One of the surprises of our stonefly investigations was the discovery in a small stream near Watson of an isoperlid nymph with a head pattern suggestive of minuta and decepta and the abdomen more like bilineata. Rearing of the nymph produced a beautiful black and orange-yellow adult. We were expecting to rear an adult dominantly whitish or lemon yellow, such as the typical bilineata or our new species decepta. Since this species is undescribed I am dedicating it to Dr. C. O. Mohr, associate entomologist of the Surver, who has accompanied the author on so many stonefly expeditions in the state, assisted with the rearing of adults from nymphs, and made the many drawings used in this report.

We know very little about the distribution of this species except its local occurrence in two localities in the watershed of the Wabash and Ohio rivers of extreme south-central and southern Illinois. These localities suggest that it is a species to be expected in those states to the south and east of our borders. The adults are diurnal, with habits like confusa. With the exception of two specimens all our adults have been reared; certainly the species is exceedingly uncommon in Illinois. Our rearing: indicate that the adults are true members of the spring fauna which emerge about the middle or last of April.

'The nymphs have habits similar to those described for conf usa, which see.

Male. - Length to apex of wings $11 \mathrm{~mm}$.; length to apex of abdomen $8 \mathrm{~mm}$. General color in life is black contrasting with orange-yellow areas. Orange-yellow areas are as follows: small spots between lateral ocelli and compound eyes extending back to pronotum; a small spot in ocellar space extending back to pronotum; a small spot anterior to median ocellus; a median longitudinal stripe on pronotum about one-fifth as wide as pronotum; median stripe and most posterior portions of meso- and metanotum; abdominal tergites except for rows of minute black spots and extreme black lateral margins.

Venter of head, thorax and abdomen essentially orange-yellow with dark fuscous stripes on each side of meso- and metasternum and on extreme lateral margins of abdomen. Tibiae and tarsi black; femora with upper portion black except for at narrow ring of yellow at articulation with tibiae and lower surface fuscous with some yellowish; coxae and trochanters yellowish. Antennac and 


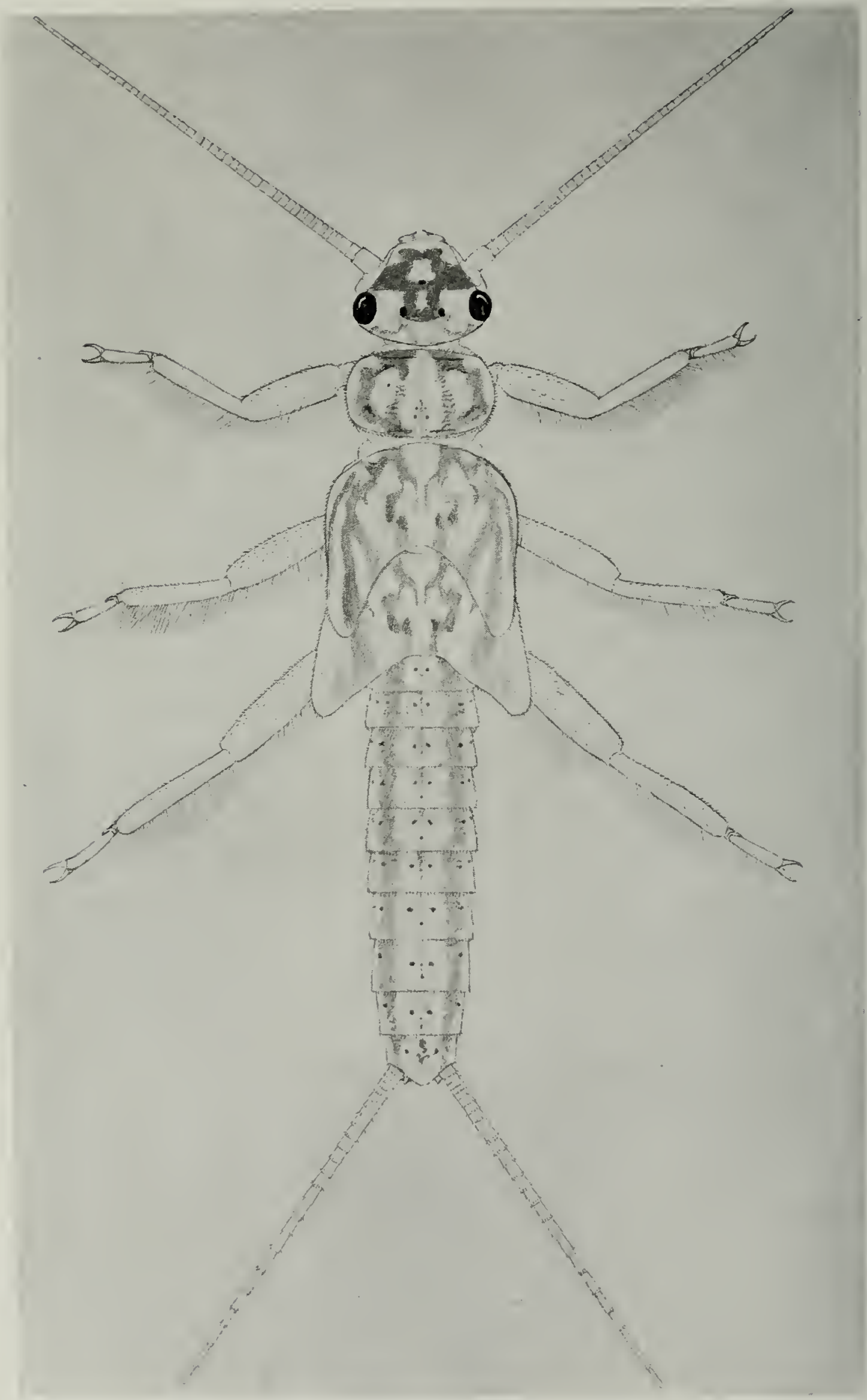

Fig. 343.-Isoperla mohri, NYMPHAL FEMALE. 
cerci black. Dorsum of abdomen with eight longitudinal rows of minute black spots on orange-yellow background, the two middle and the lateral rows of spots are closely associated so that these spots are paired. Pleurae of thorax essentially black.

In alcohol the adults lose their bright orange-yellow color and become a yellowish brown, and the black areas become dark brown.

No gill remnants on any body area.

Head slightly broader through compound eves than width of pronotum. Three ocelli nearly forming an equilateral triangle, lateral ocelli about on a line with middle of compound eyes, about as far removed from one another as from compound eyes. Antennae with numerous segments; basal segments wider than long, middle and apical segments longer than wide.

Pronotum approximately quadrangular, much broader than long; angles rather sharp, pronotal flange noticeable on anterior and posterior margins but very faint on lateral margins. A few raised rugosities on the surface, and with a longitudinal smooth depressed stripe about as wide as the distance between lateral ocelli.

Legs with first and second tarsal segments very short, first slightly longer than second, third longer than first and second combined.

Wings long, extending beyond tip of abdomen, up to $9 \mathrm{~mm}$. in length; membrane hyaline, veins very dark and contrasting; venation essentially as in type of genus.

Abdominal tergites without special apical structures. Tentl tergite not cleft, fig. 193. Eighth sternite with a small lobe in middle of posterior margin and ninth sternite strongly produced and turned upwards around tenth sternite so that it is not visible from below, and without a distinct padlike disk near middle of apical portion, fig. 333. Cerci long, many segmented; only extreme basal segments broader than long.

Female.- Length to apex of wings $12 \mathrm{~mm}$; length to apex of abdomen $10 \mathrm{~mm}$. Head, thorax, abdomen and appendages in general similar to those of male. Differs from male as follows: eighth abdominal sternite, or subgenital plate, with posterior margin slightly produced and rounded and usually but not always slightly notched in middle, fig. 238.

Holotype, male.-Watson, Ill. (trib. of Little Salt cr.): Apr. 27, 1932, reared from nymph collected by T. H. Frison and H. H. Ross.

Allotype, female.-Same data as for holotype.

Paratypes.-Same data as for holotype, $3 \sigma^{7}, 7$. Herod: Apr. 20, 1932, 19. Watson: Apr. 19, 1932, 1; Apr. 23, 1932, $5 \sigma^{7}$, 4으, reared; May 1, 1932, $5 \sigma^{\circ}$, 2\%, reared. Collected or reared by T. H. Frison, H. H. Ross, C. O. Mohr.

Nymphal male.-General color yellowish white with dark fuscous pattern upon dorsum of head, thorax and abdomen as shown in fig. 343. This dorsal pattern is featured by the large 


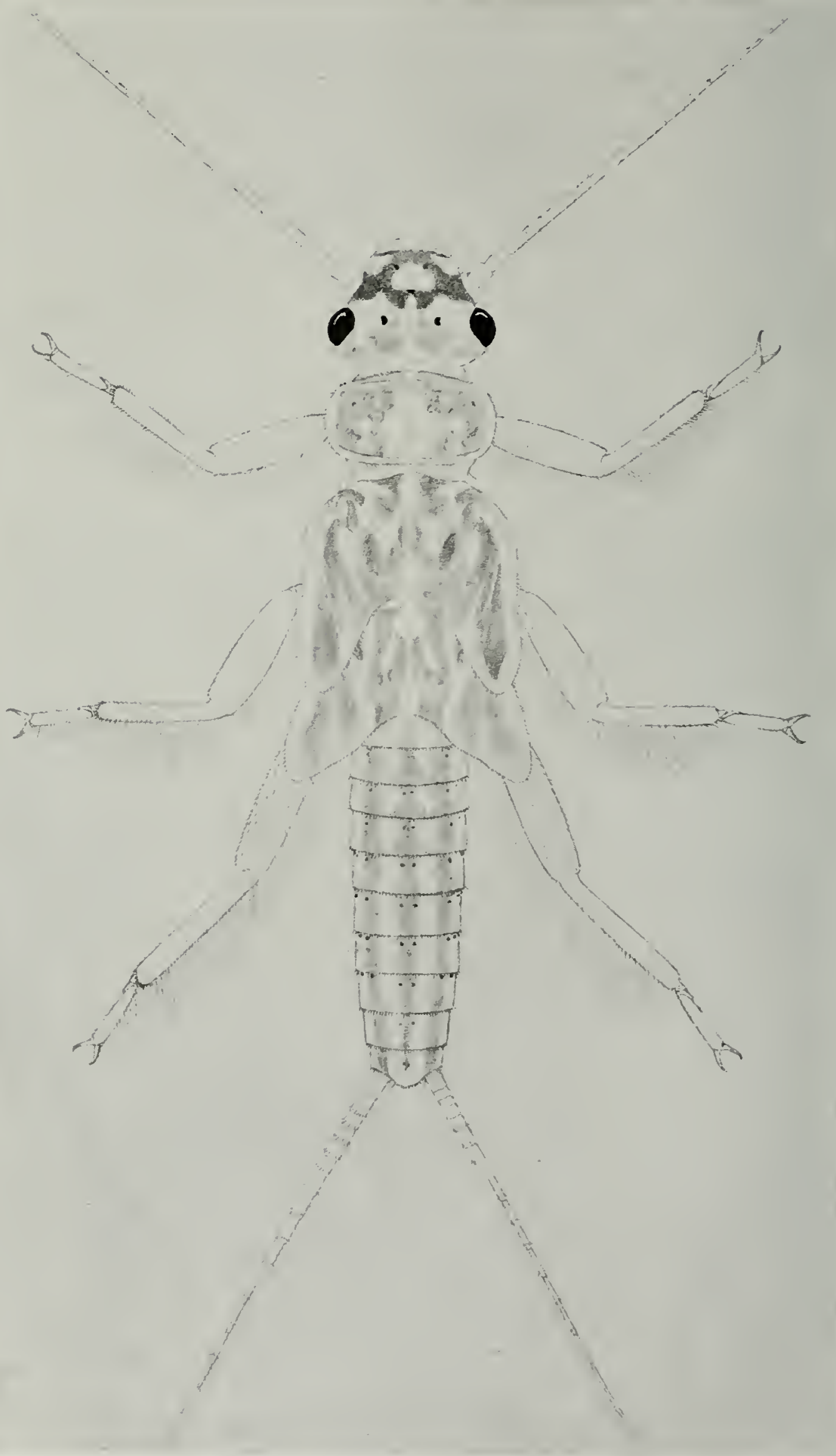

Fig. 344.-Isoperla richardsoni, NYMPHAL FEMALE. 
dark area on head extending as a quadrate shaped portion throughout the ocellar triangle and with an oval light spot in the center, the two conspicuous longitudinal dark stripes on the abdomen, the presence of definite rows of small spots and the absence of scattered freckle-like spots. A median longitudinal dark stripe on the abdominal tergites is reduced to a trace between a pair of closely associated and segmentally arranged minute dark spots in the middle of the tergites. Antennae and cerci yellowish.

Three ocelli nearly forming an equilateral triangle and occupying about same relative position as in the adult. Antennae long, many segmented. No occipital ridge. No pronounced row of stout setae associated with posterior margin of compound eye. Labrum, fig. 52, labium, fig. 142, maxilla, fig. 112, mandibles, fig. 82, and submentum, fig. 162, as illustrated.

Pronotum about twice as wide as long, all angles rounded; marginal groove present on anterior and posterior margins but absent on sides. Wing pads as in fig. 343.

Legs very little flattened and fringe of long fine hairs weakly developed on hind margins of femora, tibiae and tarsi.

Abdomen with color pattern as in fig. 343. Cerci many segmented, not as long as abdomen. Tenth tergite produced backwards and rounded on posterior margin. Eighth tergite with posterior margin straight and setal fringe not interrupted in the middle.

No gills of any type present.

Mature specimens with body length, exclusive of appendages, up to $11 \mathrm{~mm}$.

Nymphal female, fig. 343.-In color and most structural details similar to nymphal male. Eighth abdominal sternite has the setal fringe on posterior margin interrupted in the middle.

Nymphs.-Hill (trib. of Bishop cr.): Apr. 4, 1932. Watson (trib. of Little Salt cr.): Apr. 4, 11, 19, 23, 1932. Collected by T. H. Frison, H. H. Ross, C. O. Mohr. I have also some small nymphs from Little Bourboise creek, St. Claire-Rolla, Mo., collected by H. H. Ross and C. O. Molrr, which are this species.

\section{Isoperla richardsoni-NEW SPECIES}

Figs. 53, 83, 113, 143, 197, 235, 344.

'Ihis species is named in honor of Mr. R. E. Richardson, formerly' of the SURVEY, who first separated the nymphal stage from I. bilineata on the basis of its color pattern, while he was sorting bottom fauna collections taken from the Rock river from 1924 to 1927. Later and independently the nymph was again recognized as distinct from bilineata and reared. The reared adult produced definite and final proof that the color pattern of the nymph did not represent a case of color variation and that another species was involved. 
We know very little about the habits of this species. The adults are probably nocturnal and their mouthparts indicate that they do not feed. Thus far this species has been found only in the Rock river and in association with bilineata, for which it would pass in most collections. The nymphs of richardsoni however are uncommon in comparison with those of bilimeata and only careful sorting will reveal their existence. One nymph of this species was collected with a half eaten chironomid larva in its mouth-an indication that it is at least partially or at times carnivorous.

Since the adults resemble in many respects the species bilineata and decepta and likewise the nymphs have many points in common with other isoperlids, the following descriptions concern only the major points of difference. My practice in the stoneflies of selecting a male as the holotype is reversed here because the subgenital plate of the female offers better recognition characters than does the male. The male, of which I have only one reared specimen, so closely resembles bilineata that I have been unable to separate these two species in the key.

Female.- Length to apex of wings $12 \mathrm{~mm}$; length to apex of abdomen $9 \mathrm{~mm}$. In life this species is essentially yellowish white with some dark or brownish areas and strongly contrasting black ocelli and compound eyes. Superficially it resembles both I. bilineata and decepta. It differs from decepta in having the median and lateral ocelli connected by a dark $\mathrm{V}$ shaped line, and from bilineata by having the subgenital plate, fig. 235 , of the eighth sternite rounded and but slightly produced over the ninth sternite. The mandibles are flabby and not functional as in bilineata. Description of the head, thorax, abdomen and appendages of decepta fit this species very well except as above stated.

Male.-Similar to female in general color and most morphological details. Apical abdominal segments, fig. 197, so closely resembling the typical bilineata that I cannot cite a clear cut difference. It is probable that the lobe on the eighth sternite averages somewhat smaller than in bilineata but this is difficult to measure or use as a character for recognition. It is easily separated from decepta because of the characteristic $\mathrm{V}$ shaped dark line connecting the median and lateral ocelli.

Holotype, female.-Sterling, Ill. (Rock r.): May 10, 1932, reared from nymph collected by T. H. Frison and H. H. Ross.

Allotype, male.-Same data as for holotype.

Paratypes.-Same data as for holotype, 6ㅇ. Grand Detour: May 15, 1930, 1․ Rockford: May 12, 1927, 1ㅇ. Rock Island: May 16, 1931, 10. Collected by T. H. Frison, H. H. Ross, C. O. Mohr, D. H. Thompson.

Nymphal male, fig. 344.--General color pattern whitish yellow with dark colored areas as in the figure. Some minute paired dark spots longitudinally arranged on abdominal tergites 
but freckle-like spots absent. Venter without conspicuous dark markings. Appendages colored essentially as venter. Size about the same as for decepta.

Head with ocelli arranged approximately as in decepta. No occipital ridge. No conspicuous row of stout setae associated with posterior margin of compound eye. Labrum, fig. 53, labium, fig. 143, maxilla, fig. 113, and mandibles, fig. 83, as illustrated.

Pronotum and legs approximately as in decepta.

Abdomen marked as in fig. 34t. Three longitudinal stripes on tergites distinct. Cerci about as long as abdomen, many segmented; segments progressively longer apically. Apical segments approximately as in decepta.

No gills of any type.

Nymphal female.- Similar to male in general color and most morphological details. Eighth abdominal sternite with transverse row of setae on posterior margin interrupted in the middle.

Nymphs.-Camp Grant (Rock r.): May 7,"1926. Dixon (Rock r.): Apr. 3, 1928. Oregon (Rock r.): May 15, 1926; May 26, 1927; Apr. 3, 1928. Rockford (Rock r.): Apr. 21, May 4-6, 1926; Apr. 26, May 12, 1927. Rock Island (Rock r.): Apr. 3, 1928; Apr. 27, May 9, 1932. Rockton (Rock r.): May 16, 1926. Sterling (Rock r.): May 13-15, 1925; Apr. 27, 1932. Collected by T. H. Frison, H. H. Ross, C. O. Mohr, D. H. Thompson.

\section{BIBLIOGRAP HY}

\section{Albarda, Herman}

1889a Note sur la Taeniopteryx nebulosa L. et la $T$. praetexta Burmeister. Annales de la Société Entomologique de Belgique, tome 33, pp. 5168. pl. 1.

1889b Catalogue raisonné et synonymique des Nevroptères.

Tijdschrift voor Entomologie, volume XXXII, pp. 242-255.

\section{BANKS, NATHAN}

1892 A synopsis, catalog and bibliography of the neuropteroid insects of temperate North America.

Transactions of the Entomological Society of America, volume XIX, December, pp. 327-373. 6 figs.

1897 New North American neuropteroid insects.

Transactions of the American Entomological Society, volume XXIV, February, pp. 21-31.

1900 New genera and species of nearctic neuropteroid insects.

Transactions of the American F.ntomological Society, volume XXVI, May, pp. 239-259.

1905 New genera and species of Perlidae.

Psyche, volume XII, June-August, pp. 55-57. + figs.

1906a On the perlid genus Chloroperla.

Entomological News, volume XVIl, number 5, May, pp. 174-175. 
BANKS, NATHAN-CONT'D

$1906 \mathrm{~b}$ Notes on the classification of the Perlidae.

The Canadian Entomologist, volume XXXVIII, number 7, July, pp. 221-224.

1907 Catalog of the neuropteroid insects (except Odonata) of the United States. 53 pp.

American Entomological Society, Philadelphia.

1918 New neuropteroid insects.

Bulletin of the Museum of Comparative Zoology at Harvard College, volume LXII, number 1, March, pp. 3-22. 2 pls.

1920 New neuropteroid insects.

Bulletin of the Museum of Comparative Zoology at Harvard College, volume LXIV, number 3, October, pp. 299-362. 7 pls.

Brues, Charles T. and A. L. Melander

1932 Order Plecoptera.

Classification of Insects, Bulletin of the Museum of Comparative Zoology at Harvard College, volume LXXIII, pp. 176-179. figs. $327-332$.

Burmeister, $\mathrm{H}$.

1839 Plecoptera.

Handbuch der Entomologie, band II, part 2, pp. 863-881. T. C. F. Enslin, Berlin.

Claassen, Peter W.

1924 New species of North American Capniidae (Plecoptera).

Canadian Entomologist, volume LVI, number 2, February, pp. $43-48$.

1928 Additions and corrections to the monograph on the Plecoptera of North America.

Annals of the Entomological Society of America, volume XXI, number 4, December, pp. 667-668.

1931 Plecoptera nymphs of America (north of Mexico).

Thomas Say Foundation, volume III. 199 pp., figs. 1-4, 35 pls.

Clark, Robert L.

1934 The external morphology of Acroneuria evoluta Klapalek (Perlidae, Plecoptera).

The Ohio Journal of Science, volume XXXIV, number 2, March, pp. 121-128. 17 figs.

EnderLein, Günther

1909 Klassification der Plecopteren, sowie diagnosen neurer gattungen und irten.

Zoologischer Anzeiger, band XXXIV, number 13-14, June 15, pp. 385-419.

Firch, AsA

1847 Winter insects of eastern New York.

American Journal of Agriculture and Science, volume V, number 13, May, pp. 274-284. 
Frison, Theodore H.

1929 Fall and winter stoneflies, or Plecoptera, of Illinois.

Illinois Natural. History Survey Bulletin, volume xilli, article II, May, pp. 340-409. 77 figs.

1934 Four new species of stoneflies from North America (Plecoptera).

The Canadian Entomologist, volume LXVI, number 2, February, pp. 25-30. 16 figs.

Garman, H.

1888 A preliminiry report on the animals of the Mississippi bottoms near Quincy, Illinois, in August, 1888. Part I. Plecopterat.

Bulletin Illinois State Laboratory of Natural History, volume III, article IX, pp. 123, 175.

1912 A preliminary study of Kentucky localities in which pellagra is prevalent.

Kentucky Agricultural Experiment Station, Bulletin number 159, January 15 , pp. 58-60. figs. 47,48 .

Hagen, Hermann

1861 Synopsis of the Neuroptera of North America.

Smithsonian Miscellaneous Collections. July, xx\&347 pp. Smithsonian Institution, Washington, D. C.

KLAPALEK, F.

1900 Plekopterologické-Studie.

Rozpravy České Academie Cisaře Frantiska Josefa pro Vedy Slovesnost a Uměni, volume 10. 34 pp., 2 pls.

1902 Zur kenntniss der Neuropteroiden von Ungarn, Bosnien und Herzegovina. Termeszetrajzi Füzetek, Budapest, volume XXV, pp. 178-180.

1907 Europaeische arten der gattung Perla Geoff.

Rozpravy České Academie Cisaře Frantiska Josefa pro Vedy Slovesnost a Uměni, volume 16.25 pp., 15 figs.

1909a Revision der gattung Acroneuria Pict.

Bulletin International, Academie des Sciences de l'Empereur François Joseph J, XIVe Année, November, pp. 234-247. 10 figs.

1909b Plecoptera, steinfliegen.

Die Süsswasserfauna Deutschlands, heft 8, article II, pp. 33-95. figs. 54-177.

1912 Monographische revision der family Perlodidae.

Collections Zoologiques du Baron Edm. de Selys Longchamps, Catalogue Systématique et Descriptif, fascicle IV, June 25. 66 pp., 58 figs.

1921 Plecopteres nouveaux: sous-famille des Perlinae et Neoperlinae.

Annales de la Société Entomologique de Belgique, tome 61, pp. 57-67.

1923 Monographische revision der family Perlidac: unterfamilien Perlinae, Neoperlinae.

Collections Zoologiques de Baron Edm. de Selys Longchamps, Catalogue Systématique et Descriptif, fascicle IV² (Plécopterès). March 1, 193 pp., 85\&61 figs.

KOPONEN, J. S. W.

1917 Plecopterologische studien, I und II, die Plecopteren-arten Finlands. 
KOPONEN, J. S. W.-CONT'D

Acta Societatis pro Fauna et Flora Fennica, volume 44, number 3. 18 pp., 5 figs.; Same, number 4.28 pp., 12 figs.

L.ATREH.h., P. A.

1796 Précis des caractères génériques des insectes, disposés dans un ordre naturel. p. 101.

F. Bourdeaux, Paris.

1810 Considérations generales sur l'ordre naturel des animaux composant les classes des crustacés, des arachnides, et des insectes. pp. 278, 435.

F. Schoell, Paris.

LAUTERBORN, R.

1903 Tracheenkiemen an den beinen einer Perliden-larve (Taeniopteryx nebulosa L.).

Zoologischer Anzeiger, band XXVI, number 706, August 10, pp. 637-642. figs. $1,2$.

LESTAGE, J. A.

1921 Etudes sur la biologie des Plécoptères. I.-La Larve de Nephelopteryx nebulosa $\mathrm{L}$.

Annales de Biologie Lacustre, tome X, pp. 231-260. 13 figs.

1922 Notes synonymiques. (B) Plecoptera.

Bulletin de la Société Entomologique de Belgique, tome 4, p. 102.

Linne, Caroli

1758 Insecta Neuroptera.

Systema Naturae, tome I, pp. 543-552. Salvius, Stockholm.

Mertens, Hermann

1923 Biologische und morphologische untersuchungen an Plekopteren.

Archiv für Naturgeschichte, volume 89, abt. A, heft 2, pp. 1-38.

18 figs.

Morton, Kenneth J.

1894 Palaearctic Nemourae.

Transactions of the Entomological Society of London, volume 42, article XXIII, pp. 557-574. pls. XIII, XIV.

Neave, Ferris

1929 Reports of the Jasper Park lakes investigations 1925-26. II. Plecoptera.

Contributions to Canadian Biology and Fisheries, volume IV, number 13, pp. 159-168. 21 figs.

1933 Some new stoneflies from western Canada.

The Canadian Entomologist, volume L.XV, number 10, October, pp. 235-238. figs. 1-5.

1934 Stoneflies from the Purcell range, B. C.

The Canadian Entomologist, volume LXVI, number 1, pp. 1-6. pl. 1.

Needham, James G.

1901 Aquatic insects in the Adirondacks: Plecoptera.

New York State Museum, Bulletin 47, September, pp. 412-418.

figs. 4,5 . 


\section{Needham, James G. - Cont'D}

1905 New genera and species of Perlidae.

Proceedings of the Biological Society of Washington, volume XVIII. March 31, pp. 107-110.

1920 Burrowing mayflies of our larger lakes and streams.

Bulletin of the United States Bureau of Fisheries, Document 88.3. July 17, pp. 265-292.

Needham, J. G. and P. W. Claassen

1922 The North American species of the genus Acroneurial (Order Plecopter:i). Canadian Entomologist, volume 54, number 11, November, pp.249255.

1925 A monograph of the Plecoptera or stoneflies of America north of Mexico. Thomas Say Foundation of the Futomological Society of Americal, volume II. 397 pp., 50 pls., 29 figs.

Needham, J. G. and P. R. Needham

1927 Plecoptera.

A Guide to the Study of Fresh-water Biology, pp. 8-10. pl. 1. The American Viewpoint Society, New York and Albany.

NeEracher, F.

1910 Die insektenfauna des Rheins und seiner zuflüsse bei Basel.

Revue Suisse de Zoologie, tome 18, numler 2, August, pp. 497590. 19 figs.

NEWCOMER, E. J.

1918 Some stoneflies injurous to vegetation.

Journal of Agricultural Research, volume X'llI, number 1, April, pp. $37-42$. pls. 2,3 .

Newman, Edward

1836 Entomological notes.

The Entomological Magazine, volume $11 \mathrm{I}$, number V, April, article XLVII, pp. 499-501.

18.38 Entomological notes.

The Entomological Magazine, volume $V$, number 2, January, article XVI, pp. 175-178.

1839 On the synonymy of the Perlites, together with brief characters of the old, and of a few new species.

Magazine of Natural History, n. s. (ser. 2), volume 3, pp. 32-37, 84-90.

Newport, George

1844 On the existence of branchiae in the perfect state of al neuropterous insect, Pteronarcys regalis Newm. and other species of the same genus.

Annals and Magazine of Natural History, volume 13, pp. 21-25.

1851 On the anitomy and affinities of Pteronarcys regalis Newm.: with a postscript, containing descriptions of some American Perlidate, together with notes on their habits.

Transactions of the Linnean Society of London, volume XX, part III, pp. $447-452$. pl. XXI. 
Oкамото, H.

1922 Zweiter beitrag zur kenntnis der japanischen Plecopteren.

Bulletin of the Agricultural Experiment Station of the Government General of Chosen at Suigen, number 1, pp. 1-46. 6 pls., 1 text fig.

P1CTET, F. J.

1841 Histoire naturelle generale et particuliere des insectes Neuropteres.

Premiere Monographie: Famille des Perlides. 423 pp., 53 colored pls. Kessman, Geneve.

RAMBUR, M. P.

1842 Histoire naturelle des insectes-Neuropterès. xvii\&534 pp., 12 colored pls. Roret, Paris.

REUTER, E.

1904 Tidigt uppträdande af Perliden Taeniopteryx nebulosa L.

Meddelanden af Societas pro Fauna et Flora Fennica, volume 30, pp. 99, 100.

Ris, F.

1902 Die schweizerischen arten der Perliden-gattung Nemura.

Mitteilungen der Schweizerischen Entomologischen Gesellschaft, band 10, heft 9, February, pp. 378-405. 48 figs.

Rousseau, E.

1921 Plecoptera.

Les larves et nymphes aquatique des insectes d'Europe, volume 1, part VI, pp. 274-320. figs. 73-88. Lebègue, Bruxelles.

SAMAL, JarOMIR

1923 Étude morphologique et biologique de Perla abdominalis Burm.

Annales de Biologie Lacustre, volume 12, pp. 229-272. 35 figs.

SAY, ThOMAS

1823 Description of insects belonging to the order Neuroptera Lin., Latr. Collected by the expedition authorized by J. C. Calhoun, Secretary of War, under the command of Major S. H. Long.

Western Quarterly Reporter, volume II, number 11, April-MayJune, pp. 160-165.

SChoenemund, Eduard

1912 Zur biologie und morphologie einiger Perla-arten.

Zoologische Jahrbücher, Abteilung für Anatomie und Ontogenie der Tiere, band 34, heft 1, pp. 1-56. 3 figs., 2 double plates.

1925 Beiträge zurbiologie der Plecopteren-larven mit besonderer berücksichtigung der atmung.

Archiv für Hydrobiologie, band XV, pp. 339-369.

1928 Plecoptera.

Die Tierwelt Mitteleuropas, band IV, teil 1, lieferung 2, pp. V1V18. 63 figs.

Мм1тн, ЈонN B.

1910 Order Plecoptera.

Annual report of the New Jersey State Museum including a report of the insects of New Jersey, pp. 39-41. fig. 5. 
SMITH, L. W.

1913 The biology of Perla immarginata Say.

Annals of the Entomological Society of America, volume VI, number 2, June, pp. 203-211. pl. XXIlI, figs. 1, 2.

1917 Studies of North American Plecopteral (Pteronarcinate and Perlodini).

Transactions of the American Fintomological Society, volume XI.III,

December 28, pp. 433-489. pls. XXIX-XXXIV, figs. A-F.

STEPhens, J. F.

1835 Illustrations of British entomology. Volume VI: Mandibulata, pp. 134-

145. pl. XXXI. Baldwin and Cradock, London.

Tillyard, R. J.

1921 A new classification of the order Perlaria.

The Canadian Entomologist, volume LIII, number 2, February, pp. 35-43. 4 figs.

1926 Periaria.

The insects of Australia and New Zealand, Chap. XllI, pp. 113-

119. pl. 10, figs. K1-K7. Angus and Rohertson, J.td., Sydney, Australia.

Ueno, Masuzo

1929 Studies on the stoneflies of Jipan.

Memoirs of the College of Science, Kyoto Imperial University, series B, volume IV, number 2, article 5, February, pp. 97-155. 26 figs., pl. xxiv.

WALKER, F.

1852 Catalogue of the specimens of neuropterous insects in the collection of the British Museum. Part I. pp. 1-192.

London, by order of the Trustees.

WALSH, B. D.

1862 List of the Pseudoneuroptera of Illinois contained in the calbinet of the writer, with descriptions of over 10 new species, and notes on their structural affinities.

Proceedings of the Academy of Natural Sciences of Philadelphia. September, pp. 362-367.

1863 Perlina.

Notes by Benj. D. Walsh. Proceedings of the lintomological Society of Philadelphia, volume 2, number 3, October, pp. 186-188.

WU, C. F.

1923 Morphology, anatomy and ethology of Nemoura.

Bulletin Lloyd Library, number 23, Entomological Series number 3. 81 pp., pls. 1-XVI. 


\section{INDEX}

Page numbers in this index are for the occurrence of the names in the catalog of species, pp. 307-461, only. Numbers in light face type refer to mere mention of the name or its location without discussion; numbers in bold face show locations of discussions or keys in the case of families and genera, and discussion or collection records for species. Placement of names in keys and in explanation of figures is not indexed.

A

abnormis, Acroneuria 311, 388, 389, 391-95, 407

Perla 391

Acroneuria $310,311,372,373,388-91$, 409

abnormis $311,388,389,391-95,407$ arenosa $388,389,397$

arida $311,389,395-401,405$

evoluta $389,395,397,398$

internata $311,389,401-03$

pennsylvanica 391,393

rupinsulensis 394, 403

ruralis $311,389,394,403-05$

sp. a $311,389,405$

sp. b $311,389,407$

albidipennis, Nemoura 351

Allocapnia $310,311,336,337,347,354$, $355,357-63,387,390$

forbesi $311,363,364,370$

cornuta $311,363-64$

granulata $311,357,364-65,366$

illinoensis $311,365-66$

incisura 360

mystica $311,366-67$

pygmaea $311,364,367$

recta $311,364,367-70$

vivipara $311,357,370-72,386$

Alloperla $310,427,431$

Amphinemura 349

annulipes, Neophasganophora 407

apicalis, Chloroperla 429

arenosa, Acroneuria 388, 389, 397

Perla 388

arida, Acroneuria $311,389,395-401,405$

Perla 395

Atoperla $310,311,372,377,380$

ephyre $311,377,380,381$

B

lilineata, Isoperla $308,311,411,428$, $431,432,437-39,441,445,447$, $448,449,455,459,460$
Perla 431, 437

Sialis 437

bilobata, Isoperla 449

brevicauda, Capnia 309

brunnipennis, Chloroperla 386

C

capitata, Neophasganophora 311,407 , 409-12, 414

Perla 407, 409

Capnella 357

granulata 357,364

recta 367

vivipara 370

Capnia $310,311,355,356,357,371,390$

brevicauda 309

minima? $357,370,371$

nigra 356

species 311

vernalis 356,357

vernalis? $311, \mathbf{3 5 6}-57$

Capniidae $307-11,352,355-56,373$

Capnura 310,355

Chloroperla $310,311,427,429,431$

apicalis 429

brunnipennis 386

clymene 381

cydippe $311,429,431,451$

minuta 453

nana 433,453

Chloroperlidae 307-11, 372, 416, 427-29

cinctipes, Perlesta 384

claasseni, Leuctra 311, 354-55

clio, Clioperla 439

Isogenus 439

Isoperla $311,439-41,443,445$

Clioperla $428,432,438,451$

clio 439

clymene, Chloroperla 381

Neoperla $311, \mathbf{3 8 1 - 8 4}, 386$

colubrinus, Isogenus 418

colubrinus?, Isogenus +18

completa, Nemoura 351 
confusa, Isoperla $311,432,433,441-45$, 451,455

conspicua, Isoperla $311,432,4+1,445-47$ cornuta, Allocapnia forbesi $311,363-64$ crosbyi, Hydroperla $311,416,419-23$, $424,426,427,441$

Perla $+17,419$

cydippe, Chloroperla $311,429,431,451$ lsoptery 431

decepta, Isoperla 308, 311, 432, 438. $441,447-49,455,460,461$

decipiens, Perla 386

Diploperla $428,432,4+9,451$

Doddsia 310

dorsata, Pteronarcys 336,339

duplicata, Isoperla 428,432, 433, 449-53

Perla 427, 428, 449

drymo, Perla 380

Perlinella $311,380-81$

E

elongatil, Perla 380

ephyre, Atoperla $311,377,380,381$

Perla 377

Eucapnopsis $310,352,354$

evoluta, Acroneuria $389,395,397,398$

fasciata, Semblis 347

Strophopteryx 311,347

Taeniopteryx 348

Filipalpia 308-10

Aavescens, Neophasganophoril 407

Perla 409

Haviventris, Hemimelaenal +16

forbesi, Allocapnial 311, 363, 364, 370

cornuta, 311, 363-64

frontalis, Isogenus $416,+18$

fugitans, Perlat 423

fumipennis, Perla $377,380,381$

fumosa, Perla 407

\section{G}

geniculati, Leuctra 354

granulata, Allocapnia $311,357,36465$ 366

granulata, Capnella 357,364
H

harti, Hydroperla $311,416,42326,+27$, $4+5$

Hemimelatena $+16,+27$

Aaviventris 416

Holognatha $308-10$

Hydroperla $310,311,416,417-19,427$, 411

crosbyi $311,+16,419-23,+24,426$, 427,441

harti $311,416,423-26,427,445$

postica +27

varians $311,416,426-27$

\section{I}

illinoensis, Allocapnia 311, 365-66

illustris, Neophasganophora 407

immarginata, Togoperla 409, 412

incisura, Allocapnial 360

internata, Acroneuria 311, 389, 401-03

Perla 401

Isogenoides 416

Isogenus $310,416,417,418$

clio 439

colubrinus 418

colubrinus? 418

frontalis $+16,418$

postical 416

Isoperla $310,311,354,390,+27,+28$, $+29,431-37$

bilineata $308,311,411,428,431,432$, $437-39,441,445,447,448,449,455$, 459,460

bilobata $4+9$

clio $311,439-41,4+3,445$

confusa $311,+32,+33,441-45,+51,455$

conspicuil $311,432,4+1,445-47$

decepta $308,311,432,438,441,447$

$49,+55,460,461$

duplicata $428,432,433,449-53$

minuta $311,+32,433,438,+41,45355$

mohri $311,432,438,455-59$

richardsoni $311,432,438,447,459-61$

sobria 445

Isopteryx 429,431

cydipie +31

$\kappa$

kansensis, Perlat 41.5

Kathroperla 310,427 
$L$

Leuctra $309-11,337,352,354,390$ claasseni $311,354-55$ geniculata 354

Leuctridae 307-11, 352-54

limbata, Perlit 412

Togoperla 412

\section{M}

maura, Taeniopteryx 340,341 media, Perla 407,412

Togoperla 311, 409, 412-14

Megaleuctra $309,310,352$

minima?, Capnia $357,370,371$

minuta, Chloroperla 453

Isoperla $311,432,433,438,441,453-55$

mohri, Isoperla $311,432,438,455-59$

mystica, Allocapnia 311, 366-67

N

nana, Chloroperla 433,453

nebulosa, Nemoura 340

Taeniopteryx 340

Nemoura 309-11, 337, 349, 354, 390

albidipennis 351

completa 351

nebulosa 340

nivalis 341

perfecta 352

variegata 349

venosa $311, \mathbf{3 4 9 - 5 2}$

Nemouridae $307-11,339,349,352$

Nemura 349

Neoperla $310,311,372,381$

clymene $311,381-84,386$

Neophasganophora $310,311,372,407-$ 09,412

annulipes 407

capitatil $311,407,409-12,414$

flavescens 407

illustris 407

nigra, Capnia 356

nivalis, Nemoura 341

Taeniopteryx 311, 340, 341-45, 347, 348,386

nobilis, Pteronarcys 311, 336-39

occipitalis, Perla 381

occipitalis?, Perla 381
Paraperla 310,427

parvula, Taeniopteryx $311,340,345-47$

Peltoperla 310

Peltoperlidae 307-10

pennsylvanica, Acroneuria 391, 393

Perla 391, 393, 394

perfecta, Nemoura 352

Perla $372,373,388,407,409,418,449$

abnormis 391

arenosa 388

arida 395

bilineata 431,437

capitata 407,409

crosbyi 417,419

decipiens 386

drymo 380

duplicata $427,428,449$

elongata 380

ephyre 377

flavescens 409

fugitans 423

fumipennis $377,380,381$

fumosa 407

internata 401

kansensis 415

limbata 412

media 412

occipitalis 381

occipitalis? 381

pennsylvanica $391,393,394$

placida 384,386

postica 427

producta 377,378

ruralis 403

trivittata 380

varians 426

Perlesta 310, 311, 372, 384

cinctipes 384

placida $311,381,384,386-88$

virginica 381

Perlidae 307-11, 372-77, 416

Perlinella $310,311,372,377,380$

drymo $311,380-81$

Perlodes $310,416,417,418$

Perlodidae 307-11, 372, 416-17, 427

Perlodini 339

Perlomyia 310,352

Phasganophora 407

placida, Perla 384, 386

Perlesta 311, 381, 384, 386-88 
postica, Hydroperla +27

Isogenus 416

Perla 427

producta, Perla 377,378

Pseudoperla 381

Pteronarcella $310,334,336$

Pteronarcidae 307-11, 334

P'teronarcinae 339

Pteronarcys $310,311,334,336$

dorsata 336, 339

nobilis $311,336-39$

regalis 336

pygmaea, Allocapnia $311,364,367$

Semblis 367

R

recta, Allocapnia $311,364,367-70$

Capnella 367

regalis, Pteronarcys 336

richardsoni, Isoperla $311,432,438,447$, 459-61

rupinsulensis, Acroneuria 394, 403

ruralis, Acroneuria 311, 389, 394, 403-05

Perla 403

S

Semhlis fasciata 347

pygmaea 367

Setipalpia 308-10

Sialis bilineata 437

sobria, Isoperla 145

species, Capnia 311

sp. a, Acroneuria $311,389,405$

Togoperla 311, 414-16 sp. b, Acroneuria 311, 389, 407

Strophopteryx 310, 311, 337, 334, 347, 360

fasciata 311,347

Subulipalpia 308-10

Systellognatbat $308-10$

Tatuionema 310

Taeniopterygidae $307-11,339-40,352$ 373

'Taenioptery'x 309-11, 337, 339, 340 41, 347,360

fasciata 348

maura $340,3+1$

nebulosa 340

nivalis $311,340,341-45,347,348,386$

parvula $311,340,345-47$

'logoperla $310,311,372,409,412$

immarginata $109, \pm 12$

limbata 412

media $311,409,412-14$

sp. a $311,414-16$

trivitatta, Perla 380

\section{V}

varians, Hydroperla $311,416,426-27$

Perla 426

variegata, nemoura 349

venosa, Nemoura $311,349-52$

vernalis, Capnia 356,357

vernalis?, Capnia 311, 356-57

virginica, Perlesta 384

vivipara, Allocapnia $311,357,370-72$, 386

Capnella 370 